\title{
Evaluation of Variable Refrigerant Flow Systems Performance on Oak Ridge National Laboratory's Flexible Research Platform: Part 3 Simulation Analysis
}

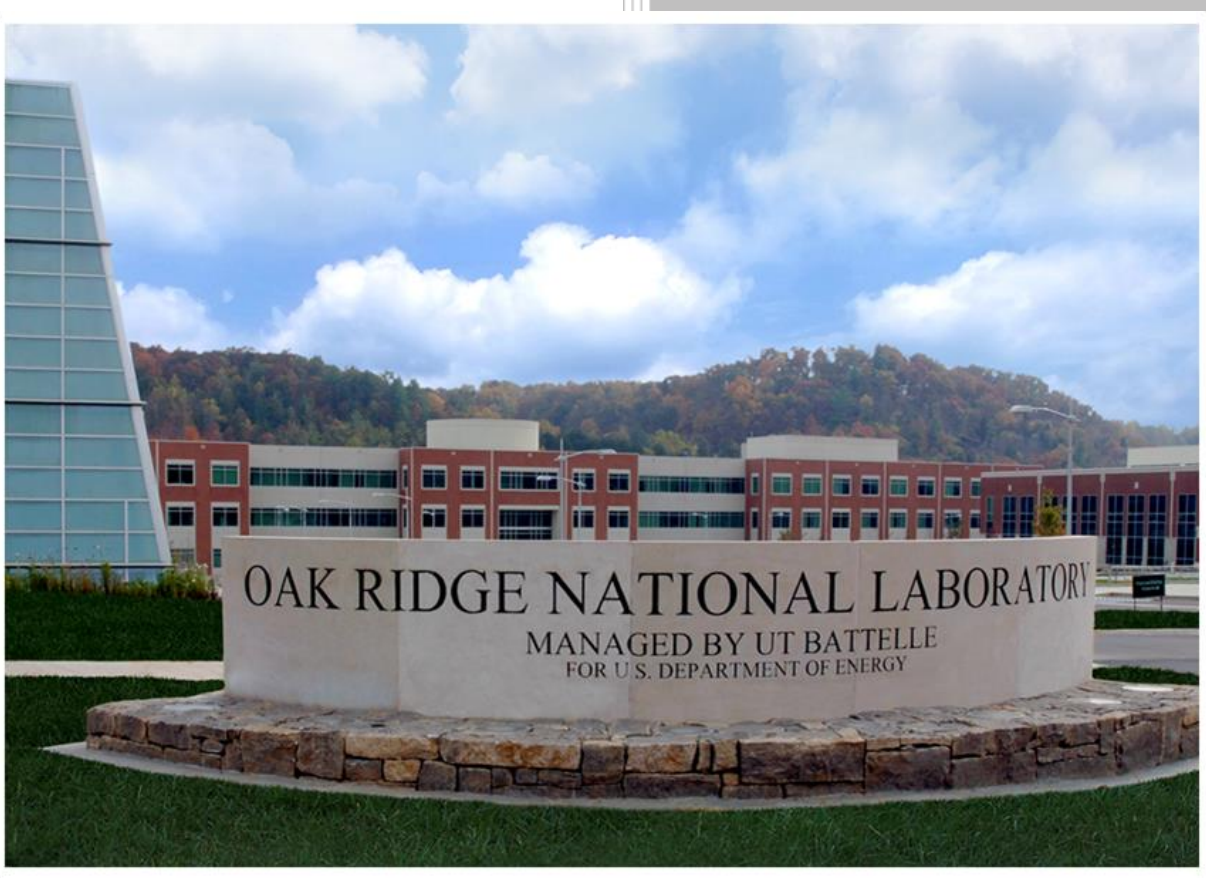

Piljae Im, PhD Heejin Cho, PhD Dongsu Kim Sam Cox

August 2016 


\title{
DOCUMENT AVAILABILITY
}

Reports produced after January 1, 1996, are generally available free via US Department of Energy (DOE) SciTech Connect.

Website http://www.osti.gov/scitech/

Reports produced before January 1, 1996, may be purchased by members of the public from the following source:

\author{
National Technical Information Service \\ 5285 Port Royal Road \\ Springfield, VA 22161 \\ Telephone 703-605-6000 (1-800-553-6847) \\ TDD 703-487-4639 \\ Fax 703-605-6900 \\ E-mail info@ntis.gov \\ Website http://www.ntis.gov/help/ordermethods.aspx
}

Reports are available to DOE employees, DOE contractors, Energy Technology Data Exchange representatives, and International Nuclear Information System representatives from the following source:

Office of Scientific and Technical Information

PO Box 62

Oak Ridge, TN 37831

Telephone 865-576-8401

Fax 865-576-5728

E-mail reports@osti.gov

Website http://www.osti.gov/contact.html

This report was prepared as an account of work sponsored by an agency of the United States Government and Samsung Electronics. Neither the United States Government nor any agency thereof, nor any of their employees, makes any warranty, express or implied, or assumes any legal liability or responsibility for the accuracy, completeness, or usefulness of any information, apparatus, product, or process disclosed, or represents that its use would not infringe privately owned rights. Reference herein to any specific commercial product, process, or service by trade name, trademark, manufacturer, or otherwise, does not necessarily constitute or imply its endorsement, recommendation, or favoring by the United States Government or any agency thereof. The views and opinions of authors expressed herein do not necessarily state or reflect those of the United States Government or any agency thereof. 
Energy and Transportation Science Division

Final Report:

Evaluation of Variable Refrigerant Flow Systems Performance on Oak Ridge National Laboratory's Flexible Research Platform: Part 3 Simulation Analysis

\author{
Piljae Im, PhD \\ Heejin Cho, $\mathrm{PhD}$ \\ Dongsu Kim \\ Sam Cox
}

Date Published: August 2016

\author{
Prepared by \\ OAK RIDGE NATIONAL LABORATORY \\ Oak Ridge, TN 37831-6283 \\ managed by \\ UT-BATTELLE, LLC \\ for the \\ US DEPARTMENT OF ENERGY \\ under contract DE-AC05-00OR22725
}





\section{CONTENTS}

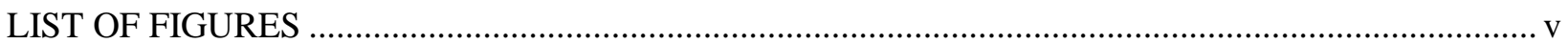

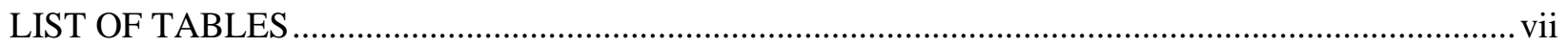

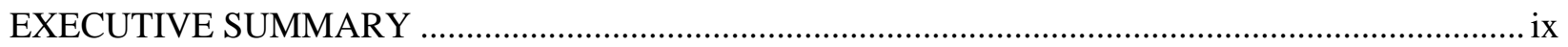

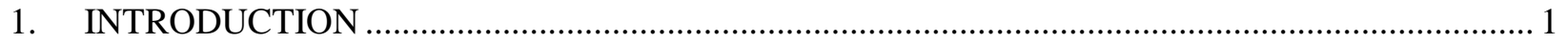

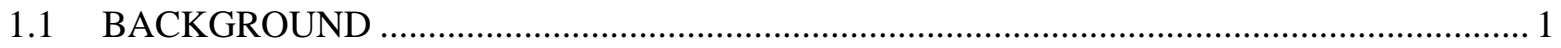

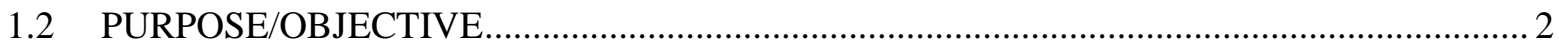

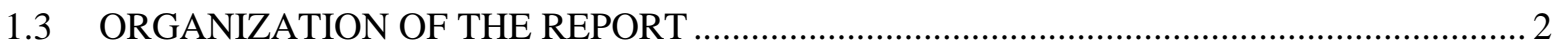

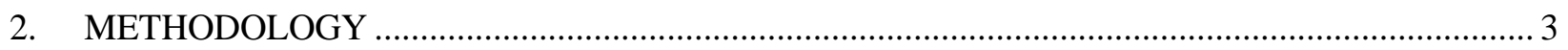

2.1 TEST FACILITY: TWO-STORY FLEXIBLE RESEARCH PLATFORM ......................... 3

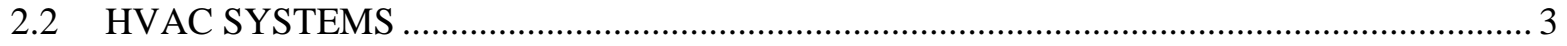

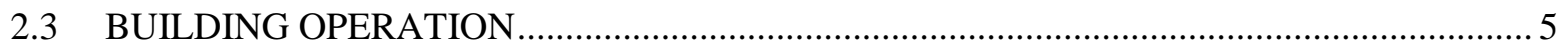

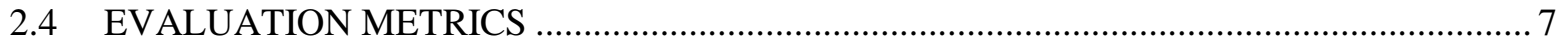

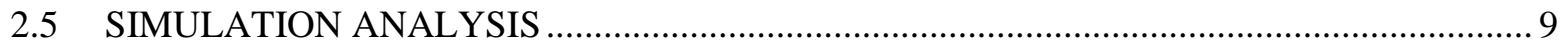

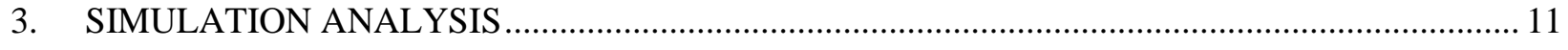

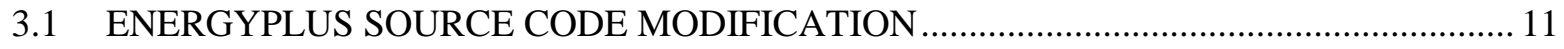

3.2 MODELING AND CALIBRATION OF THE VRF AND RTU SYSTEMS ....................... 15

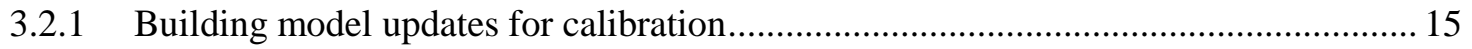

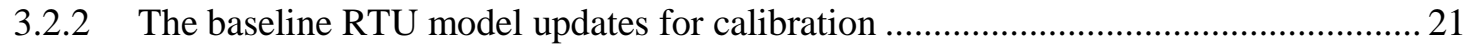

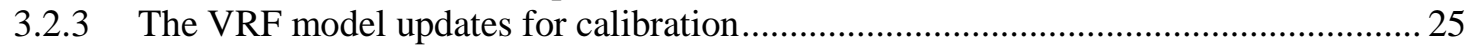

3.2.4 Statistical evaluation of the energy simulation models ............................................... 28

3.2.5 Annual simulation comparison of the VRF and RTU models for the FRP in

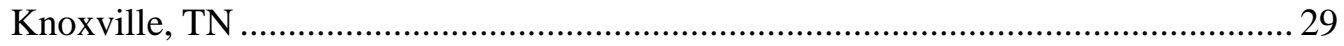

3.3 EVALUATION OF THE ENERGY SAVINGS POTENTIAL OF VRF FROM RTU IN

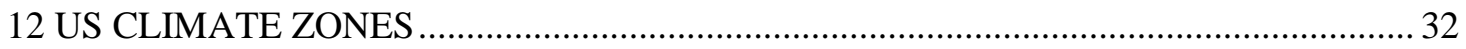

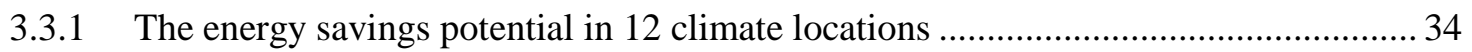

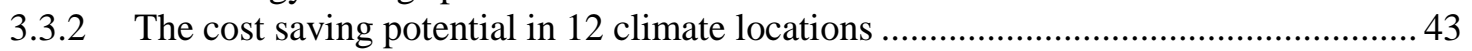

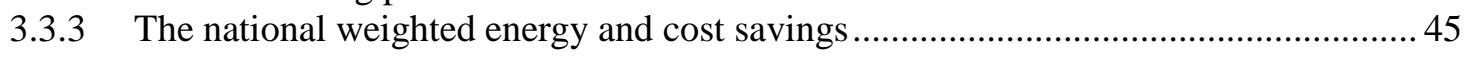

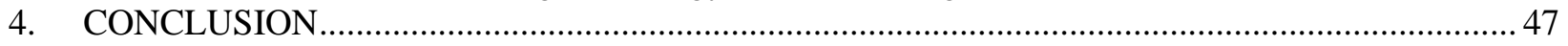

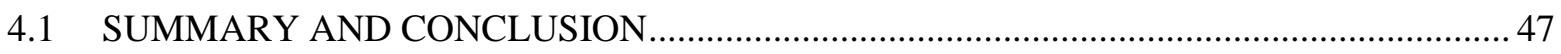

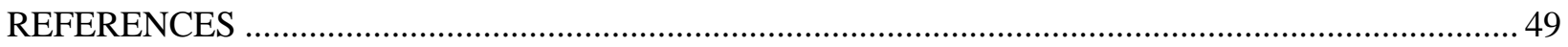

APPENDIX A. INPUT/OUTPUT REFERENCE-THE MODIFIED ENERGYPLUS ...................... A-1

APPENDIX B. ENGINEERING REFERENCE-THE MODIFIED ENERGYPLUS .......................... B-1

APPENDIX C. A SUMMARY OF TEST RESULTS - THE MODIFIED ENERGYPLUS.................... C-1

APPENDIX D. TABLES OF THE MONTHLY TRENDS-MONTHLY HVAC ENERGY USE

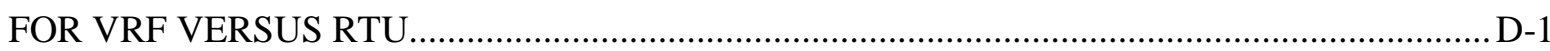





\section{LIST OF FIGURES}

Figure 1. Test facility (left), VRF system outdoor unit (center), and indoor unit (right)......................... 3

Figure 2. System schematic and monitoring points for RTU system (above) and VRF system

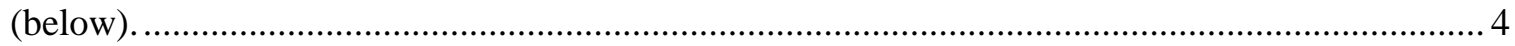

Figure 3. Outdoor air reset schedule for RTU discharge temperature. .............................................. 5

Figure 4. Installation of dedicated outdoor air system.............................................................. 6

Figure 5. Schematic of operation to emulate (a) 50\% load, (b) 75\% load, and (c) 100\% load................... 7

Figure 6. Three-dimensional rendering of the EnergyPlus model of the two-story FRP........................... 11

Figure 7. A system diagram of a VRF system with an OA mixer in the original version of

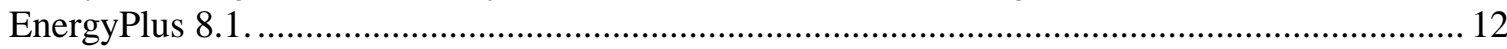

Figure 8. A system diagram of a VRF system with an air-loop DOAS in the original version of

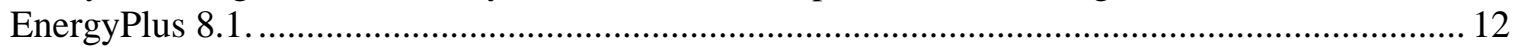

Figure 9. A system diagram of a VRF system with a DOAS coupled with a VRF outdoor unit............... 13

Figure 10. Process of the modified EnergyPlus simulation for the VRF-DOAS.................................... 14

Figure 11. End use comparison between original and modified EnergyPlus models.............................. 15

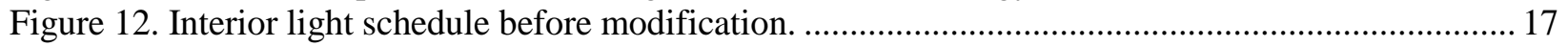

Figure 13. Interior light schedule after modification. ...................................................................... 17

Figure 14. Interior plug load schedule before modification............................................................. 18

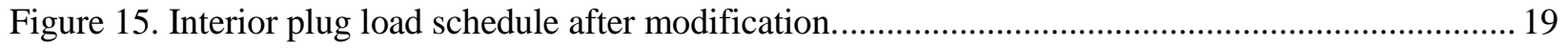

Figure 16. Measured versus simulated hourly VRF total delivered loads. ...............................................20

Figure 17. Measured versus simulated hourly RTU total delivered loads.............................................. 20

Figure 18. Measured vs. simulated hourly cooling coil energy use ...................................................... 22

Figure 19. Measured vs. simulated hourly reheat coil energy use. .................................................... 23

Figure 20. Measured vs. simulated hourly HVAC system energy use ............................................... 23

Figure 21. Measured vs. simulated hourly HVAC system energy use trend of the RTU model. .............. 24

Figure 22. Measured vs. simulated hourly whole-building energy use trend of the RTU model.............. 24

Figure 23. Comparison of the whole-building energy of the RTU model. ..............................................25

Figure 24. Measured vs. simulated hourly HVAC system energy use ................................................... 26

Figure 25. Measured vs. simulated hourly HVAC energy use trend of the VRF model. ..........................2 27

Figure 26. Measured vs. simulated hourly whole-building energy use trend of the VRF model. ............. 27

Figure 27. Comparison of the whole-building energy use of the VRF model.......................................28

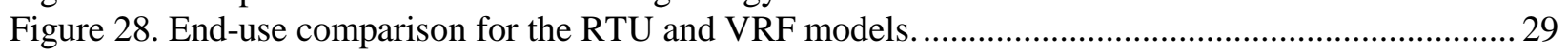

Figure 29. Monthly whole-building energy comparison for the RTU and VRF models........................... 30

Figure 30. Monthly HVAC energy comparison for the RTU and VRF models.................................... 30

Figure 31. Monthly heating and cooling comparison for the RTU and VRF models.............................. 31

Figure 32. Monthly fan energy comparison for the RTU and VRF models. .......................................... 31

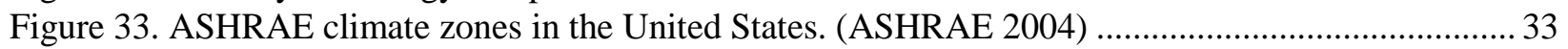

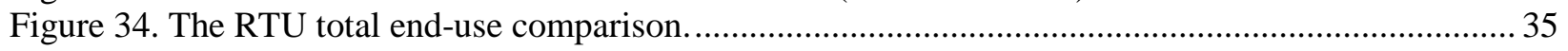

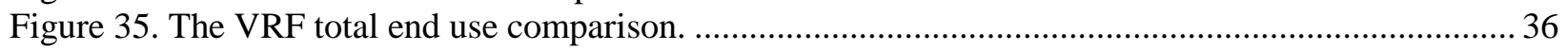

Figure 36. Simulated annual whole-building site energy use for the RTU vs. the VRF system in

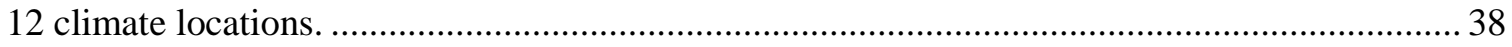

Figure 37. Simulated annual whole-building source energy use in 12 climate locations.......................... 38

Figure 38. Simulated annual HVAC site energy use for the RTU vs. the VRF system in 12

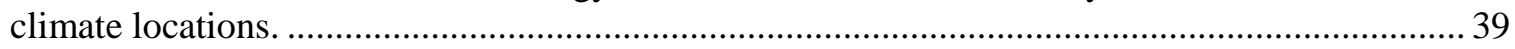

Figure 39. Simulated annual HVAC source energy use in 12 climate locations. ..................................... 40

Figure 40. Simulated heating energy use for the RTU vs. the VRF system in 12 climate locations.......... 41

Figure 41. Simulated cooling energy use for the RTU vs. the VRF system in 12 climate locations.......... 41

Figure 42. Simulated HVAC fan energy use for the RTU vs. the VRF system in 12 climate locations. 
Figure 43. Calculated annual whole-building energy cost for the RTU vs. the VRF system in 12 climate locations.

Figure 44. Calculated annual HVAC energy cost for the RTU vs. the VRF system in 12 climate locations. 


\section{LIST OF TABLES}

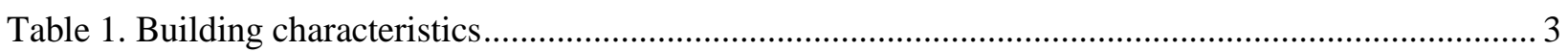

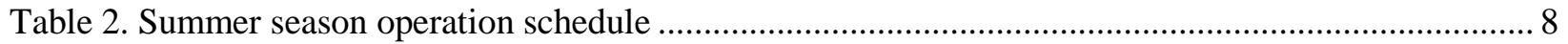

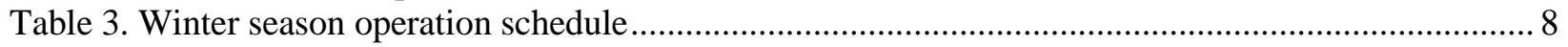

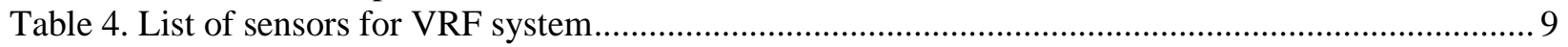

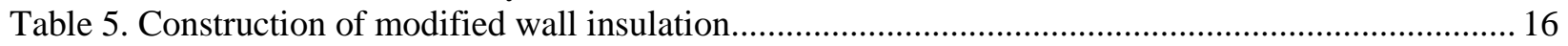

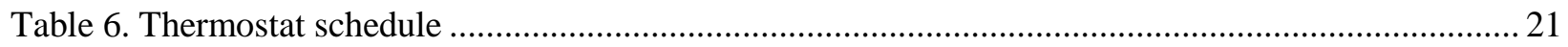

Table 7. The whole-building energy use of the RTU model............................................................. 25

Table 8. Comparison of the whole-building energy use of the VRF model ............................................2 28

Table 9. Statistical evaluation of the energy simulation models.............................................................22

Table 10. Monthly whole-building and HVAC energy use for the RTU and VRF models....................... 32

Table 11. Monthly HVAC component energy use for the RTU and VRF models ................................... 32

Table 12. Twelve representative locations in selected US climate zones ............................................... 33

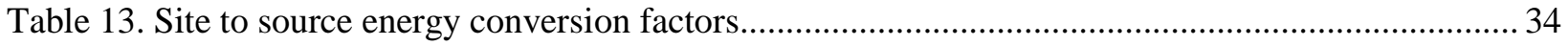

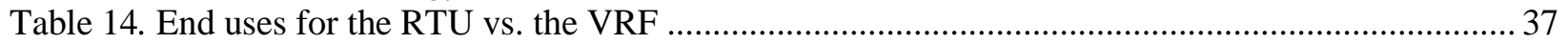

Table 15. Simulated annual whole-building energy use and savings for the VRF system from the

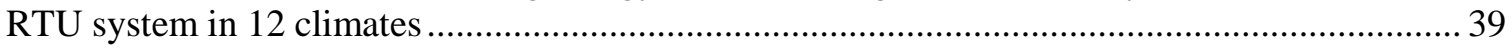

Table 16. Simulated annual HVAC energy use and savings for the VRF system from the RTU

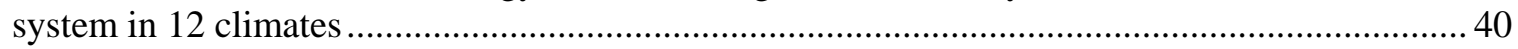

Table 17. Simulated annual heating and cooling energy use and savings for the VRF system from

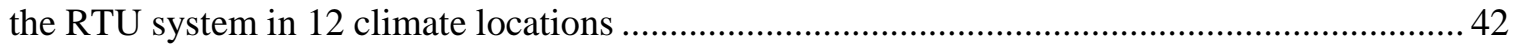

Table 18. Simulated HVAC fan energy use and savings for the VRF system from the RTU system

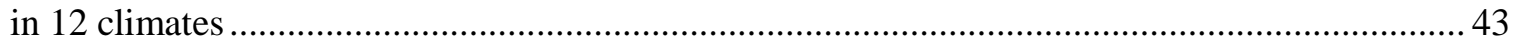

Table 19. The average electricity and natural gas prices in different locations (EIA 2016a and

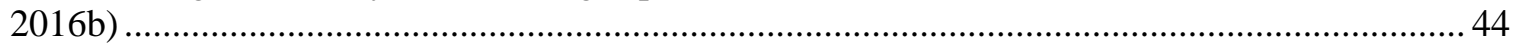

Table 20. Calculated energy cost and savings for the RTU versus the VRF system in 12 climate

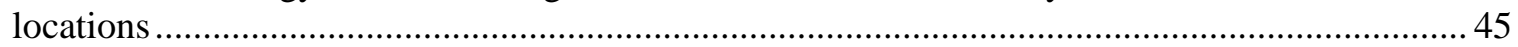

Table 21. Construction area weights by building type and climate location (Jarnagin and

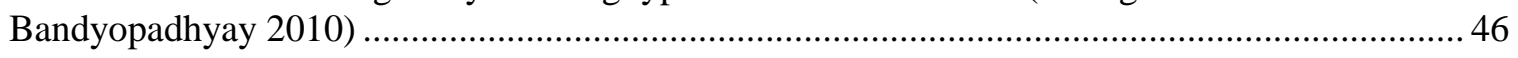

Table 22. Construction area weights and savings potential impact by climate location ........................... 46 



\section{EXECUTIVE SUMMARY}

This report provides second-year project simulation results for the multi-year project titled "Evaluation of Variable Refrigeration Flow (VRF) system on Oak Ridge National Laboratory (ORNL)'s Flexible Research Platform (FRP)." The purpose of the second-year project was to

- Evaluate the full- and part-load performance of a VRF system compared with the existing baseline heating, ventilation, and air-conditioning (HVAC) system, which is a conventional rooftop unit (RTU) variable-air-volume (VAV) system with electric resistance heating

- Evaluate the energy savings potential of using VRF systems in major US cities, using hourly building energy simulation

This report focuses on the second purpose of the second-year project; the first purpose is presented in separate reports. The second-year project performance period was from July 2015 through June 2016. Three separate reports for cooling season analysis, heating season analysis, and simulation analysis are provided based on the analysis results; this report presents the simulation analysis results.

The performance of two HVAC systems was evaluated using ORNL's Flexible Research Platform (FRP), which is a two-story, 3,200 $\mathrm{ft}^{2}\left(297.3 \mathrm{~m}^{2}\right)$ multi-zone unoccupied building that represents a typical lowrise, small office building common in the US existing building stock. The FRP is equipped with a conventional 12.5 ton $(44 \mathrm{~kW})$ RTU-VAV reheat system as a baseline system. For this study, a 12 ton $(42 \mathrm{~kW}) \mathrm{VRF}$ with a dedicated outdoor air system (DOAS) was installed to be compared with the baseline RTU system. The data collected during the project performance period were used to develop and calibrate energy simulation models of the two HVAC systems installed in the FRP. The models were developed and simulated using EnergyPlus 8.1. It was determined that the original version of EnergyPlus was not suitable to model the VRF-DOAS system installed in the FRP (i.e., particularly the use of the VRF heating and cooling coils to condition outdoor air in a DOAS). To be able to model the existing VRF-DOAS settings in the FRP, the source code of the original EnergyPlus was modified. The source code modification added two new objects, a VRF air-loop cooling coil and a VRF air-loop heating coil, to enable modeling of the DOAS coupled with a VRF outdoor unit providing $100 \%$ conditioned outdoor air to individual zones.

The VRF and RTU models from project year one were updated and calibrated with the measured data. Normalized mean bias error (NMBE) and coefficient of variation of the root mean square error (CVRMSE) from ASHRAE Guideline 14 were used to evaluate the validity of the calibrated models. The calibration results show that the baseline RTU model would result in a 20.2\% CV-RMSE and a 3.6\% NMBE. For the VRF simulation model, hourly CV-RMSE and NMBE would be within 15.7 and 3.8\%, respectively. These results indicate that the calibrated models of both the VRF and the RTU were reasonably calibrated based on the criteria from ASHRAE Guideline 14.

With the calibrated simulation model, the energy savings potential of the VRF system was evaluated in 12 climate locations in the United States using the corresponding typical meteorological year 2 weather data. The comparison results show that VRF systems would use less overall energy compared with RTU systems in all 12 climate locations. The predicted site energy savings was $33 \%$ (25,304.0 kWh/year) for San Francisco, the location with the highest savings, and 21\% (17,663.0 kWh/year) for Miami, the location with the lowest savings, among the 12 climate locations. After the model output was converted to source energy savings, the highest predicted energy savings was 33\% (80,065.0 kWh/year) for San Francisco, and the lowest was $24 \%(64,643.0 \mathrm{kWh} /$ year) for Miami. 
The energy cost savings potential of the VRF system was estimated in 12 climate locations in the United States using the states' average 2015 electricity and natural gas prices. The estimated overall wholebuilding annual percentage cost savings for the VRF system compared with the RTU system was approximately $24-33 \%$, and the corresponding whole-building annual energy cost savings was approximately $\$ 2,090.0$ to $\$ 3,534.0$ per year. The corresponding percentage cost savings for annual HVAC energy use was $\sim 43-68 \%$. San Francisco had the highest predicted cost savings - 68\% (\$3,534.0/year), and Miami had the lowest-43\% (\$2,090/year).

National weighted HVAC energy and cost savings were calculated by the construction area weights of the representative building types (i.e., the small and medium office types) in the 12 climate locations. The national weighted average HVAC energy and cost savings for the VRF system compared with the RTU system were $51.1 \%\left(82.0 \mathrm{kWh} / \mathrm{m}^{2}\right.$.year $)$ and $50.8 \%\left(7.4 \$ / \mathrm{m}^{2}\right.$.year) based on the 12 US climate locations. 


\section{INTRODUCTION}

\subsection{BACKGROUND}

This report provides test results from the second year of the multi-year project titled "Evaluation of Variable Refrigeration Flow system on Oak Ridge National Laboratory's Flexible Research Platform." The research for the first year of the 3-year project was performed from July 2014 through April 2015. The purpose of the first year was

1. To design and install a variable refrigerant flow (VRF) system in the new Flexible Research Platform (FRP) test facility at Oak Ridge National Laboratory (ORNL)

2. To evaluate the energy savings potential by comparing the energy use of the VRF system with that of the existing baseline heating, ventilation, and air conditioning (HVAC) system, a conventional rooftop unit (RTU) with a variable-air-volume (VAV) system and electric resistance heating

In addition, a newly developed enhanced control algorithm called CCM (the comfort control method), was implemented to estimate the potential for additional energy savings. The final report from the first year includes the background of the research, FRP building characteristics, baseline HVAC and VRF system characteristics, and the final results of the estimated energy savings of the VRF system and CCM control algorithm (Im et al. 2015).

Based on the lessons learned and findings from the project's first year, and further discussions with the manufacturer, the goal of the second year was developed. The first-year research confirmed the potential of a VRF system to reduce energy use and enhance indoor thermal comfort. At the same time, it emphasized the need to explore several other aspects of the performance of the VRF systems, including the following:

- Analysis of part-load performance of VRF and baseline HVAC system: VRF systems are known for their superior part-load performance compared with conventional HVAC systems. The future study could include evaluation and comparison of the part-load performance of the VRF system and the baseline system in ORNL's FRP.

- Analysis of VRF and baseline HVAC system performance in different climates: To evaluate the performance of a VRF system in different climates, a simulation-based energy analysis could be performed. A building energy model could be developed, calibrated using the measured VRF and baseline HVAC system performance data, and simulated with corresponding typical meteorological year (TMY) weather files.

- Application of a dedicated outdoor air system (DOAS): After the first year, it was suggested that a DOAS be included with the VRF system to provide adequate fresh air to the indoor space according to the requirements of the American Society of Heating, Refrigerating and Air-Conditioning Engineers (ASHRAE) Standard 62.1 (ASHRAE 2013). In the first year, unconditioned outdoor air (OA) was introduced into the plenum space by continuous operation of an exhaust fan. 


\subsection{PURPOSE/OBJECTIVE}

Therefore, for the second-year project, the following two main research objectives are defined.

1. To modify the previously installed VRF system and add the DOAS on the two-story FRP as one of multiple HVAC options and compare the full- and part-load performance with that of another baseline HVAC system (i.e., rooftop packaged HVAC with VAV reheat).

2. To evaluate the energy savings potential of using VRF systems in various US climate zones based on calibrated simulation modeling.

\subsection{ORGANIZATION OF THE REPORT}

Chapter 2 describes a methodology to measure full- and part-load performance of the VRF and the RTU systems and to evaluate the nationwide energy savings potential of VRF systems using calibrated simulation modeling. Chapter 3 provides a simulation analysis for various US climates locations using the calibrated simulation modeling. Chapter 4 concludes the study with a summary, findings, and discussion of future work. 


\section{METHODOLOGY}

\subsection{TEST FACILITY: TWO-STORY FLEXIBLE RESEARCH PLATFORM}

The test facility is a two-story, 3,200 $\mathrm{ft}^{2}\left(297.3 \mathrm{~m}^{2}\right)$ multi-zone unoccupied building that represents a typical low-rise, small office building common in the US existing building stock (Figure 1). The occupancy in the building can be simulated by process control of lighting and other internal loads. On this building, retrofits and alternative building components and systems can be implemented and their performance monitored. In addition, a dedicated weather station is installed on the roof that provides actual weather data for use in performance analysis and energy modeling. The building is equipped with a conventional 12.5 ton $(44 \mathrm{~kW})$ RTU-VAV reheat system. For this study, a 12 ton ( $42 \mathrm{~kW}) \mathrm{VRF}$ with a DOAS was installed (Figure 1, center and left); the existing RTU system served as the baseline system. Table 1 summarizes the baseline building and system characteristics.
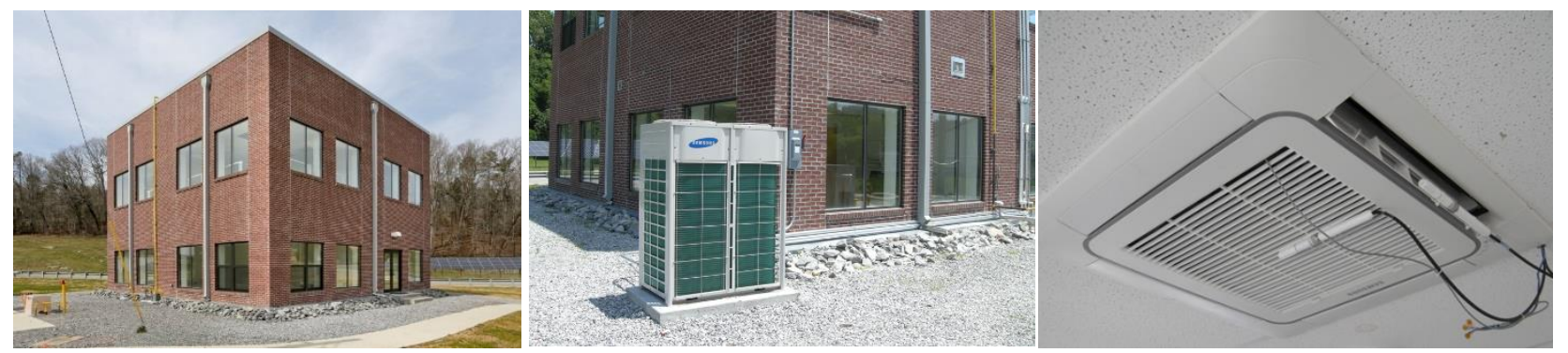

Figure 1. Test facility (left), VRF system outdoor unit (center), and indoor unit (right).

Table 1. Building characteristics

\begin{tabular}{l|l}
\hline Location & Oak Ridge, Tennessee, USA \\
Building size & Two-story, $40 \times 40 \mathrm{ft}(12.2 \times 12.2 \mathrm{~m}), 14 \mathrm{ft}(4.3 \mathrm{~m})$ floor-to-floor height \\
Exterior walls & Concrete masonry units with face brick, RUs-11 (Rs-1.9) fiberglass insulation \\
Floor & Slab-on-grade \\
Roof & Metal deck with RUs $-18\left(\mathrm{R}_{\mathrm{SI}}-3.17\right)$ polyisocyanurate insulation \\
Windows & Double-pane clear glazing, $28 \%$ window-to-wall ratio \\
Baseloads & $0.85 \mathrm{~W} / \mathrm{ft}^{2}\left(9.18 \mathrm{~W} / \mathrm{m}^{2}\right)$ lighting power density, $1.3 \mathrm{~W} / \mathrm{ft}^{2}\left(14.04 \mathrm{~W} / \mathrm{m}^{2}\right)$ equipment power density \\
Baseline HVAC system & 12.5 ton, $9.7 \mathrm{EER}$ rooftop unit; $81 \%$ AFUE natural gas furnace; VAV terminal units and electric \\
& reheat \\
VRF system & 12 ton $(42 \mathrm{~kW})$ VRF system with a DOAS at OA rate of $0.189 \mathrm{~m}^{3} / \mathrm{s}(400 \mathrm{CFM})$ \\
\hline
\end{tabular}

\subsection{HVAC SYSTEMS}

Figure 2 shows a schematic of the two systems. The RTU provides direct expansion (DX) cooling, heating with a natural gas furnace, and electric resistance reheat at VAV terminal units. The return air is drawn from each room through an above-ceiling plenum on each floor. Fresh air is introduced through the fan of the DOAS to provide adequate ventilation in accordance with ASHRAE Standard 62.1-2013 (ASHRAE 2013). An exhaust fan is located on each floor and operates continuously. The RTU is programmed to maintain a constant discharge air temperature at $14^{\circ} \mathrm{C}\left(57^{\circ} \mathrm{F}\right)$ during the cooling season. During the heating season, the RTU discharge air temperature was adjusted based on an OA reset schedule (See Figure 3). The natural gas furnace would engage if the return air temperature to the RTU dropped below the discharge air set point temperature. In the cooling mode (i.e., discharge temperature 
set at $14^{\circ} \mathrm{C}$ ), the electric resistance reheat in the VAV terminal boxes in individual zones activates to provide necessary heat to maintain the desired zone temperature.
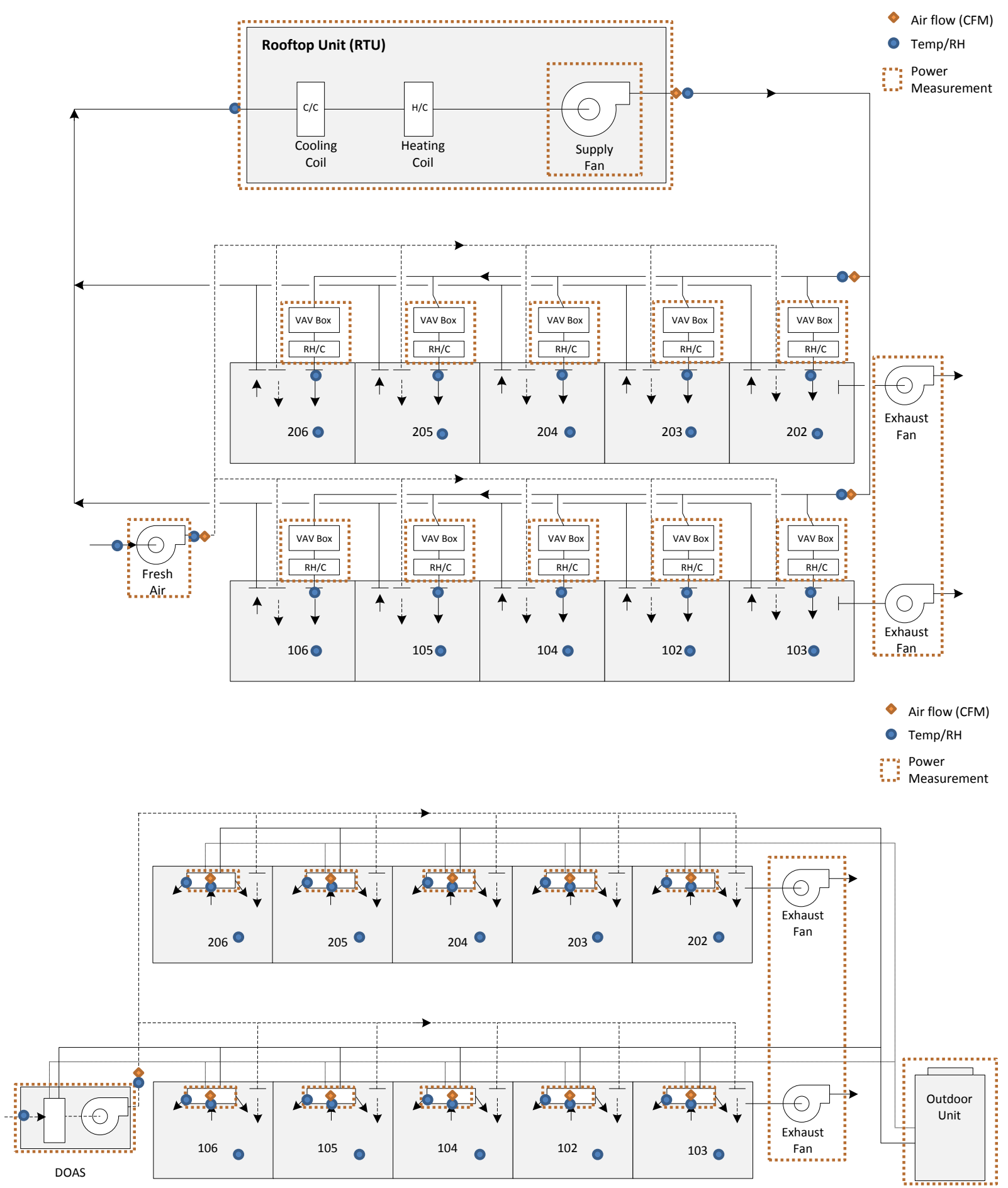

Figure 2. System schematic and monitoring points for RTU system (above) and VRF system (below). 


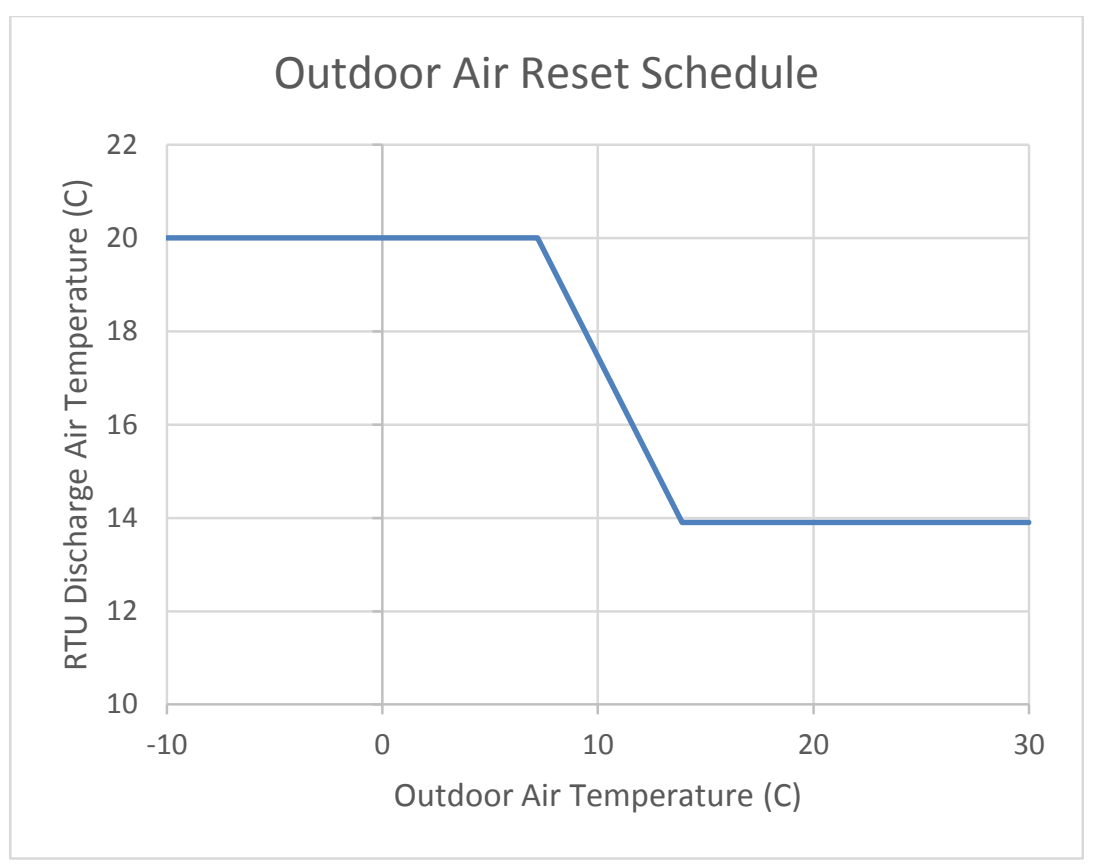

Figure 3. Outdoor air reset schedule for RTU discharge temperature.

The VRF system has a 12-ton (42 kW) outdoor unit, one DOAS unit, and ten indoor units with capacities ranging from 0.5 to 1.5 tons $(1.8-5.3 \mathrm{~kW}$ ). The ten indoor units and the DOAS (Figure 4) are connected to the same VRF outdoor condensing unit, and the DOAS provides conditioned OA to ten zones at 0.189 $\mathrm{m}^{3} / \mathrm{s}$ (400 CFM). Note that the VRF system in this test is a heat pump-type system that provides only cooling or heating at any single time and cannot provide simultaneous heating and cooling for different thermal zones.

\subsection{BUILDING OPERATION}

The VRF and the baseline RTU system performance was evaluated by comparing their hourly and daily energy use and the indoor thermal condition (i.e., temperature). In year 1, the entire building was conditioned for the performance evaluation, which had a limitation in part-load performance evaluation. In year 2, the building was partially and fully conditioned to compare the part-load performance of the systems in more detail. Figure 5 illustrates the schematic of operation to emulate (a) 50\% load, (b) $75 \%$ load, and (c) $100 \%$ load. ${ }^{1}$ Each system was operated alternately for 8 consecutive days with 3 days each for 50 and $75 \%$ and 2 days for $100 \%$ loads. Unlike in year 1, there was no discrete weekday and weekend schedule; the same occupancy schedule was used for all days. Table 2 and Table 3 provide each schedule for the cooling and heating seasons, respectively.

\footnotetext{
${ }^{1}$ The operation scenarios were named 50 and $75 \%$ loads based on the combined rated capacity of the indoor units.
} 


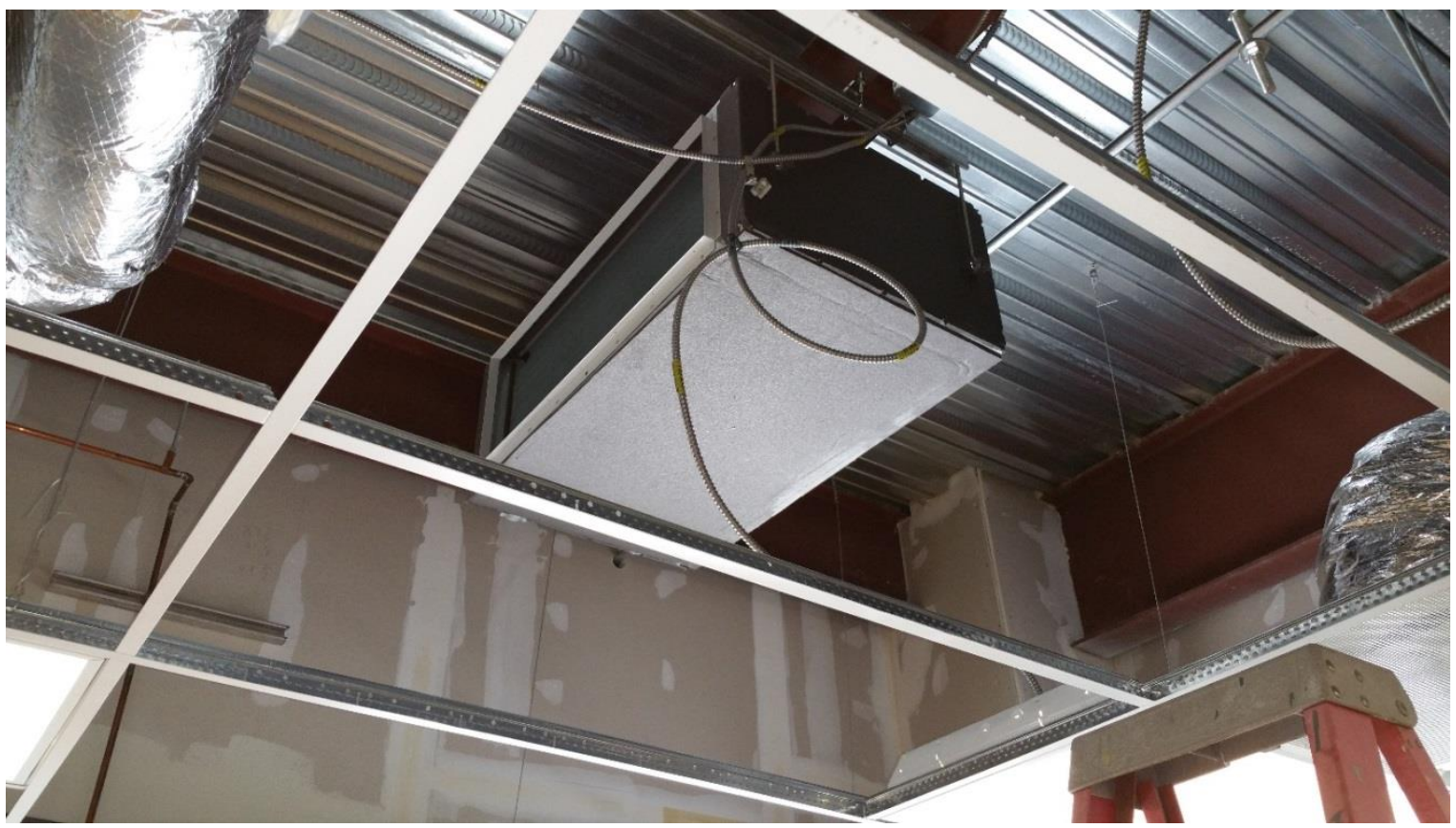

Figure 4. Installation of dedicated outdoor air system.

As shown in Table 2, the cooling season analysis was based on the measured data from July 11, 2015, through September 12, 2015. During this period, the RTU system was operated for 9 days at 50\% load, 13 days at $75 \%$ load, and 8 days at 100\% load. The VRF system was operated for 9 days at 50\% load, 9 days at $75 \%$ load, and 6 days at 100\% load. Table 3 shows the heating season operation schedules of the RTU and VRF systems under different loads. In both tables, the green-shaded cells indicate the days of VRF system operation and the orange-shaded cells indicate the days of VRF system operation. As shown in Table 3, the heating season analysis was based on the measured data from December 30, 2015, through March 6, 2016. During this period, the RTU system was operated for 9 days at 50\% load, 9 days at $75 \%$ load, and 13 days at $100 \%$ load. The VRF system was operated for 9 days at $50 \%$ load, 12 days at $75 \%$ load, and 11 days at $100 \%$ load.

Based on the schedule, occupancy emulation also was controlled so that only the conditioned rooms had emulated occupancy. 


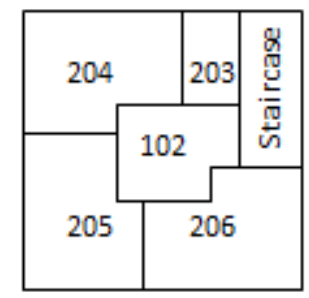

Secondfloor

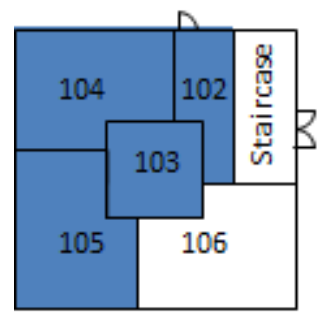

First floor

$50 \%$ load

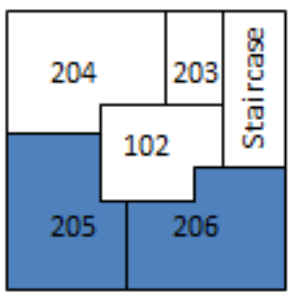

Secondfloor

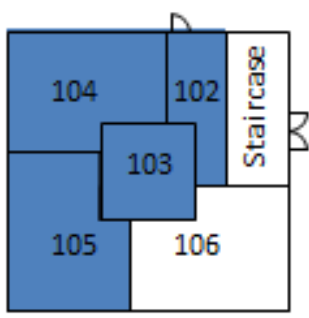

First floor

$75 \%$ load

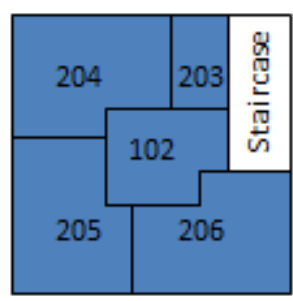

Secondfloor

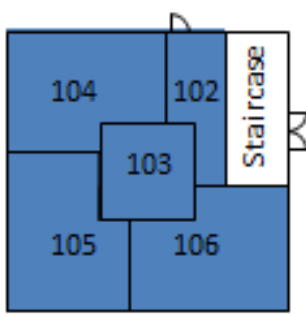

First floor

$100 \%$ load

Figure 5. Schematic of operation to emulate (a) $50 \%$ load, (b) $75 \%$ load, and (c) $100 \%$ load.

\subsection{EVALUATION METRICS}

The performance of the RTU and VRF systems was compared in terms of (1) energy use, (2) ability to maintain room temperature, and (3) system efficiency. The energy use and thermal performance comparison were performed using measured hourly data for occupied hours only (i.e., 8 a.m. to 6 p.m.), excluding the startup hours. The coefficient of performance (COP) analysis was performed using both hourly and 1-minute data. Figure 2 shows the air-side monitoring points, which include the room temperature and relative humidity, supply, return, and mixed-air temperature and relative humidity. The airflow rate was measured at the RTU supply, upstairs and downstairs of the supply duct, and at the fresh air supply for the RTU system. For the VRF system, one-time airflow measurements were conducted for each indoor unit; and the DOAS supply side for the VRF system was measured continuously. Power measurements were obtained separately for the RTU unit, the supply fan, and the DOAS fan for the baseline RTU system. Power consumption for the VRF outdoor unit, each VRF indoor unit, and the DOAS was measured as well. Table 4 shows the list of sensors that were installed for the VRF system. The measured supply, return temperature and relative humidity, and airflow were used to calculate the delivered heating and cooling loads to the building and the system COP as well. 
Table 2. Summer season operation schedule

\begin{tabular}{|c|c|c|c|c|c|c|c|c|c|c|c|c|c|}
\hline Date & RTU50 & RTU75 & RTU100 & VRF50 & VRF75 & VFR100 & Date & RTU50 & RTU75 & RTU100 & VRF50 & VRF75 & VFR100 \\
\hline 11-Jul & & & & & & & 12-Aug & & & & & & \\
\hline 12-Jul & & & & & & & 13-Aug & & & & & & \\
\hline 13-Jul & & & & & & & 14-Aug & & & & & & \\
\hline 14-Jul & & & & & & & 15-Aug & & & & & & \\
\hline 15-Jul & & & & & & & 16-Aug & & & & & & \\
\hline 16-Jul & & & & & & & 17-Aug & & & & & & \\
\hline 17-Jul & & & & & & & $18-\mathrm{Aug}$ & & & & & & \\
\hline 18-Jul & & & & & & & 19-Aug & & & & & & \\
\hline 19-Jul & & & & & & & 20-Aug & & & & & & \\
\hline 20-Jul & & & & & & & 21-Aug & & & & & & \\
\hline 21-Jul & & & & & & & 22-Aug & & & & & & \\
\hline 22-Jul & & & & & & & 23-Aug & & & & & & \\
\hline 23-Jul & & & & & & & 24-Aug & & & & & & \\
\hline 24-Jul & & & & & & & 25-Aug & & & & & & \\
\hline 25-Jul & & & & & & & 26-Aug & & & & & & \\
\hline 26-Jul & & & & & & & 27-Aug & & & & & & \\
\hline 27-Jul & & & & & & & 28-Aug & & & & & & \\
\hline 28-Jul & & & & & & & 29-Aug & & & & & & \\
\hline 29-Jul & & & & & & & 30-Aug & & & & & & \\
\hline 30-Jul & & & & & & & 31-Aug & & & & & & \\
\hline 31-Jul & & & & & & & 1-Sep & & & & & & \\
\hline 1-Aug & & & & & & & 2-Sep & & & & & & \\
\hline 2-Aug & & & & & & & 3-Sep & & & & & & \\
\hline 3-Aug & & & & & & & 4-Sep & & & & & & \\
\hline 4-Aug & & & & & & & $5-$ Sep & & & & & & \\
\hline 5-Aug & & & & & & & 6-Sep & & & & & & \\
\hline 6-Aug & & & & & & & 7-Sep & & & & & & \\
\hline 7-Aug & & & & & & & 8-Sep & & & & & & \\
\hline 8-Aug & & & & & & & 9-Sep & & & & & & \\
\hline 9-Aug & & & & & & & 10-Sep & & & & & & \\
\hline 10-Aug & & & & & & & 11-Sep & & & & & & \\
\hline 11-Aug & & & & & & & 12-Sep & & & & & & \\
\hline
\end{tabular}

Table 3. Winter season operation schedule

\begin{tabular}{|c|c|c|c|c|c|c|c|c|c|c|c|c|c|}
\hline Date & RTU50 & RTU75 & RTU100 & VRF50 & VRF75 & VFR100 & Date & RTU50 & RTU75 & RTU100 & VRF50 & VRF75 & VFR100 \\
\hline 30-Dec & & & & & & & 2-Feb & & & & & & \\
\hline 31-Dec & & & & & & & $3-\mathrm{Feb}$ & & & & & & \\
\hline 1-Jan & & & & & & & 4-Feb & & & & & & \\
\hline 2-Jan & & & & & & & 5-Feb & & & & & & \\
\hline 3-Jan & & & & & & & 6-Feb & & & & & & \\
\hline 4-Jan & & & & & & & 7-Feb & & & & & & \\
\hline 5-Jan & & & & & & & $8-\mathrm{Feb}$ & & & & & & \\
\hline 6-Jan & & & & & & & 9-Feb & & & & & & \\
\hline 7-Jan & & & & & & & $10-\mathrm{Feb}$ & & & & & & \\
\hline 8-Jan & & & & & & & $11-\mathrm{Feb}$ & & & & & & \\
\hline 9-Jan & & & & & & & $12-\mathrm{Feb}$ & & & & & & \\
\hline 10-Jan & & & & & & & $13-\mathrm{Feb}$ & & & & & & \\
\hline 11-Jan & & & & & & & $14-\mathrm{Feb}$ & & & & & & \\
\hline 12-Jan & & & & & & & $15-\mathrm{Feb}$ & & & & & & \\
\hline 13-Jan & & & & & & & $16-\mathrm{Feb}$ & & & & & & \\
\hline 14-Jan & & & & & & & $17-\mathrm{Feb}$ & & & & & & \\
\hline 15-Jan & & & & & & & $18-\mathrm{Feb}$ & & & & & & \\
\hline 16-Jan & & & & & & & $19-\mathrm{Feb}$ & & & & & & \\
\hline 17-Jan & & & & & & & $20-\mathrm{Feb}$ & & & & & & \\
\hline 18-Jan & & & & & & & 21-Feb & & & & & & \\
\hline 19-Jan & & & & & & & $22-\mathrm{Feb}$ & & & & & & \\
\hline 20-Jan & & & & & & & $23-\mathrm{Feb}$ & & & & & & \\
\hline 21-Jan & & & & & & & $24-\mathrm{Feb}$ & & & & & & \\
\hline 22-Jan & & & & & & & 25-Feb & & & & & & \\
\hline 23-Jan & & & & & & & 26-Feb & & & & & & \\
\hline 24-Jan & & & & & & & $27-\mathrm{Feb}$ & & & & & & \\
\hline 25-Jan & & & & & & & $28-\mathrm{Feb}$ & & & & & & \\
\hline 26-Jan & & & & & & & $29-\mathrm{Feb}$ & & & & & & \\
\hline 27-Jan & & & & & & & 1-Mar & & & & & & \\
\hline 28-Jan & & & & & & & 2-Mar & & & & & & \\
\hline 29-Jan & & & & & & & 3-Mar & & & & & & \\
\hline 30-Jan & & & & & & & 4-Mar & & & & & & \\
\hline 31-Jan & & & & & & & 5-Mar & & & & & & \\
\hline 1-Feb & & & & & & & 6-Mar & & & & & & \\
\hline
\end{tabular}


Table 4. List of sensors for VRF system

\begin{tabular}{|c|c|c|c|c|c|}
\hline Function & Sensor & Sensor model & Location & Quantity & Accuracy \\
\hline \multirow{2}{*}{$\begin{array}{l}\text { Indoor } \\
\text { thermal } \\
\text { condition } \\
\text { heating } \\
\text { and } \\
\text { cooling } \\
\text { capacities }\end{array}$} & Temp/RH & Campbell Sci HC2S3-L & All air side & 20 & $\begin{array}{c} \pm 0.1^{\circ} \mathrm{C} \text { and } \pm 0.1 \% \mathrm{RH} \\
\text { @ } 23^{\circ} \mathrm{C}\end{array}$ \\
\hline & $\begin{array}{l}\text { Air flow } \\
\text { sensors (For } \\
\text { DOAS) }\end{array}$ & $\begin{array}{l}\text { Air monitor fan evaluators paired to } \\
\text { DPT2500 Plus transmitters }\end{array}$ & DOAS & 1 & $\begin{array}{l}\text { DTP2500: } 0.25 \% \text { of } \\
\text { natural span, including } \\
\text { hysteresis, deadband, } \\
\text { nonlinearity, and } \\
\text { nonrepeatability; fan } \\
\text { evaluator: } \pm 2 \%\end{array}$ \\
\hline \multirow[t]{4}{*}{ Power } & Wattnode & $\begin{array}{l}\text { Continental Controls WNB-3D- } \\
240 \mathrm{P}, \\
100 \mathrm{~Hz} \text { option }\end{array}$ & ID units & 11 & $\pm 0.5 \%$ of reading \\
\hline & $\mathrm{CT}$ & $\begin{array}{l}\text { Continental Controls ACT-0750- } \\
005\end{array}$ & ID units & 22 & $\pm 0.75 \%$ of reading \\
\hline & Wattnode & $\begin{array}{l}\text { Continental Controls WNB-3D- } \\
240 \mathrm{P}, \\
100 \mathrm{~Hz} \text { option }\end{array}$ & OD unit & 1 & $\pm 0.5 \%$ of reading \\
\hline & CT & $\begin{array}{l}\text { Continental Controls ACT-0750- } \\
020\end{array}$ & OD unit & 3 & $\pm 0.75 \%$ of reading \\
\hline
\end{tabular}

\subsection{SIMULATION ANALYSIS}

Once the cooling and heating season data were available, calibrated simulation models were developed for the FRP with the RTU and VRF systems. Since the FRP was operated with each system alternately to determine the energy performance of each HVAC system, the full-year energy use for the FRP with each system cannot be obtained. Therefore, the calibrated energy simulation was used to evaluate the annual energy performance of each HVAC system.

For the building energy simulation, the US Department of Energy's (DOE) flagship building energy modeling software, EnergyPlus 8.1, was used. Version 8.1 of EnergyPlus provides the capability for modeling VRF systems as well as single-package RTUs with VAV reheat, but that version of EnergyPlus could not be used to model the current VRF-DOAS system configuration in the FRP. Therefore, the EnergyPlus source code of the current version was modified. In the modified version of EnergyPlus 8.1, OA was provided through an air-loop DOAS linked with a VRF outdoor unit to model the VRF-DOAS installed in the FRP.

The energy simulation model of the VRF system was developed using the modified version of EnergyPlus 8.1, and the simulation model was calibrated by comparing its results with the hourly measured data until they reasonably matched based on the definition from ASHRAE Guideline 14P (ASHRAE 2002). In addition, the calibrated simulation models for the RTU and the VRF systems were run with various weather files corresponding with ASHRAE climate zones to evaluate the energy and cost savings potential in various US climates locations. 



\section{SIMULATION ANALYSIS}

This chapter discusses (1) the source code modification of EnergyPlus 8.1, (2) the calibration of the energy simulation modeling of the FRP with the VRF-DOAS and the baseline RTU systems, and (3) the performance evaluation of the VRF system in 12 major climate locations in the United States. To evaluate the annual energy performance of the VRF system, the energy simulation modeling was particularly useful in this project because the FRP was operated with multiple HVAC systems alternately to evaluate the energy performance of various HVAC systems. It was not available to obtain a complete full year of data for each system type. In addition, the energy modeling allows a comparison of the simulated annual energy performance of the VRF and RTU systems in various climate locations in the United States.

EnergyPlus 8.1 was used for the energy simulation modeling. The original EnergyPlus version 8.1 is capable of modeling zonal VRF systems as well as single-packaged RTUs with VAV reheat. However, that version of EnergyPlus could not be used to model the current VRF-DOAS system setting in the FRP (particularly the use of VRF heating and cooling coils to condition OA in a DOAS). Therefore, the EnergyPlus 8.1 source code was modified to allow for OA to be provided through an air-loop DOAS directly to individual zones and to be conditioned with VRF heating and cooling coils connected to the outdoor unit supplying the indoor unit for each zone of the VRF system.

The energy simulation models of the RTU and VRF systems were developed using the modified version of EnergyPlus 8.1, and the models were calibrated by comparing them with the hourly measured data until they reasonably matched, based on the definition from ASHRAE Guideline 14P (ASHRAE 2002). Then the calibrated models were run with weather files from various US climate locations corresponding to 12 ASHRAE climate zones to evaluate the energy and cost savings potential in various locations.

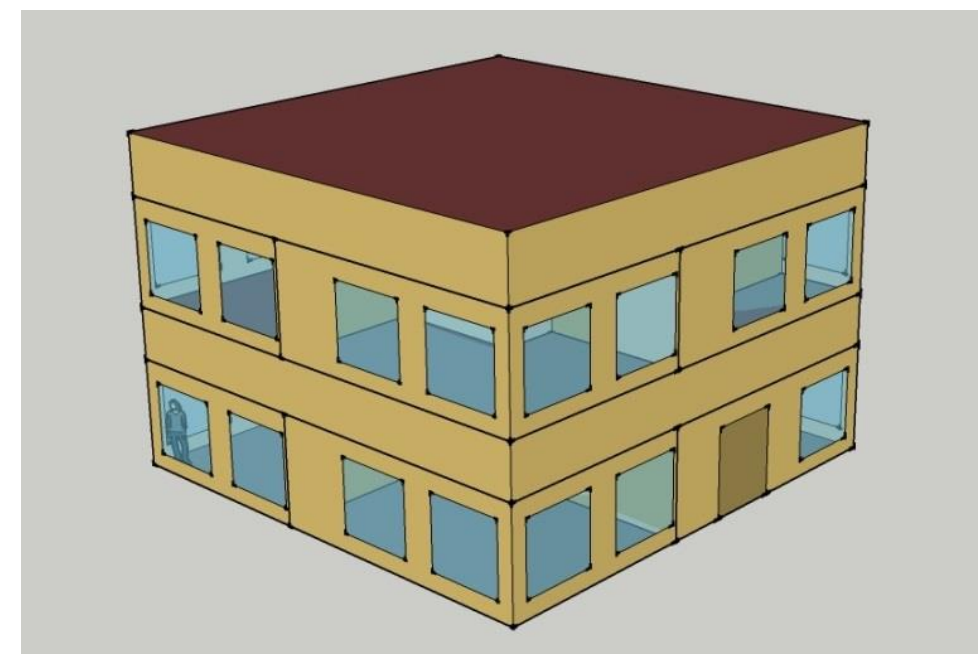

Figure 6. Three-dimensional rendering of the EnergyPlus model of the two-story FRP.

\subsection{ENERGYPLUS SOURCE CODE MODIFICATION}

In the original version of EnergyPlus, OA could be introduced only through individual zonal VRF indoor units with an OA mixer or an air-loop DOAS with HVAC DX coils from a separate HVAC system. It could not be introduced through VRF coils connected to the outdoor units for a zonal VRF system, as is illustrated in Figure 7 and Figure 8. 


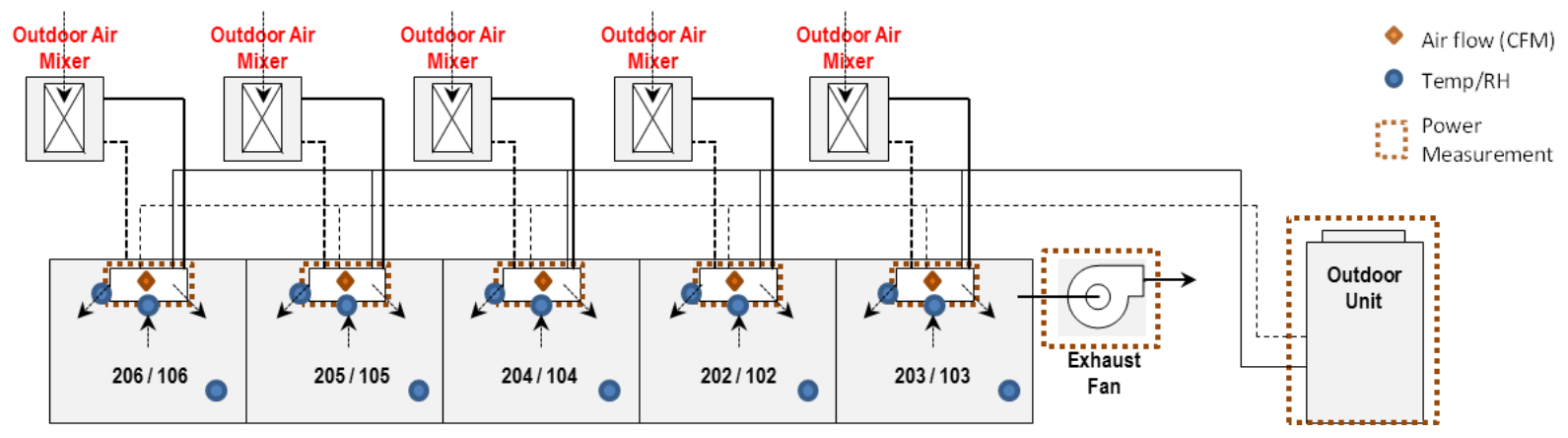

Figure 7. A system diagram of a VRF system with an OA mixer in the original version of EnergyPlus 8.1.

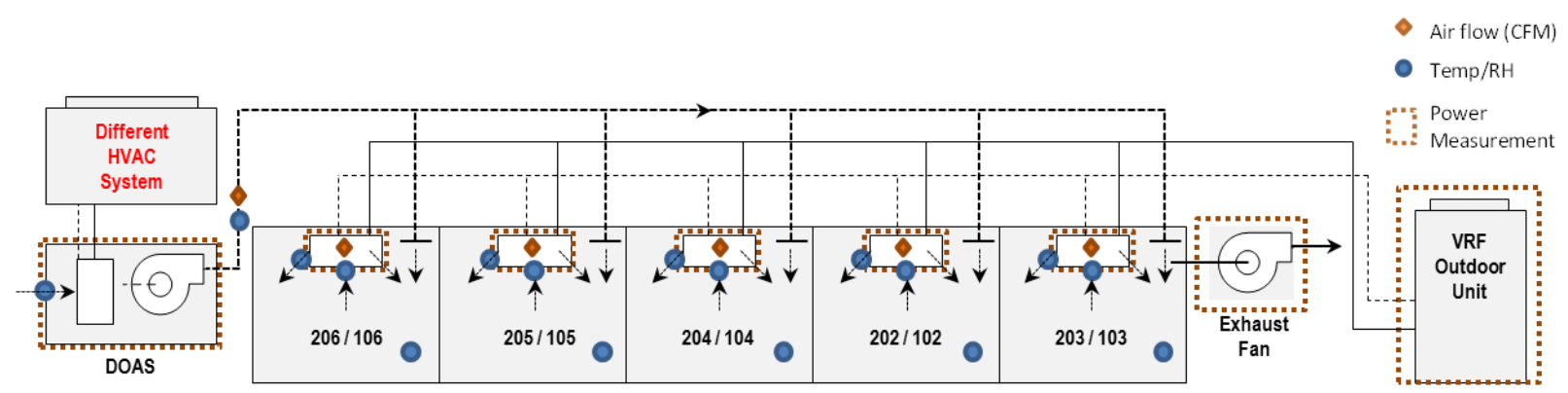

Figure 8. A system diagram of a VRF system with an air-loop DOAS in the original version of EnergyPlus 8.1.

To model the current settings of the VRF-DOAS system installed in the FRP, the following EnergyPlus air loop and VRF subroutines were modified.

- $\quad$ SimAirServingZones.f90

$\circ$ Modified error handling and severe warning outputs for new VRF air loop coils.

- SystemReports.f90

- Added VRF air loop heating and cooling reporting variables.

- AirFlowNetworkBalanceManager.f90

$\circ$ Added error handling for VRF air loop heating and cooling coils.

- DXCoil.f90

- Added VRF air loop heating and cooling coils based on DX single-speed coils. Creating new coils allowed the VRF parent unit to "recognize" the DOAS air loop coils that belong to it.

- HVACDXSystem.f90

- Allowed two new coil objects to be called and controlled by Coil System wrapper object.

- HVACVariableRefrigerantFlow.f90

- Modified load and energy calculations to include the VRF air-loop coils in the calculations.

- Modified coil limiting routines so the DOAS coil would have priority over the terminal units in case capacity was exceeded.

- Added new Autosizing routines to account for the incorporation of the DOAS and VRF terminal units.

- Created utility subroutines (e.g., object index and name lookup) to be used in different subroutine modules.

With this source code modification, two new objects, VRF air-loop cooling and heating coils (object names Coil:Cooling:DX:VRFAirloopCoil and Coil:Heating:DX:VRFAirloopCoil), were added to enable a DOAS system coupled with a VRF outdoor unit to provide $100 \%$ conditioned OA to individual zones, as 
illustrated in Figure 9. Figure 10 demonstrates the simulation process of the modified EnergyPlus version. The new VRF air-loop coil objects calculated the coil performance similar to the single-speed DX heating and cooling coils. Then the coil capacities were accounted into the VRF condenser calculations along with the average inlet wet-bulb conditions for each coil linked to the VRF condenser. In the current modification, only one VRF condenser can be used. The model uses performance information at rated conditions along with curve fits for variations in total capacity, energy input ratio, and part-load fraction to determine the performance of the unit at part-load conditions. The Input-Output Reference and Engineering Reference documents of this modification with the new objects are provided in Appendices B and C. After the source code modification of EnergyPlus 8.1, the new EnergyPlus executable file and input data dictionary (idd) file were generated and made available to model the VRF-DOAS system installed in the FRP.

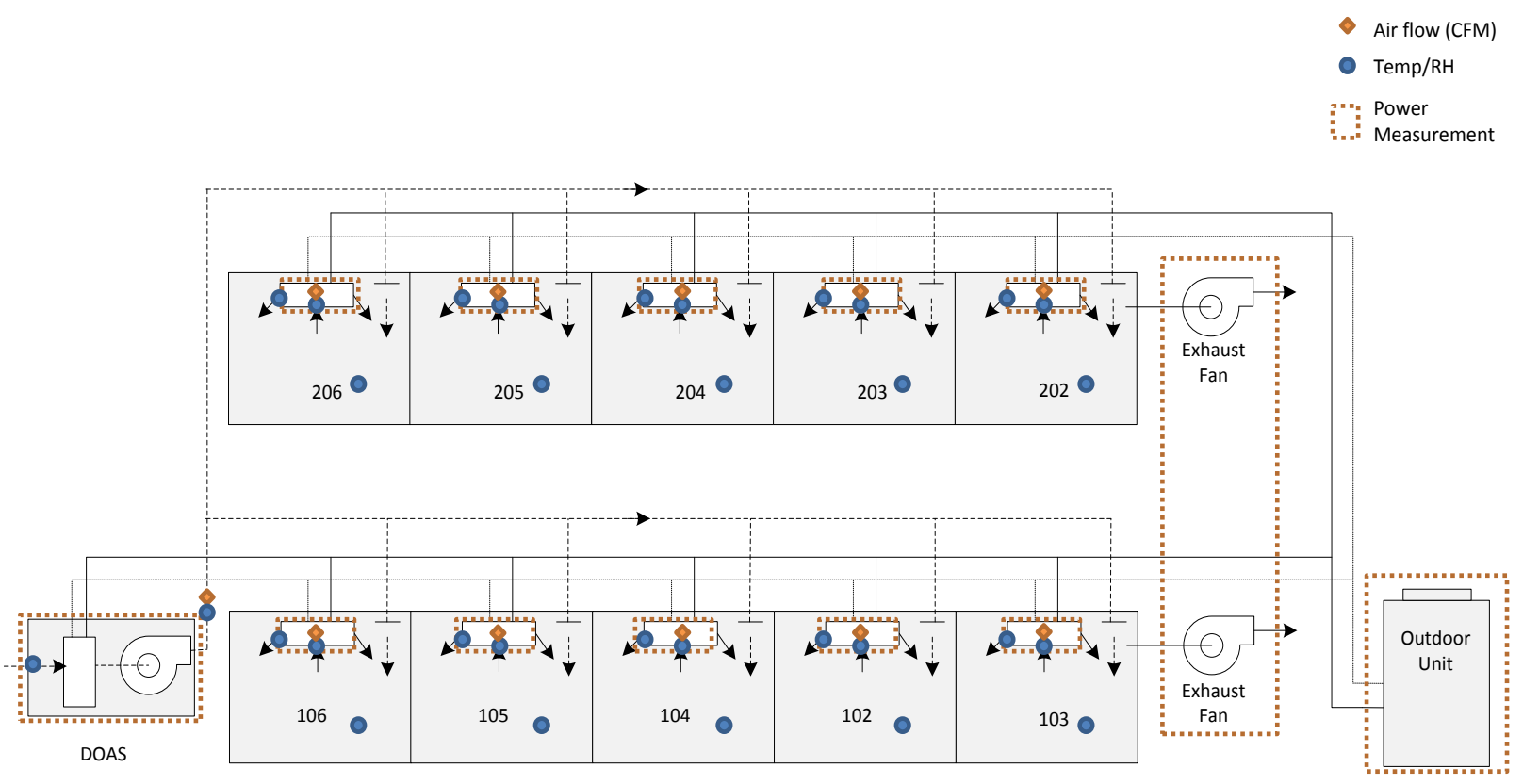

Figure 9. A system diagram of a VRF system with a DOAS coupled with a VRF outdoor unit. 


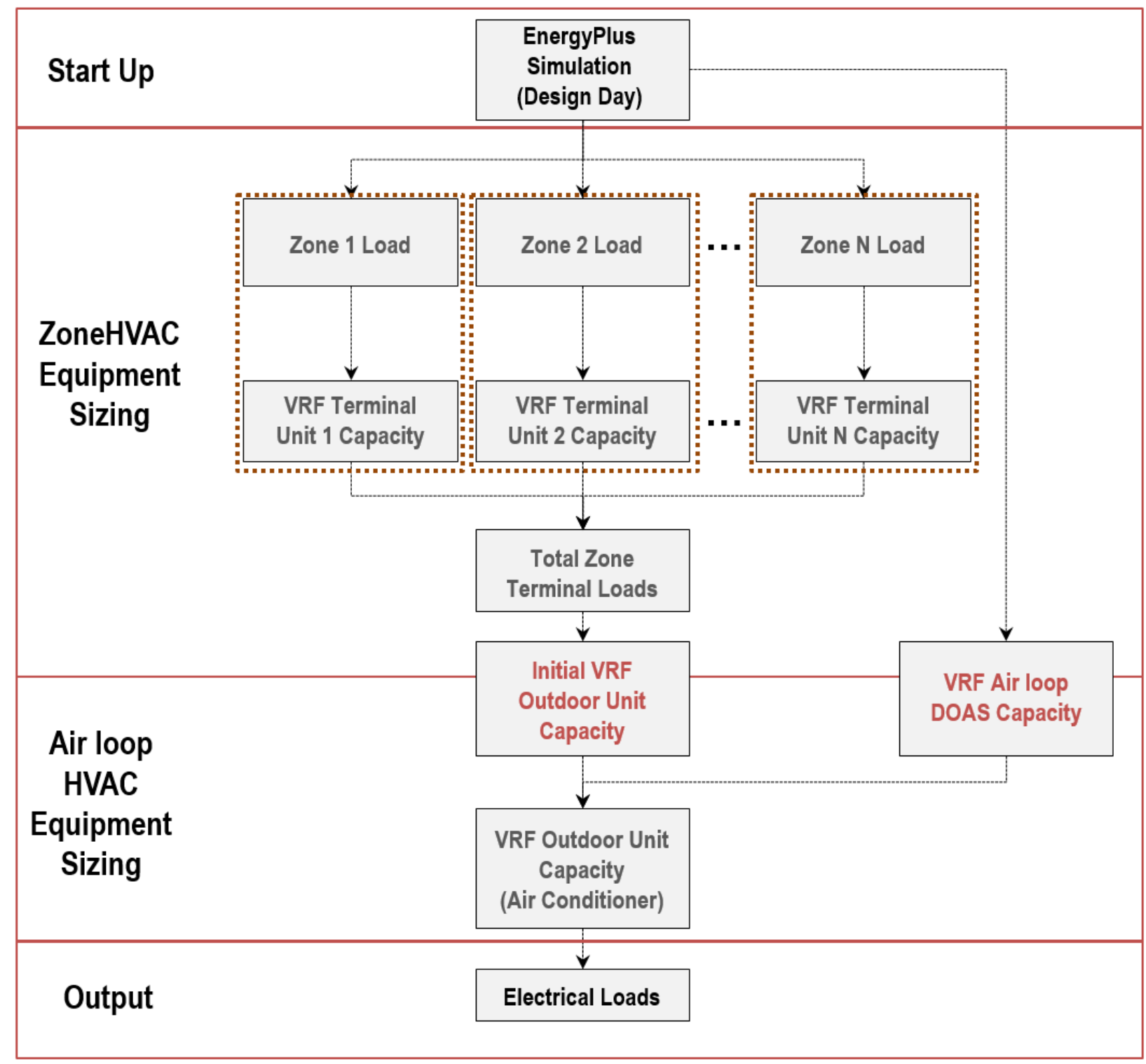

Figure 10. Process of the modified EnergyPlus simulation for the VRF-DOAS.

To check the validity of the modified version of EnergyPlus 8.1, a simulation test was performed with a single-zone building model. The building model descriptions are summarized in Table 23 in Appendix C. Two HVAC systems were modeled in each version of EnergyPlus as described in Table 24in Appendix C: a VRF terminal unit with an OA mixer for the original EnergyPlus (VRF+OAmixer) and a VRF terminal unit with an air-loop DOAS for the modified version of EnergyPlus (VRF+Airloop DOAS). The identical weather file (i.e., USA_TN_Knoxville-McGhee-TMY3.epw) was used to compare two different models; it is for a summer period in July and a winter period in January. Figure 11 shows the comparison of the end-use energy. The results show that the modified EnergyPlus model uses slightly more heating and cooling energy than the original model. That was expected because in the modified model, the zone and OA loads were removed separately using the terminal VRF and the air-loop DOAS with a VRF coil; whereas the original model removed the zone and OA loads simultaneously by mixing $\mathrm{OA}$ and return air from the zone and by using a single VRF coil to remove the mixed total heating or cooling energy. As two systems provide heating and cooling in the modified model, it has a tendency to 
overheat or overcool the zone because two units may try to provide heating and cooling at the same time separately to the zone.

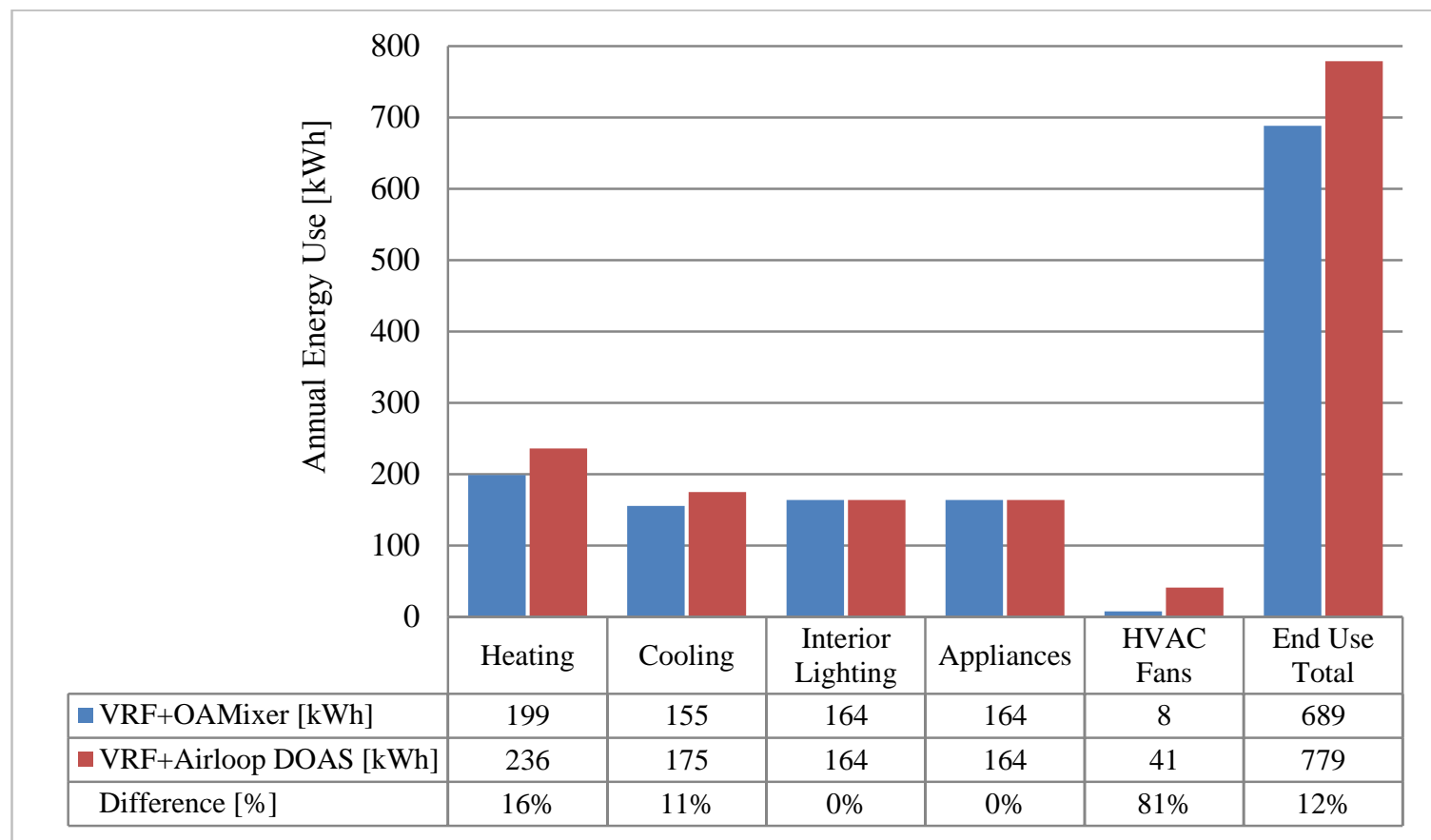

Figure 11. End use comparison between original and modified EnergyPlus models.

\subsection{MODELING AND CALIBRATION OF THE VRF AND RTU SYSTEMS}

In the first year of the project, the initial simulation models of the VRF and RTU systems were developed using the original version of EnergyPlus 8.1. Note that an OA system was not included in the models developed during the first project year. In the current study (i.e., project year two), the initial VRF and RTU models were modified to reflect changes in the FRP (i.e., the addition of a DOAS for both the VRF and RTU systems and changes in building envelope and operations), and both models were further calibrated with the measured data for both cooling and heating seasons. The actual weather data collected by a dedicated weather station installed on the roof of the two-story FRP were used in the calibration process.

Each model was calibrated using the corresponding data collected from the FRP during the following period for each system:

- $\quad$ RTU system performance data collected for 16 days from August 7, 2015, through February 6, 2016.

- VRF system performance data collected for 25 days from August 15, 2015, through February 19, 2016.

\subsubsection{Building model updates for calibration}

Before HVAC system performance was calibrated in each model, the building load was calibrated first by updating the building model based on the changes made in the FRP building configurations and operations in project year two. The building model updates includes

1. Infiltration

2. Wall insulation 
3. Interior light intensity and schedule

4. Plug load intensity and schedule

5. Shading device

6. Zone capacitance multiplier

Following is a detailed description of each update.

A blower door test was performed in project year two to measure the airtightness of the FRP. The measurement was used to calculate the infiltration value for the FRP building model in EnergyPlus based on an infiltration calculation method developed by Pacific Northwest National Laboratory (Gowri et al. 2009).

The exterior wall construction for two zones was updated in the building model to reflect modifications made in the FRP during project year two. A description of the modified wall construction is provided in Table 5 .

Table 5. Construction of modified wall insulation

\begin{tabular}{l|l|l|l|l|l|l|l}
\hline Room \# & 204 (Upstairs) \\
Direction & North facing
\end{tabular}

The intensities and schedules of the interior lights and plug loads were also updated based on the changes made in the FRP. Figure 12 and Figure 13 show the output trends of the interior lights before and after modification in the EnergyPlus model. The interior lights shown in Figure 12 and Figure 13 are hourly average values in EnergyPlus shown in terms of the electric energy for ten zones during the measurement period of 6 days. Figure 14 and Figure 15 show the output trends of the interior plug loads before and after modification in EnergyPlus. The interior plugs in Figure 14 and Figure 15 are hourly average values in EnergyPlus for rooms 102, 104, 105, 106, 203, and 205. Although there are ten rooms under the operation mode in the FRP, six rooms were modified to calibrate the energy simulation modeling, since the initial model already shows a good match with the measured data. 


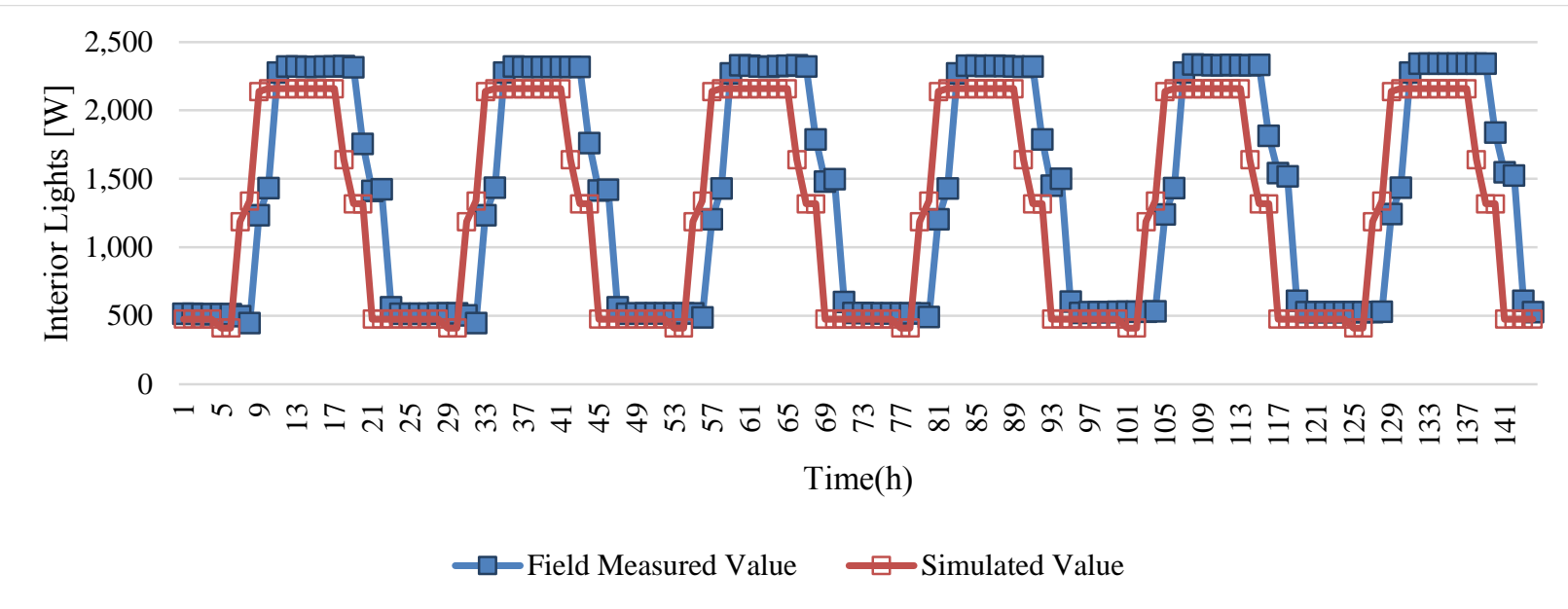

Figure 12. Interior light schedule before modification.

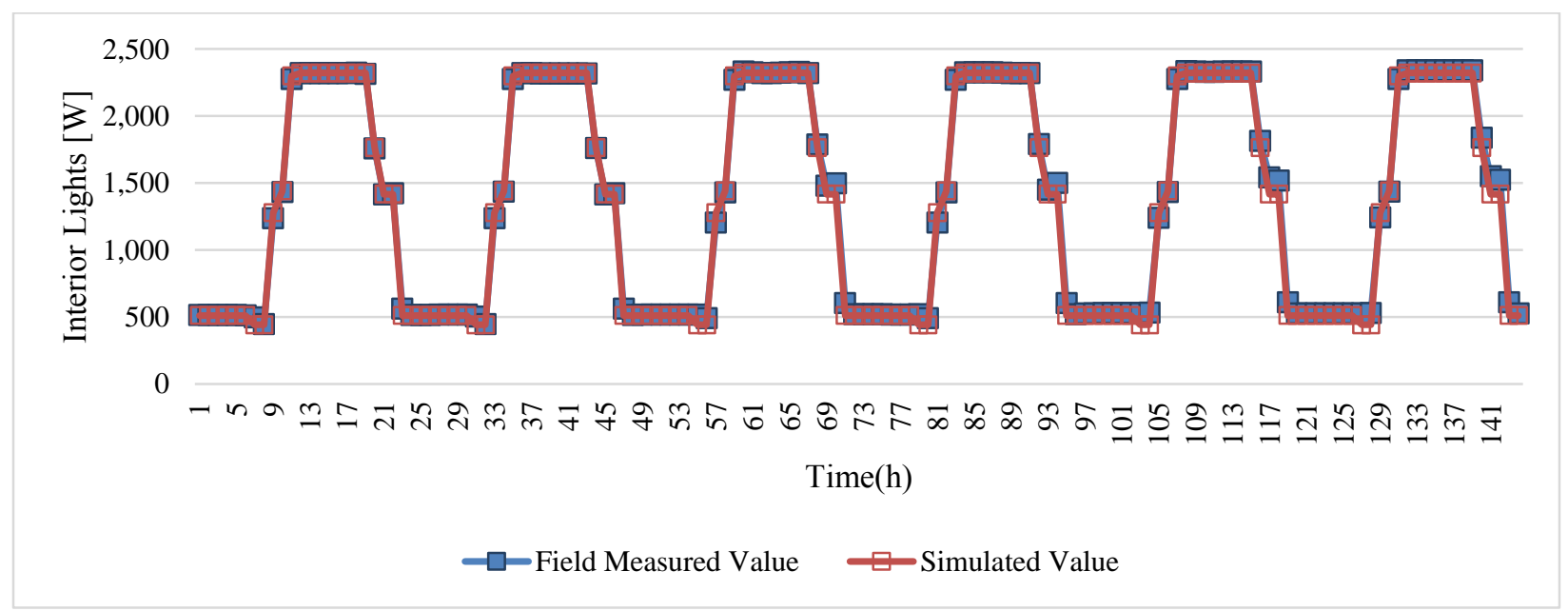

Figure 13. Interior light schedule after modification.

In addition, venetian blinds, which were installed in the FRP building, were applied to the energy study. Inputs for the venetian blinds were estimated by calculating the reflectance value and slat angle on the basis of the color and opening ratios of the blinds.

Finally, the zone capacitance multiplier was changed to match two different models. This input is used to control the effective storage capacity of the zones; the multiplier can be increased if the zone air capacitance needs to be increased for the stability of the energy simulation or to allow the energy simulation modeling higher or lower levels of damping of behavior over time. The capacitance multiplier was set to be 10, so that the building model can behave as close to the FRP building in terms of thermal response. 


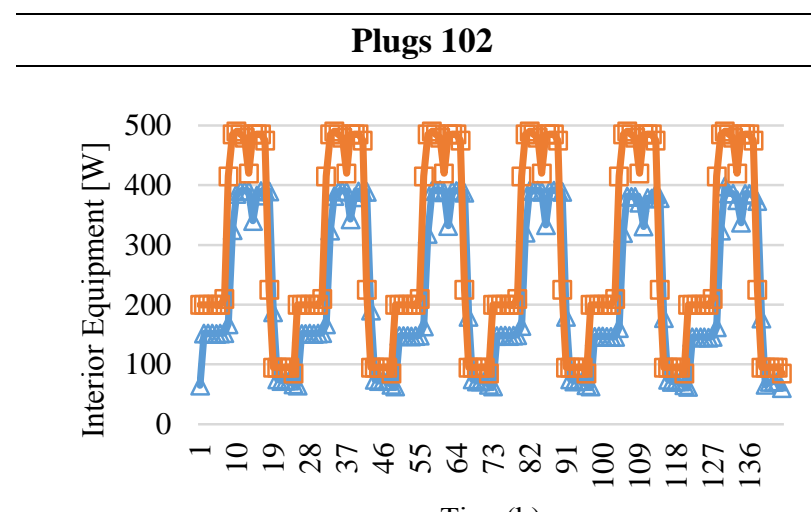

Time(h)

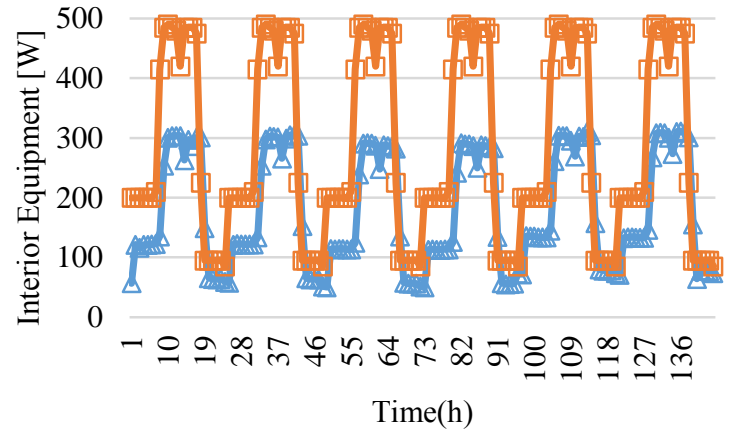

Plugs 106

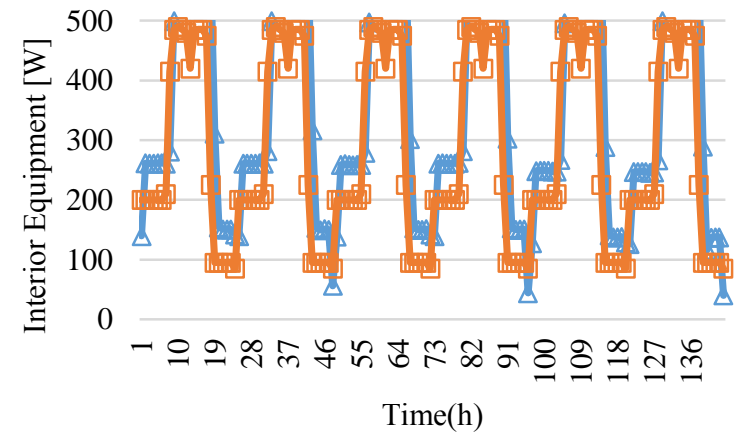

Plugs 205

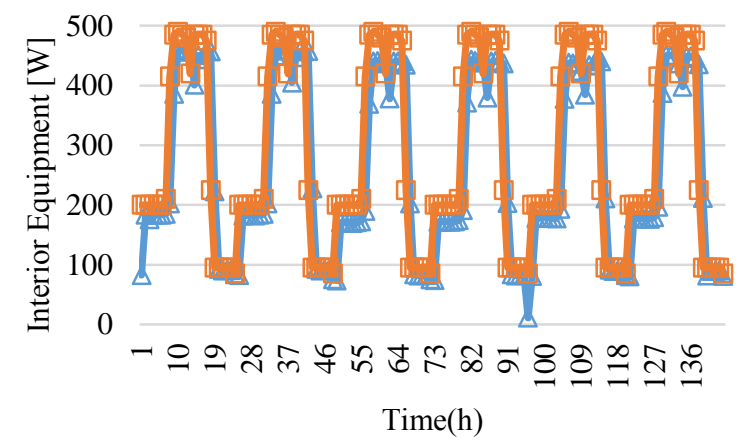

Figure 14. Interior plug load schedule before modification. 

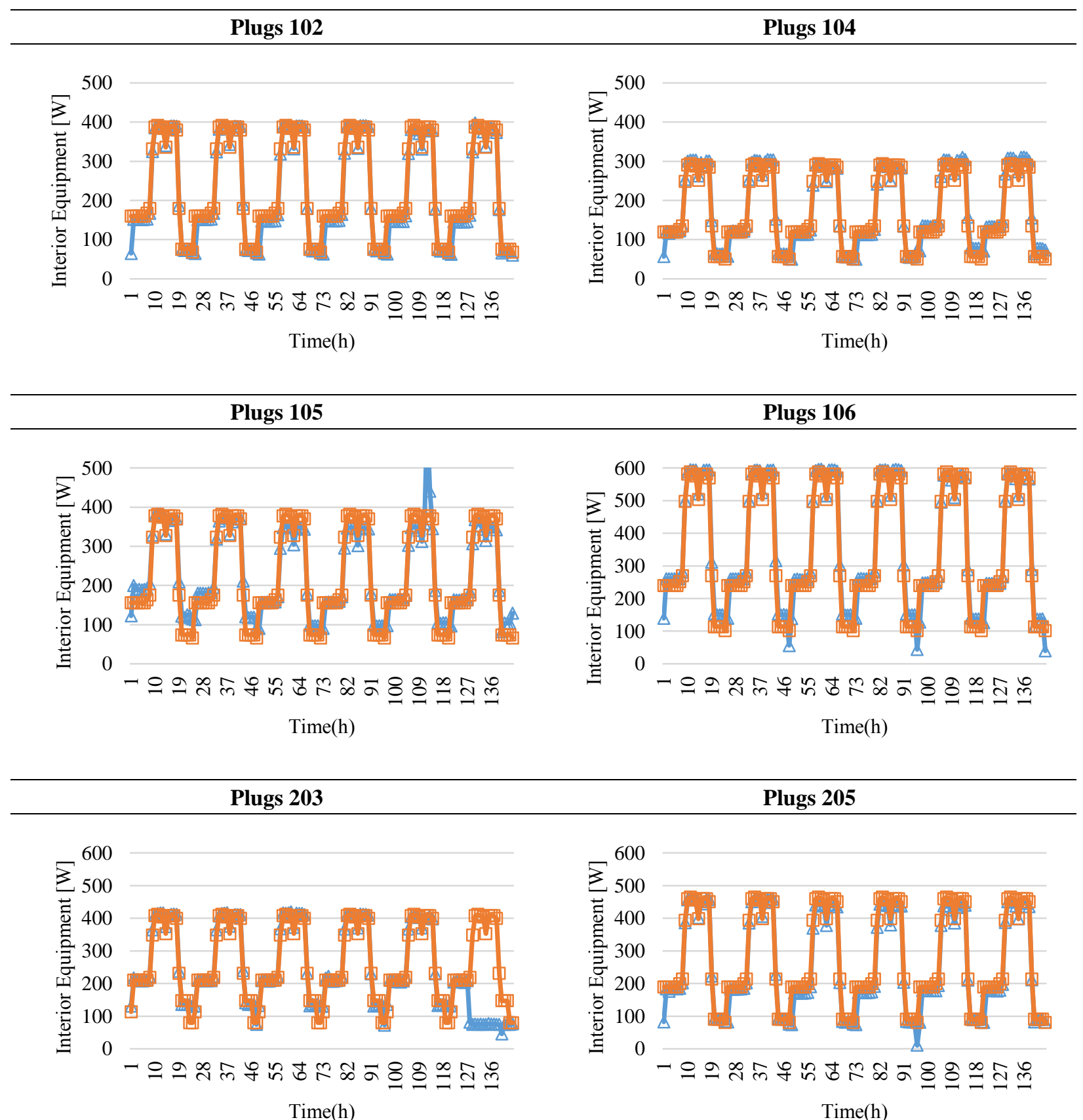

Plugs 205

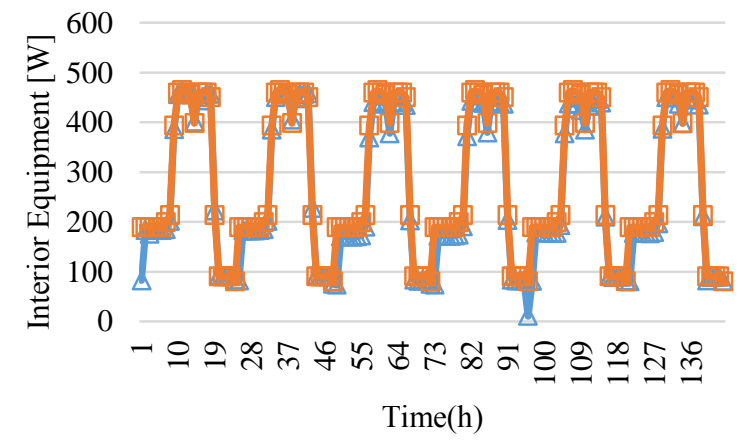

Figure 15. Interior plug load schedule after modification.

Figure 16 and Figure 17 represent scatter-plots of hourly delivered load of the RTU and VRF models versus hourly average OA temperature during the occupied hours. The simulated delivered loads of the VRF system shown in Figure 16 were compared with the measured data for 25 days during occupied hours. The loads of the RTU system shown in Figure 17 were compared with the measured data for 16 days during occupied hours. The comparison shows that the simulated delivered loads for both systems are reasonably well matched. Comparing the building delivered load allowed the building components for the energy simulation model to be well calibrated before the HVAC systems were adjusted to finally match the measured energy performance. 


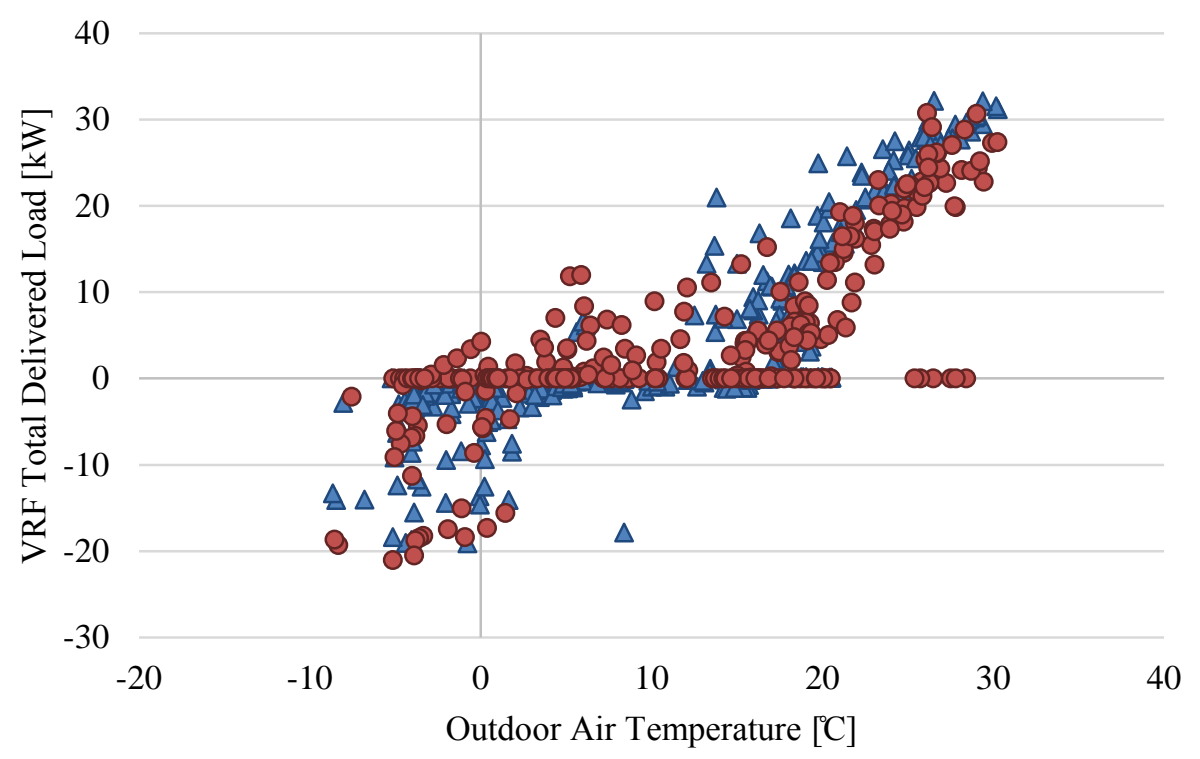

$\Delta$ Total Delivered Load Measured $\quad$ Total Delivered Load Simulated

Figure 16. Measured versus simulated hourly VRF total delivered loads.

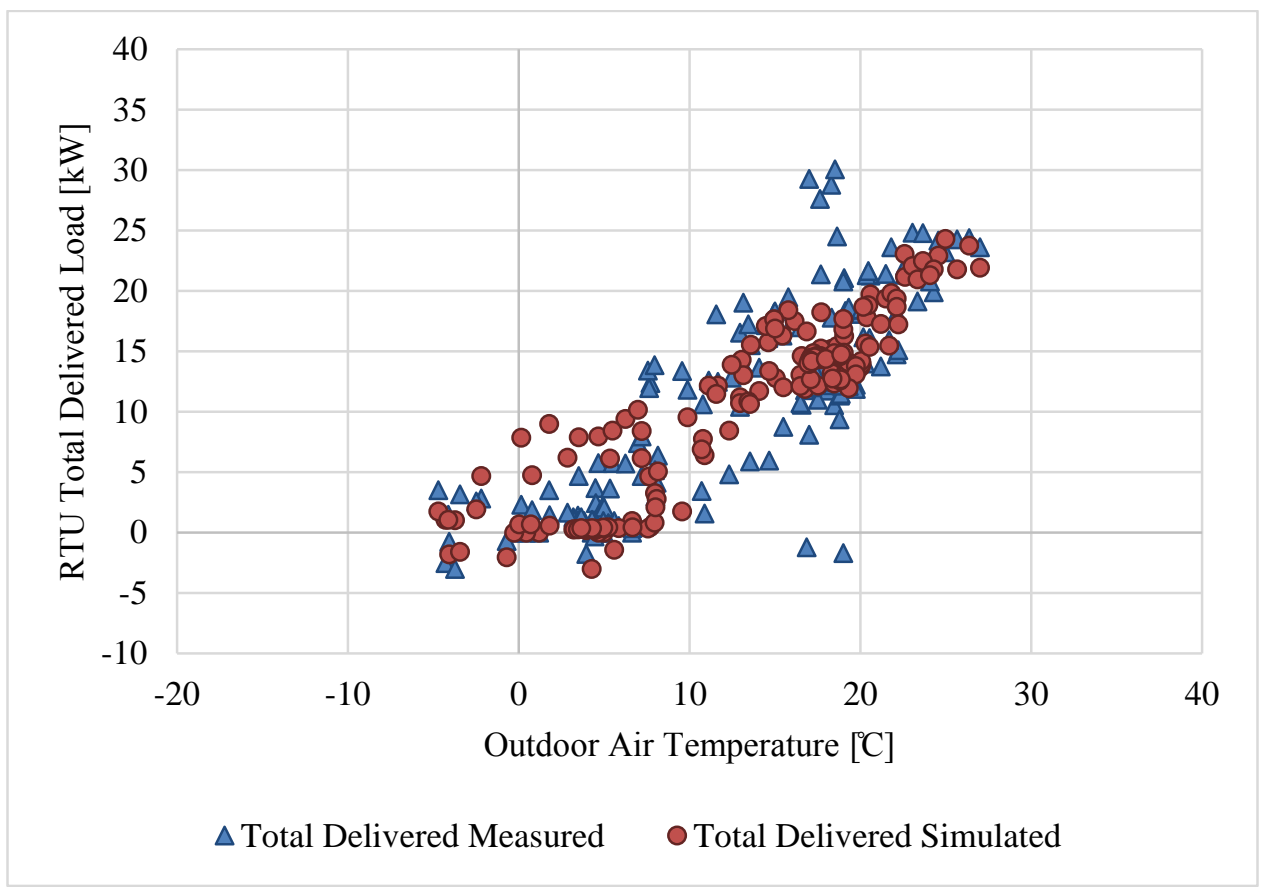

Figure 17. Measured versus simulated hourly RTU total delivered loads. 


\subsubsection{The baseline RTU model updates for calibration}

After the building load calibration was done for both systems, the baseline RTU model was further calibrated by adding and updating the following items:

1. DOAS

2. OA flow rate schedule

3. Supply air temperature set point reset based on OA condition

4. RTU operation schedule

5. Maximum supply airflow rate

6. Cooling COP of RTU

The following are detailed descriptions of each update.

In project year two, a DOAS was added as a separate system in the FRP to deliver OA directly to the individual zones and was used for both RTU and VRF operation. When the RTU was used to condition the building, the DOAS provided unconditioned OA directly to the zones without any interaction with the RTU system. In EnergyPlus 8.1, this type of physical setting cannot be modeled because EnergyPlus at this point is not capable of modeling two or more air-loop systems that can serve the same zones simultaneously. Alternatively, zonal DOAS units were applied to the RTU model to provide unconditioned OA to the zones. The OA flow rate was designed using the Energy Management System (EMS) feature in EnergyPlus to match the actual OA rate in the FRP. Using the EMS, the OA rate was controlled based on the OA temperature, the occupied hours, and the heating and cooling period. The DOAS was set to be always on during occupied hours in cooling season, and to turn on during occupied hours in heating season (i.e., December-March) if the OA temperature was higher than $2.5^{\circ} \mathrm{C}$.

A supply air temperature set point reset strategy described in Chapter 2 was implemented using the EMS feature for RTU model calibration to reflect the actual implementation in the FRP. Using the EMS, the supply air temperature set point was set to $15.0^{\circ} \mathrm{C}$ if the OA temperature was higher than or equal to 13.9 ${ }^{\circ} \mathrm{C}$ in the cooling season, and it was set to $20^{\circ} \mathrm{C}$ if the OA temperature was less than or equal to $7.7^{\circ} \mathrm{C}$ in the heating season. If the OA temperature was between 13.9 and $7.7^{\circ} \mathrm{C}$, the set point temperature was decreased linearly from 20 to $15.0^{\circ} \mathrm{C}$.

The RTU operation schedule in the model was also adjusted to reflect the actual operation schedule in the FRP. Table 6 shows the thermostat schedule for the base system operation, and there was no separate weekday and weekend schedule during the calibrated period. The zone set point temperature was set to $24^{\circ} \mathrm{C}$ during occupied hours (i.e., 6 a.m. to 6 p.m.), and the setback temperature, $31^{\circ} \mathrm{C}$, was set for unoccupied hours.

Table 6. Thermostat schedule

\begin{tabular}{lcc}
\hline & $\begin{array}{c}\text { During occupied hours } \\
(\mathbf{6} \text { a.m. }-6 \text { p.m. })\end{array}$ & $\begin{array}{c}\text { During unoccupied hours } \\
(\mathbf{6} \text { p.m. }-6 \text { a.m. })\end{array}$ \\
\hline Cooling & $24^{\circ} \mathrm{C}$ & $31^{\circ} \mathrm{C}$ \\
Heating & $21.1^{\circ} \mathrm{C}$ & $12.8^{\circ} \mathrm{C}$ \\
\hline
\end{tabular}

The modification of the maximum airflow rate was also implemented for the RTU model. The initial value for the maximum airflow rate of the RTU model was $2.124 \mathrm{~m}^{3} / \mathrm{s}(4500 \mathrm{CFM})$ to $1.6518 \mathrm{~m}^{3} / \mathrm{s}$ (3500 CFM) in EnergyPlus to calibrate the simulation model based on the actual operation (i.e., measured supply airflow rate). 
The cooling COPs of the RTU model were finally modified to calibrate the simulation model by comparing the hourly energy use with the measured data. The final COP was set to 3.5 to be reasonably close to the measured energy use and close to the manufacturer's specification as well. The final heating system efficiencies were set to 0.81 and 1.0 for the natural gas furnace and VAV reheat coil, respectively.

After the parameters described above were updated, the HVAC energy use was compared with the measured data. Figure 18 shows the comparison of the simulated hourly cooling coil energy use with the measured data. The cooling energy data were plotted as a function of the OA temperature during occupied hours for 16 days of RTU operation from August 2015 through February 2016. Figure 19 presents the scatter-plot of the hourly VAV reheat energy use for simulated vs. measured data. Figure 20 shows a comparison of the total HVAC energy use for the measured data vs, simulated data. Figure 18 through Figure 22 illustrate that the simulation results from the calibrated RTU model reasonably fit well with the measured data.

Table 7 and Figure 23 show the aggregated building energy use for the before and after calibrated RTU models. They show that the difference in the whole-building energy use from the measured data decreased from 46.7\% to 4.6\% during the comparison period from August, 2015, through February, 2016. Note that the percentage difference of the gas heating energy use after calibration shown in Table 7 is still high because the model cannot effectively capture the variation of air temperature between the gas and electric reheat coils in the actual system although the simulated and measured supply air temperatures after the reheat coils were reasonably matched.

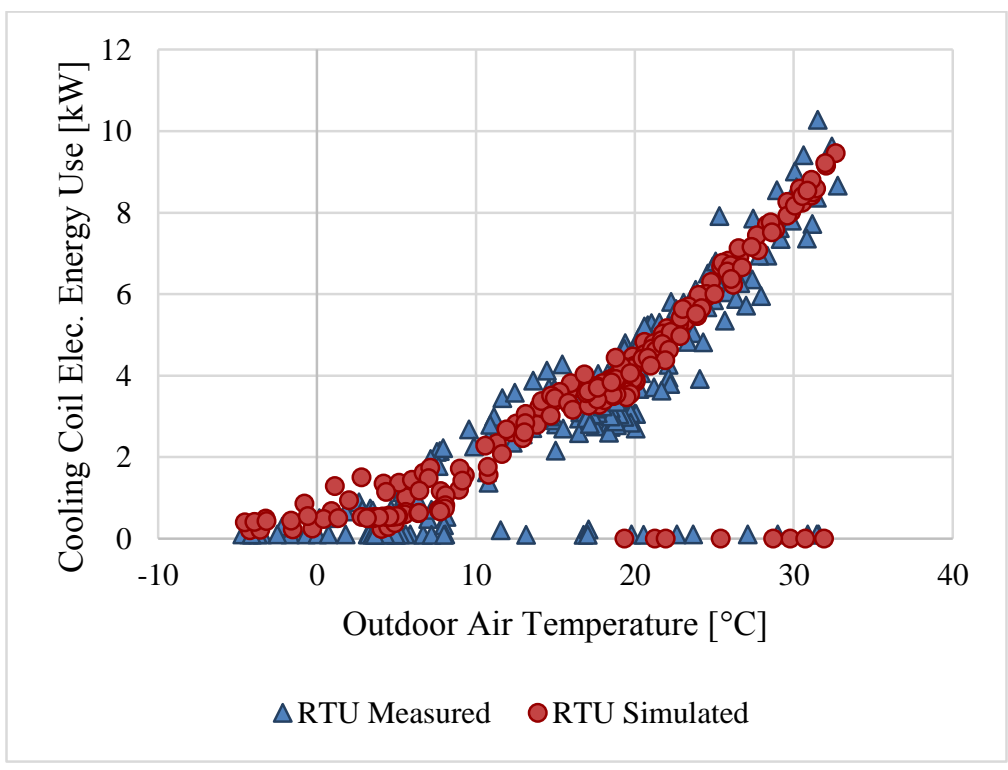

Figure 18. Measured vs. simulated hourly cooling coil energy use. 


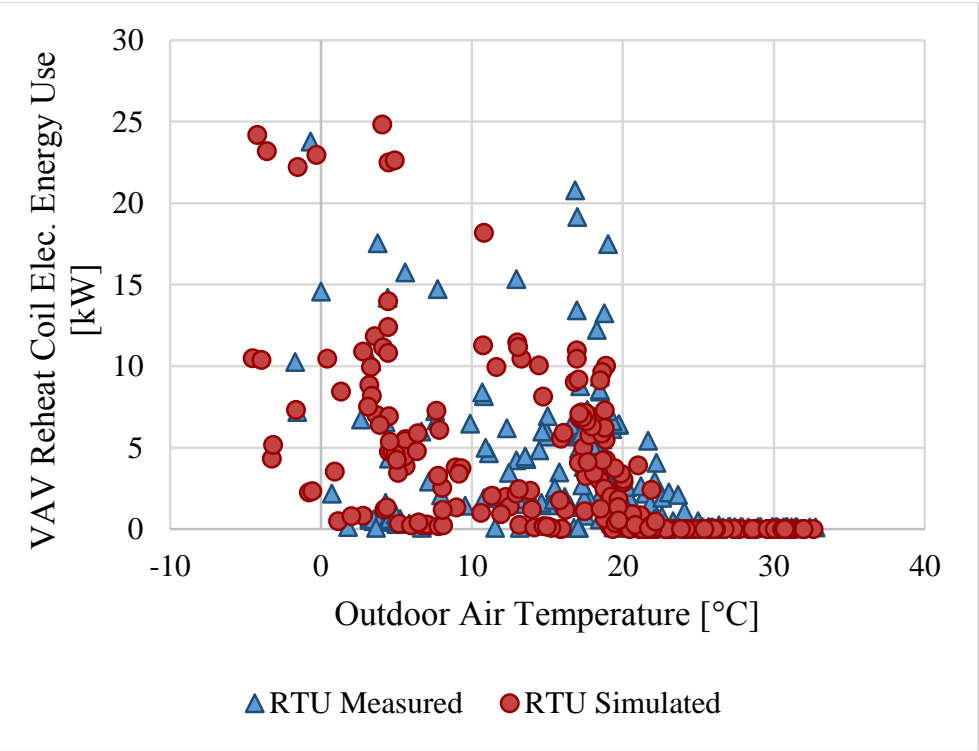

Figure 19. Measured vs. simulated hourly reheat coil energy use.

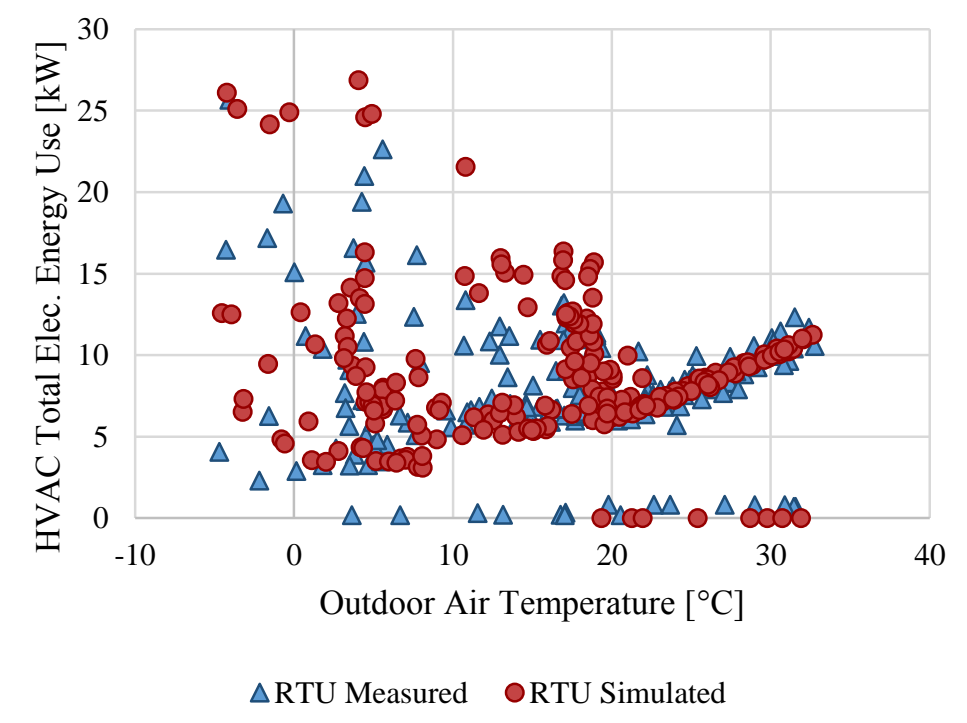

Figure 20. Measured vs. simulated hourly HVAC system energy use. 


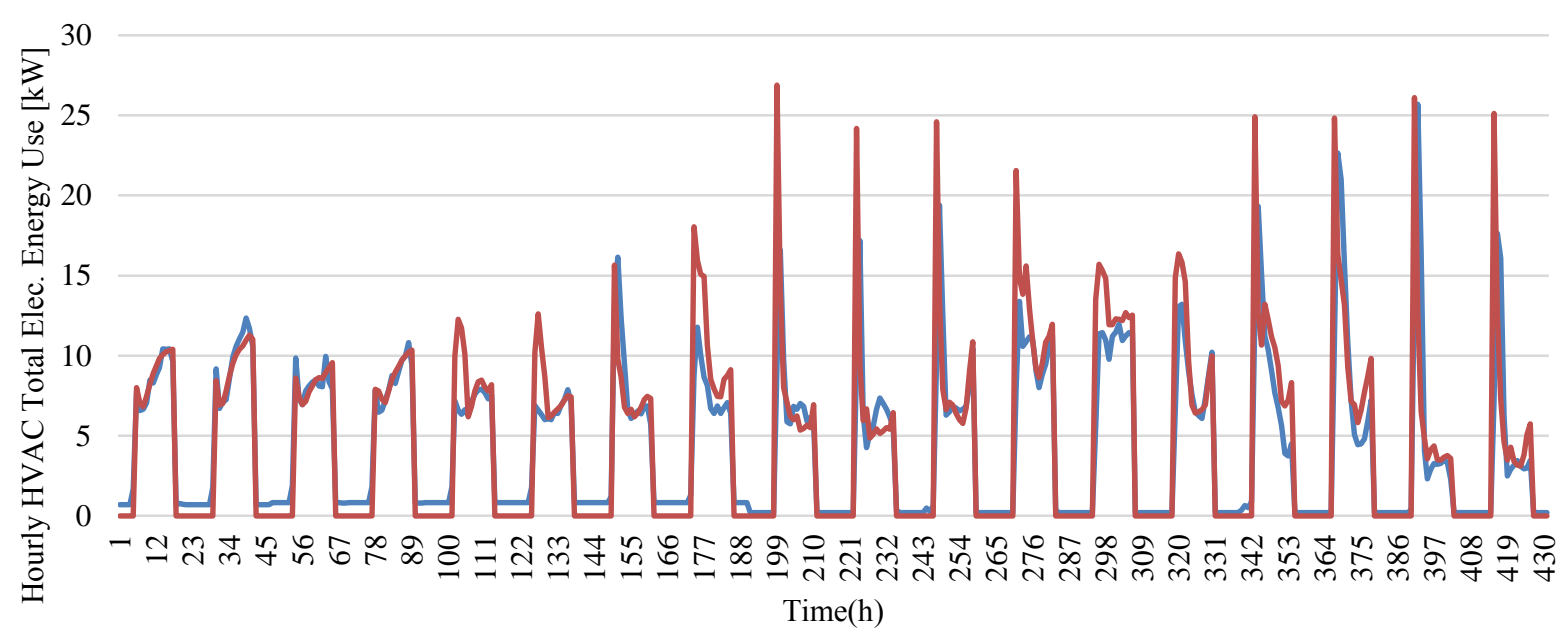

$\longrightarrow$ RTU Measured $\quad$ RTU Simulated

Figure 21. Measured vs. simulated hourly HVAC system energy use trend of the RTU model.

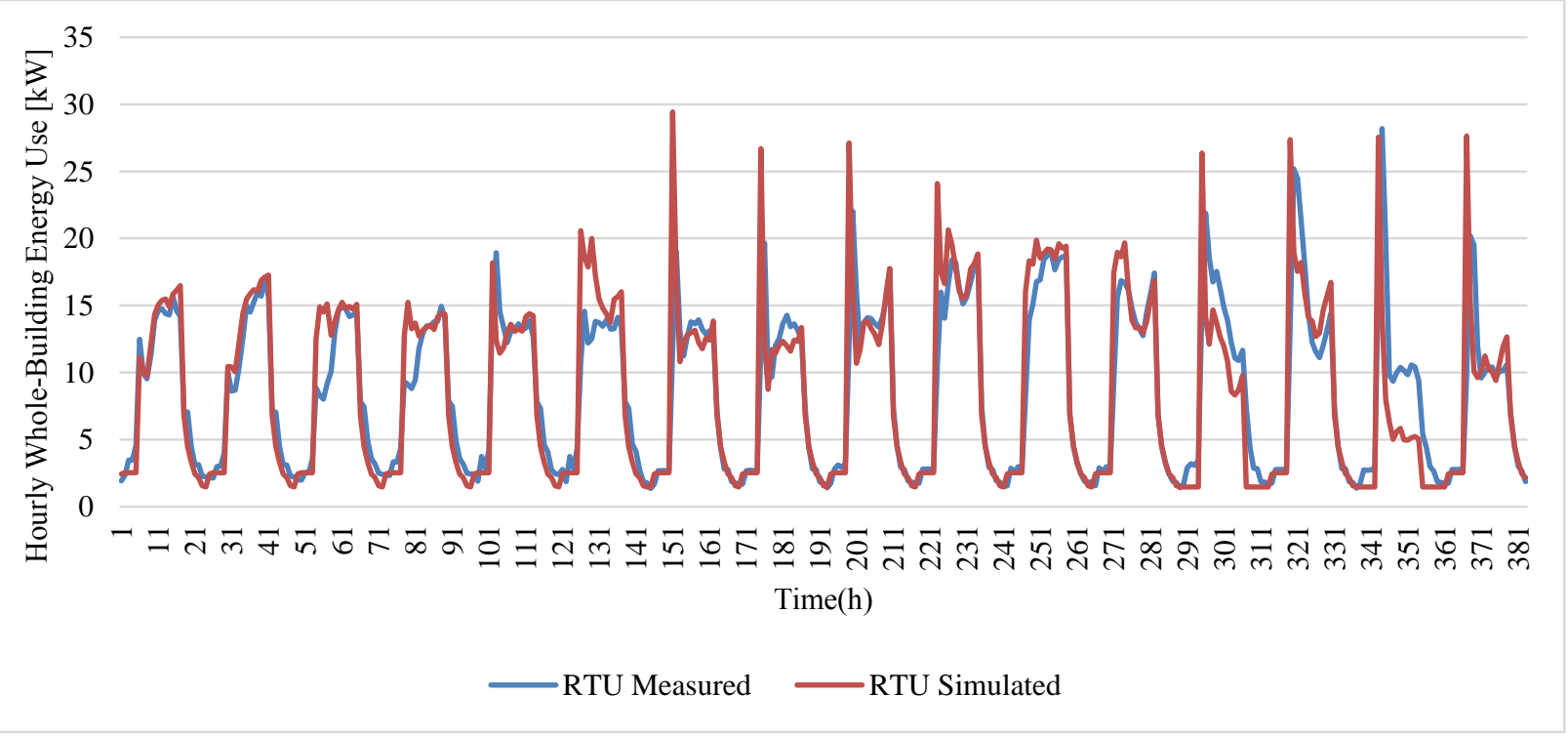

Figure 22. Measured vs. simulated hourly whole-building energy use trend of the RTU model. 


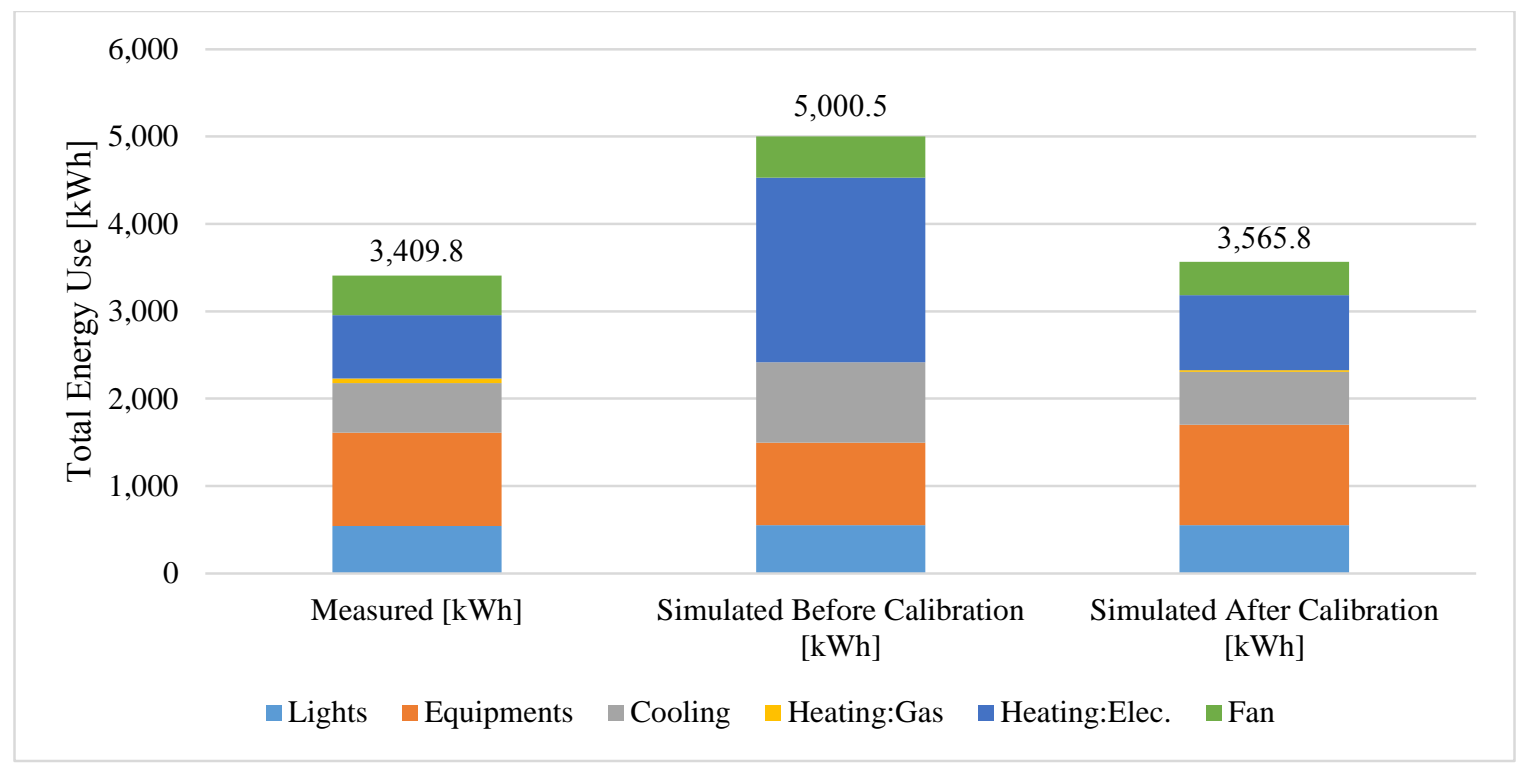

Figure 23. Comparison of the whole-building energy of the RTU model.

Table 7. The whole-building energy use of the RTU model

\begin{tabular}{cccccccc}
\hline & Lights & Equipment & Cooling & $\begin{array}{c}\text { Heating: } \\
\text { gas }\end{array}$ & $\begin{array}{c}\text { Heating: } \\
\text { electricity }\end{array}$ & Fan & Total \\
\hline $\begin{array}{c}\text { Measured [kWh] } \\
\text { Simulated before }\end{array}$ & 541.1 & 1071.7 & 563.4 & 56.9 & 722.6 & 454.0 & 3409.8 \\
calibration [kWh] & 551.2 & 945.9 & 918.6 & 0.0 & 2113.2 & 471.6 & 5000.5 \\
$\begin{array}{c}\text { Simulated after } \\
\text { calibration [kWh] }\end{array}$ & 551.1 & 1151.1 & 605.9 & 16.3 & 862.5 & 378.8 & 3565.8 \\
$\begin{array}{c}\text { Difference before } \\
\text { calibration [\%] }\end{array}$ & $1.9 \%$ & $11.7 \%$ & $63.0 \%$ & $100.0 \%$ & $192.4 \%$ & $3.9 \%$ & $46.7 \%$ \\
$\begin{array}{c}\text { Difference after } \\
\text { calibration [\%] }\end{array}$ & $1.8 \%$ & $7.4 \%$ & $7.5 \%$ & $71.3 \%$ & $19.4 \%$ & $16.6 \%$ & $4.6 \%$ \\
\hline
\end{tabular}

\subsubsection{The VRF model updates for calibration}

The VRF model was also calibrated after the building load calibration. The same building model and approach used for the RTU model were used to calibrate the VRF simulation model based on the measured data. The following items were added and modified in the VRF calibration process:

1. DOAS using the modified version of EnergyPlus 8.1

2. OA flow rate schedule and set point temperature

3. VRF operation schedule

4. Heating and cooling COPs of the VRF system

Each update is described in the following paragraphs in this section.

An air-loop DOAS was implemented in the VRF simulation model using the modified version of EnergyPlus 8.1 described in Section 5.1, based on the specifications of the installed DOAS in the FRP. As 
illustrated in Figure 10, this implementation allows for OA to be provided through an air-loop DOAS directly to individual zones and be conditioned with VRF heating and cooling coils that are connected to the outdoor units for the zonal VRF indoor units.

The DOAS schedule and the OA supply air temperature set point were specified based on the measured data for the VRF system in the FRP. The DOAS operation in the model was controlled by the EMS. The DOAS was always turned on during all hours in summer, but it was operated only during occupied hours during heating season (December-March).

The VRF operation schedule was modified according to the actual system operation. The VRF system installed in the FRP cannot provide simultaneous cooling and heating. Therefore, the VRF cooling and heating operation schedules were specified separately for the cooling (i.e., April-November) and heating (December-March) seasons to calibrate the VRF simulation model. The thermostat schedule shown in Table 6 used for the RTU model was also applied to the VRF simulation model.

Finally, the heating and cooling COPs of the VRF model were modified to reflect the actual performance of the VRF system in the FRP. The final COP values for the cooling and heating coils were set to 3.0 and 2.5 , respectively.

As a final step of the calibration, the simulated VRF energy use was compared against the measured data. Figure 24 shows the simulated hourly VRF system energy use compared with the measured use for occupied hours from August, 2015, through February, 2016. The simulation results of the calibrated VRF model shown in Figure 24 through Figure 26 agree with the measured data. Table 8 and Figure 27 show the whole-building energy use for the before and after calibration of the VRF model, which indicates that the difference in the whole-building energy based on the measured data decreased from $9.3 \%$ to $1.9 \%$ for the chosen 25 days from August, 2015, through February, 2016.

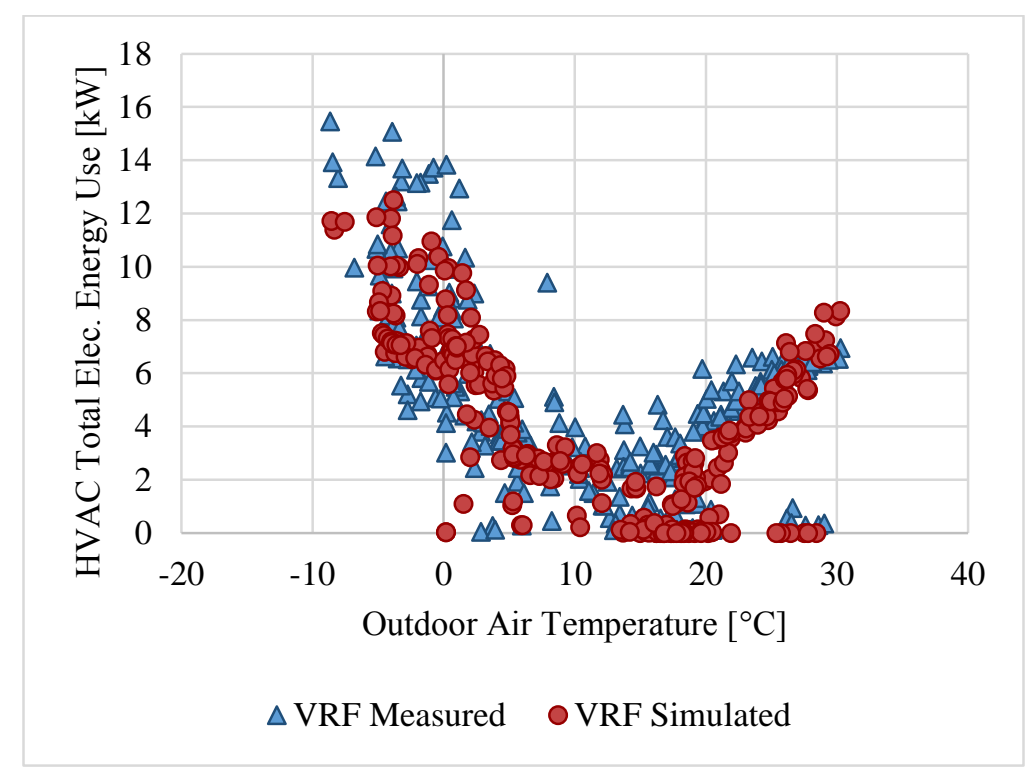

Figure 24. Measured vs. simulated hourly HVAC system energy use. 


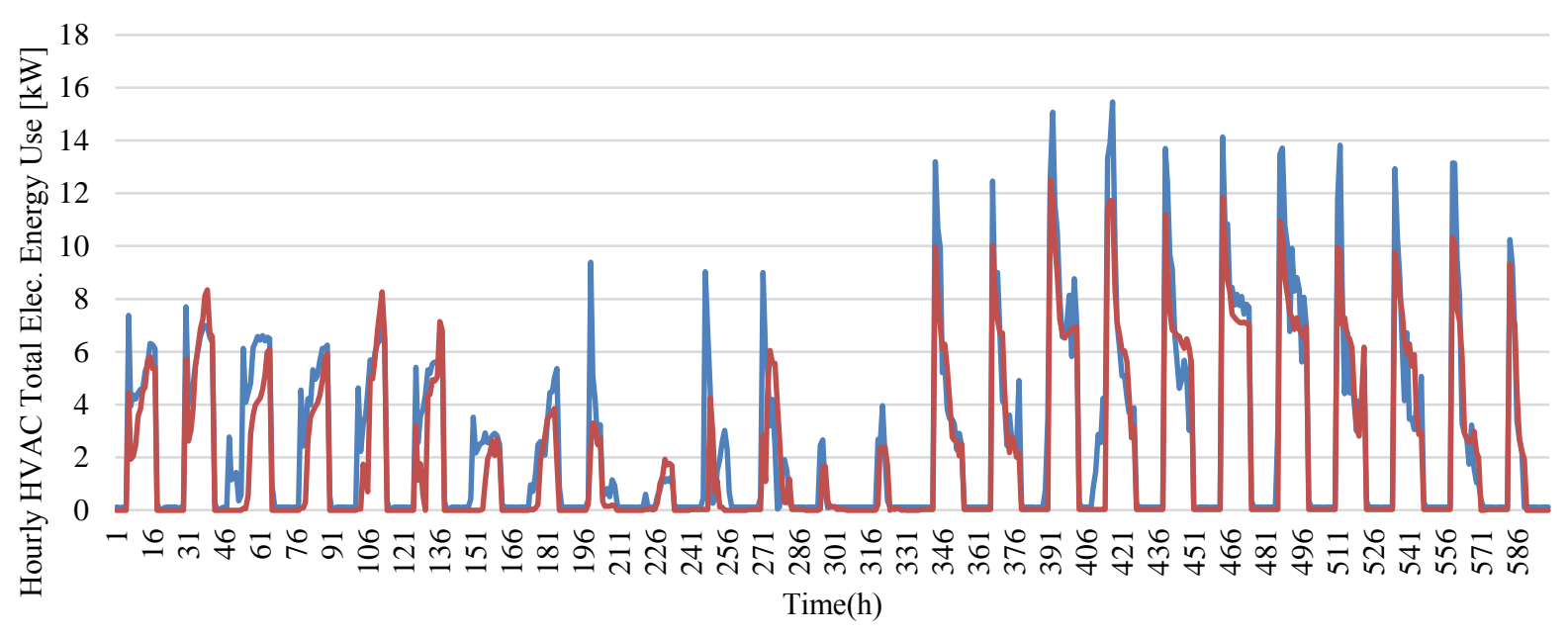

- VRF Measured $\quad$ VRF Simulated

Figure 25. Measured vs. simulated hourly HVAC energy use trend of the VRF model.

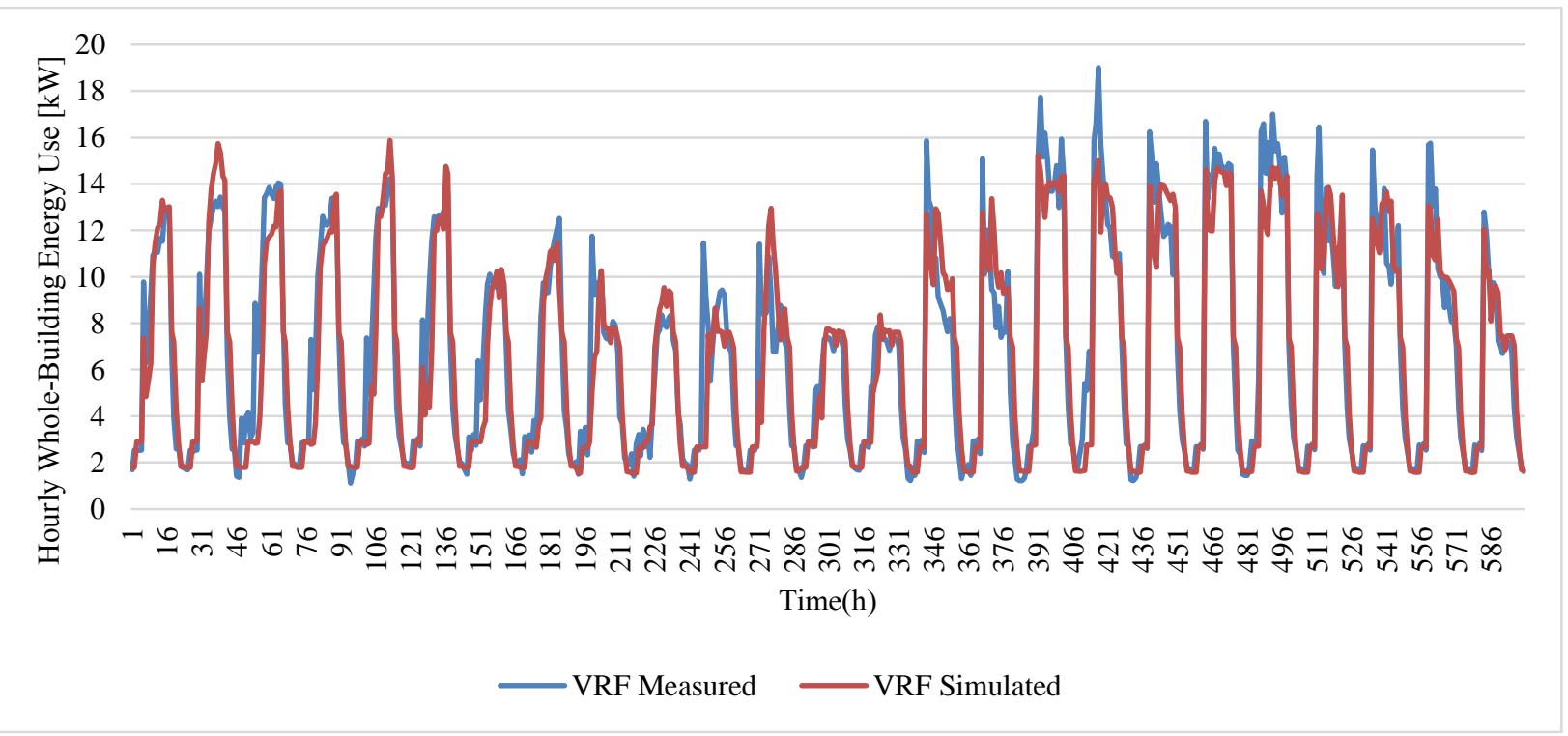

Figure 26. Measured vs. simulated hourly whole-building energy use trend of the VRF model. 


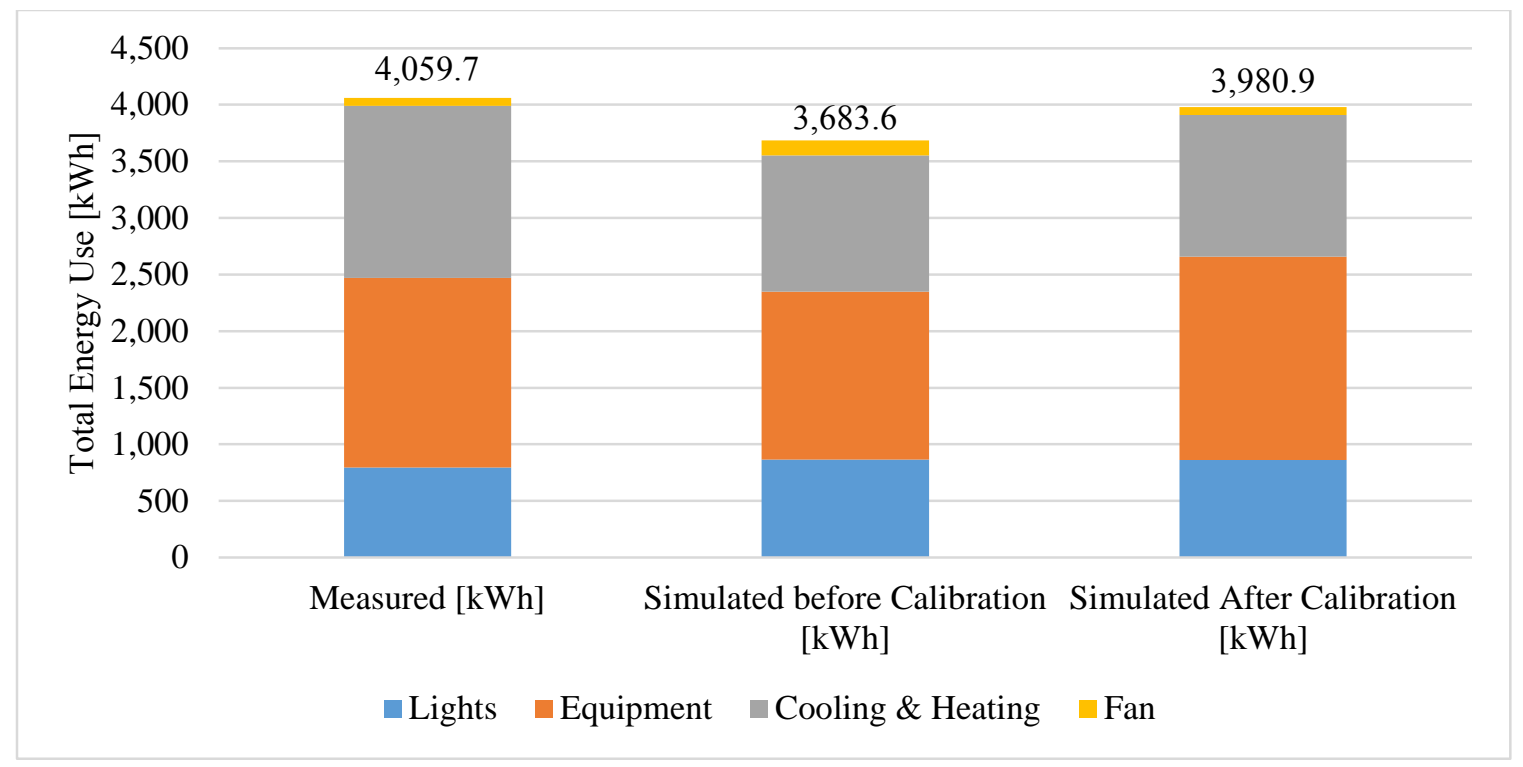

Figure 27. Comparison of the whole-building energy use of the VRF model.

Table 8. Comparison of the whole-building energy use of the VRF model

\begin{tabular}{cccccc}
\hline & Lights & Equipment & $\begin{array}{c}\text { Cooling and } \\
\text { heating }\end{array}$ & Fan & Total \\
\hline $\begin{array}{c}\text { Measured [kWh] } \\
\text { Simulated before }\end{array}$ & 795.0 & 1674.8 & 1521.7 & 68.2 & 4059.7 \\
calibration [kWh] & 864.3 & 1483.4 & 1203.1 & 132.8 & 3683.6 \\
$\begin{array}{c}\text { Simulated after } \\
\text { calibration [kWh] }\end{array}$ & 861.1 & 1798.6 & 1249.7 & 71.5 & 3980.9 \\
$\begin{array}{c}\text { Difference before } \\
\text { calibration [\%] }\end{array}$ & $8.7 \%$ & $11.4 \%$ & $20.9 \%$ & $94.6 \%$ & $9.3 \%$ \\
$\begin{array}{c}\text { Difference after } \\
\text { calibration [\%] }\end{array}$ & $8.3 \%$ & $7.4 \%$ & $17.9 \%$ & $4.8 \%$ & $1.9 \%$ \\
\hline
\end{tabular}

\subsubsection{Statistical evaluation of the energy simulation models}

ASHRAE Guideline 14 (ASHRAE 2002) was used to evaluate the validity of the calibrated models. It states that models are declared to be calibrated if they produce NMBE within $\pm 10 \%$ and CV-RMSE within $\pm 30 \%$ when hourly data are used, or $5 \%$ and 15 , respectively, with monthly data. Table 9 summarizes the CV-RMSE and NMBE for the VRF and RTU models before and after calibration. The results in Table 9 show that the calibrated models of both the VRF and the RTU were reasonably calibrated, based on the criteria from the ASHRAE Guideline 14. 
Table 9. Statistical evaluation of the energy simulation models

\begin{tabular}{cccc}
\hline & & Before calibration (\%) & After calibration (\%) \\
\hline \multirow{2}{*}{ RTU (daily) } & CV-RMSE & 52.1 & 7.7 \\
& NMBE & 49.3 & 4.8 \\
\multirow{2}{*}{ RTU (hourly) } & CV-RMSE & 132.9 & 20.2 \\
& NMBE & 103.1 & 3.6 \\
\multirow{2}{*}{ VRF (daily) } & CV-RMSE & 20.1 & 8.7 \\
& NMBE & 9.6 & 0.2 \\
VRF (hourly) & CV-RMSE & 32.3 & 15.7 \\
& NMBE & 10.9 & 3.8 \\
\hline
\end{tabular}

\subsubsection{Annual simulation comparison of the VRF and RTU models for the FRP in Knoxville, TN}

Obtaining complete year-around data for the VRF and RTU systems in the FRP was not possible because the FRP was operated with multiple HVAC systems alternately to evaluate the energy performance of various HVAC systems. For this reason, the calibrated VRF and RTU EnergyPlus models described in the previous sections were used to evaluate the annual energy performance of both systems installed in the FRP. Knoxville TMY3 weather data (i.e., USA_TN_Knoxville-McGhee-TMY3.epw) were used to evaluate the annual energy performance for both systems.

Figure 28 shows the comparison of the end-use energy for the FRP between the VRF and RTU models. The results indicate that the VRF system can save $29 \%(24,103.0 \mathrm{kWh} /$ year) of the whole-building energy use and 56\% (24,103.0 kWh/year) of the HVAC energy use compared with the RTU system.

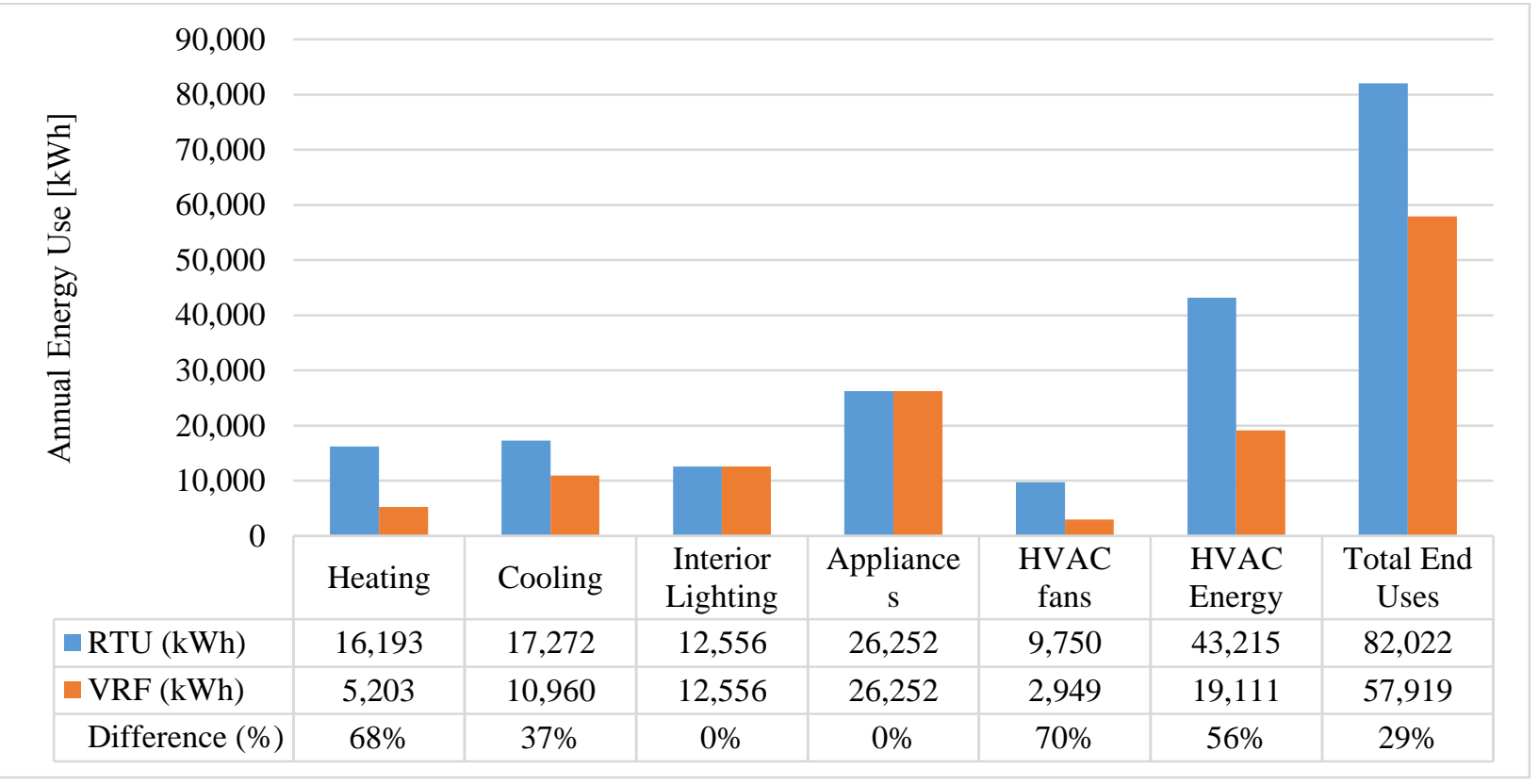

Figure 28. End-use comparison for the RTU and VRF models.

Figure 29 through Figure 32, Table 10, and Table 11 show the monthly energy comparison for the FRP between the RTU and VRF systems. Overall, the VRF model shows lower energy use compared with the RTU model throughout all months. 


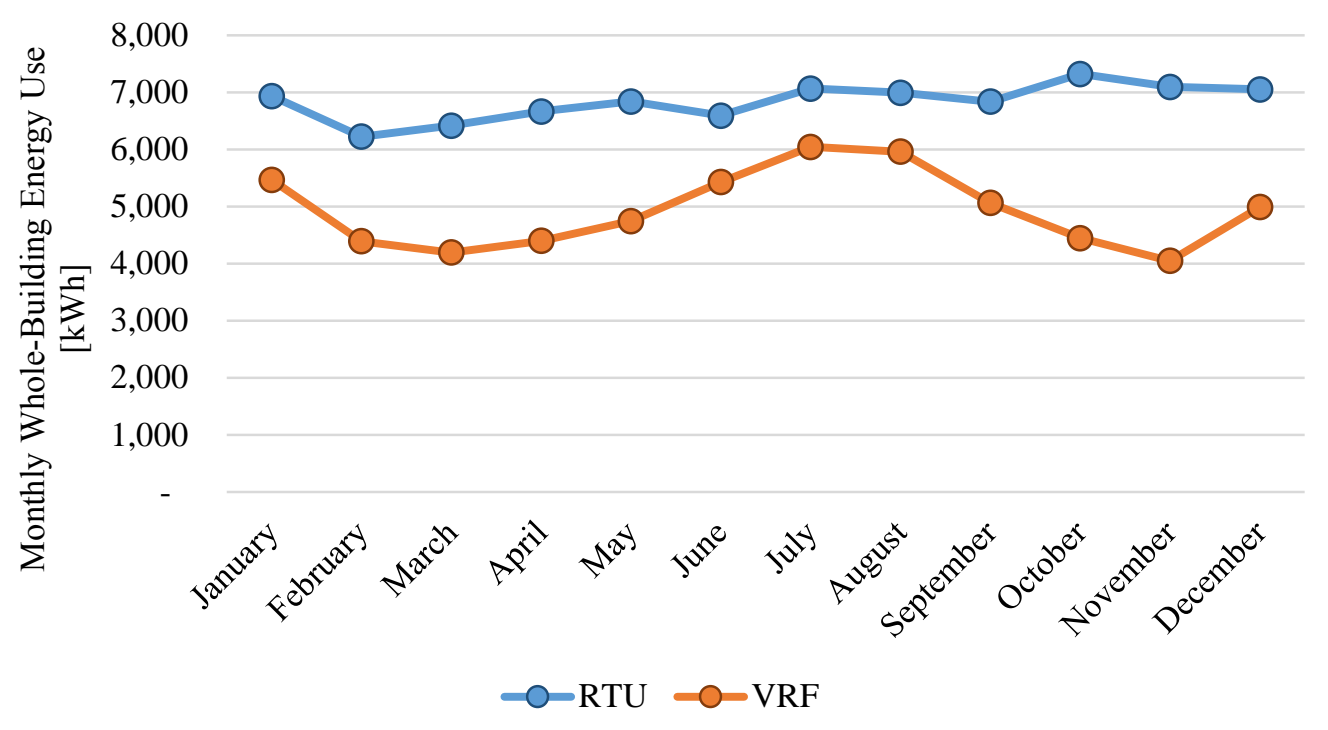

Figure 29. Monthly whole-building energy comparison for the RTU and VRF models.

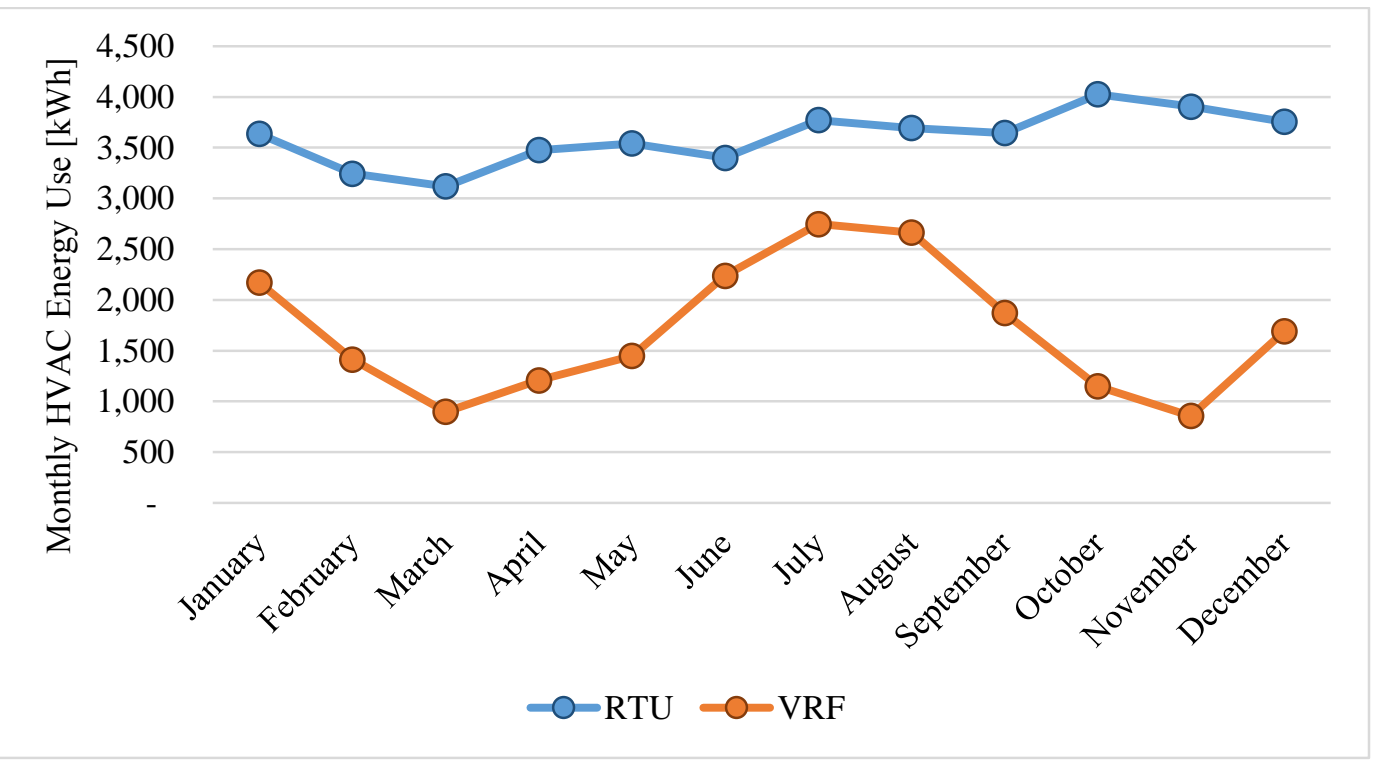

Figure 30. Monthly HVAC energy comparison for the RTU and VRF models. 


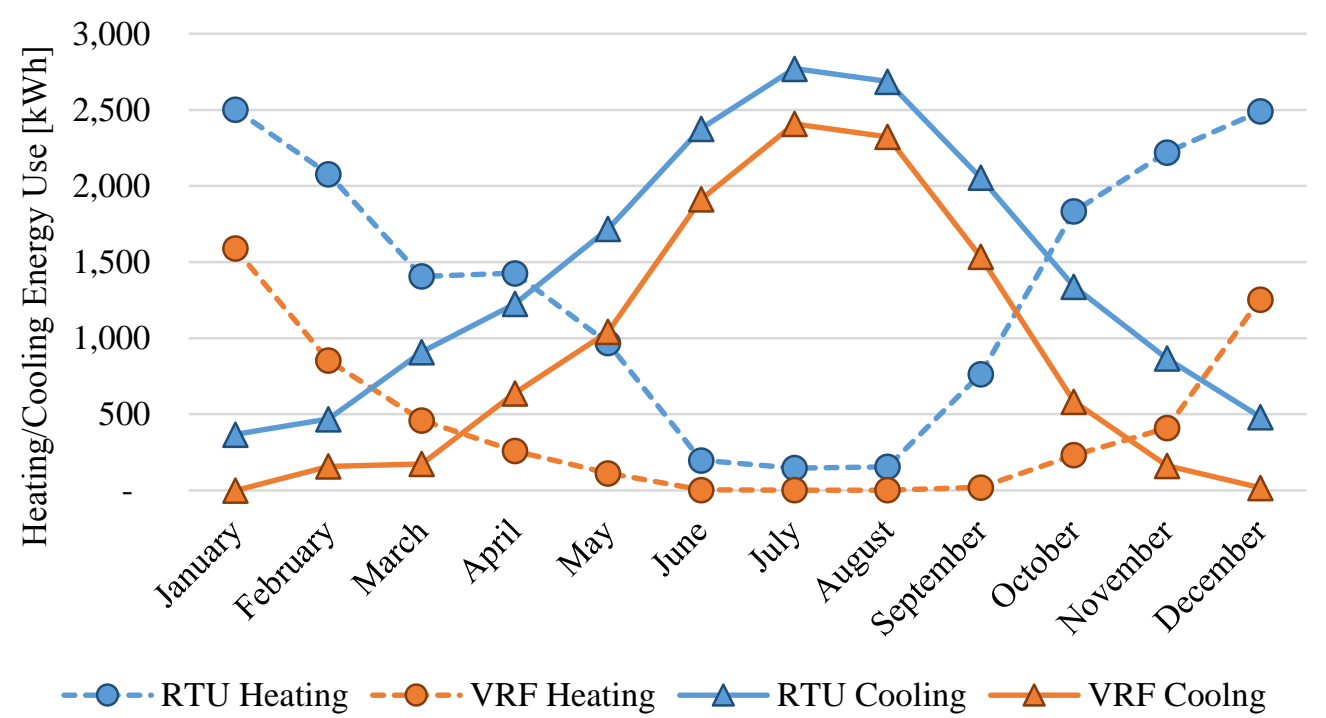

Figure 31. Monthly heating and cooling comparison for the RTU and VRF models.

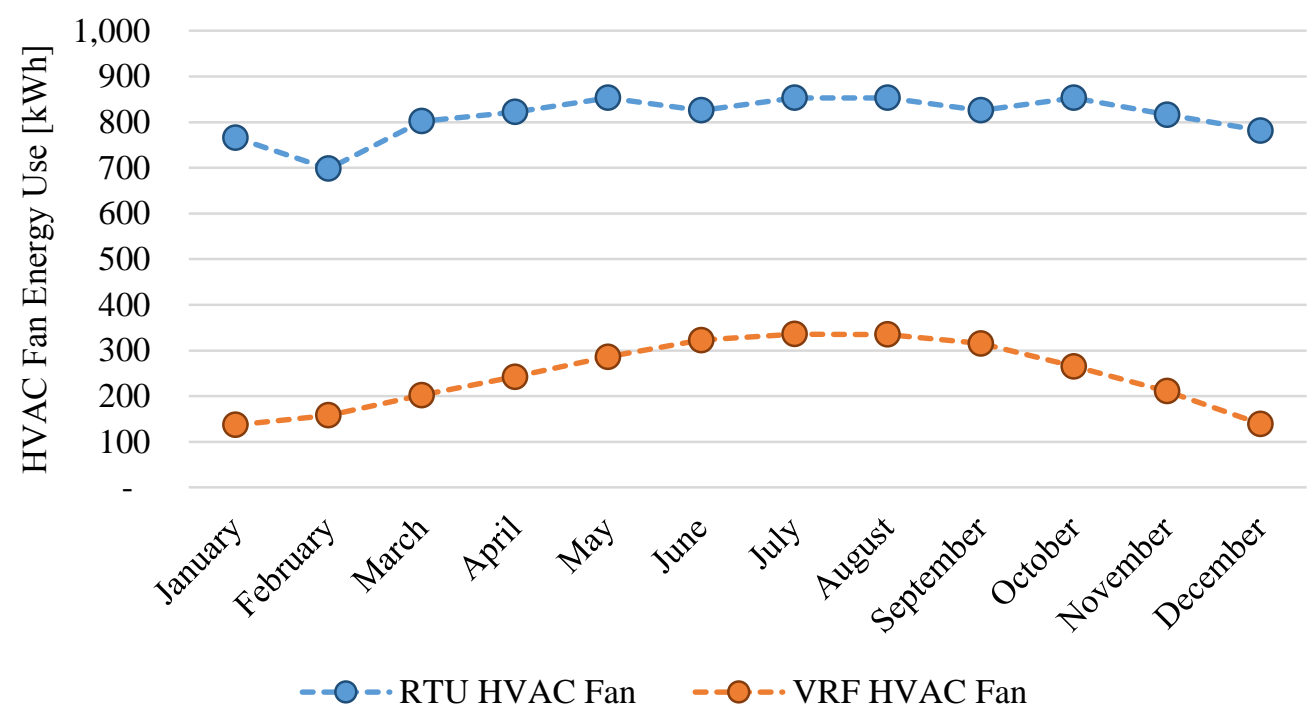

Figure 32. Monthly fan energy comparison for the RTU and VRF models. 
Table 10. Monthly whole-building and HVAC energy use for the RTU and VRF models

\begin{tabular}{ccccccc}
\hline & $\begin{array}{c}\text { RTU } \\
\text { whole- } \\
\text { building } \\
\text { energy use } \\
\text { (kWh) }\end{array}$ & $\begin{array}{c}\text { VRF whole- } \\
\text { building } \\
\text { energy use } \\
(\mathbf{k W h})\end{array}$ & $\begin{array}{c}\text { RTU HVAC } \\
\text { energy use } \\
\mathbf{( k W h )}\end{array}$ & $\begin{array}{c}\text { VRF HVAC } \\
\text { energy use } \\
(\mathbf{k W h})\end{array}$ & $\begin{array}{c}\text { Whole- } \\
\text { building } \\
\text { energy use } \\
\text { difference } \\
(\%)\end{array}$ & $\begin{array}{c}\text { HVAC } \\
\text { energy use } \\
\text { difference } \\
(\%)\end{array}$ \\
\hline January & 6,933 & 5,022 & 3,637 & 1,726 & 27.6 & 52.5 \\
February & 6,222 & 4,148 & 3,245 & 1,171 & 33.3 & 63.9 \\
March & 6,415 & 4,133 & 3,119 & 837 & 35.6 & 73.2 \\
April & 6,665 & 4,330 & 3,476 & 1,141 & 35.0 & 67.2 \\
May & 6,837 & 4,738 & 3,541 & 1,442 & 30.7 & 59.3 \\
June & 6,590 & 5,428 & 3,401 & 2,238 & 17.6 & 34.2 \\
July & 7,067 & 6,043 & 3,771 & 2,747 & 14.5 & 27.1 \\
August & 6,990 & 5,958 & 3,694 & 2,662 & 14.8 & 28.0 \\
September & 6,834 & 5,061 & 3,645 & 1,871 & 26.0 & 48.7 \\
October & 7,322 & 4,378 & 4,026 & 1,082 & 40.2 & 73.1 \\
November & 7,094 & 3,973 & 3,904 & 783 & 44.0 & 79.9 \\
December & 7,051 & 4,707 & 3,755 & 1,411 & 33.3 & 62.4 \\
\hline
\end{tabular}

Table 11. Monthly HVAC component energy use for the RTU and VRF models

\begin{tabular}{cccccccccc}
\hline & $\begin{array}{c}\text { RTU } \\
\text { heating } \\
(\mathbf{k W h})\end{array}$ & $\begin{array}{c}\text { VRF } \\
\text { heating } \\
\mathbf{( k W h )}\end{array}$ & $\begin{array}{c}\text { RTU } \\
\mathbf{c o o l i n g} \\
\mathbf{( k W h )}\end{array}$ & $\begin{array}{c}\text { VRF } \\
\mathbf{c o o l i n g} \\
\mathbf{( k W h )}\end{array}$ & $\begin{array}{c}\text { RTU } \\
\text { HVAC } \\
\mathbf{f a n} \\
\mathbf{( k W h )}\end{array}$ & $\begin{array}{c}\text { VRF } \\
\text { HVAC } \\
\mathbf{f a n} \\
\mathbf{( k W h )}\end{array}$ & $\begin{array}{c}\text { Heating } \\
\text { difference } \\
\mathbf{( \% )}\end{array}$ & $\begin{array}{c}\text { Cooling } \\
\text { difference } \\
\mathbf{( \% )}\end{array}$ & $\begin{array}{c}\text { HVAC fan } \\
\text { difference } \\
(\boldsymbol{\%})\end{array}$ \\
\hline January & 2,503 & 1,590 & 367 & 0 & 766 & 137 & $36.5 \%$ & 100.0 & 82.1 \\
February & 2,078 & 854 & 469 & 159 & 698 & 158 & $58.9 \%$ & 66.2 & 77.4 \\
March & 1,407 & 461 & 910 & 174 & 802 & 202 & $67.3 \%$ & 80.8 & 74.8 \\
April & 1,427 & 259 & 1,226 & 639 & 822 & 242 & $81.8 \%$ & 47.9 & 70.5 \\
May & 969 & 113 & 1,719 & 1,043 & 853 & 286 & $88.3 \%$ & 39.4 & 66.5 \\
June & 198 & 3 & 2,377 & 1,913 & 826 & 322 & $98.3 \%$ & 19.6 & 60.9 \\
July & 147 & 3 & 2,771 & 2,409 & 853 & 336 & $98.3 \%$ & 13.1 & 60.6 \\
August & 156 & 3 & 2,686 & 2,324 & 853 & 335 & $98.1 \%$ & 13.5 & 60.7 \\
September & 764 & 21 & 2,055 & 1,535 & 826 & 315 & $97.3 \%$ & 25.3 & 61.8 \\
October & 1,834 & 232 & 1,339 & 585 & 853 & 265 & $87.3 \%$ & 56.4 & 68.9 \\
November & 2,220 & 410 & 868 & 163 & 816 & 211 & $81.5 \%$ & 81.2 & 74.2 \\
December & 2,491 & 1,254 & 483 & 18 & 782 & 139 & $49.7 \%$ & 96.3 & 82.2 \\
\hline
\end{tabular}

\subsection{EVALUATION OF THE ENERGY SAVINGS POTENTIAL OF VRF FROM RTU IN 12 US CLIMATE ZONES}

Using the calibrated EnergyPlus models in Section 5.2, the performance of each system was evaluated in 12 US climate locations, and the comparative energy savings potential of the two systems was investigated for each climate zone while keeping the building envelope characteristics the same for all climate zones. The 16 climate zones designated by the International Energy Conservation Code and ASHRAE (2004), as illustrated in Figure 33, were considered in this study. Several cold climate zones 
(e.g., 6A, 6B, 7, and 8) were not included in this study because the VRF system subject to this study has a limited heating capacity when the $\mathrm{OA}$ temperature falls lower than $-20^{\circ} \mathrm{C}$. Table 12 lists the 12 representative locations in the selected US climate zones for this study.

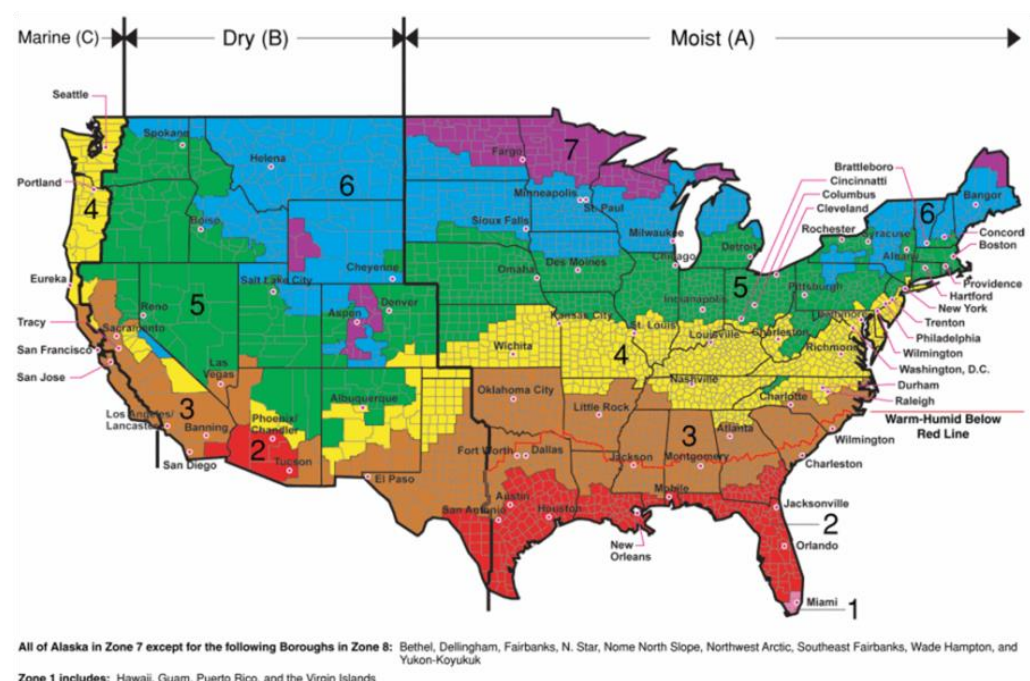

Figure 33. ASHRAE climate zones in the United States. (ASHRAE 2004)

Table 12. Twelve representative locations in selected US climate zones

\begin{tabular}{ll}
\hline \multicolumn{1}{c}{ Climate zone } & \multicolumn{1}{c}{ Representative city } \\
\hline 1A & Miami, Florida (very hot, humid) \\
2A & Houston, Texas (hot, humid) \\
2B & Phoenix, Arizona (hot, dry) \\
3A & Atlanta, Georgia (warm, humid) \\
3B-Coast & Los Angeles, California (warm, dry) \\
3B & Las Vegas, Nevada (warm, dry) \\
3C & San Francisco, California (warm, marine) \\
4A & Baltimore, Maryland (mixed, humid) \\
4B & Albuquerque, New Mexico (mixed, dry) \\
4C & Seattle, Washington (mixed, marine) \\
5A & Chicago, Illinois (cool, humid) \\
5B & Boulder, Colorado (cool, dry) \\
\hline
\end{tabular}

The calibrated VRF and RTU models described in the previous sections, with a few modifications, were used to evaluate the energy savings potential in the selected climate locations. The modifications to the calibrated VRF and RTU models include

1. Location information

2. Design days of the weather profile

3. Ground temperature of the outside environment

4. Autosize values for HVAC systems

5. OA mixer option for the OA system of the RTU model 
For this climate zone analysis, the OA mixer object in EnergyPlus was used to provide the OA through the RTU model, instead having OA provided through the zonal DOAS units, which were used for the calibration model. The OA mixer option is used mainly because it is a typical setup in RTU units to have an OA mixing box bring OA into the building. Another reason is that unconditioned OA entering via the zonal DOAS units tends to affect zone load calculations and increase the design supply air fan sizing when the autosize inputs are used for the simulation model. Especially in the cooling season, an oversized supply airflow rate brings a higher volume of cooled air through the VAV reheat coils, resulting in higher reheat coil energy use. The "source" energy was calculated from the "site" energy. Source energy is the energy use at the utility generating facility needed to provide the electricity used at the site, and the embedded energy of fuel delivered to the site, such as natural gas. Source energy was determined from site energy reported from the EnergyPlus simulation table outputs by converting each factor from the EnergyPlus table output. Table 13 presents the conversion factors from site energy to source energy.

Table 13. Site to source energy conversion factors

\begin{tabular}{cc}
\hline Sources & Conversion factors \\
\hline Electricity & 3.167 (source $\mathrm{kWh}$ per site $\mathrm{kWh})$ \\
Natural gas & $1.084($ source $\mathrm{kWh}$ per site $\mathrm{kWh})$ \\
\hline
\end{tabular}

\subsubsection{The energy savings potential in 12 climate locations}

The modified calibrated models were used to evaluate the annual energy performance of both VRF and RTU systems in the selected climate zones. TMY2 weather data files for 12 selected climate locations were used in this analysis. The simulation results of the hourly RTU and VRF system energy comparison for each climate location are presented in Figure 34 through Figure 42 and Table 14 through Table 18.

- In general, the simulation analysis shows that VRF system uses less energy than the baseline RTU system in all climate zones. The whole-building energy savings are about 21 to $33 \%$ for the 12 climate zones.

- Table 15 lists the simulated whole-building site and source energy uses and savings for VRF systems compared with the RTU systems in the 12 climate locations. The site energy savings are 33\% $(25,304.0 \mathrm{kWh} /$ year) for San Francisco, the location with the highest savings, and 21\% (17,663.0 $\mathrm{kWh} /$ year) for Miami, the location with the lowest savings, within the 12 climate locations. After conversion to source energy savings, the energy savings are 33\% (80,065.0 kWh/year) for San Francisco and $24 \%(64,643.0 \mathrm{kWh} /$ year) for Chicago, IL, the location with the lowest savings.

- Table 16 lists the simulated HVAC site and source energy uses and savings for VRF systems compared with RTU systems in the 12 climate locations. The HVAC site energy savings are $68 \%$ $(25,304.0 \mathrm{kWh} /$ year) for San Francisco, the location with the highest energy savings, and $40 \%$ $(17,663.0 \mathrm{kWh} /$ year) for Miami, the location with the lowest savings. The HVAC source energy savings are 68\% (80,065.0 kWh/year) for San Francisco and 43\% (64,643.0 kWh/year) for Miami, the highest and lowest savings within the 12 climate locations.

- Figure 40 represents the simulated heating energy uses for VRF and RTU systems in the 12 climate locations. Overall, the heating energy-use results for the VRF system in all climate zones are lower than those for the RTU system. Table 17 shows that the highest percentage savings for heating energy use is around $92 \%(1,041.0 \mathrm{kWh} /$ year) for Miami, and the lowest percentage savings is around $15 \%$ $(879.0 \mathrm{kWh} /$ year) for Albuquerque, NM. It also shows that the percentage savings for VRF systems are significantly higher in several climate zones — such as Miami, San Francisco, and Los Angeles- 
because the RTU VAV systems use more electric reheat coil energy to maintain the room temperature set point during the cooling season. Especially in San Francisco and Los Angeles, the mild climate caused more reheat energy use to prevent overcooling the zones, which was the main reason for the larger whole-building and HVAC energy savings in these two locations compared with other climate locations.

- Figure 41 highlights the simulated cooling energy uses for the VRF and RTU systems in 12 climate locations. The simulation results show that the RTU cooling energy use is greater than the VRF cooling energy use in the 12 climate locations. Table 17 shows the highest percentage savings for the VRF system compared with the RTU system for cooling energy use is around $51 \%(7,880.0$ $\mathrm{kWh} / \mathrm{year})$ for San Francisco and the lowest is around 18\% (5,481.0 kWh/year) for Miami.

- Figure 42 and Table 18 show the HVAC fan energy use and savings for the VRF and RTU systems in the 12 climate locations. The overall fan energy percentage savings for VRF systems compared with the RTU systems are approximately from $83 \%(11,142.0 \mathrm{kWh} /$ year $)$ to $86 \%(12,035.0 \mathrm{kWh} /$ year $)$ for all climate locations.

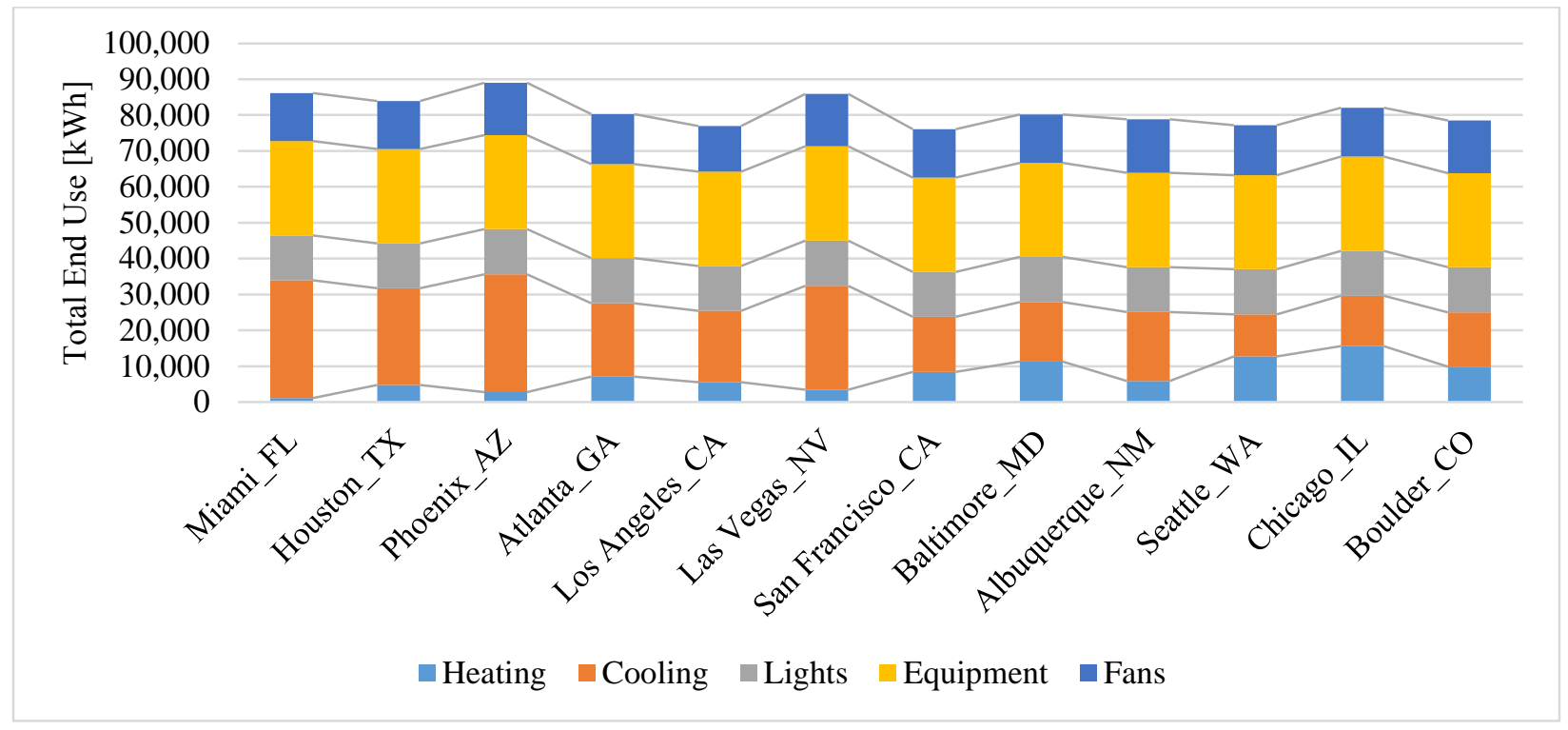

Figure 34. The RTU total end-use comparison. 


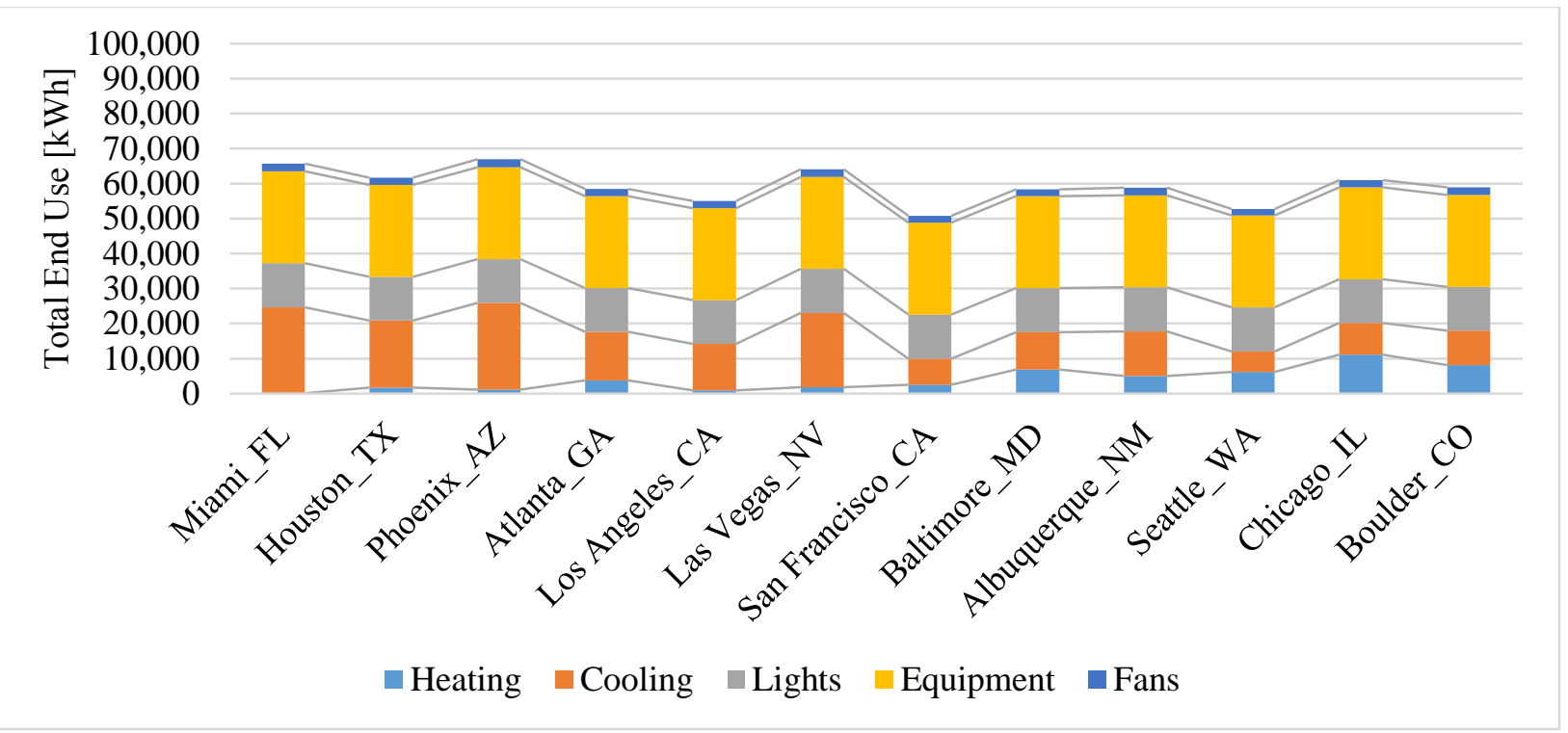

Figure 35. The VRF total end use comparison. 
Table 14. End uses for the RTU vs. the VRF

\begin{tabular}{|c|c|c|c|c|c|c|c|c|c|c|c|c|}
\hline & $\begin{array}{c}\text { RTU } \\
\text { heating } \\
(\mathbf{k W h})\end{array}$ & $\begin{array}{c}\text { VRF } \\
\text { heating } \\
\text { (kWh) }\end{array}$ & $\begin{array}{c}\text { RTU } \\
\text { cooling } \\
\text { (kWh) }\end{array}$ & $\begin{array}{c}\text { VRF } \\
\text { cooling } \\
(\mathbf{k W h})\end{array}$ & $\begin{array}{c}\text { RTU } \\
\text { lights } \\
(\mathbf{k W h})\end{array}$ & $\begin{array}{c}\text { VRF } \\
\text { lights } \\
\text { (kWh) }\end{array}$ & $\begin{array}{c}\text { RTU } \\
\text { eqpt. } \\
\text { (kWh) }\end{array}$ & $\begin{array}{c}\text { VRF } \\
\text { eqpt. } \\
(\mathbf{k W h})\end{array}$ & $\begin{array}{c}\text { RTU } \\
\text { fans } \\
(\mathbf{k W h})\end{array}$ & $\begin{array}{c}\text { VRF } \\
\text { fans } \\
(\mathbf{k W h})\end{array}$ & $\begin{array}{c}\text { RTU } \\
\text { total end } \\
\text { uses } \\
\text { (kWh) }\end{array}$ & $\begin{array}{c}\text { VRF } \\
\text { total end } \\
\text { uses } \\
(\mathbf{k W h})\end{array}$ \\
\hline Miami, FL & 1,131 & 90 & 30,053 & 24,572 & 12,556 & 12,556 & 26,252 & 26,252 & 13,339 & 2,197 & 83,330 & 65,667 \\
\hline Houston, TX & 4,721 & 1,718 & 26,963 & 19,071 & 12,556 & 12,556 & 26,252 & 26,252 & 13,436 & 2,112 & 83,928 & 61,709 \\
\hline Phoenix, AZ & 2,764 & 1,076 & 32,842 & 24,759 & 12,556 & 12,556 & 26,252 & 26,252 & 14,586 & 2,243 & 89,000 & 66,885 \\
\hline Atlanta, GA & 7,078 & 3,794 & 20,469 & 13,822 & 12,556 & 12,556 & 26,252 & 26,252 & 13,926 & 2,085 & 80,280 & 58,508 \\
\hline Los Angeles, CA & 5,516 & 892 & 19,891 & 13,264 & 12,556 & 12,556 & 26,252 & 26,252 & 12,701 & 2,016 & 76,915 & 54,980 \\
\hline Las Vegas, NV & 3,400 & 1,765 & 29,052 & 21,286 & 12,556 & 12,556 & 26,252 & 26,252 & 14,647 & 2,214 & 85,906 & 64,073 \\
\hline San Francisco, CA & 8,374 & 2,498 & 15,369 & 7,490 & 12,556 & 12,556 & 26,252 & 26,252 & 13,477 & 1,929 & 76,028 & 50,724 \\
\hline Baltimore, MD & 11,270 & 6,803 & 16,636 & 10,767 & 12,556 & 12,556 & 26,252 & 26,252 & 13,394 & 1,985 & 80,108 & 58,363 \\
\hline Albuquerque, NM & 5,847 & 4,968 & 19,218 & 12,805 & 12,556 & 12,556 & 26,252 & 26,252 & 15,006 & 2,214 & 78,878 & 58,794 \\
\hline Seattle, WA & 12,751 & 6,184 & 11,701 & 5,871 & 12,556 & 12,556 & 26,252 & 26,252 & 13,932 & 1,897 & 77,192 & 52,760 \\
\hline Chicago, IL & 15,590 & 11,106 & 14,007 & 9,040 & 12,556 & 12,556 & 26,252 & 26,252 & 13,595 & 1,973 & 82,000 & 60,927 \\
\hline Boulder, CO & 9,873 & 8,112 & 15,122 & 9,821 & 12,556 & 12,556 & 26,252 & 26,252 & 14,749 & 2,135 & 78,551 & 58,876 \\
\hline
\end{tabular}




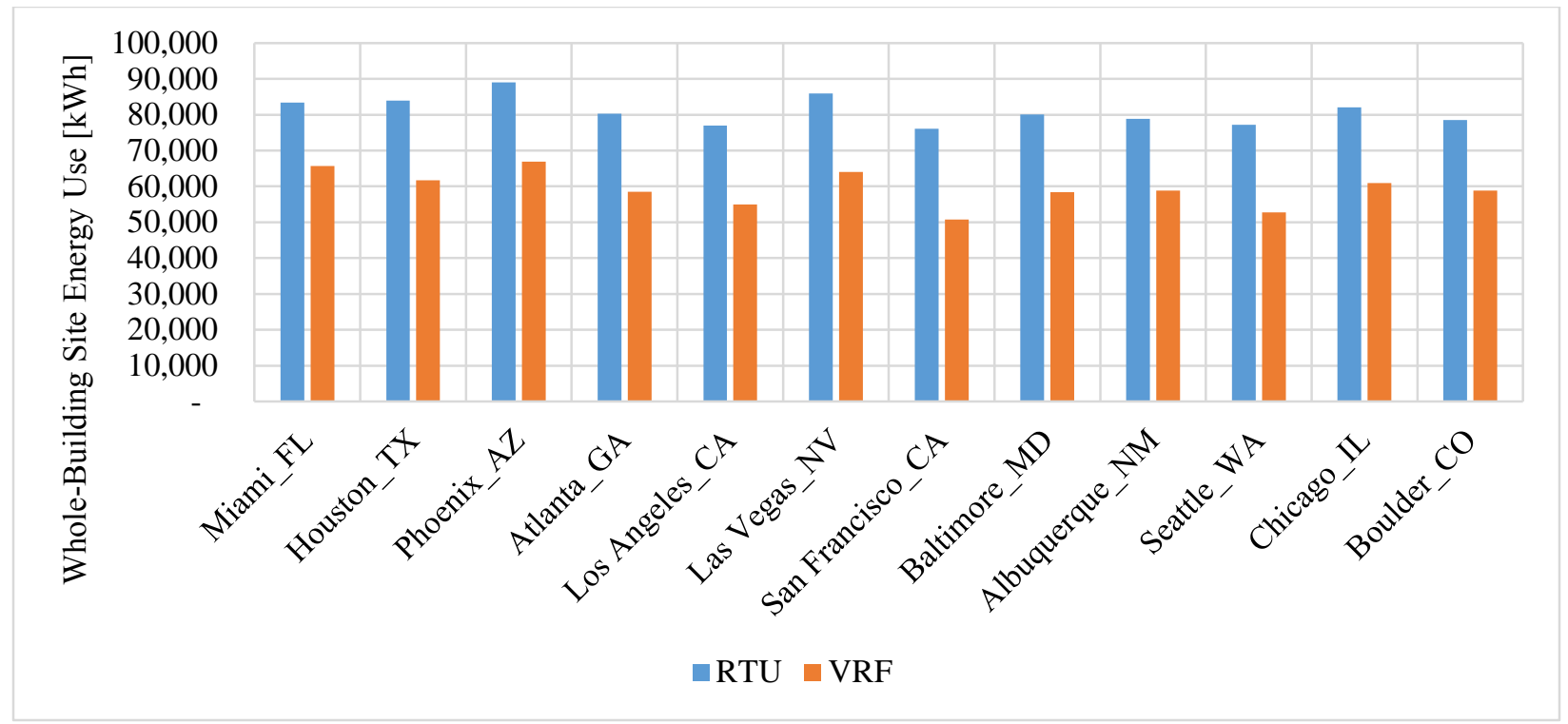

Figure 36. Simulated annual whole-building site energy use for the RTU vs. the VRF system in 12 climate locations.

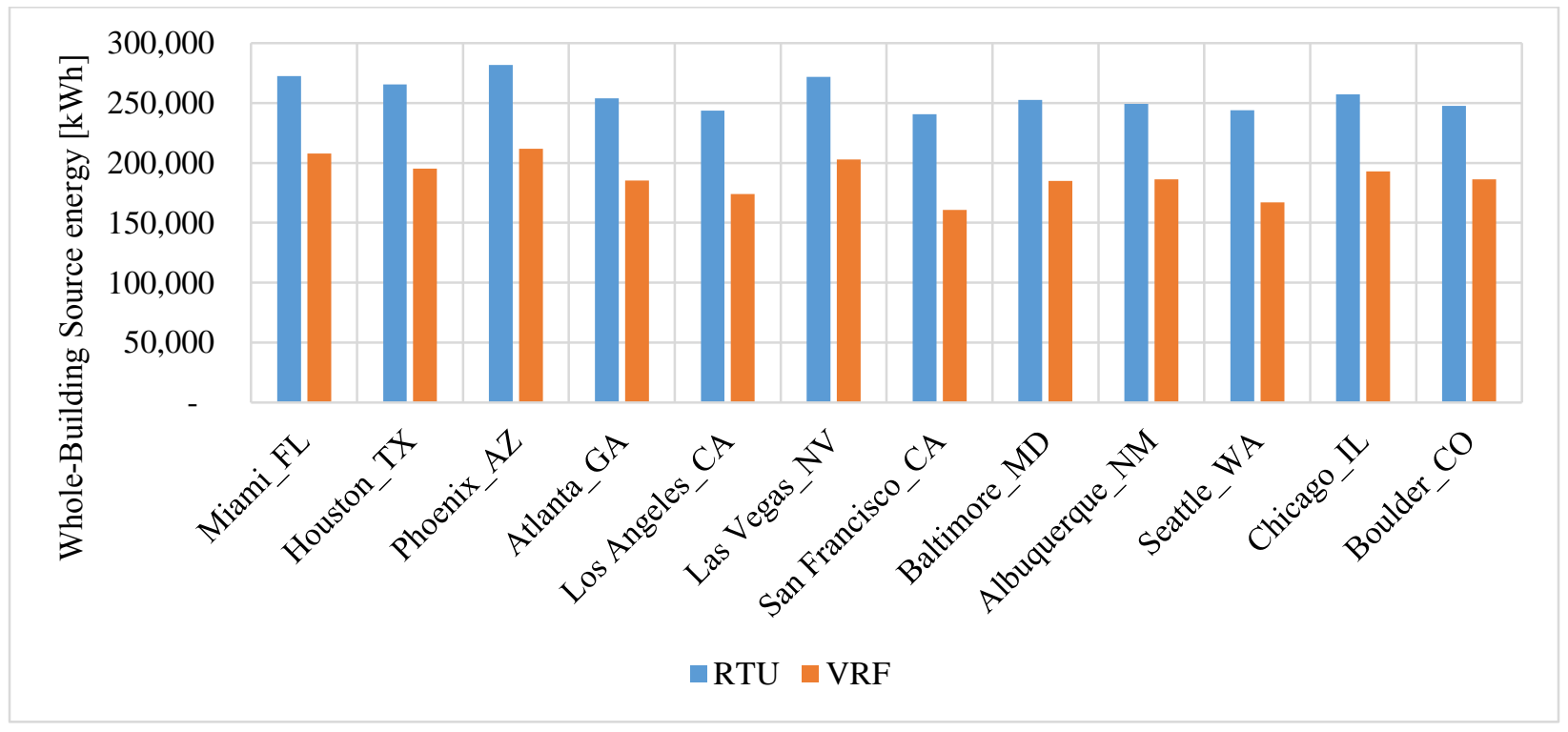

Figure 37. Simulated annual whole-building source energy use in 12 climate locations. 
Table 15. Simulated annual whole-building energy use and savings for the VRF system from the RTU system in 12 climates

\begin{tabular}{|c|c|c|c|c|c|c|c|c|}
\hline & $\begin{array}{c}\text { RTU site } \\
\text { energy } \\
{[\mathrm{kWh}]}\end{array}$ & $\begin{array}{c}\text { VRF site } \\
\text { energy } \\
\text { [kWh] }\end{array}$ & $\begin{array}{c}\text { RTU } \\
\text { source } \\
\text { energy } \\
{[\mathrm{kWh}]}\end{array}$ & $\begin{array}{c}\text { VRF } \\
\text { source } \\
\text { energy } \\
{[\mathrm{kWh}]}\end{array}$ & $\begin{array}{c}\text { VRF site } \\
\text { savings } \\
\text { from } \\
\text { RTU } \\
\text { [kWh] }\end{array}$ & $\begin{array}{l}\text { VRF site } \\
\text { savings } \\
\text { from } \\
\text { RTU [\%] }\end{array}$ & $\begin{array}{c}\text { VRF } \\
\text { source } \\
\text { savings } \\
\text { from } \\
\text { RTU } \\
{[\mathrm{kWh}]}\end{array}$ & $\begin{array}{c}\text { VRF } \\
\text { source } \\
\text { savings } \\
\text { from } \\
\text { RTU [\%] }\end{array}$ \\
\hline Miami, FL & 83,330 & 65,667 & 272,609 & 207,966 & 17,663 & 21.2 & 64,643 & 23.7 \\
\hline Houston, TX & 83,928 & 61,709 & 265,644 & 195,431 & 22,219 & 26.5 & 70,213 & 26.4 \\
\hline Phoenix, AZ & 89,000 & 66,885 & 281,830 & 211,826 & 22,114 & 24.8 & 70,004 & 24.8 \\
\hline Atlanta, GA & 80,280 & 58,508 & 253,832 & 185,295 & 21,771 & 27.1 & 68,537 & 27.0 \\
\hline Los Angeles, CA & 76,915 & 54,980 & 243,586 & 174,121 & 21,935 & 28.5 & 69,465 & 28.5 \\
\hline Las Vegas, NV & 85,906 & 64,073 & 271,915 & 202,918 & 21,833 & 25.4 & 68,997 & 25.4 \\
\hline $\begin{array}{l}\text { San Francisco, } \\
\text { CA }\end{array}$ & 76,028 & 50,724 & 240,709 & 160,644 & 25,304 & 33.3 & 80,065 & 33.3 \\
\hline Baltimore, MD & 80,108 & 58,363 & 252,559 & 184,834 & 21,745 & 27.1 & 67,724 & 26.8 \\
\hline Albuquerque, NM & 78,878 & 58,794 & 249,298 & 186,202 & 20,083 & 25.5 & 63,097 & 25.3 \\
\hline Seattle, WA & 77,192 & 52,760 & 243,916 & 167,089 & 24,432 & 31.7 & 76,827 & 31.5 \\
\hline Chicago, IL & 82,000 & 60,927 & 257,446 & 192,957 & 21,072 & 25.7 & 64,490 & 25.0 \\
\hline Boulder, $\mathrm{CO}$ & 78,551 & 58,876 & 247,597 & 186,460 & 19,675 & 25.0 & 61,136 & 24.7 \\
\hline
\end{tabular}

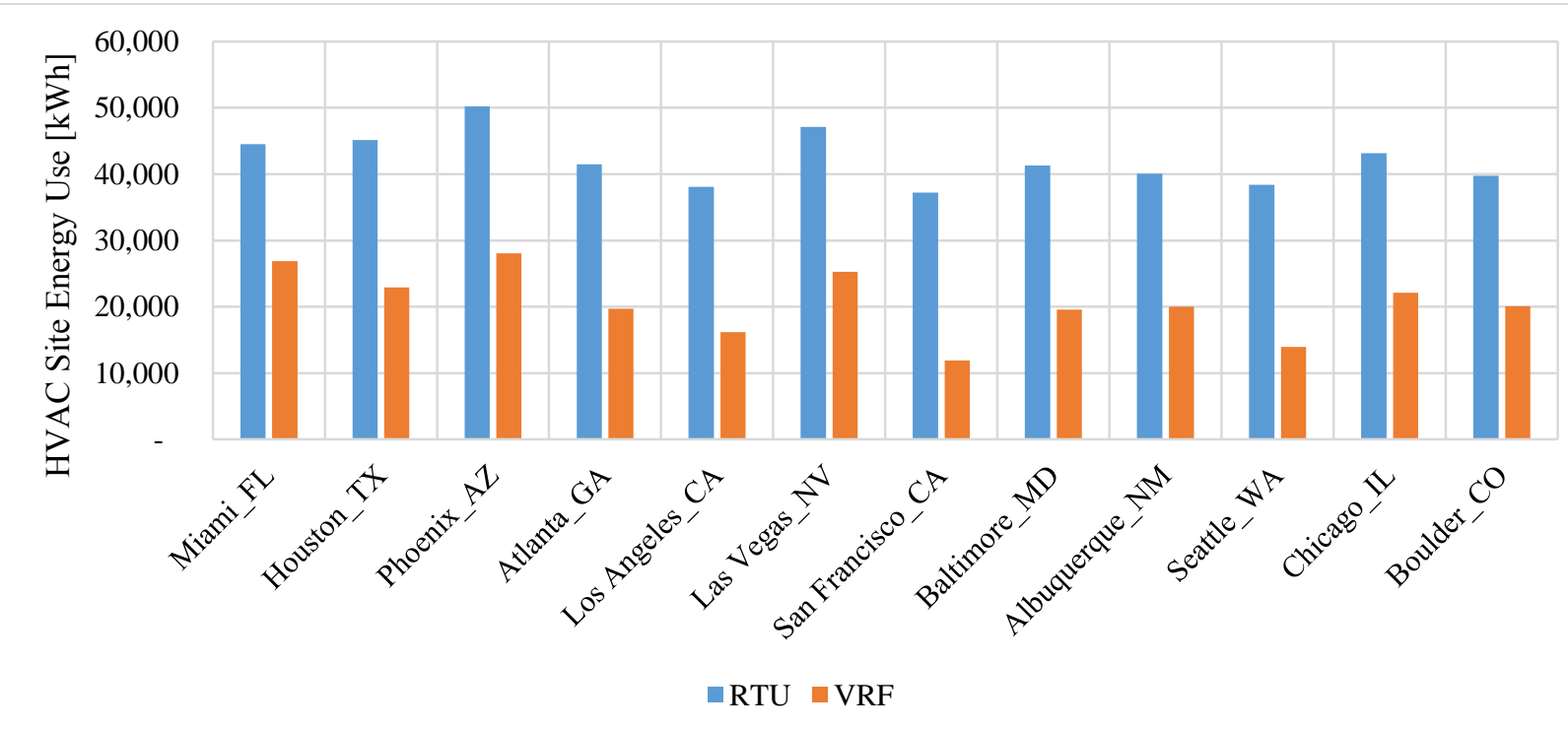

Figure 38. Simulated annual HVAC site energy use for the RTU vs. the VRF system in 12 climate locations. 


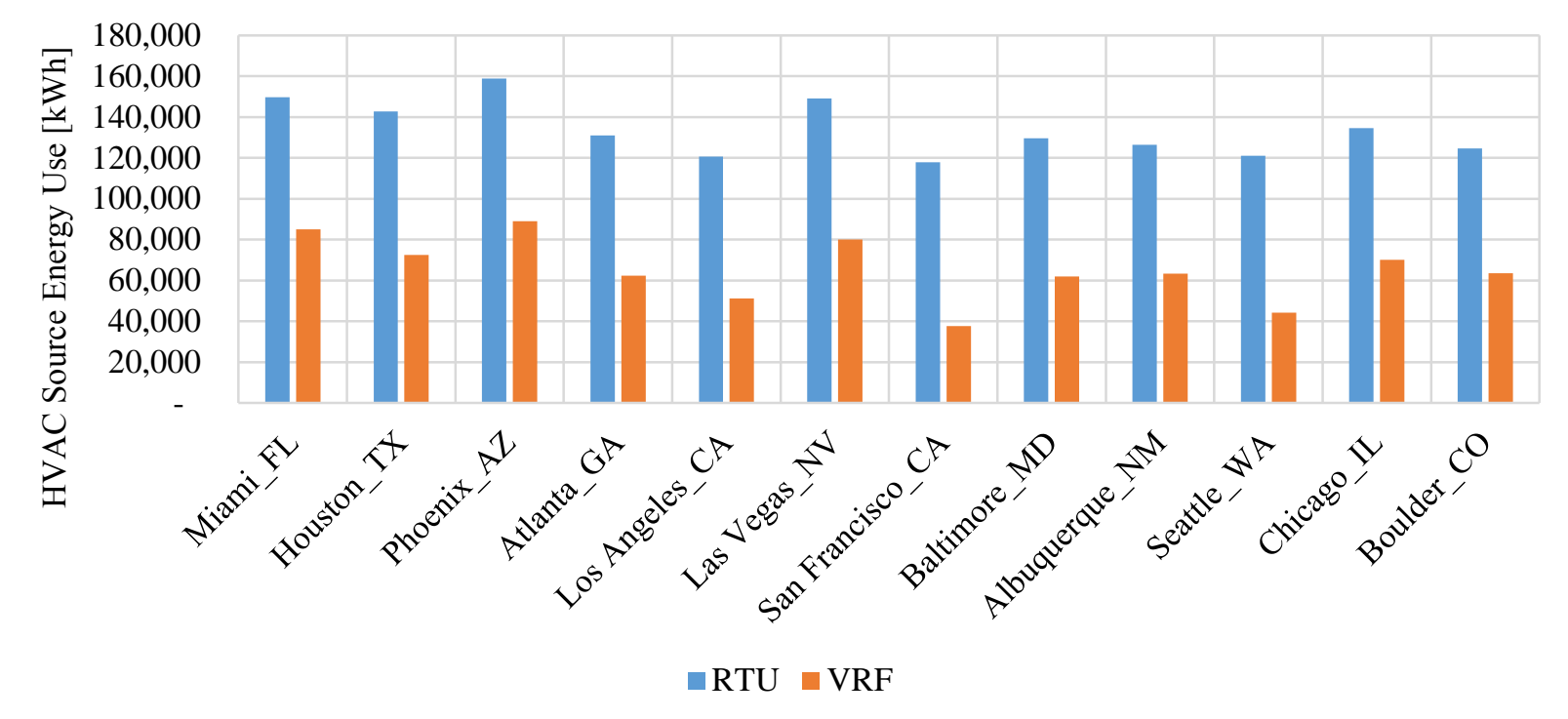

Figure 39. Simulated annual HVAC source energy use in 12 climate locations.

Table 16. Simulated annual HVAC energy use and savings for the VRF system from the RTU system in 12 climates

\begin{tabular}{|c|c|c|c|c|c|c|c|c|}
\hline & $\begin{array}{c}\text { RTU site } \\
\text { energy } \\
{[\mathrm{kWh}]}\end{array}$ & $\begin{array}{c}\text { VRF site } \\
\text { energy } \\
\text { [kWh] }\end{array}$ & $\begin{array}{c}\text { RTU } \\
\text { source } \\
\text { energy } \\
{[\mathrm{kWh}]}\end{array}$ & $\begin{array}{c}\text { VRF } \\
\text { source } \\
\text { energy } \\
{[\mathrm{kWh}]}\end{array}$ & $\begin{array}{c}\text { VRF site } \\
\text { savings } \\
\text { from } \\
\text { RTU } \\
\text { [kWh] }\end{array}$ & $\begin{array}{l}\text { VRF site } \\
\text { savings } \\
\text { from } \\
\text { RTU [\%] }\end{array}$ & $\begin{array}{c}\text { VRF } \\
\text { source } \\
\text { savings } \\
\text { from } \\
\text { RTU } \\
{[\text { kWh] }} \\
\end{array}$ & $\begin{array}{c}\text { VRF } \\
\text { source } \\
\text { savings } \\
\text { from } \\
\text { RTU [\%] }\end{array}$ \\
\hline Miami, FL & 44,523 & 26,859 & 149,706 & 85,063 & 17,663 & 39.7 & 64,643 & 43.2 \\
\hline Houston, TX & 45,121 & 22,901 & 142,741 & 72,528 & 22,219 & 49.2 & 70,213 & 49.2 \\
\hline Phoenix, AZ & 50,192 & 28,078 & 158,927 & 88,923 & 22,114 & 44.1 & 70,004 & 44.0 \\
\hline Atlanta, GA & 41,472 & 19,701 & 130,929 & 62,392 & 21,771 & 52.5 & 68,537 & 52.3 \\
\hline Los Angeles, CA & 38,108 & 16,172 & 120,683 & 51,218 & 21,935 & 57.6 & 69,465 & 57.6 \\
\hline Las Vegas, NV & 47,099 & 25,265 & 149,012 & 80,015 & 21,833 & 46.4 & 68,997 & 46.3 \\
\hline $\begin{array}{l}\text { San Francisco, } \\
\text { CA }\end{array}$ & 37,221 & 11,917 & 117,806 & 37,741 & 25,304 & 68.0 & 80,065 & 68.0 \\
\hline Baltimore, MD & 41,300 & 19,555 & 129,656 & 61,931 & 21,745 & 52.7 & 67,724 & 52.2 \\
\hline Albuquerque, NM & 40,070 & 19,987 & 126,395 & 63,299 & 20,083 & 50.1 & 63,097 & 49.9 \\
\hline Seattle, WA & 38,384 & 13,952 & 121,013 & 44,186 & 24,432 & 63.7 & 76,827 & 63.5 \\
\hline Chicago, IL & 43,192 & 22,120 & 134,543 & 70,054 & 21,072 & 48.8 & 64,490 & 47.9 \\
\hline Boulder, CO & 39,744 & 20,069 & 124,694 & 63,557 & 19,675 & 49.5 & 61,136 & 49.0 \\
\hline
\end{tabular}




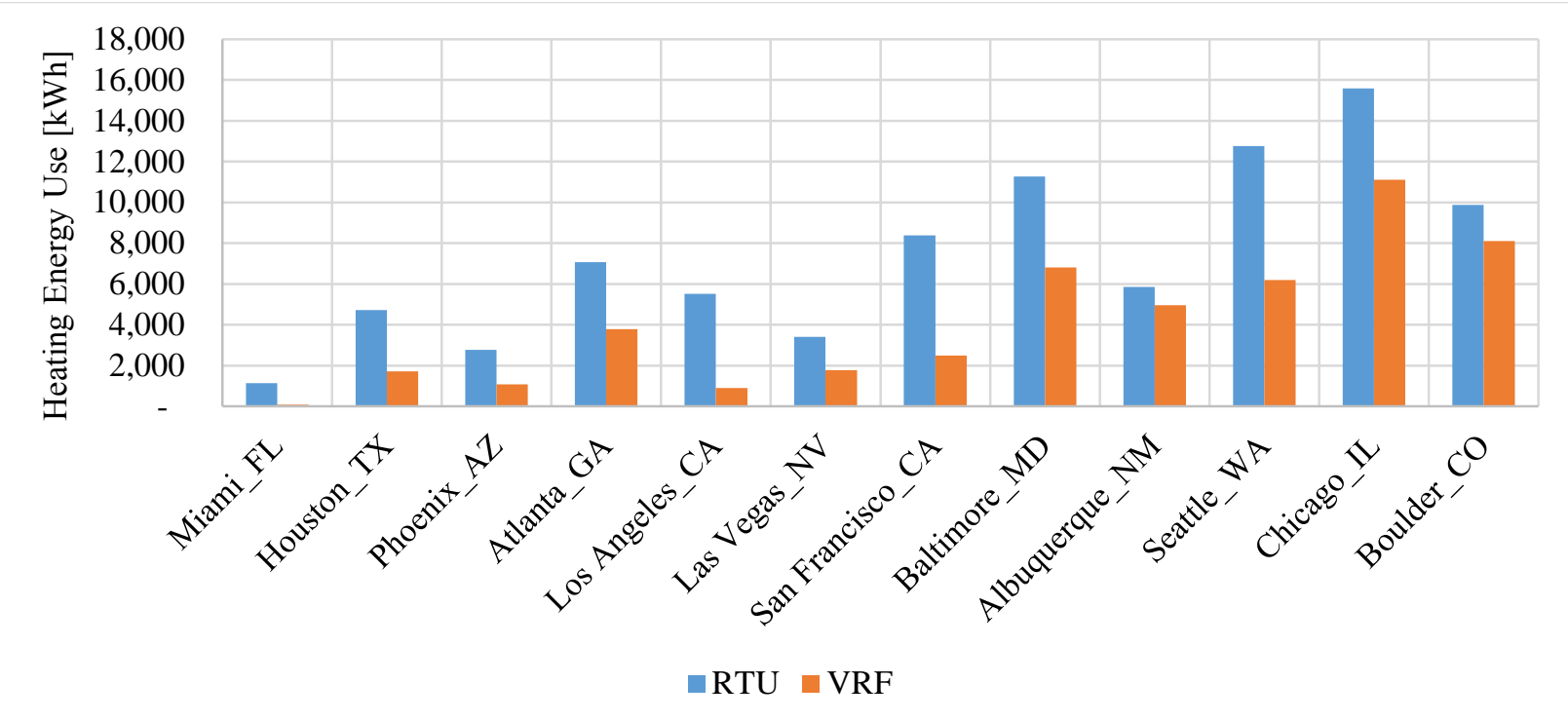

Figure 40. Simulated heating energy use for the RTU vs. the VRF system in 12 climate locations.

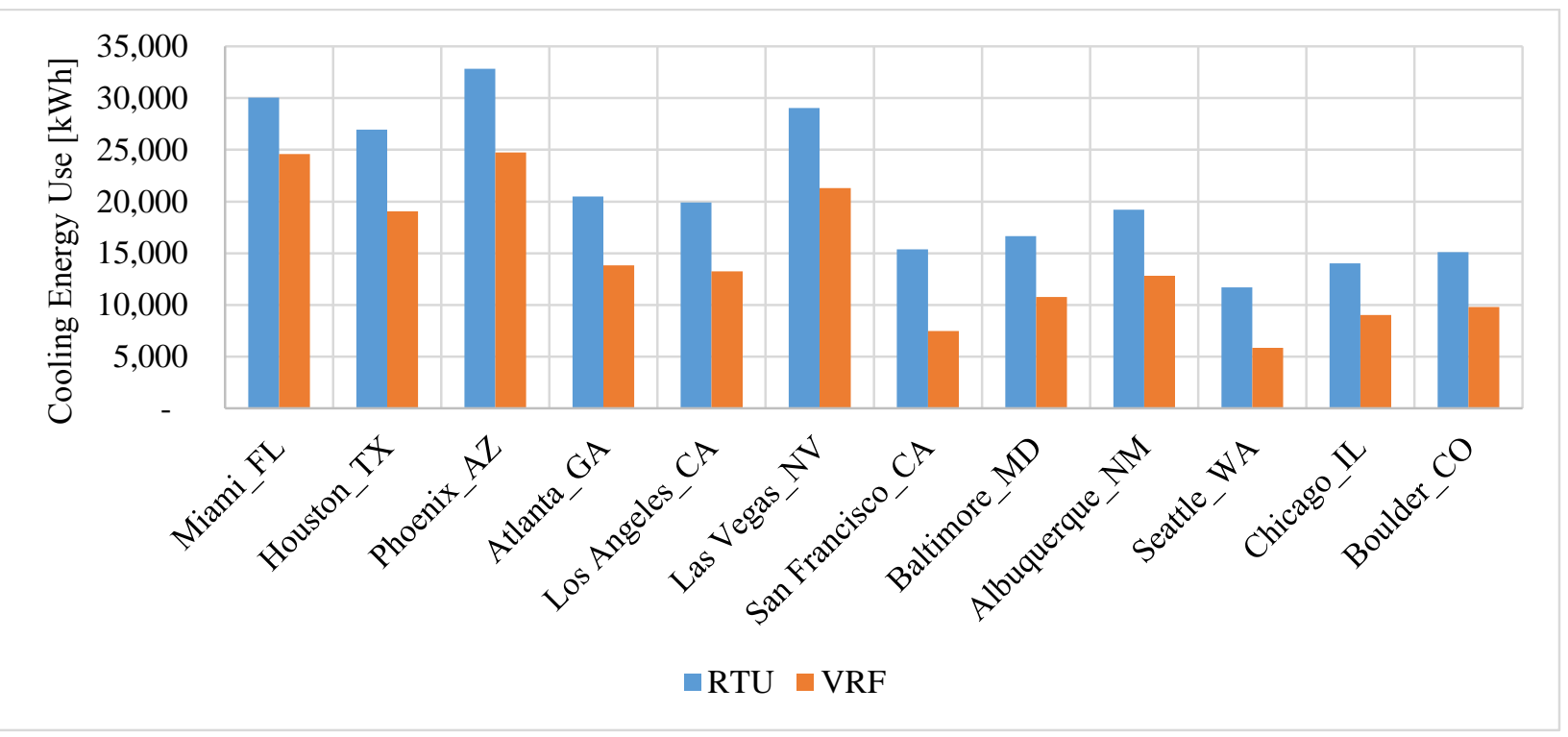

Figure 41. Simulated cooling energy use for the RTU vs. the VRF system in 12 climate locations. 
Table 17. Simulated annual heating and cooling energy use and savings for the VRF system from the RTU system in 12 climate locations

\begin{tabular}{|c|c|c|c|c|c|c|c|c|}
\hline & $\begin{array}{c}\text { RTU } \\
\text { heating } \\
{[\mathrm{kWh}]}\end{array}$ & $\begin{array}{c}\text { VRF } \\
\text { heating } \\
{[\mathrm{kWh}]}\end{array}$ & $\begin{array}{c}\text { RTU } \\
\text { cooling } \\
{[\mathrm{kWh}]}\end{array}$ & $\begin{array}{c}\text { VRF } \\
\text { cooling } \\
{[\mathrm{kWh}]}\end{array}$ & $\begin{array}{c}\text { VRF } \\
\text { heating } \\
\text { savings } \\
\text { from } \\
\text { RTU } \\
\text { [kWh] }\end{array}$ & $\begin{array}{c}\text { VRF } \\
\text { cooling } \\
\text { savings } \\
\text { from } \\
\text { RTU } \\
{[\mathrm{kWh}]} \\
\end{array}$ & $\begin{array}{c}\text { VRF } \\
\text { heating } \\
\text { savings } \\
\text { from } \\
\text { RTU [\%] }\end{array}$ & $\begin{array}{c}\text { VRF } \\
\text { cooling } \\
\text { savings } \\
\text { from } \\
\text { RTU [\%] }\end{array}$ \\
\hline Miami, FL & 1,131 & 90 & 30,053 & 24,572 & 1,041 & 5,481 & 92.0 & 18.2 \\
\hline Houston, TX & 4,721 & 1,718 & 26,963 & 19,071 & 3,003 & 7,892 & 63.6 & 29.3 \\
\hline Phoenix, AZ & 2,764 & 1,076 & 32,842 & 24,759 & 1,688 & 8,083 & 61.1 & 24.6 \\
\hline Atlanta, GA & 7,078 & 3,794 & 20,469 & 13,822 & 3,284 & 6,646 & 46.4 & 32.5 \\
\hline Los Angeles, CA & 5,516 & 892 & 19,891 & 13,264 & 4,624 & 6,627 & 83.8 & 33.3 \\
\hline Las Vegas, NV & 3,400 & 1,765 & 29,052 & 21,286 & 1,635 & 7,766 & 48.1 & 26.7 \\
\hline $\begin{array}{l}\text { San Francisco, } \\
\text { CA }\end{array}$ & 8,374 & 2,498 & 15,369 & 7,490 & 5,877 & 7,880 & 70.2 & 51.3 \\
\hline Baltimore, MD & 11,270 & 6,803 & 16,636 & 10,767 & 4,467 & 5,869 & 39.6 & 35.3 \\
\hline Albuquerque, NM & 5,847 & 4,968 & 19,218 & 12,805 & 879 & 6,412 & 15.0 & 33.4 \\
\hline Seattle, WA & 12,751 & 6,184 & 11,701 & 5,871 & 6,568 & 5,830 & 51.5 & 49.8 \\
\hline Chicago, IL & 15,590 & 11,106 & 14,007 & 9,040 & 4,484 & 4,967 & 28.8 & 35.5 \\
\hline Boulder, $\mathrm{CO}$ & 9,873 & 8,112 & 15,122 & 9,821 & 1,760 & 5,301 & 17.8 & 35.1 \\
\hline
\end{tabular}

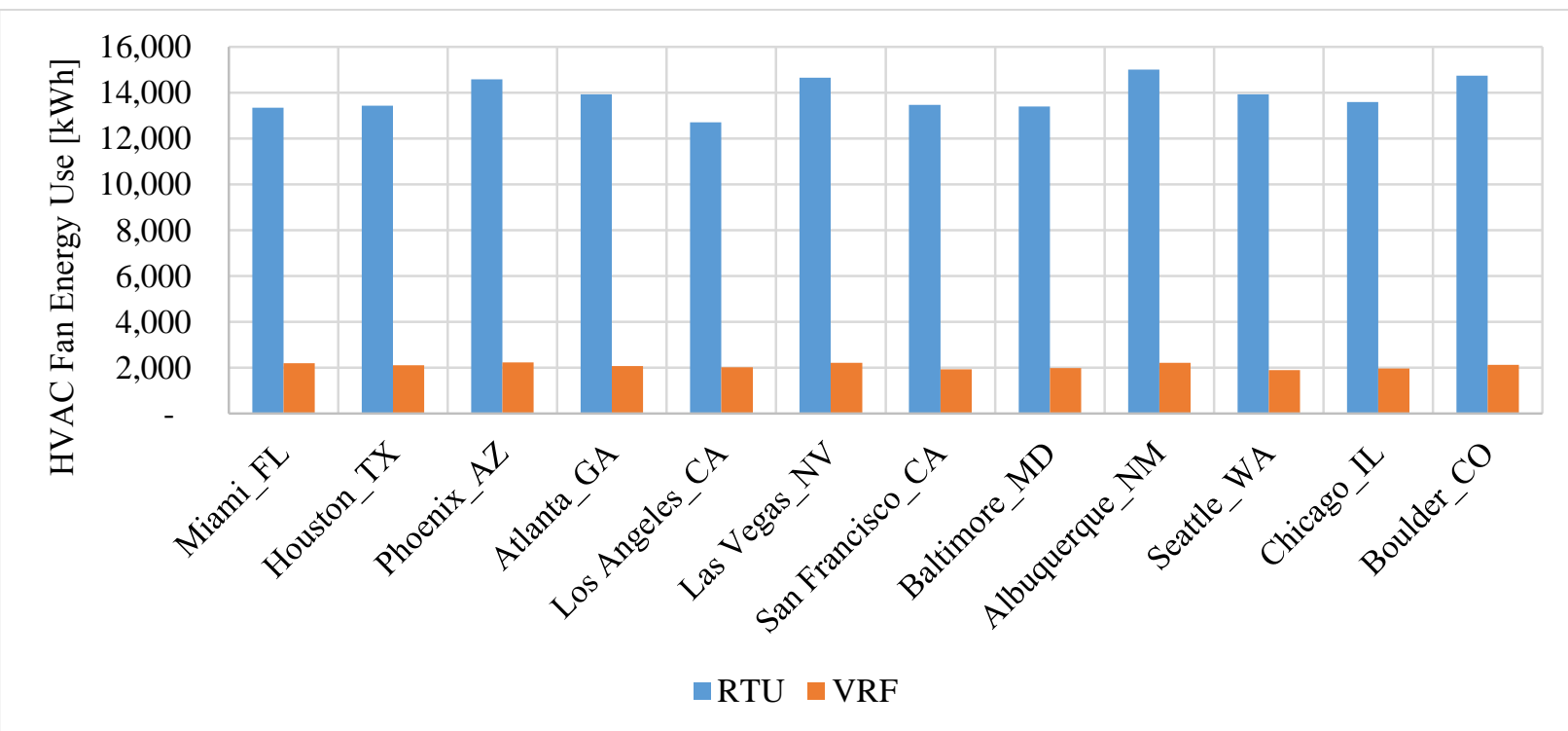

Figure 42. Simulated HVAC fan energy use for the RTU vs. the VRF system in 12 climate locations. 
Table 18. Simulated HVAC fan energy use and savings for the VRF system from the RTU system in 12 climates

\begin{tabular}{lcccc}
\hline & RTU [kWh] & VRF [kWh] & $\begin{array}{c}\text { VRF savings from } \\
\text { RTU [kWh] }\end{array}$ & $\begin{array}{c}\text { VRF savings from } \\
\text { RTU[\%] }\end{array}$ \\
\hline Miami, FL & 13,339 & 2,197 & 11,142 & 83.5 \\
Houston, TX & 13,436 & 2,112 & 11,324 & 84.3 \\
Phoenix, AZ & 14,586 & 2,243 & 12,343 & 84.6 \\
Atlanta, GA & 13,926 & 2,085 & 11,841 & 85.0 \\
Los Angeles, CA & 12,701 & 2,016 & 10,684 & 84.1 \\
Las Vegas, NV & 14,647 & 2,214 & 12,433 & 84.9 \\
San Francisco, CA & 13,477 & 1,929 & 11,548 & 85.7 \\
Baltimore, MD & 13,394 & 1,985 & 11,409 & 85.2 \\
Albuquerque, NM & 15,006 & 2,214 & 12,792 & 85.2 \\
Seattle, WA & 13,932 & 1,897 & 12,035 & 86.4 \\
Chicago, IL & 13,595 & 1,973 & 11,622 & 85.5 \\
Boulder, CO & 14,749 & 2,135 & 12,614 & 85.5 \\
\hline
\end{tabular}

\subsubsection{The cost saving potential in 12 climate locations}

The energy cost savings potential of the VRF system compared with the baseline RTU system was estimated within the 12 climate locations using the modified calibrated simulation model. The average electricity and natural gas prices for the states in 2015, taken from the US Energy Information Administration (EIA 2016a and 2016b) were used in the cost savings analysis for each representative climate location as listed in Table 19.

The energy costs and savings for the VRF systems compared with the RTU systems in the 12 climate locations, in whole-building and HVAC system savings, are summarized in Figure 43, Figure 44, and Table 20 .

- Table 20 and Figure 43 show the calculated annual whole-building energy costs for 12 climate locations. It is shown that the percentage annual whole-building cost savings for the VRF system range between 24 and $33 \%$ among the 12 climate zones. These correspond to annual whole-building energy cost savings between $\$ 2,090.0 /$ year and $\$ 3,534.0 /$ year. It appears the highest and lowest energy cost savings would be achieved in San Francisco and Miami, respectively.

- Table 20 and Figure 44 represent the calculated annual HVAC energy cost trends. It is shown that the percentage HVAC cost savings are around 43 to $68 \%$. The magnitude of the cost savings for wholebuilding and HVAC energy use is the same, because the energy use for lighting and other building equipment for both the VRF and RTU systems is assumed to be the same. 
Table 19. The average electricity and natural gas prices in different locations (EIA 2016a and 2016b)

\begin{tabular}{|c|c|c|}
\hline & $\begin{array}{c}\text { Average price of electricity } \\
(\$ \text { per } k W h)\end{array}$ & $\begin{array}{l}\text { Average price of natural gas } \\
\quad\left(\$ \text { per Mcf }\left[1,000 \mathrm{ft}^{3}\right]\right)\end{array}$ \\
\hline Miami, FL & 0.102 & 10.7 \\
\hline Houston, TX & 0.081 & 8.3 \\
\hline Phoenix, AZ & 0.097 & 10.5 \\
\hline Atlanta, GA & 0.102 & 8.5 \\
\hline Los Angeles, CA & 0.140 & 8.0 \\
\hline Las Vegas, NV & 0.098 & 8.7 \\
\hline San Francisco, CA & 0.140 & 8.0 \\
\hline Baltimore, MD & 0.116 & 10.0 \\
\hline Albuquerque, NM & 0.104 & 7.9 \\
\hline Seattle, WA & 0.082 & 9.1 \\
\hline Chicago, IL & 0.087 & 7.3 \\
\hline Boulder, CO & 0.097 & 8.2 \\
\hline
\end{tabular}

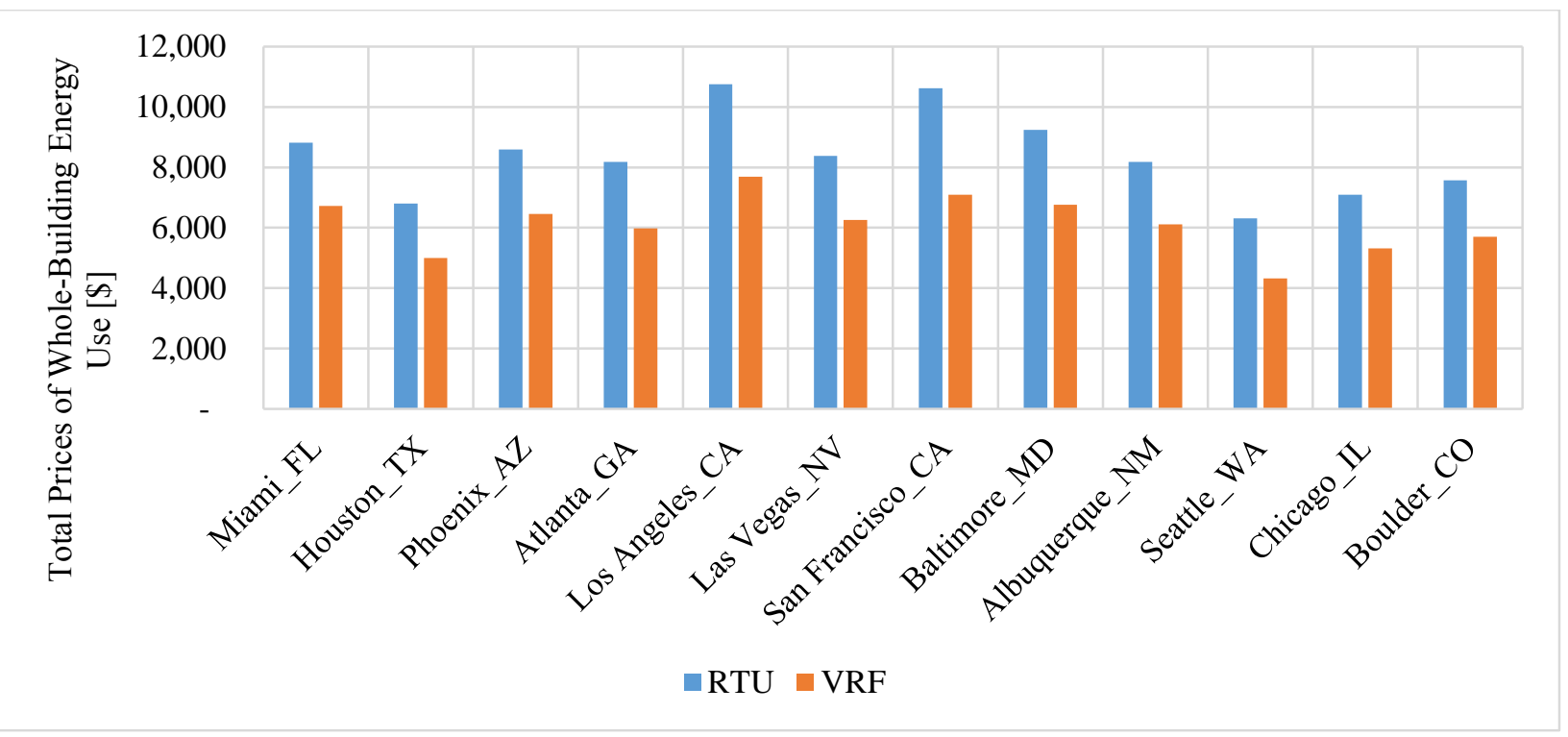

Figure 43. Calculated annual whole-building energy cost for the RTU vs. the VRF system in 12 climate locations. 


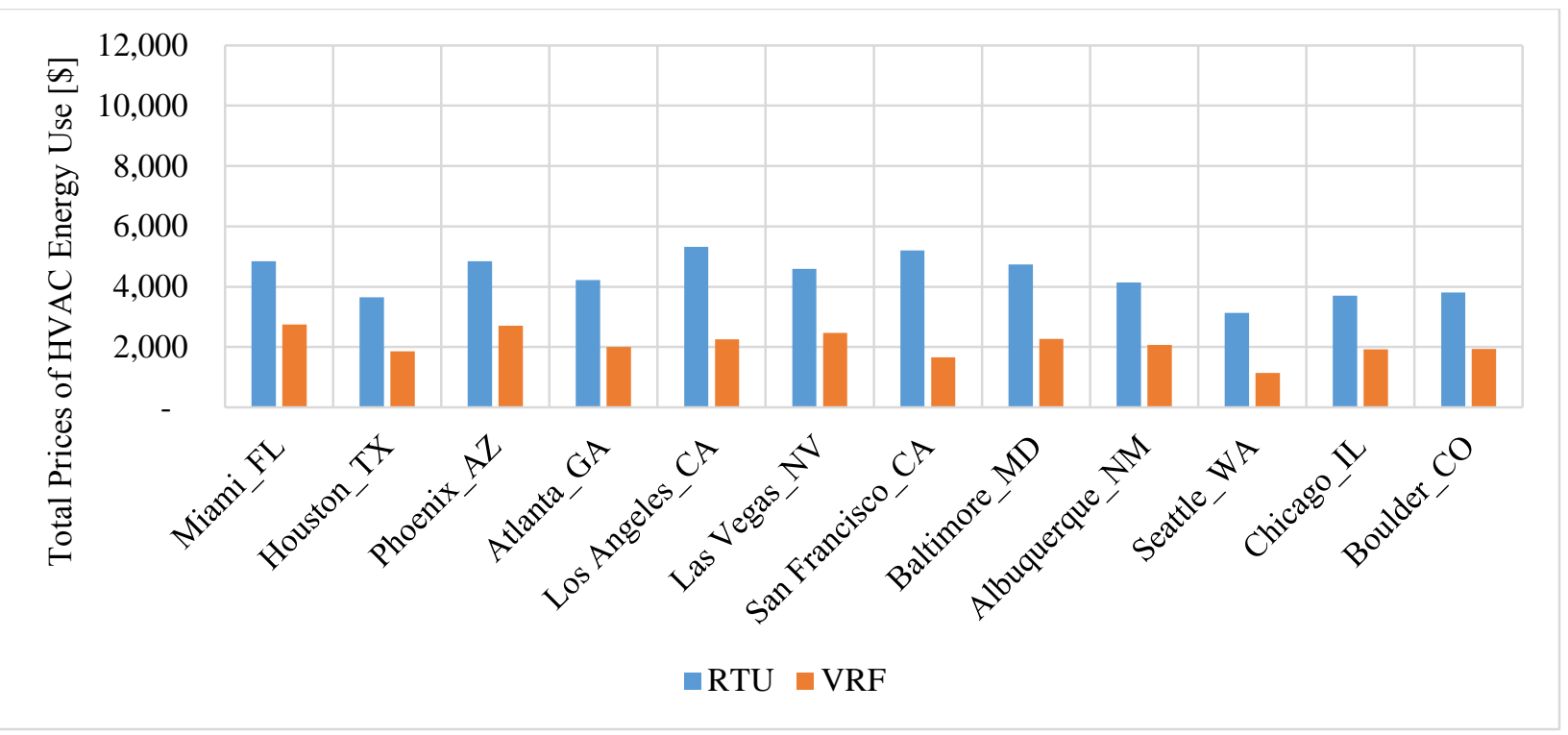

Figure 44. Calculated annual HVAC energy cost for the RTU vs. the VRF system in 12 climate locations.

Table 20. Calculated energy cost and savings for the RTU versus the VRF system in 12 climate locations

\begin{tabular}{ccccccccc}
\hline & $\begin{array}{c}\text { RTU } \\
\text { whole- } \\
\text { building } \\
\text { cost [\$] }\end{array}$ & $\begin{array}{c}\text { VRF } \\
\text { whole- } \\
\text { building } \\
\text { cost [\$] }\end{array}$ & $\begin{array}{c}\text { RTU } \\
\text { HVAC } \\
\text { cost [\$] }\end{array}$ & $\begin{array}{c}\text { VRF } \\
\text { HVAC } \\
\text { cost [\$] }\end{array}$ & $\begin{array}{c}\text { Whole- } \\
\text { building } \\
\text { cost } \\
\text { savings } \\
{[\$]}\end{array}$ & $\begin{array}{c}\text { Whole- } \\
\text { building } \\
\text { cost } \\
\text { savings } \\
{[\%]}\end{array}$ & $\begin{array}{c}\text { HVAC } \\
\text { cost } \\
\text { savings } \\
{[\$]}\end{array}$ & $\begin{array}{c}\text { HVAC } \\
\text { cost } \\
\text { savings } \\
{[\%]}\end{array}$ \\
\hline Miami, FL & 8,814 & 6,724 & 4,841 & 2,750 & 2,090 & 23.7 & 2,090 & 43.2 \\
Houston, TX & 6,794 & 4,998 & 3,651 & 1,855 & 1,796 & 26.4 & 1,796 & 49.2 \\
Phoenix, AZ & 8,596 & 6,461 & 4,848 & 2,712 & 2,135 & 24.8 & 2,135 & 44.0 \\
Atlanta, GA & 8,182 & 5,974 & 4,220 & 2,011 & 2,208 & 27.0 & 2,208 & 52.3 \\
Los Angeles, CA & 10,752 & 7,686 & 5,327 & 2,261 & 3,066 & 28.5 & 3,066 & 57.6 \\
Las Vegas, NV & 8,380 & 6,253 & 4,592 & 2,466 & 2,126 & 25.4 & 2,126 & 46.3 \\
San Francisco, CA & 10,625 & 7,091 & 5,200 & 1,666 & 3,534 & 33.3 & 3,534 & 68.0 \\
Baltimore, MD & 9,240 & 6,764 & 4,742 & 2,266 & 2,475 & 26.8 & 2,475 & 52.2 \\
Albuquerque, NM & 8,177 & 6,109 & 4,145 & 2,077 & 2,068 & 25.3 & 2,068 & 49.9 \\
Seattle, WA & 6,309 & 4,321 & 3,130 & 1,143 & 1,988 & 31.5 & 1,988 & 63.5 \\
Chicago, IL & 7,091 & 5,319 & 3,703 & 1,931 & 1,772 & 25.0 & 1,772 & 47.9 \\
Boulder, CO & 7,565 & 5,699 & 3,808 & 1,943 & 1,866 & 24.7 & 1,866 & 49.0 \\
\hline
\end{tabular}

\subsubsection{The national weighted energy and cost savings}

Construction area weight factors in the various climate locations, determined by Jarnagin and Bandyopadhyay (2010), were used to estimate the national weighted energy and cost savings impact. Table 21 lists the weighting factors for each building type in all 12 climate locations. This study used the weight factors for the sum of the small and medium categories because the building type in the simulation models for the VRF and the RTU systems can be considered as a small or medium office type. Table 22 summarizes the national weighted HVAC energy and cost savings potential for the 12 climate locations. 
The national weighted averages of the HVAC energy and energy cost savings for VRF systems compared with RTU systems were calculated as $51.1 \%\left(82.0 \mathrm{kWh} / \mathrm{m}^{2} /\right.$ year $)$ and $50.8 \%\left(\$ 7.4 / \mathrm{m}^{2} /\right.$ year $)$, respectively. The results also indicate that the highest weighted HVAC energy savings is $68.0 \%\left(95.7 \mathrm{kWh} / \mathrm{m}^{2} / \mathrm{year}\right)$ for San Francisco, which is $16.9 \%$ higher than the national weighted average; and the lowest weighted HVAC energy savings is $39.7 \%\left(66.8 \mathrm{kWh} / \mathrm{m}^{2} /\right.$ year $)$ for Miami, which is $11.4 \%$ lower than the national weighted average. The results in Table 22 also show that the highest weighted HVAC cost savings is $68.0 \%$ ( $\$ 11.9 / \mathrm{m}^{2} /$ year) for San Francisco, and the lowest weighted HVAC cost savings is around $43.2 \%$ $\left(\$ 7.0 / \mathrm{m}^{2} /\right.$ year $)$ in Miami.

Table 21. Construction area weights by building type and climate location (Jarnagin and Bandyopadhyay 2010)

\begin{tabular}{cccc}
\hline & Small office & Medium office & $\begin{array}{c}\text { Sum of small and } \\
\text { medium offices }\end{array}$ \\
\hline Miami, FL & $0.08 \%$ & $0.13 \%$ & $0.21 \%$ \\
Houston, TX & $1.06 \%$ & $0.81 \%$ & $1.88 \%$ \\
Phoenix, AZ & $0.29 \%$ & $0.29 \%$ & $0.58 \%$ \\
Atlanta, GA & $0.96 \%$ & $0.77 \%$ & $1.73 \%$ \\
Los Angeles, CA & $0.48 \%$ & $0.72 \%$ & $1.19 \%$ \\
Las Vegas, NV & $0.48 \%$ & $0.72 \%$ & $1.19 \%$ \\
San Francisco, CA & $0.08 \%$ & $0.14 \%$ & $0.21 \%$ \\
Baltimore, MD & $0.94 \%$ & $1.19 \%$ & $2.13 \%$ \\
Albuquerque, NM & $0.05 \%$ & $0.04 \%$ & $0.08 \%$ \\
Seattle, WA & $0.12 \%$ & $0.20 \%$ & $0.32 \%$ \\
Chicago, IL & $0.92 \%$ & $1.06 \%$ & $1.98 \%$ \\
Boulder, CO & $0.32 \%$ & $0.34 \%$ & $0.66 \%$ \\
Weights by Building Type & $5.78 \%$ & $6.39 \%$ & $12.17 \%$ \\
\hline
\end{tabular}

Table 22. Construction area weights and savings potential impact by climate location

\begin{tabular}{cccccc}
\hline & $\begin{array}{c}\text { The sum of small } \\
\text { and medium } \\
\text { office weights }\end{array}$ & $\begin{array}{c}\text { HVAC site } \\
\text { energy savings } \\
\text { [kWh/m2/year] }\end{array}$ & $\begin{array}{c}\text { HVAC site } \\
\text { energy savings } \\
{[\% \text { \% }}\end{array}$ & $\begin{array}{c}\text { HVAC cost } \\
\text { savings } \\
\text { [\$/m2/year] }\end{array}$ & $\begin{array}{c}\text { HVAC cost } \\
\text { savings [\%] }\end{array}$ \\
\hline Miami, FL & $0.21 \%$ & 66.8 & 39.7 & 7.0 & 43.2 \\
Houston, TX & $1.88 \%$ & 84.0 & 49.2 & 6.0 & 49.2 \\
Phoenix, AZ & $0.58 \%$ & 83.6 & 44.1 & 7.2 & 44.0 \\
Atlanta, GA & $1.73 \%$ & 82.3 & 52.5 & 7.4 & 52.3 \\
Los Angeles, CA & $1.19 \%$ & 82.9 & 57.6 & 10.3 & 57.6 \\
Las Vegas, NV & $1.19 \%$ & 82.5 & 46.4 & 7.2 & 46.3 \\
San Francisco, CA & $0.21 \%$ & 95.7 & 68.0 & 11.9 & 68.0 \\
Baltimore, MD & $2.13 \%$ & 82.2 & 52.7 & 8.3 & 52.2 \\
Albuquerque, NM & $0.08 \%$ & 75.9 & 50.1 & 7.0 & 49.9 \\
Seattle, WA & $0.32 \%$ & 92.4 & 63.7 & 6.7 & 63.5 \\
Chicago, IL & $1.98 \%$ & 79.7 & 48.8 & 6.0 & 47.9 \\
Boulder, CO & $0.66 \%$ & $\mathbf{7 4 . 4}$ & 49.5 & 6.3 & 49.0 \\
Total & $\mathbf{1 2 . 2 \%}$ & & & & \\
National weighted & & $\mathbf{8 2 . 0}$ & $\mathbf{5 1 . 1 \%}$ & $\mathbf{7 . 4}$ & $\mathbf{5 0 . 8 \%}$ \\
average & & & &
\end{tabular}




\section{CONCLUSION}

\subsection{SUMMARY AND CONCLUSION}

The predicted performance of the VRF system was evaluated by comparing it with the predicted performance of the baseline RTU system in 12 major US climate locations. A modified version of EnergyPlus 8.1, which is capable of zonal VRF system modeling with the current DOAS setting in the FRP, was used for the energy simulation models of the VRF and RTU systems installed in the FRP, a two-story, $300 \mathrm{~m}^{2}$ multi-zone building with emulated office occupancy.

To calibrate the RTU and the VRF systems, 16 days and 25 days, under full-load conditions (i.e., 100\% loads) in the FRP, were chosen for the calibration period of the RTU and the VRF systems. The calibration process was implemented in several stages - (1) building model updates for calibration, (2) baseline RTU model updates, and (3) VRF model updates for calibration - until they reasonably matched based on the definition from ASHRAE Guideline 14P (ASHRAE 2002). Then the energy and cost savings potential of using VRF systems in 12 major US cities was evaluated using an hourly building energy simulation calibrated with data from the measured data from the FRP. The following are the key findings of this case study.

\section{Simulation Analysis}

- Energy simulation models were developed and simulated using EnergyPlus 8.1 for the RTU and VRF systems installed in the FRP. To model the VRF-DOAS system installed in the FRP, the source code of the original EnergyPlus model was modified. With the source code modifications, two new objects, VRF air loop cooling coil and VRF air loop heating coil, were added to enable the DOAS coupled with a VRF outdoor unit to provide $100 \%$ conditioned OA to individual zones.

- $\quad$ The VRF and RTU models from project year one were updated and calibrated with the measured data. NMBE and CV-RMSE from ASHRAE Guideline 14 were used to evaluate the validity of the calibrated models. The calibration results show that the baseline RTU model would result in 20.2 hourly CV-RMSE and 3.6\% hourly NMBE. For the VRF simulation model, the CV-RMSE and NMBE would be within 15.7 and 3.8\%, respectively. These results indicate that the calibrated models of both the VRF and the RTU were reasonably calibrated, based on the criteria from ASHRAE Guideline 14.

- With the calibrated simulation model, the energy savings potential of the VRF system was evaluated in 12 climate locations using the corresponding TMY2 weather data. The comparison results show that VRF systems would use lower overall energy than RTU systems in the 12 climate locations. The site energy savings for VRF systems compared with RTU systems are 33\% (25,304.0 kWh/year) for San Francisco, the location with the highest savings, and 21\% (17,663.0 kWh/year) for Miami, the location with the lowest savings, among the 12 climate locations. The highest source energy savings are $33 \%$ (80,065.0 kWh/year) for San Francisco, and the lowest savings are 24\% (64,643.0 kWh/year) for Miami.

- The energy cost savings potential of the VRF system was estimated for 12 climate locations using the average electricity and natural gas prices for the states from 2015. The overall whole-building annual percentage cost savings for the VRF system compared with the RTU system are approximately 24 to $33 \%$, and the corresponding annual whole-building energy cost savings are around \$2,090.0/year to $\$ 3,534.0 / y e a r$. The corresponding percentage cost savings of the annual HVAC energy use are $43-$ 
$68 \%$. The model shows the highest percentage cost savings are for San Francisco-68\%, and the lowest percentage cost savings are for Chicago- $43 \%$.

- The weighted HVAC energy and cost savings were calculated on the national scale by construction area weights in 12 climate locations. The national weighted average of the VRF HVAC energy and cost savings, respectively, from the RTU system is $51.1 \%(82.0 \mathrm{kWh} / \mathrm{m} 2 /$ year) and $50.8 \%$ (7.4 $\$ / \mathrm{m} 2 /$ year) based on the 12 US climate locations. 


\section{REFERENCES}

ASHRAE. 2002. ASHRAE Guideline 14-2002. Measurement of Energy and Demand Savings, ISSN 1049-894X, American Society of Heating, Refrigeration and Air-conditioning Engineers, Atlanta, GA.

ASHRAE. 2004. ANSI/ASHRAE/IESNA Standard 90.1-2004. Energy Standard for Buildings Except Low-Rise Residential Buildings, American Society of Heating, Refrigerating and Air-Conditioning Engineers, Inc., Atlanta, GA.

ASHRAE. 2013. ANSI/ASHRAE Standard 62.1-2013. Ventilation for Acceptable Indoor Air Quality, American Society of Heating, Refrigeration and Air-Conditioning Engineers, Atlanta, GA.

Deru, M., and P. Tocellini. 2007. Source Energy and Emission Factors for Energy Use in Buildings, Technical Report, NREL/TP-550-38617, National Renewable Energy Laboratory, Golden, CO.

EIA. 2016a. Electric Power Monthly with Data For March 2016. Energy Information Administration, U.S. Department of Energy, Washington, D.C. Last accessed in June, 2016 at https://www.eia.gov/electricity/monthly/pdf/epm.pdf

EIA. 2016b. Natural Gas 2016. Energy Information Administration, U.S. Department of Energy, Washington, D.C. Last accessed in Jun, 2016 at http://www.eia.gov/dnav/ng/ng_pri_sum_a_EPG0_PCS_DMcf_a.htm

Gowri, K. et al. 2009. Infiltration Modeling Guidelines for Commercial Building Energy Analysis, PNNL-18898, Pacific Northwest National Laboratory, Richland, WA.

Im et al. 2015. Evaluation of Variable Refrigerant Flow Systems Performance and the Enhanced Control Algorithm on Oak Ridge National Laboratory's Flexible Research Platform. ORNL/TM-2015/225, Oak Ridge National Laboratory, Oak Ridge, TN.

Jarnagin, R. E., and G. K. Bandyopadhyay. (2010). Weighting Factors for the Commercial Building Prototypes Used in the Development of ANSI/ASHRAE/IESNA 90.1-2010. PNNL-19116, Pacific Northwest National Laboratory, Richland, WA. 


\title{
APPENDIX A. INPUT/OUTPUT REFERENCE-THE MODIFIED ENERGYPLUS
}

\author{
TABLE OF CONTENTS
}

1) Document Overview

2) ZoneHVAC:TerminalUnit:VariableRefrigerantFlow

3) Variable Refrigerant Flow (VRF) Terminal Unit (ZoneHVAC) Outputs

4) Coil:Cooling:DX:VRFAirloop

5) Coil:Heating:DX:VRFAirloop

6) CoilSystem:Cooling:DX

7) DX Cooling Coil System Outputs

8) CoilSystem:Heating:DX

9) DX Heating Coil System Outputs

10) Variable Refrigerant Flow (VRF) Terminal Unit (ZoneHVAC) Outputs

11) Variable Refrigerant Flow (VRF) Terminal Unit (ZoneHVAC) Outputs

\section{DOCUMENT OVERVIEW}

This document provides input/output descriptions of newly added or modified EnergyPlus objects that are required to enable an air-loop dedicated outdoor air system (DOAS) with a variable refrigerant flow (VRF) heating and cooling coil. The objects shown below are partly revised to include inputs and outputs of the modified EnergyPlus objects based on an original EnergyPlus input/output document. This document is also intended to be an encyclopedic reference for the EnergyPlus Input Data Dictionary (IDD), Input Data File (IDF) and potential resultant outputs (various output files).

\section{ZONEHVAC:TERMINALUNIT:VARIABLEREFRIGERANTFLOW}

Zone terminal units with VRF direct-expansion (DX) coils are used exclusively with VRF airconditioning systems (Ref. AirConditioner:VariableRefrigerantFlow object). The zone terminal units are connected to a zone using the inlet and exhaust node names specified in a ZoneHVAC:EquipmentConnections object. The zone exhaust node has the same name as the terminal unit air inlet node. The zone inlet node has the same name as the terminal unit air outlet node. The zone terminal unit is also listed in a zone's equipment list and will typically be the first equipment operating for both cooling and heating (i.e., Sequence $=1$ in the ZoneHVAC:EquipmentList). Other ZoneHVAC equipment may be used in the same zone and should be sequenced to operate after the zone terminal units (i.e., sequence $=2$ or higher)

The terminal units operate to satisfy a heating or cooling load in a zone based on a zone thermostat temperature set point. A DX cooling and/or DX heating coil is specified depending on the operating mode 
required. Both a DX cooling and DX heating coil will typically be installed in the terminal unit; however, only one may be used if desired. Outdoor ventilation air is modeled with the use of an optional outside air mixer object. Outside air may be provided to the zone only when the coil is operating or can be supplied continuously even when the coil is not operating. A supply air fan is also required and can be modeled as either draw through or blow through.

Field: Zone Terminal Unit Name

This alpha field defines a unique user-assigned name for an instance of a VRF zone terminal unit. Any reference to this terminal unit by another object will use this name. The zone terminal unit name must be specified in a ZoneTerminalUnitList object to connect this terminal unit to an AirConditioner:VariableRefrigerantFlow object.

\section{Field: Availability Schedule Name}

This alpha field defines the name of the schedule (ref: Schedule) that denotes whether the terminal unit operates during a given time period. A schedule value equal to 0 denotes that the terminal unit must be off for that time period. A value greater than 0 denotes that the terminal unit is available to operate during that time period. This schedule may be used to completely disable the terminal unit as required. If this field is left blank, the schedule has a value of 1 for all time periods.

\section{Field: Terminal Unit Air Inlet Node Name}

This alpha field defines the name of the terminal unit air inlet node. This node name should be the same as a zone exhaust node (ref: ZoneHVAC:EquipmentConnections).

\section{Field: Terminal Unit Air Outlet Node Name}

This alpha field defines the name of the terminal unit air outlet node. This node name should be the same as a zone inlet node (ref: ZoneHVAC:EquipmentConnections).

\section{Field: Supply Air Flow Rate During Cooling Operation}

This numeric field defines the terminal unit's operating volumetric air flow rate in cubic meters per second. This volumetric air flow rate is used when the terminal unit is operating in cooling mode.

\section{Field: Supply Air Flow Rate When No Cooling is Needed}

This numeric field defines the terminal unit's operating volumetric air flow rate in cubic meters per second. This volumetric air flow rate is used when the terminal unit's cooling coil is not operating and the previous mode was cooling.

\section{Field: Supply Air Flow Rate During Heating Operation}

This numeric field defines the terminal unit's operating volumetric air flow rate in cubic meters per second. This volumetric air flow rate is used when the terminal unit is operating in heating mode.

\section{Field: Supply Air Flow Rate When No Heating is Needed}

This numeric field defines the terminal unit's operating volumetric air flow rate in cubic meters per second. This volumetric air flow rate is used when the terminal unit's heating coil is not operating and the previous mode was heating. 


\section{Field: Outdoor Air Flow Rate During Cooling Operation}

This numeric field defines the outdoor air volumetric air flow rate in cubic meters per second. This volumetric air flow rate is used when the terminal unit is operating in cooling mode.

\section{Field: Outdoor Air Flow Rate During Heating Operation}

This numeric field defines the outdoor air volumetric air flow rate in cubic meters per second. This volumetric air flow rate is used when the terminal unit is operating in heating mode.

\section{Field: Outdoor Air Flow Rate When No Cooling or Heating is Needed}

This numeric field defines the outdoor air volumetric air flow rate in cubic meters per second. This volumetric air flow rate is used when the terminal unit is not operating in cooling or heating mode.

\section{Field: Supply Air Fan Operating Mode Schedule Name}

This alpha field defines the name of the supply air fan operating mode schedule. Schedule values equal to 0 denote cycling fan/cycling coil operation. All other schedule values denote constant fan/cycling coil operation.

\section{Field: Supply Air Fan Placement}

This alpha field has two choices: BlowThrough or DrawThrough. If this field is left blank, the default is blow through. The first choice stands for "blow through fan." This means that the unit consists of a fan followed by the DX coils. The fan "blows through" the cooling and heating coils. If an outside air mixer is used, the fan inlet connects to the outside air mixer's mixed air node. If an outside air mixer is not used, the fan inlet connects to the zone exhaust node. For this configuration, the fan outlet always connects to the DX cooling coil inlet node (or if a DX cooling coil is not used, the DX heating coil inlet node).

The second choice stands for "draw through fan." This means that the unit consists of the DX coil(s) followed by a fan. The fan "draws air through" the DX coil(s). In this case the fan inlet always connects to the DX heating coil outlet node (or if a DX heating coil is not used, the DX cooling coil outlet node) and the fan outlet node always connects to the zone inlet node.

\section{Field: Supply Air Fan Object Type}

This choice field contains the identifying type of supply air fan specified for the furnace. Fan type must be Fan:OnOff or Fan:ConstantVolume. Fan:ConstantVolume is used when the Supply Air Fan Operating Mode Schedule values are never 0 and the fan operates continuously. Fan:OnOff is used when the fan cycles on and off with the cooling or heating coil (i.e. Supply Air Fan Operating Mode Schedule values are at times 0 ).

\section{Field: Supply Air Fan Object Name}

This alpha field defines the name of the terminal unit's supply air fan.

\section{Field: Outside Air Mixer Object Type}

This alpha field contains the identifying type of outside air mixer specified for the terminal unit. Outside air mixer type must be OutsideAir:Mixer. This field should be left blank when an outside air mixer is not simulated. 
Field: Outside Air Mixer Object Name

This alpha field defines the name of the terminal unit's outside air mixer. If this field is left blank, an outside air mixer is not simulated.

Field: DX Cooling Coil Object Type

This choice field contains the identifying type of the terminal unit's DX cooling coil. The only valid DX cooling coil type is Coil:Cooling:DX:VariableRefrigerantFlow. This field should be left blank when a DX cooling coil is not simulated.

Field: DX Cooling Coil Name

This alpha field defines the name of the terminal unit's DX cooling coil. If this field is left blank, a DX cooling coil is not simulated.

Field: DX Heating Coil Object Type

This choice field contains the identifying type of the terminal unit's DX heating coil. The only valid DX heating coil type is Coil:Heating:DX:VariableRefrigerantFlow. This field should be left blank when a DX heating coil is not simulated.

\section{Field: DX Heating Coil Object Name}

This alpha field defines the name of the terminal unit's DX heating coil. This field should be left blank when a DX heating coil is not simulated.

\section{Field: Zone Terminal Unit On Parasitic Electric Energy Use}

This numeric field defines the parasitic electrical energy use of the zone terminal unit when either terminal unit coil is operating. When in cooling mode, this electric energy use is reported in a zone terminal unit cooling electric consumption output variable. When in heating mode, this electric energy use is reported in a zone terminal unit heating electric consumption output variable.

\section{Field: Zone Terminal Unit Off Parasitic Electric Energy Use}

This numeric field defines the parasitic electrical energy use of the zone terminal unit when the terminal unit coil(s) is not operating. When the previous mode was cooling, this electric energy use is reported in a zone terminal unit cooling electric consumption output variable. When the previous mode was heating, this electric energy use is reported in a zone terminal unit heating electric consumption output variable.

\section{Field: Rated Total Heating Capacity Sizing Ratio}

This numeric field defines the ratio of the heating coil to cooling coil size when autosizing is used. The model assumes that when used, this value will be assumed to be 1 .

\section{Field: DOAS System Connected to Zone}

This choice field indicates whether an air-loop DOAS is connected to a zone object; this field affects only the autosize of the VRF coil capacities. This object should be chosen as either Yes or No. If Yes, the zone VRF coils will be autosized based on the zone internal load exclusively, and the air loop VRF coils will 
be autosized based on the outdoor air load exclusively. If No, the zone VRF coils will be autosized based on the zone thermal load including the outdoor air load.

\section{VARIABLE REFRIGERANT FLOW (VRF) TERMINAL UNIT (ZONEHVAC) OUTPUTS}

\section{Zone VRF Air Terminal Total Cooling Rate [W]}

This field is the total (sensible and latent) cooling rate output of the terminal unit in watts.

This is determined by terminal unit inlet and outlet air conditions and the air mass flow rate through the unit. This value describes the total energy rate delivered to the zone.

\section{Zone VRF Air Terminal Total Cooling Energy [J]}

This is the total (sensible plus latent) cooling output of the terminal unit in Joules over the time step being reported. This is determined by the terminal unit inlet and outlet air conditions and the air mass flow rate through the unit. This value describes the total cooling energy delivered to the zone.

\section{Zone VRF Air Terminal Sensible Cooling Rate [W]}

This output is the moist air sensible cooling rate output of the terminal unit in watts. This is determined by the enthalpy difference between the inlet and outlet air temperature at a constant humidity ratio, using the minimum of the inlet and outlet air node humidity ratios and the air mass flow rate through the unit. This value describes the sensible cooling energy rate delivered to the zone.

\section{Zone VRF Air Terminal Sensible Cooling Energy [J]}

This is the moist air sensible cooling output of the terminal unit in Joules for the time step being reported. This is determined by the enthalpy difference between the inlet and outlet air temperature at a constant humidity ratio, using the minimum of the inlet and outlet air node humidity ratios, and the air mass flow rate through the unit. This value describes the sensible cooling energy delivered to the zone.

\section{Zone VRF Air Terminal Latent Cooling Rate [W]}

This is the latent cooling rate output of the terminal unit in watts. This is determined by the inlet and outlet air humidity ratios and the air mass flow rate through the unit. This value describes the latent cooling energy rate delivered to the zone.

\section{Zone VRF Air Terminal Latent Cooling Energy [J]}

This is the latent cooling output of the terminal unit in Joules for the time step being reported. This is determined by the inlet and outlet air humidity ratios and the air mass flow rate through the unit. This value describes the latent cooling energy delivered to the zone.

\section{Zone VRF Air Terminal Total Heating Rate [W]}

This field is the total enthalpic heating rate output of the terminal unit in watts. This is determined by the terminal unit inlet and outlet air conditions and the air mass flow rate through the unit. This value describes the total heating energy rate delivered to the zone. 


\section{Zone VRF Air Terminal Total Heating Energy [J]}

This is the total enthalpic heating output of the terminal unit in Joules over the time step being reported. This is determined by the terminal unit inlet and outlet air conditions and the air mass flow rate through the unit. This value describes the total heating energy delivered to the zone.

\section{Zone VRF Air Terminal Sensible Heating Rate [W]}

This output is the moist air sensible heating rate output of the terminal unit in watts. This is determined by enthalpy difference between the inlet and outlet air temperature at a constant humidity ratio, using the minimum of the inlet and outlet air node humidity ratios, and the air mass flow rate through the unit. This value describes the sensible heating energy rate delivered to the zone.

\section{Zone VRF Air Terminal Sensible Heating Energy [J]}

This is the moist air sensible heating output of the terminal unit in Joules for the time step being reported. This is determined by enthalpy difference between the inlet and outlet air temperature at a constant humidity ratio, using the minimum of the inlet and outlet air node humidity ratios, and the air mass flow rate through the unit. This value describes the sensible heating energy delivered to the zone.

\section{Zone VRF Air Terminal Latent Heating Rate [W]}

This is the latent heating rate output of the terminal unit in watts. This is determined by the inlet and outlet air specific humidity ratios and the air mass flow rate through the unit. This value describes the latent heating energy rate delivered to the zone.

\section{Zone VRF Air Terminal Latent Heating Energy [J]}

This is the latent heating output of the terminal unit in Joules for the time step being reported. This is determined by the inlet and outlet air specific humidity ratios and the air mass flow rate through the unit. This value describes the latent heating energy delivered to the zone.

\section{Zone VRF Air Terminal Cooling Electric Power [W]}

This output field is the parasitic electricity consumption rate of the zone terminal unit in watts.

The consumption rate includes parasitic electricity used by the zone terminal unit's transformers, controls, or other electricity consuming devices. This value is calculated for each HVAC system time step being simulated, and the results are averaged for the time step being reported. The terminal unit parasitic on and off electricity is reported in this cooling output variable when the unit operates in cooling mode or the most recent operation was for cooling.

\section{Zone VRF Air Terminal Cooling Electric Energy [J]}

This output field is the electricity consumption of the zone terminal unit in Joules for the time period being reported. The consumption includes parasitic electricity used by the zone terminal unit's transformers, controls, or other electricity consuming devices. This value is calculated for each HVAC system time step being simulated, and the results are summed for the time step being reported. The terminal unit parasitic on and off electricity consumption is reported in this cooling output variable when the unit operates in cooling mode or the most recent operation was for cooling. This output is also added 
to a meter with Resource Type $=$ Electricity, End Use Key = Cooling, Group Key $=$ System (ref. Output:Meter objects).

\section{Zone VRF Air Terminal Heating Electric Power [W]}

This output field is the parasitic electricity consumption rate of the zone terminal unit in watts.

The consumption rate includes parasitic electricity used by the zone terminal unit's transformers, controls, or other electricity consuming devices. This value is calculated for each HVAC system time step being simulated, and the results are averaged for the time step being reported. The terminal unit parasitic on and off electricity is reported in this heating output variable when the unit operates in heating mode or the most recent operation was for heating.

\section{Zone VRF Air Terminal Heating Electric Energy [J]}

This output field is the electricity consumption of the zone terminal unit in Joules for the time period being reported. The consumption includes parasitic electricity used by the zone terminal unit's transformers, controls, or other electricity consuming devices. This value is calculated for each HVAC system time step being simulated, and the results are summed for the time step being reported. The terminal unit parasitic on and off electricity consumption is reported in this heating output variable when the unit operates in heating mode or the most recent operation was for heating. This output is also added to a meter with Resource Type = Electricity, End Use Key = Heating, Group Key = System (ref. Output:Meter objects).

\section{Zone VRF Air Terminal Fan Availability Status []}

This is the availability status of the Zone Terminal Unit fan. This status flag is a result of the calculations made by the Availability Manager(s) listed in an AvailabilityManagerAssignmentList object and/or calculations made by Hybrid Ventilation Manager Object. The AvailabilityManagerAssignmentList is an optional input in the Zone Terminal Unit object. When a single availability manager is used in an Availability Manager Assignment List, this is also the availability status reported by the specific availability manager (Ref. AvailabilityManager:* Outputs). For multiple availability managers in an Availability Manager Assignment List along with Hybrid Ventilation Manager, rules to determine fan availability status are described in the section 'Group - System Availability Managers'. The control status outputs are represented using integers 0 through 3 . These integers represent NoAction (0), ForceOff (1), CycleOn (2), and CycleOnZoneFansOnly (3). Since the status output is averaged, the output result may not correspond to the values described here when output variable frequencies other than detailed are used. Use the "detailed" reporting frequency (Ref. Output:Variable object) to view the availability status at each simulation timestep.

\section{COIL:COOLING:DX:VRFAIRLOOP}

This Cooling:DX:VRFAirloop cooling coil input requires an availability schedule, the gross rated total cooling capacity, the gross rated SHR, and the rated air volume flow rate. The latter three inputs determine the coil performance at the rated conditions (i.e., air entering the cooling coil at $26.7^{\circ} \mathrm{C}$ drybulb $/ 19.4^{\circ} \mathrm{C}$ wetbulb and air entering the outdoor condenser coil at $35^{\circ} \mathrm{C}$ drybulb $/ 23.9^{\circ} \mathrm{C}$ wetbulb). The rated air volume flow rate should be between $.00004027 \mathrm{~m}_{3} / \mathrm{s}$ and $.00006041 \mathrm{~m}_{3} / \mathrm{s}$ per watt of gross rated total cooling capacity (300 to $450 \mathrm{cfm} / \mathrm{ton}$ ).

The rated volumetric air flow to total cooling capacity ratio for $100 \%$ DOAS application DX cooling coils should be between $0.00001677(\mathrm{~m} 3 / \mathrm{s}) / \mathrm{W}(125 \mathrm{cfm} / \mathrm{ton})$ and $0.00003355(\mathrm{~m} 3 / \mathrm{s}) / \mathrm{W}(250 \mathrm{cfm} / \mathrm{ton})$. 
This model requires 2 curves as follows:

1. The total cooling capacity modifier curve (function of temperature) is a biquadratic curve with two independent variables: wet-bulb temperature of the air entering the cooling coil, and dry-bulb temperature of the air entering the air-cooled condenser coil (wet-bulb temperature if modeling an evaporative-cooled condenser). The output of this curve is multiplied by the gross rated total cooling capacity to give the gross total cooling capacity at specific temperature operating conditions (i.e., at temperatures different from the rating point temperatures).

2. The total cooling capacity modifier curve (function of flow fraction) is a quadratic or cubic curve with the independent variable being the ratio of the actual air flow rate across the cooling coil to the rated air flow rate (i.e., fraction of full load flow). The output of this curve is multiplied by the gross rated total cooling capacity and the total cooling capacity modifier curve (function of temperature) to give the gross total cooling capacity at the specific temperature and air flow conditions at which the coil is operating.

The curves are simply specified by name. Curve inputs are described in the curve manager section of this document (see Performance Curves in this document). The next input specifies the VRF air conditioner object to use the VRF outdoor unit for the Airloop DOAS cooling coil.

\section{Field: Name}

A unique user-assigned name for an instance of a DX cooling coil. Any reference to this DX coil by another object will use this name.

\section{Field: Availability Schedule Name}

The name of the schedule (ref: Schedule) that denotes whether the DX cooling coil can run during a given time period. A schedule value greater than 0 (usually 1 is used) indicates that the unit can be on during a given time period. A value less than or equal to 0 (usually 0 is used) denotes that the unit must be off. If this field is blank, the schedule has values of 1 for all time periods.

\section{Field: Gross Rated Total Cooling Capacity}

The total, full-load gross cooling capacity (sensible plus latent) in watts of the DX coil unit at rated conditions (air entering the cooling coil at $26.7^{\circ} \mathrm{C}$ drybulb $/ 19.4^{\circ} \mathrm{C}$ wetbulb, air entering the outdoor condenser coil at $35^{\circ} \mathrm{C}$ drybulb $/ 23.9^{\circ} \mathrm{C}$ wetbulb7, and a cooling coil air flow rate defined by field "rated air flow rate" below). Capacity should be "gross" (i.e., the effect of supply air fan heat is NOT accounted for). When used in a heat pump, the gross rated total cooling capacity should be within $20 \%$ of the gross rated heating capacity, otherwise a warning message is issued. The $23.9^{\circ} \mathrm{C}$ wet-bulb temperature condition is not applicable for air-cooled condensers which do not evaporate condensate.

\section{Field: Gross Rated Sensible Heat Ratio}

The sensible heat ratio ( $\mathrm{SHR}=$ gross sensible cooling capacity divided by gross total cooling capacity) of the DX cooling coil at rated conditions (air entering the cooling coil at $26.7^{\circ} \mathrm{C}$ drybulb $/ 19.4^{\circ} \mathrm{C}$ wetbulb, air entering the outdoor condenser coil at $35^{\circ} \mathrm{C}$ drybulb $/ 23.9^{\circ} \mathrm{C}$ wetbulb), and a cooling coil air flow rate defined by field "rated air flow rate" below). Both the sensible and total cooling capacities used to define the Rated SHR should be "gross" (i.e., the effect of supply air fan heat is NOT accounted for). 


\section{Field: Rated Air Flow Rate}

The air volume flow rate, in $\mathrm{m}_{3}$ per second, across the DX cooling coil at rated conditions. The rated air volume flow rate should be between $0.00004027 \mathrm{~m}_{3} / \mathrm{s}$ and $0.00006041 \mathrm{~m}_{3} / \mathrm{s}$ per watt of gross rated total cooling capacity (300 to $450 \mathrm{cfm} / \mathrm{ton}$ ). For DOAS applications the rated air volume flow rate should be between $0.00001677 \mathrm{~m}_{3} / \mathrm{s}$ and $0.00003355 \mathrm{~m}_{3} / \mathrm{s}$ per watt of gross rated total cooling capacity (125 to 250 $\mathrm{cfm} /$ ton). The gross rated total cooling capacity, gross rated SHR and gross rated COP should be performance information for the unit with air entering the cooling coil at $26.7^{\circ} \mathrm{C}$ drybulb $/ 19.4^{\circ} \mathrm{C}$ wetbulb, air entering the outdoor condenser coil at $35^{\circ} \mathrm{C}$ drybulb $/ 23.9^{\circ} \mathrm{C}$ wetbulb, and the rated air volume flow rate defined here.

\section{Field: Total Cooling Capacity Function of Temperature Curve Name}

The name of a biquadratic performance curve (ref: Performance Curves) that parameterizes the variation of the gross total cooling capacity as a function of the wet-bulb temperature of the air entering the cooling coil, and the dry-bulb temperature of the air entering the aircooled condenser coil (wet-bulb temperature if modeling an evaporative-cooled condenser). The output of this curve is multiplied by the gross rated total cooling capacity to give the gross total cooling capacity at specific temperature operating conditions (i.e., at temperatures different from the rating point temperatures). The curve is normalized to have the value of 1.0 at the rating point.

\section{Field: Total Cooling Capacity Function of Flow Fraction Curve Name}

The name of a quadratic or cubic performance curve (ref: Performance Curves) that parameterizes the variation of the gross total cooling capacity as a function of the ratio of actual air flow rate across the cooling coil to the rated air flow rate (i.e., fraction of full load flow). The output of this curve is multiplied by the gross rated total cooling capacity and the total cooling capacity modifier curve (function of temperature) to give the gross total cooling capacity at the specific temperature and air flow conditions at which the coil is operating. The curve is normalized to have the value of 1.0 when the actual air flow rate equals the rated air flow rate.

Field: Air Inlet Node Name

The name of the HVAC system node from which the DX cooling coil draws its inlet air.

\section{Field: Air Outlet Node Name}

The name of the HVAC system node to which the DX cooling coil sends its outlet air.

Field: Air Conditioner: Variable Refrigerant Flow Object that Coil is linked to:

This alpha field defines the name of the variable refrigerant flow (VRF) air conditioner. The only valid the air conditioner type is AirConditioner:VariableRefrigerantFlow. The field should be left blank when a VRFAirloop Cooling coil is not simulated.

\section{COIL:HEATING:DX:VRFAIRLOOP}

The Heating:DX:VRFAirloop coil model uses performance information at rated conditions along with curve fits for variations in total capacity, energy input ratio and part load fraction to determine performance at part load conditions. The impacts of various defrost strategies (reverse cycle, resistive, 
timed or on-demand) are modeled based on a combination of user inputs and empirical models taken from the air-to-air heat pump algorithms in DOE-2.1E.

The single speed heating DX coil input requires an availability schedule, the gross rated heating capacity, and the rated air volume flow rate. The latter 3 inputs determine the coil performance at the rating point (outdoor air dry-bulb temperature of $8.33 \mathrm{C}$, outdoor air wet-bulb temperature of $6.11 \mathrm{C}$, coil entering air dry-bulb temperature of $21.11 \mathrm{C}$, coil entering air wet-bulb temperature of $15.55 \mathrm{C}$ ). The rated air volume flow rate should be between $0.00004027 \mathrm{~m}_{3} / \mathrm{s}$ and $.00006041 \mathrm{~m}_{3} / \mathrm{s}$ per watt of gross rated heating capacity. Up to 2 curves are required depending on the defrost strategy selected.

1) The heating capacity modifier curve (function of temperature) can be a function of both the outdoor and indoor air dry-bulb temperature or only the outdoor air dry-bulb temperature. User has the choice of a bi-quadratic curve with two independent variables or a quadratic curve as well as a cubic curve with a single independent variable. The bi-quadratic curve is recommended if sufficient manufacturer data is available as it provides sensitivity to the indoor air dry-bulb temperature and a more realistic output. The output of this curve is multiplied by the gross rated heating capacity to give the gross heating capacity at specific temperature operating conditions (i.e., at an outdoor or indoor air temperature different from the rating point temperature).

2) The heating capacity modifier curve (function of flow fraction) is a quadratic or cubic curve with the independent variable being the ratio of the actual air flow rate across the heating coil to the rated air flow rate (i.e., fraction of full load flow). The output of this curve is multiplied by the gross rated heating capacity and the heating capacity modifier curve (function of temperature) to give the gross heating capacity at the specific temperature and air flow conditions at which the coil is operating.

The next input specifies the VRF air conditioner object to use the VRF outdoor unit for the Airloop DOAS heating coil.

\section{Field: Name}

This alpha field defines a unique user-assigned name for an instance of a DX heating coil. Any reference to this DX heating coil by another object will use this name.

\section{Field: Availability Schedule Name}

This alpha field defines the name of the schedule (ref: Schedule) that denotes whether the DX heating coil can run during a given time period. A schedule value greater than 0 (usually 1 is used) indicates that the unit can be on during the time period. A value less than or equal to 0 (usually 0 is used) denotes that the unit must be off for the time period. If this field is blank, the schedule has values of 1 for all time periods.

\section{Field: Gross Rated Heating Capacity}

This numeric field defines the total, full load gross heating capacity in watts of the DX coil unit at rated conditions (outdoor air dry-bulb temperature of $8.33 \mathrm{C}$, outdoor air wet-bulb temperature of $6.11 \mathrm{C}$, heating coil entering air dry-bulb temperature of $21.11 \mathrm{C}$, heating coil entering air wet-bulb temperature of $15.55 \mathrm{C}$, and a heating coil air flow rate defined by field "rated air flow volume" below). The value entered here must be greater than 0 . Capacity should not account for supply air fan heat. The gross rated heating capacity should be within $20 \%$ of the gross rated total cooling capacity, otherwise a warning message is issued. The gross heating capacity should NOT include the effect of supply air fan heat. 


\section{Field: Rated Air Flow Rate}

This numeric field defines the volume air flow rate, in $\mathrm{m}_{3}$ per second, across the DX heating coil at rated conditions. The value entered here must be greater than 0 . The rated air volume flow rate should be between $0.00004027 \mathrm{~m}_{3} / \mathrm{s}$ and $0.00006041 \mathrm{~m}_{3} / \mathrm{s}$ per watt of the gross rated heating capacity. The gross rated heating capacity and gross rated COP should be performance information for the unit with outdoor air dry-bulb temperature of $8.33 \mathrm{C}$, outdoor air wet-bulb temperature of $6.11 \mathrm{C}$, heating coil entering air dry-bulb temperature of $21.11 \mathrm{C}$, heating coil entering air wet-bulb temperature of $15.55 \mathrm{C}$, and the rated air volume flow rate defined here.

\section{Field: Heating Capacity Function of Temperature Curve Name}

This alpha field defines the name of a bi-quadratic, quadratic or cubic performance curve (ref: Performance Curves) that parameterizes the variation of the total heating capacity as a function of the both the indoor and outdoor air dry-bulb temperature or just the outdoor air dry-bulb temperature depending on the type of curve selected. The bi-quadratic curve is recommended if sufficient manufacturer data is available as it provides sensitivity to the indoor air dry-bulb temperature and a more realistic output. The output of this curve is multiplied by the gross rated heating capacity to give the gross total heating capacity at specific temperature operating conditions (i.e., at an indoor air dry-bulb temperature or outdoor air dry-bulb temperature different from the rating point temperature). The curve is normalized to have the value of 1.0 at the rating point.

\section{Field: Heating Capacity Function of Flow Fraction Curve Name}

This alpha field defines the name of a quadratic or cubic performance curve (ref: Performance Curves) that parameterizes the variation of total heating capacity as a function of the ratio of actual air flow rate across the heating coil to the rated air flow rate (i.e., fraction of full load flow). The output of this curve is multiplied by the gross rated heating capacity and the heating capacity modifier curve (function of temperature) to give the gross heating capacity at the specific temperature and air flow conditions at which the coil is operating. The curve is normalized to have the value of 1.0 when the actual air flow rate equals the rated air flow rate.

Field: Air Inlet Node Name

This alpha field defines the name of the HVAC system node from which the DX heating coil draws its inlet air.

Field: Air Outlet Node Name

This alpha field defines the name of the HVAC system node to which the DX heating coil sends its outlet air.

Field: Air Conditioner: Variable Refrigerant Flow Object that Coil is linked to:

This alpha field defines the name of the (VRF air conditioner. The only valid air conditioner type is AirConditioner:VariableRefrigerantFlow. The field should be left blank when a VRFAirloop heating coil is not simulated. 


\section{COILSYSTEM:COOLING:DX}

The CoilSystem:Cooling:DX object is a "virtual" container component that consists of a DX cooling coil component and its associated controls, as shown in Figure 45 below. This control object supports several different types of DX cooling coils (see field Cooling Coil Object Type).

This component may be used as a cooling coil in constant volume or variable volume systems, as blow through or draw through, with or without humidity controls. Unlike AirLoopHVAC:Unitary system types, this component controls only the DX coil, not the supply fan. CoilSystem:Cooling:DX is added to a system by placing it in an air loop branch (see Branch object) or in an

AirLoopHVAC:OutdoorAirSystem:EquipmentList or in a ZoneHVAC:OutdoorAirUnit:EquipmentList . It requires one or more set point manager (see SetpointManager:*) objects to specify temperature and/or humidity set points (unless it is used in a ZoneHVAC:OutdoorAirUnit which has its own temperature set points). This object is the one that is listed in the branch or equipment list object rather than the coil itself. A constant volume or variable volume fan is modeled separately from this cooling system. These are the only fan types allowed for this system type (ref. Fan:ConstantVolume and Fan:VariableVolume). Cycling fan operation is not available with this model.

The CoilSystem:Cooling:DX object can also be placed on DOAS air-loop branches or in air-loop branches where the air flow to capacity ratio range is between $100-300 \mathrm{cfm} / \mathrm{ton} .100 \%$ of DOAS DX cooling coils operate in lower flow to capacity ratio range compared with regular DX cooling coils. The CoilSystem:Cooling:DX is selected to operate in DOAS application or in low flow to capacity ratio range by specifying "YES" to the input field "Use Outdoor Air DX Cooling Coil". If this optional input field is left blank or specified as "NO", then the coil is modeled as regular DX cooling coil. If the CoilSystem:Cooling:DX object is in an AirLoopHVAC:OutdoorAirSystem:EquipmentList or in a ZoneHVAC:OutdoorAirUnit:EquipmentList then it is treated as 100\% DOAS DX cooling coil only if the choice input field "Use Outdoor Air DX Cooling Coil" is set to "YES." All the control options of the regular DX cooling coils are available to DOAS DX coils as well. Heating DX coils in the DOAS airloop operate at the same flow to capacity ratio limits as the DOAS DX cooling coils.

In the current installation of the DOAS in the FRP, the DOAS unit is connected to VRF outdoor units corresponding to VRF indoor units, and $100 \%$ outdoor air is conditioned through this DOAS unit and distributed to thermal zones. Therefore, the CoilSystem:Cooling:DX object can be used to satisfy 100\% DOAS DX cooling coils using a Coil:Cooling:DX:VRFAirloop object, which is created for specific cases. 


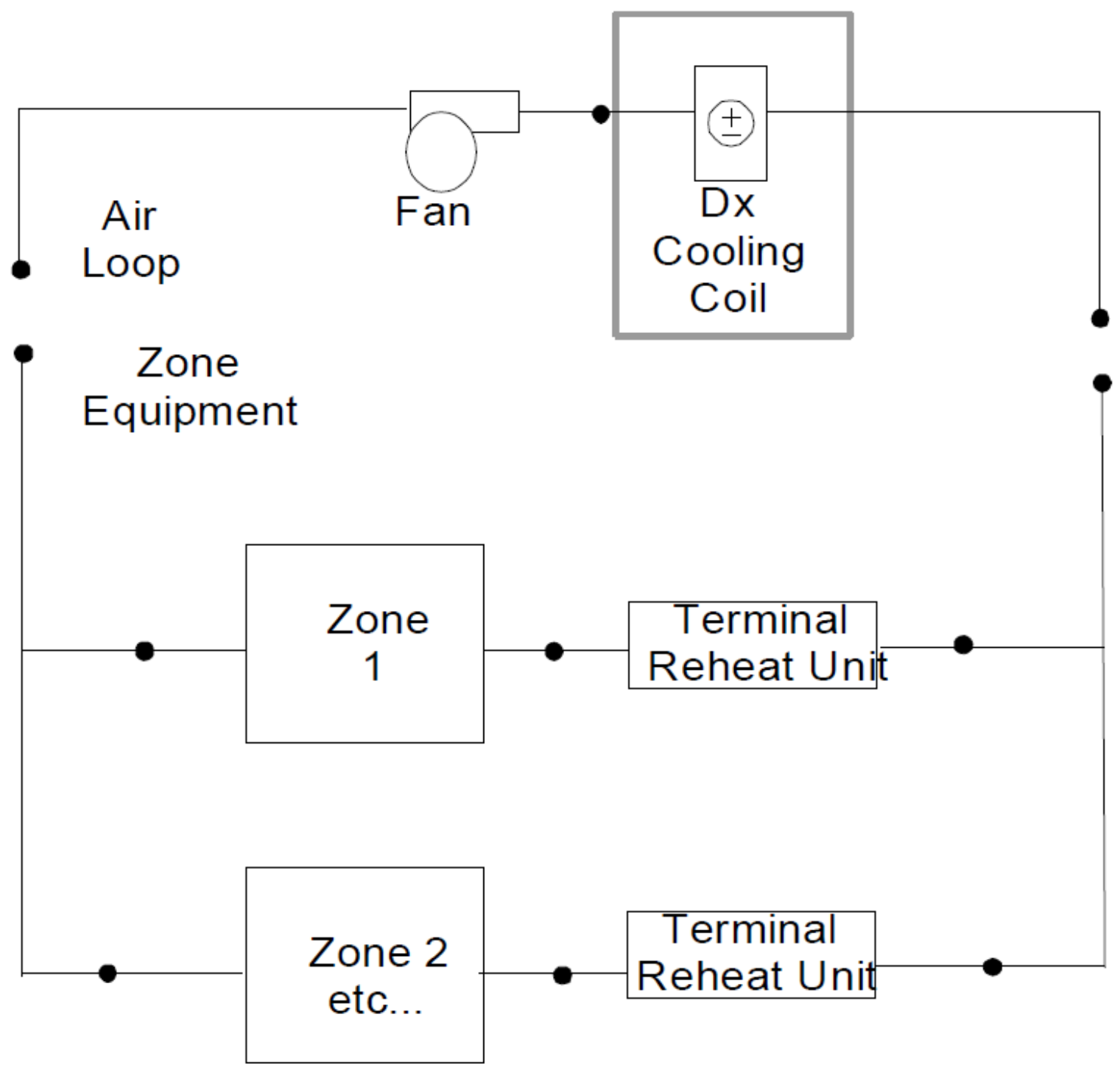

Figure 45. Schematic of Coil:System:Cooling:DX Object in an Air Loop for a Blow Through Application.

\section{Field: Name}

This alpha field contains the identifying name for this component.

\section{Field: Availability Schedule Name}

This alpha field contains the schedule name that contains information on the availability of the DX coil to operate. A schedule value of 0 indicates that the coil is off for that time period. A schedule value greater than 0 indicates that the coil can operate during the time period. If this field is blank, the schedule has values of 1 for all time periods.

\section{Field: DX Cooling Coil System Inlet Node Name}

This alpha field contains the identifying name given to the DX cooling coil inlet node, as specified in the DX cooling coil object. 
Field: DX Cooling Coil System Outlet Node Name

This alpha field contains the identifying name given to the DX cooling coil outlet node, as specified in the cooling coil object.

Field: DX Cooling Coil System Sensor Node Name

This alpha field contains the identifying name given to the DX cooling coil control node. This is the node at which the temperature set point is specified by the set point manager.

Field: Cooling Coil Object Type

This alpha field specifies the type of DX cooling coil. The valid choices for this field are

Coil:Cooling:DX:SingleSpeed

Coil:Cooling:DX:VRFAirloop

CoilSystem:Cooling:DX:HeatExchangerAssisted

Coil:Cooling:DX:TwoSpeed

Coil:Cooling:DX:TwoStageWithHumidityControlMode

Coil:Cooling:DX:VariableSpeed

With the modified EnergyPlus model, a Coil:Cooling:DX:VRFAirloop field was added to calculate the DOAS system linked to VRF coils.

Field: Cooling Coil Name

This alpha field contains the identifying name of the DX cooling coil.

As shown in the example below, correct specification of this system requires specification of the DX Cooling Coil object in addition to the CoilSystem:Cooling:DX object.

\section{Field: Dehumidification Control Type}

This alpha field contains the type of dehumidification control. The following options are valid for this field:

None - meet sensible load only, no active dehumidification control

MultiMode - activate enhanced dehumidification mode as needed and operate to meet the sensible load. If a sensible load exists, the system will operate to meet that sensible load and may not meet the latent load. If no sensible load exists, and Run on Latent Load = Yes, the system will operate to meet the entire latent load. This option is used to model DX equipment with a switchable option such as subcool reheat. It is valid only with Cooling coil type= Coil:Cooling:DX:TwoStageWithHumidityControlMode or CoilSystem:Cooling:DX:HeatExchangerAssisted. If the Run on Latent Load option below is set to Yes, this option may require the use of a heating coil and heating coil outlet air temperature set point manager downstream of this cooling coil to maintain the temperature set point.

CoolReheat - cool beyond the dry-bulb set point as required to meet the humidity set point. It is valid only with Cooling coil type=Coil:Cooling:DX:TwoStageWithHumidityControlMode. This option requires the use of a heating coil and heating coil outlet air temperature set point manager downstream of this cooling coil to maintain the temperature set point. The default is None. For all dehumidification 
controls, the max humidity set point on the control node is used. This must be set using a

ZoneControl:Humidistat

ZoneControl:Humidistat and one of the following

SetpointManager:SingleZone:Humidity:Maximum

SetpointManager:MultiZone:Humidity:Maximum

SetpointManager:MultiZone:MaximumHumidity:Average

objects and SetpointManager:OutdoorAirPretreat (optional) objects. When extra dehumidification is required, the equipment may not be able to meet the humidity set point if its full capacity is not adequate.

\section{Field: Run on Sensible Load}

This alpha field specifies if the unit will operate to meet a sensible load as determined by the inlet node dry-bulb temperature and the dry-bulb temperature set point on the control node. There are two valid choices, Yes or No. If Yes, unit will run if there is a sensible load. If No, unit will not run if there is only a sensible load. The default is Yes.

\section{Field: Run on Latent Load}

This alpha field specifies if the unit will operate to meet a latent load as determined by the inlet node humidity ratio and the max humidity set point on the control node. There are two valid choices, Yes or No. If Yes, unit will run if there is a latent load. If both a sensible and latent load exist, the system will operate to maintain the temperature set point. When only a latent load exists, the system will operate to meet the humidity ratio set point and requires the use of a heating coil and heating coil outlet air temperature set point manager downstream of this cooling coil to maintain the temperature set point. If No, unit will not run if there is only a latent load. The default is No.

\section{Field: Use Outdoor Air DX Cooling Coil}

This input field enables the Coil System DX Coil to be used for low air flow to capacity ratio range ( $100-300 \mathrm{cfm} / \mathrm{ton}$ ). This flow to capacity ratio range is common in 100\% DOAS applications. Other airloop or zone HVAC systems may use this input filed if they operate at such a low flow to capacity ratio range. There are two valid choices, Yes or No. If Yes, the DX cooling coil is forced to operate in this flow to capacity ratio range or runs as $100 \%$ DOAS DX coil. If No, the DX coil is used as a regular DX coil. This input field is optional.

\section{Field: Outdoor Air DX Cooling Coil Leaving Minimum Air Temperature}

This input field is the DX cooling coil leaving supply air minimum temperature specified for frost control. The DX cooling coil leaving air temperature is not allowed to exceed this minimum coil leaving air temperature. The DX cooling coil frost controller adjusts or limits the desired coil outlet air set point temperature when the coil outlet temperature exceeds this minimum temperature limit specified. This input field is optional and only used along with in the input field above. The minimum and maximum values of this input field are $0.0 \mathrm{C}$ and $7.2 \mathrm{C}$, and the default value is $2.0^{\circ} \mathrm{C}$.

An example IDF specification:

CoilSystem:Cooling:DX,

DOAS DX Cooling Coil System,!- Name 
Always on, !- Availability Schedule Name

DOAS Supply Fan Outlet, !- DX Cooling Coil System Inlet Node Name

DOAS Cooling Coil Outlet, !- DX Cooling Coil System Outlet Node Name

DOAS Cooling Coil Outlet, !- DX Cooling Coil System Sensor Node Name

Coil:Cooling:DX:VRFAirloop, !- Cooling Coil Object Type

DOAS Heat Pump ACDXCoil1, !- Cooling Coil Name

None, !- Dehumidification Control Type

Yes, !- Run on Sensible Load

No, !- Run on Latent Load

Yes, !- Use DOAS DX Cooling Coil

2.0; !- DOAS DX Cooling Coil Leaving Minimum Air Temperature

Coil:Cooling:DX:SingleSpeed,

DOAS Heat Pump ACDXCoil 1, !- Name

Always on, !- Availability Schedule Name

autosize, !- Gross Rated Total Cooling Capacity $\{\mathrm{W}\}$

autosize, !- Gross Rated Sensible Heat Ratio

3.3, !- Gross Rated Cooling COP

autosize, !- Rated Air Flow Rate $\{\mathrm{m} 3 / \mathrm{s}\}$

DOAS Supply Fan Outlet, !- Air Inlet Node Name

DOAS Cooling Coil Outlet, !- Air Outlet Node Name

WindACCoolCapFT, !- Total Cooling Capacity Function of Temperature Curve Name

WindACCoolCapFFF, !- Total Cooling Capacity Function of Flow Fraction Curve Name

WindACEIRFT, !- Energy Input Ratio Function of Temperature Curve Name

WindACEIRFFF, !- Energy Input Ratio Function of Flow Fraction Curve Name

WindACPLFFPLR; !- Part Load Fraction Correlation Curve Name

\section{COILSYSTEM:HEATING:DX}

The CoilSystem:Heating:DX object is a "virtual" container component for a DX heating coil that provides the controls needed to operate the coil. Only single-speed DX air-to-air heating coils are supported; therefore, Coil:Heating:DX:VRFAirloop object that is used for the DOAS system providing 100\% outdoor air to each zone is based on single-speed DX heating coils. This component may be used as a heating coil in constant volume or variable volume air handlers. It can also be used in an outside air system (by including it in an AirLoopHVAC:OutdoorAirSystem:EquipmentList object) or in a zone outdoor air unit (by including it in an ZoneHVAC:OutdoorAirUnit:EquipmentList object). This object is the one that is listed in the Branch or equipment list object rather than the coil itself.

The inlet and outlet nodes for the DX heat pump system are defined in the heating coil DX VRFAirloop object. The control node is always the outlet node of the coil. This DX heat pump heating system requires that a (drybulb) temperature set point be placed on the outlet node using either a set point manager or the energy management system. The coil is controlled to attempt to meet that set point using a part load ratio modeling approach. This model only supports continuous fan and cycling compressor operation-cycling fan modeling is not available with this model.

\section{Field: Name}

This alpha field contains the identifying name for this component. 
Field: Availability Schedule Name

This alpha field contains the schedule name that contains information on the availability of the DX coil to operate. A schedule value of 0 indicates that the coil is off for that time period.

A schedule value greater than 0 indicates that the coil can operate during the time period. If this field is blank, the schedule has values of 1 for all time periods.

\section{Field: Heating Coil Object Type}

This alpha field specifies the type of DX heating coil. This model currently supports only single-speed DX heat pump heating coils, and the only options for this field are Coil:Heating:DX:VRFAirloop, Coil:Heating:DX:SingleSpeed, Coil:Heating:DX:VRFairloop, and Coil:Heating:DX:VariableSpeed.

\section{Field: Heating Coil Name}

This alpha field specifies the unique name of the DX heating coil. This field references the name of a Coil:Heating:DX:VRFAirloop that needs to be defined elsewhere in the input file.

An example of a DX heating coil system follows:

CoilSystem:Heating:DX,

HeatPump DX Coil 1, !- Name

FanAndCoilAvailSched, !- Availability Schedule Name

Coil:Heating:DX:SingleSpeed, !- Heating Coil Object Type

Heat Pump DX Heating Coil 1; !- Heating Coil Name

Coil:Heating:DX:SingleSpeed,

Heat Pump DX Heating Coil 1, !- Name

FanAndCoilAvailSched, !- Availability Schedule Name

autosize, !- Gross Rated Heating Capacity $\{\mathrm{W}\}$

2.75, !- Gross Rated Heating COP $\{\mathrm{W} / \mathrm{W}\}$

autosize, !- Rated Air Flow Rate $\{\mathrm{m} 3 / \mathrm{s}\}$

Heating Coil Air Inlet Node, !- Air Inlet Node Name

SuppHeating Coil Air Inlet Node, !- Air Outlet Node Name

HPACHeatCapFT, !- Heating Capacity Function of Temperature Curve Name

HPACHeatCapFFF, !- Heating Capacity Function of Flow Fraction Curve Name

HPACHeatEIRFT, !- Energy Input Ratio Function of Temperature Curve Name

HPACHeatEIRFFF, !- Energy Input Ratio Function of Flow Fraction Curve Name

HPACCOOLPLFFPLR, !- Part Load Fraction Correlation Curve Name

, !- Defrost Energy Input Ratio Function of Temperature Curve Name

-8.0, !- Minimum Outdoor Dry-Bulb Temperature for Compressor Operation $\{\mathrm{C}\}$

5.0, !- Maximum Outdoor Dry-Bulb Temperature for Defrost Operation $\{\mathrm{C}\}$

200.0, !- Crankcase Heater Capacity $\{\mathrm{W}\}$

10.0, !- Maximum Outdoor Dry-Bulb Temperature for Crankcase Heater Operation $\{\mathrm{C}\}$

Resistive, !- Defrost Strategy

TIMED, !- Defrost Control

0.166667, !- Defrost Time Period Fraction

autosize, !- Resistive Defrost Heater Capacity $\{\mathrm{W}\}$

Heat Pump 1 Evaporator Node; 


\section{COOLING COIL SYSTEM OUTPUTS}

\section{All DX Coils:}

HVAC,Average,Coil System Frost Control Status

Coil Type=Coil:Cooling:DX:TwoStage WithHumidityControlMode

HVAC,Average,Coil System Cycling Ratio

HVAC,Average,Coil System Compressor Speed Ratio

Coil types=Coil:Cooling:DX:SingleSpeed \&

CoilSystem:Cooling:DX:HeatExchangerAssisted

HVAC,Average,Coil System Part Load Ratio

\section{Coil System Cycling Ratio}

The system may operate for the entire system timestep, but to meet the load, the compressor can cycle on and off. This reports the fraction of the system timestep at which the compressor is operating. (1.0 is continuous, 0.0 is off).

\section{Coil System Compressor Speed Ratio}

This is the ratio of time in a system timestep for which the compressor is at rated speed. The compressor speed ratio reports (1.0 is max, 0.0 is $\mathrm{min}$ ), and any value in between as it is averaged over the timestep.

\section{Coil System Part Load Ratio}

The DX system can operate with a cycling compressor or a varying speed compressor; this variable reports the fraction of the full load that is met during the system timestep. This can differ from the cycling part-load ratio or the compressor speed ratio. (1.0 is full load and 0.0 is no load)

\section{Coil System Frost Control Status}

This is a flag indicating whether frost control is active at current time step or not. Frost control is activated or enforced when the sensible load control requires a DX cooling coil outlet air temperature below the user-specified minimum temperature, or when the dehumidification load control requires a DX cooling coil outlet air humidity ratio below the saturation humidity ratio corresponding to the userspecified minimum temperature for frost control. A frost control status of zero means no active frost control; a value of 1 or 2 indicates that frost control is active. If the frost control status is 1 , then the frost control is enforced when the cooling coil is run to meet sensible load. If the frost control status value is 2, then the control is enforced when the cooling coil is run to meet latent load. When frost control is active the DX cooling coil set point value is modified based on the user-specified limit.

\section{Cooling Coil Total Cooling Rate [W]}

This field is the total (sensible and latent) cooling rate output of the DX coil in watts. This is determined by the coil inlet and outlet air conditions and the air mass flow rate through the coil. 


\section{Cooling Coil Total Cooling Energy [J]}

This is the total (sensible plus latent) cooling output of the DX coil in Joules over the timestep being reported. This is determined by the coil inlet and outlet air conditions and the air mass flow rate through the coil. This output is also added to a meter with Resource Type $=$ EnergyTransfer, End Use Key $=$ CoolingCoils, Group Key = System (Ref. Output:Meter objects).

\section{Cooling Coil Sensible Cooling Rate [W]}

This output is the moist air sensible cooling rate output of the DX coil in watts. This is determined by the inlet and outlet air conditions and the air mass flow rate through the coil.

\section{Cooling Coil Sensible Cooling Energy [J]}

This is the moist air sensible cooling output of the DX coil in Joules for the timestep being reported. This is determined by the inlet and outlet air conditions and the air mass flow rate through the coil.

\section{Cooling Coil Latent Cooling Rate [W]}

This is the latent cooling rate output of the DX coil in watts. This is determined by the inlet and outlet air conditions and the air mass flow rate through the coil.

\section{Cooling Coil Latent Cooling Energy [J]}

This is the latent cooling output of the DX coil in Joules for the timestep being reported. This is determined by the inlet and outlet air conditions and the air mass flow rate through the coil.

\section{Cooling Coil Electric Power [W]}

This output is the electricity consumption rate of the DX coil compressor and condenser fan(s) in watts. This value is calculated for each HVAC system timestep, and the results are averaged for the timestep being reported.

\section{Cooling Coil Electric Energy [J]}

This is the electricity consumption of the DX coil compressor and condenser fan(s) in Joules for the timestep being reported. This output is also added to a meter with Resource Type = Electricity, End Use Key = Cooling, Group Key = System (Ref. Output:Meter objects).

\section{Cooling Coil Runtime Fraction []}

This is the runtime fraction of the DX coil compressor and condenser fan(s) for the timestep being reported.

\section{Cooling Coil Crankcase Heater Electric Power [W]}

This is the average electricity consumption rate of the DX coil compressor's crankcase heater in watts for the timestep being reported. If the DX cooling coil is used in a heat pump, the crankcase heater is reported only for the heating coil. 


\section{Cooling Coil Crankcase Heater Electric Energy [J]}

This is the electricity consumption of the DX coil compressor's crankcase heater in Joules for the timestep being reported. This output is also added to a meter with Resource Type = Electricity, End Use Key $=$ Cooling, Group Key = System (ref. Output:Meter objects). This output variable appears only when the DX cooling coil is not used as part of a heat pump, otherwise the crankcase heater is reported only for the heating coil.

\section{Cooling Coil Condenser Inlet Temperature [C]}

This is the inlet air temperature to the condenser coil in degrees $C$. This value can represent the outdoor air dry-bulb temperature, wet-bulb temperature, or somewhere in between from the weather data being used, depending on the value used in the input field "Evaporative Condenser Effectiveness." The temperature reported here is used in the various modifier curves related to temperature (e.g., Total Cooling Capacity Modifier Curve [function of temperature]). This output variable appears only when the DX cooling coil is not used as part of a heat pump, otherwise the crankcase heater is reported only for the heating coil.

\section{Cooling Coil Evaporative Condenser Water Volume [m3]}

This output is the amount of water used to evaporatively cool the condenser coil inlet air, in cubic meters. This output is also added to a meter with Resource Type $=$ Water, End Use Key $=$ Cooling, Group Key $=$ System (ref. Output:Meter objects). This output variable appears only when the DX cooling coil is evaporatively cooled.

\section{Cooling Coil Evaporative Condenser Mains Supply Water Volume [m3]}

This is the volume of water drawn from mains water service for the evaporatively cooled condenser.

\section{Cooling Coil Evaporative Condenser Pump Electric Power [W]}

This is the average electricity consumption rate of the evaporative condenser water pump in watts for the timestep being reported. This output variable appears only when the DX cooling coil is evaporatively cooled.

\section{Cooling Coil Evaporative Condenser Pump Electric Energy [J]}

This is the electricity consumption rate of the evaporative condenser water pump in Joules for the timestep being reported. This output is also added to a meter with Resource Type = Electricity, End Use Key = Cooling, Group Key = System (ref. Output:Meter objects). This output variable appears only when the DX cooling coil is evaporatively cooled.

\section{Cooling Coil Stage 2 Runtime Fraction []}

This is the runtime fraction of the stage $2 \mathrm{DX}$ coil compressor and condenser fan(s) for the timestep being reported. Applicable only for COIL Coil:Cooling:DX:TwoStageWithHumidityControlMode when 2 capacity stages are specified. For 2-stage systems, Cooling Coil Runtime Fraction is the stage 1 runtime fraction. These runtime fractions overlap, because stage 2 will not run unless stage 1 is already running. For example, a system where stage 1 is $60 \%$ of total capacity is passed a load of $70 \%$. The Cooling Coil Runtime Fraction (stage 1) will be 1.0, and the Cooling Coil Stage 2 Runtime Fraction will be 0.25 $[(70 \%-60 \%) /(100 \%-60 \%)]$. 


\section{Cooling Coil Dehumidification Mode []}

This is the dehumidification mode for the timestep being reported. Applicable only for Coil:Cooling:DX:TwoStageWithHumidityControlMode when enhanced dehumidification mode is available. A value of 0 indicates normal mode (extra dehumidification not active). A value of 1 indicates dehumidification mode 1 is active. Note that this is an averaged variable, so fractional values are likely to be reported for reporting frequencies longer than "detailed."

\section{Cooling Coil Condensate Volume Flow Rate [m3/s]}

\section{Cooling Coil Condensate Volume [m3]}

These outputs are the rate and volume of water collected as condensate from the coil. These reports only appear if a water storage tank is named in the input object.

\section{Cooling Coil Evaporative Condenser Mains Supply Water Volume [m3]}

This is the water consumed by the DX cooling coil evaporatively cooled condenser that is met by the mains water. This output variable appears only when the DX cooling coil is evaporatively cooled.

\section{Cooling Coil Basin Heater Electric Power [W]}

This is the average electricity consumption rate of the basin heater in watts for the timestep being reported. This output variable appears only when the DX cooling coil is evaporatively cooled and the Basin Heater Capacity is greater than 0.

\section{Cooling Coil Basin Heater Electric Energy [J]}

This is the electricity consumption rate of the basin heater in Joules for the timestep being reported. This output is also added to a meter with Resource Type $=$ Electricity, End Use Key $=$ Cooling, Group Key $=$ System (ref. Output:Meter objects). This output variable appears only when the DX cooling coil is evaporatively cooled and the Basin Heater Capacity is greater than 0.

\section{Cooling Coil <Fuel Type > Power [W]}

This output variable appears only when using the Coil:Cooling:DX:Multispeed object and a fuel type other than electricity is used. This variable describes the input fuel type power for the cooling coil in watts, averaged during the timestep being reported.

\section{Cooling Coil <Fuel Type $>$ Energy [J]}

This output variable appears only when using the Coil:Cooling:DX:Multispeed object and a fuel type other than electricity is used. This variable describes the input fuel type consumption for the multispeed cooling coil in the unit of Joules, summed for the timestep being reported. The electric consumption is excluded..This output is added to a meter with Resource Type $=\langle$ Fuel Type $\rangle$, End Use Key $=$ Cooling, Group Key = System (ref. Output:Meter objects). 


\section{HEATING COIL SYSTEM OUTPUTS}

\section{Coil System Part Load Ratio}

The DX system can operate with a cycling compressor or a varying speed compressor. This variable reports the fraction of the full load that is met during the system timestep. This can differ from the cycling part load ratio or the compressor speed ratio. (1.0 is full load and 0.0 is no load).

\section{Heating Coil Total Heating Rate [W]}

This field is the total heating rate output of the DX coil in watts. This is determined by the coil inlet and outlet air conditions and the air mass flow rate through the coil.

\section{Heating Coil Total Heating Energy [J]}

This is the total heating output of the DX coil in Joules over the timestep being reported. This is determined by the coil inlet and outlet air conditions and the air mass flow rate through the coil. This output is also added to a meter with Resource Type = EnergyTransfer, End Use Key = CoolingCoils, Group Key = System (ref. Output:Meter objects).

\section{Heating Coil Electric Power [W]}

This output is the electricity consumption rate of the DX coil compressor and outdoor fan(s) in watts. This rate is applicable when the unit is providing heating to the conditioned zone(s), and excludes periods when the unit is in reverse-cycle defrost mode.

\section{Heating Coil Electric Energy [J]}

This is the electricity consumption of the DX coil compressor and condenser fan(s) in Joules for the timestep being reported. This consumption is applicable when the unit is providing heating to the conditioned zone(s), and excludes periods when the unit is in reverse-cycle defrost mode. This output is also added to a meter with Resource Type $=$ Electricity, End Use Key = Cooling, Group Key = System (ref. Output:Meter objects).

\section{Heating Coil Defrost Electric Power [W]}

This is the electricity consumption rate of the DX coil unit in watts when the unit is in defrost mode (reverse-cycle or resistive).

\section{Heating Coil Defrost Electric Energy [J]}

This is the electricity consumption of the DX coil unit in Joules for the timestep being reported. This consumption is applicable when the unit is in defrost mode (reverse-cycle or resistive).

\section{Heating Coil Crankcase Heater Electric Power [W]}

This is the average electricity consumption rate of the DX coil compressor's crankcase heater in watts for the timestep being reported. 


\section{Heating Coil Crankcase Heater Electric Energy [J]}

This is the electricity consumption of the DX coil compressor's crankcase heater in Joules for the timestep being reported. This output is also added to a meter with Resource Type = Electricity, End Use Key $=$ Miscellaneous, Group Key $=$ System (ref. Output:Meter objects).

\section{Heating Coil Runtime Fraction []}

This is the runtime fraction of the DX heating coil compressor and outdoor fan(s) for the timestep being reported.

\section{VARIABLE REFRIGERANT FLOW (VRF) TERMINAL UNIT (ZONEHVAC) OUTPUTS}

\section{Zone VRF Air Terminal Total Cooling Rate [W]}

This field is the total (sensible and latent) cooling rate output of the terminal unit in watts.

This is determined by terminal unit inlet and outlet air conditions and the air mass flow rate through the unit. This value describes the total energy rate delivered to the zone.

\section{Zone VRF Air Terminal Total Cooling Energy [J]}

This is the total (sensible plus latent) cooling output of the terminal unit in Joules over the time step being reported. This is determined by the terminal unit inlet and outlet air conditions and the air mass flow rate through the unit. This value describes the total cooling energy delivered to the zone.

\section{Zone VRF Air Terminal Sensible Cooling Rate [W]}

This output is the moist air sensible cooling rate output of the terminal unit in watts. This is determined by the enthalpy difference between the inlet and outlet air temperature at a constant humidity ratio, using the minimum of the inlet and outlet air node humidity ratios, and the air mass flow rate through the unit. This value describes the sensible cooling energy rate delivered to the zone.

\section{Zone VRF Air Terminal Sensible Cooling Energy [J]}

This is the moist air sensible cooling output of the terminal unit in Joules for the time step being reported. This is determined by the enthalpy difference between the inlet and outlet air temperature at a constant humidity ratio, using the minimum of the inlet and outlet air node humidity ratios, and the air mass flow rate through the unit. This value describes the sensible cooling energy delivered to the zone.

\section{Zone VRF Air Terminal Latent Cooling Rate [W]}

This is the latent cooling rate output of the terminal unit in watts. This is determined by the inlet and outlet air humidity ratios and the air mass flow rate through the unit. This value describes the latent cooling energy rate delivered to the zone.

\section{Zone VRF Air Terminal Latent Cooling Energy [J]}

This is the latent cooling output of the terminal unit in Joules for the time step being reported.

This is determined by the inlet and outlet air humidity ratios and the air mass flow rate through the unit. This value describes the latent cooling energy delivered to the zone. 


\section{Zone VRF Air Terminal Total Heating Rate [W]}

This field is the total enthalpic heating rate output of the terminal unit in watts. This is determined by the terminal unit inlet and outlet air conditions and the air mass flow rate through the unit. This value describes the total heating energy rate delivered to the zone.

\section{Zone VRF Air Terminal Total Heating Energy [J]}

This is the total enthalpic heating output of the terminal unit in Joules over the time step being reported. This is determined by the terminal unit inlet and outlet air conditions and the air mass flow rate through the unit. This value describes the total heating energy delivered to the zone.

\section{Zone VRF Air Terminal Sensible Heating Rate [W]}

This output is the moist air sensible heating rate output of the terminal unit in watts. This is determined by the enthalpy difference between the inlet and outlet air temperature at a constant humidity ratio, using the minimum of the inlet and outlet air node humidity ratios, and the air mass flow rate through the unit. This value describes the sensible heating energy rate delivered to the zone.

\section{Zone VRF Air Terminal Sensible Heating Energy [J]}

This is the moist air sensible heating output of the terminal unit in Joules for the time step being reported. This is determined by enthalpy difference between the inlet and outlet air temperature at a constant humidity ratio, using the minimum of the inlet and outlet air node humidity ratios, and the air mass flow rate through the unit. This value describes the sensible heating energy delivered to the zone.

\section{Zone VRF Air Terminal Latent Heating Rate [W]}

This is the latent heating rate output of the terminal unit in watts. This is determined by the inlet and outlet air specific humidity ratios and the air mass flow rate through the unit. This value describes the latent heating energy rate delivered to the zone.

\section{Zone VRF Air Terminal Latent Heating Energy [J]}

This is the latent heating output of the terminal unit in Joules for the time step being reported. This is determined by the inlet and outlet air specific humidity ratios and the air mass flow rate through the unit. This value describes the latent heating energy delivered to the zone.

\section{Zone VRF Air Terminal Cooling Electric Power [W]}

This output field is the parasitic electricity consumption rate of the zone terminal unit in watts. The consumption rate includes parasitic electricity used by the zone terminal unit's transformers, controls, or other electricity consuming devices. This value is calculated for each HVAC system time step being simulated, and the results are averaged for the time step being reported. The terminal unit parasitic on and off electricity is reported in this cooling output variable when the unit operates in cooling mode or the most recent operation was for cooling.

\section{Zone VRF Air Terminal Cooling Electric Energy [J]}

This output field is the electricity consumption of the zone terminal unit in Joules for the time period being reported. The consumption includes parasitic electricity used by the zone terminal unit's 
transformers, controls, or other electricity consuming devices. This value is calculated for each HVAC system time step being simulated, and the results are summed for the time step being reported. The terminal unit parasitic on and off electricity consumption is reported in this cooling output variable when the unit operates in cooling mode or the most recent operation was for cooling. This output is also added to a meter with Resource Type $=$ Electricity, End Use Key $=$ Cooling, Group Key $=$ System (ref. Output:Meter objects).

\section{Zone VRF Air Terminal Heating Electric Power [W]}

This output field is the parasitic electricity consumption rate of the zone terminal unit in watts. The consumption rate includes parasitic electricity used by the zone terminal unit's transformers, controls, or other electricity consuming devices. This value is calculated for each HVAC system time step being simulated, and the results are averaged for the time step being reported. The terminal unit parasitic on and off electricity is reported in this heating output variable when the unit operates in heating mode or the most recent operation was for heating.

\section{Zone VRF Air Terminal Heating Electric Energy [J]}

This output field is the electricity consumption of the zone terminal unit in Joules for the time period being reported. The consumption includes parasitic electricity used by the zone terminal unit's transformers, controls, or other electricity consuming devices. This value is calculated for each HVAC system time step being simulated, and the results are summed for the time step being reported. The terminal unit parasitic on and off electricity consumption is reported in this heating output variable when the unit operates in heating mode or the most recent operation was for heating. This output is also added to a meter with Resource Type = Electricity, End Use Key = Heating, Group Key = System (ref. Output:Meter objects).

\section{Zone VRF Air Terminal Fan Availability Status []}

This is the availability status of the Zone Terminal Unit fan. This status flag is a result of the calculations made by the Availability Manager(s) listed in an AvailabilityManagerAssignmentList object and/or calculations made by Hybrid Ventilation Manager Object. The AvailabilityManagerAssignmentList is an optional input in the Zone Terminal Unit object. When a single availability manager is used in an Availability Manager Assignment List, this is also the availability status reported by the specific availability manager (Ref. AvailabilityManager:* Outputs). For multiple availability managers in an Availability Manager Assignment List along with Hybrid Ventilation Manager, rules to determine fan availability status are described in the section 'Group - System Availability Managers'. The control status outputs are represented using integers 0 through 3 . These integers represent NoAction (0), ForceOff (1), CycleOn (2), and CycleOnZoneFansOnly (3). Since the status output is averaged, the output result may not correspond to the values described here when output variable frequencies other than detailed are used. Use the "detailed" reporting frequency (Ref. Output:Variable object) to view the availability status at each simulation timestep.

\section{VARIABLE REFRIGERANT FLOW (VRF) TERMINAL UNIT (ZONEHVAC) OUTPUTS}

\section{VRF Heat Pump Total Cooling Rate [W]}

This output field is the operating total cooling capacity of the variable refrigerant flow heat pump in watts. This value is calculated for each HVAC system time step being simulated, and the results are averaged for the time step being reported. This value should match the sum of the individual zone terminal unit output variables for Zone VRF Air Terminal Total Cooling Rate. 


\section{VRF Heat Pump Total Heating Rate [W]}

This output field is the operating total heating capacity of the variable refrigerant flow heat pump in watts. The capacity includes any degradation due to defrost mode. This value is calculated for each HVAC system time step being simulated, and the results are averaged for the time step being reported. This value should match the sum of the individual zone terminal unit output variables for Zone VRF Air Terminal Total Heating Rate.

\section{VRF Heat Pump Cooling Electric Power [W]}

This output field is the cooling mode electricity consumption rate of the variable refrigerant flow heat pump in watts. The consumption includes electricity used by the compressor (including crankcase heater), and the condenser fan. This value is calculated for each HVAC system time step being simulated, and the results are averaged for the time step being reported. The choice of an alternate fuel type (see Fuel Type input) will result in a change in the output variable name (e.g., Variable Refrigerant Flow Heat Pump Cooling Natural Gas Consumption Rate).

\section{VRF Heat Pump Cooling Electric Energy [J]}

This output field is the cooling mode electricity consumption of the variable refrigerant flow heat pump in Joules for the time period being reported. The consumption includes electricity used by the compressor (including crankcase heater), and the condenser fan. This value is calculated for each HVAC system time step being simulated, and the results are summed for the time step being reported. This output is also added to a meter with Resource Type $=$ Electricity, End Use Key $=$ Cooling, Group Key $=$ System $($ Ref . Output:Meter objects). The choice of an alternate fuel type (see Fuel Type input) will result in a change in the output variable name (e.g., Variable Refrigerant Flow Heat Pump Cooling NaturalGas Consumption). The resource type meter will also be modified to reflect the chosen fuel type (e.g., Resource Type = NaturalGas).

\section{VRF Heat Pump Heating Electric Power [W]}

This output field is the heating mode electricity consumption rate of the variable refrigerant flow heat pump in Watts. The consumption includes electricity used by the compressor (including crankcase heater), additional energy required for defrost, and the condenser fan. This value is calculated for each HVAC system time step being simulated, and the results are averaged for the time step being reported. The choice of an alternate fuel type (see Fuel Type input) will result in a change in the output variable name (e.g., Variable Refrigerant Flow Heat Pump Heating NaturalGas Consumption Rate).

\section{VRF Heat Pump Heating Electric Energy [J]}

This output field is the heating mode electricity consumption of the VRF heat pump in Joules for the time period being reported. The consumption includes electricity used by the compressor (including crankcase heater), additional energy required for defrost, and the condenser fan. This value is calculated for each HVAC system time step being simulated, and the results are summed for the time step being reported. This output is also added to a meter with Resource Type = Electricity, End Use Key = Heating, Group Key = System (Ref. Output:Meter objects). The choice of an alternate fuel type (see Fuel Type input) will result in a change in the output variable name (e.g., Variable Refrigerant Flow Heat Pump Heating NaturalGas Consumption). The resource type meter will also be modified to reflect the chosen fuel type (e.g., Resource Type $=$ NaturalGas). 


\section{VRF Heat Pump Cooling COP []}

This is the operating cooling COP for the heat pump. This value is calculated using the ratio of VRF Heat Pump Total Cooling Rate and Variable Refrigerant Flow Heat Pump Cooling Electric Consumption Rate output variables. Crankcase heater (usually 0 in cooling mode), evaporative condenser water pump, and defrost (usually 0 in cooling mode) consumption rate output variables are included in this calculation. This value is specific to outdoor unit performance in cooling mode and is calculated for each HVAC system time step being simulated; the results are averaged for the time step being reported.

\section{VRF Heat Pump Heating COP []}

This is the operating heating coefficient of performance for the heat pump. This value is calculated using the ratio of VRF Heat Pump Total Heating Rate and Variable Refrigerant Flow Heat Pump Heating Electric Consumption Rate output variables. Crankcase heater, evaporative condenser water pump (usually 0 in heating mode), and defrost consumption rate output variables are included in this calculation. This value is specific to outdoor unit performance in heating mode, is calculated for each HVAC system time step being simulated, and the results are averaged for the time step being reported.

\section{VRF Heat Pump COP []}

This is the operating COP for the heat pump. This value is calculated using the ratio of the total terminal unit coil capacity (cooling plus heating and accounts for piping losses) and total system electric consumption rate (compressor, crankcase heater, evaporative condenser water pump, defrost, and terminal unit parasitic electric consumption rate). This output variable does not include pump power for a watercooled system. This value is specific to overall system performance and is calculated for each HVAC system time step being simulated; the results are averaged for the time step being reported.

\section{VRF Heat Pump Defrost Electric Power [W]}

This is the electricity consumption rate of the heat pump defrost in watts when the unit is in defrost mode (timed, reverse-cycle). . The choice of an alternate fuel type (see Fuel Type input) will result in a change in the output variable name (e.g., Variable Refrigerant Flow Heat Pump Natural Gas Defrost Consumption Rate).

\section{VRF Heat Pump Defrost Electric Energy [J]}

This is the electricity consumption of the heat pump in Joules for the time step being reported. This consumption is applicable when the unit is in defrost mode (reverse-cycle or resistive). This output is also added to a meter with Resource Type $=$ Electricity, End Use Key $=$ Heating, Group Key $=$ System $($ Ref. Output:Meter objects). The choice of an alternate fuel type (see Fuel Type input) will result in a change in the output variable name (e.g., Variable Refrigerant Flow Heat Pump Natural Gas Defrost Consumption). The resource type meter will also be modified to reflect the chosen fuel type (e.g., Resource Type $=$ Natural Gas).

\section{VRF Heat Pump Part Load Ratio}

This output field is the part-load ratio of the heat pump condenser. Heat pump part-load ratio is defined as the total coil load divided by the heat pump's maximum available capacity at the current operating conditions. This value is calculated for each HVAC system time step being simulated, and the results are averaged for the time step being reported. 


\section{VRF Heat Pump Runtime Fraction []}

This output field is the runtime fraction of the heat pump condenser's first stage compressor. The heat pump runtime fraction is defined as the fraction of time the first stage compressor is on during a given time period and includes cycling losses. This value is calculated as the ratio of the VRF Heat Pump Cycling Ratio and the output of the Cooling Part-Load Fraction Correlation Curve object as the specific cycling ratio. This value is calculated for each HVAC system time step being simulated, and the results are averaged for the time step being reported.

\section{VRF Heat Pump Cycling Ratio []}

This output field is the cycling ratio of the heat pump condenser's first stage compressor. The heat pump cycling ratio is defined as the fraction of time the first stage compressor is on during a given time period. This value is calculated for each HVAC system time step being simulated, and the results are averaged for the time step being reported.

\section{VRF Heat Pump Operating Mode []}

This output field is an integer representation of the operating mode of the VRF heat pump. The operating mode for cooling mode is indicated by a 1 and heating mode is indicated by a 2 . A value of 0 is reported if the heat pump is off. This value is calculated for each HVAC system time step being simulated, and the results are averaged for the time step being reported.

\section{VRF Heat Pump Condenser Inlet Temperature [C]}

This is the inlet air temperature entering the condenser coil in degrees $\mathrm{C}$. This value can represent the outdoor air dry-bulb temperature, wet-bulb temperature, or somewhere in between from the weather data being used, depending on the value used in the input field "Evaporative Condenser Effectiveness". The temperature reported here is used in the various modifier curves related to temperature (e.g., Total Cooling Capacity Modifier Curve [function of temperature]). (The use of the word "condenser" here is taken from cooling operation - the same device can also be an evaporator during heating operation.)

\section{VRF Heat Pump Condenser Outlet Temperature [C]}

This is the condenser coil outlet water temperature in degrees $\mathrm{C}$. This value is calculated for each HVAC system time step being simulated, and the results are averaged for the time step being reported. This value is only reported for water-cooled systems. (The use of the word "condenser" here is taken from cooling operation - the same device can also be an evaporator during heating operation.)

\section{VRF Heat Pump Condenser Mass Flow Rate [kg/s]}

This is the condenser coil outlet water mass flow rate in kilograms per second. This value is calculated for each HVAC system time step being simulated, and the results are averaged for the time step being reported. This value is only reported for water-cooled systems. (The use of the word "condenser" here is taken from cooling operation - the same device can also be an evaporator during heating operation.)

\section{VRF Heat Pump Condenser Heat Transfer Rate [W]}

This is the condenser coil heat transfer rate in watts. This value is calculated for each HVAC system time step being simulated, and the results are averaged for the time step being reported. This value is only 
reported for water-cooled systems. (The use of the word "condenser" here is taken from cooling operation - the same device can also be an evaporator during heating operation.)

\section{VRF Heat Pump Condenser Heat Transfer Energy [J]}

This is the condenser coil heat transfer in Joules. This value is calculated for each HVAC system time step being simulated, and the results are summed for the time step being reported. This value is only reported for water-cooled systems. (The use of the word "condenser" here is taken from cooling operation - the same device can also be an evaporator during heating operation.)

\section{VRF Heat Pump Maximum Capacity Cooling Rate [W]}

This output field is the maximum available terminal unit cooling capacity in watts allowed for the current time step being reported. If the terminal units request more capacity than is actually available from the variable refrigerant flow heat pump, the individual terminal units will be limited to this value. A maximum limit of $1 \mathrm{E}+20$ is reported when there is sufficient capacity available to meet all requests from the terminal units. This output variable easily identifies times when the total terminal unit cooling load exceeds the heat pump's available cooling capacity.

\section{VRF Heat Pump Maximum Capacity Heating Rate [W]}

This output field is the maximum available terminal unit heating capacity in watts allowed for the current time step being reported. If the terminal units request more capacity than is actually available from the VRF heat pump, the individual terminal units will be limited to this value. A maximum limit of $1 \mathrm{E}+20$ is reported when there is sufficient capacity available to meet all requests from the terminal units. This output variable easily identifies times when the total terminal unit heating load exceeds the heat pump's available heating capacity.

\section{VRF Heat Pump Terminal Unit Cooling Load Rate [W]}

This output field is the sum of the terminal unit cooling coil loads in watts for the current time step being reported. This value is derived directly from the cooling coils and represents the total cooling load on the VRF system after piping losses have been accounted for. The total cooling load will be less than the variable refrigerant flow total cooling capacity reported when piping losses are modeled (i.e., when piping losses are $<1)$.

\section{VRF Heat Pump Terminal Unit Heating Load Rate [W]}

This output field is the sum of the terminal unit heating coil loads in watts for the current time step being reported. This value is derived directly from the heating coils and represents the total heating load on the VRF system after piping losses have been accounted for. The total heating load will be less than the variable refrigerant flow total heating capacity reported when piping losses are modeled (i.e., when piping losses are $<1)$.

\section{VRF Heat Pump Crankcase Heater Electric Power [W]}

This output field is the average electricity consumption rate of the heat pump's crankcase heaters in watts for the time step being reported. 


\section{VRF Heat Pump Crankcase Heater Electric Energy [J]}

This output field is the electricity consumption rate of the heat pump's crankcase heaters in Joules for the time step being reported. This output is also added to a meter with Resource Type = Electricity, End Use Key = Cooling, Group Key = System (ref. Output:Meter objects).

\section{VRF Heat Pump Evaporative Condenser Water Use Volume [m3]}

This output is the amount of water used to evaporatively cool the condenser coil inlet air, in cubic meters. This output is also added to a meter with Resource Type $=$ Water, End Use Key $=$ Cooling, Group Key $=$ System (ref. Output:Meter objects).

\section{VRF Heat Pump Evaporative Condenser Pump Electric Power [W]}

This is the average electricity consumption rate of the evaporative condenser water pump in watts for the time step being reported.

\section{VRF Heat Pump Evaporative Condenser Pump Electric Energy [J]}

This is the electricity consumption rate of the evaporative condenser water pump in Joules for the time step being reported. This output is also added to a meter with Resource Type = Electricity, End Use Key = Cooling, Group Key = System (ref. Output:Meter objects).

\section{VRF Heat Pump Basin Heater Electric Power [W]}

This output is the electric consumption rate of the heat pump's basin heater (for evaporatively-cooled condenser type) in watts. This basin heater only operates when the VRF heat pump's compressor(s) is off and therefore is reported as 0 any time the compressor operates. If the compressor is cycling (see VRF Heat Pump Cycling Ratio output variable above), the basin heater electric power is proportional to one minus the cycling ratio of the compressor (i.e., the basin heater is on when the compressor is off).

\section{VRF Heat Pump Basin Heater Electric Energy [J]}

This output is the electric consumption of the heat pump's basin heater (for evaporativelycooled condenser type) in Joules. This output is also added to a meter with Resource Type = Electricity, End Use Key $=$ Cooling, Group Key = System (Ref. Output:Meter objects).

\section{VRF Heat Pump Heat Recovery Status Change Multiplier []}

This output applies only when heat recovery is used and represents the multiplier used to derate the capacity of the system when transitioning from cooling or heating mode to heat recovery mode. This value is 1 when derating does not apply (i.e., the system has not recently changed modes to provide heat recovery). Derating during a transition period is applied according to the inputs for Heat Recovery Fraction and Heat Recovery Time Constant. To turn transition derating off, set Heat Recovery Fraction to 1. Refer to the engineering reference document discussion on the VRF heat pump model section for transition from cooling only mode to heat recovery mode for a more detailed description. 


\title{
APPENDIX B. ENGINEERING REFERENCE-THE MODIFIED ENERGYPLUS
}

\author{
TABLE OF CONTENTS
}

1) Document Overview

2) Coil:Cooling:DX:VRFAirloopCoil

3) Coil:Heating:DX:VRFAirloopCoil

\section{DOCUMENT OVERVIEW}

In the original EnergyPlus 8.1, variable refrigerant flow (VRF) heating and cooling coils are not allowed to be used in air-loop systems. For this reason, an air-loop dedicated outdoor air system (DOAS) linked to a VRF outdoor system cannot be modeled in EnergyPlus 8.1 in conjunction with terminal VRF systems. This document provides the engineering references of the modified objects based on EnergyPlus 8.1 to enable the capability to model terminal VRF systems and an air-loop DOAS with VRF coils simultaneously. This document has been partially revised to describe a modified EnergyPlus based on the original EnergyPlus 8.1 Engineering Reference document. Discussions during the modeling process may reference specific "object names" as found in the Input/Output Reference document.

The VRF DX coil calculation in EnergyPlus 8.1 is identical to the single-speed direct expansion (DX) coil models (Coil:Cooling:DX:SingleSpeed and Coil:Heating:DX:SingleSpeed). Two new objects,

Coil:Cooling:DX:VRFAirloop and Coil:Heating:DX:VRFAirloop, are added to enable a DOAS coupled with a VRF outdoor unit providing $100 \%$ conditioned outdoor air to individual zones. These new objects are calculated the same way as the single-speed DX heating and cooling coils. Then the coil capacities are added into the VRF Condenser calculations along with the average inlet wet-bulb conditions for each coil linked to the VRF condenser. In the current modification, only one VRF condenser can be used. The engineering references for those two new objects are provided below.

\section{COIL:COOLING:DX:VRFAIRLOOPCOIL}

\section{Overview}

This VRFAirloop coil model is based on Coil:Cooling:DX:SingleSpeed model that simulates the performance of an air-cooled or evaporative-cooled DX air conditioner. The model uses performance information at rated conditions along with curve fits for variations in total capacity, energy input ratio, and part-load fraction to determine the performance of the unit at part-load conditions. Sensible/latent capacity splits are determined by the rated sensible heat ratio (SHR) and the apparatus dewpoint (ADP)/bypass factor (BF) approach. This approach is analogous to the NTU-effectiveness calculations used for sensible-only heat exchanger calculations, extended to a cooling and dehumidifying coil.

This model simulates the thermal performance of the DX cooling coil and the power consumption of the coupled VRF outdoor condensing unit (compressor, fan, crankcase heater and condenser water pump). The performance of the indoor supply air fan varies widely from system to system depending on control strategy (e.g., constant fan vs. AUTO fan, constant air volume vs. variable air volume), fan type, fan motor efficiency, and pressure losses through the air distribution system. Therefore, this DX system model does not account for the thermal effects or electric power consumption of the indoor supply air fan. 


\section{Auto Sizing}

The cooling coil is sized given the sizing day outdoor air conditions, the mixing ratio (100\% outdoor air if DOAS unit), total flow rate, and supply air set point. The method is outlined in the following equation.

$$
Q=\frac{\rho \dot{V}\left(H_{\text {mix }}-H_{s p}\right)}{\text { TotCapTempModFac }}
$$

The density, mix enthalpy, and supply enthalpy are determined using EnergyPlus built in psychrometric functions given, pressure, humidity ratio, and dry-bulb temperature. The TotCapTempModFac is the Total cooling capacity modifier curve (function of temperature) outlined below.

\section{Model Inputs}

The user must input the total cooling capacity, sensible heat ratio (SHR), coefficient of performance (COP), and volumetric air flow rate across the cooling coil at rated conditions. The capacity, SHR, and COP inputs should be "gross" values, excluding any thermal or energy impacts due to the indoor supply air fan. The rated conditions are considered to be air entering the cooling coil at $26.7^{\circ} \mathrm{C}$ drybulb $/ 19.4^{\circ} \mathrm{C}$ wetbulb and air entering the outdoor condenser coil at $35^{\circ} \mathrm{C}$ drybulb $/ 23.9^{\circ} \mathrm{C}$ wetbulb. The rated volumetric air flow should be between $0.00004027 \mathrm{~m} 3 / \mathrm{s}$ and $0.00006041 \mathrm{~m} 3 / \mathrm{s}$ per watt of rated total cooling capacity (300-450 cfm/ton). The rated volumetric air flow to total cooling capacity ratio for a $100 \%$ DOAS application DX cooling coils should be between $0.00001677(\mathrm{~m} 3 / \mathrm{s}) / \mathrm{W}(125 \mathrm{cfm} / \mathrm{ton})$ and $0.00003355(\mathrm{~m} 3 / \mathrm{s}) / \mathrm{W}(250 \mathrm{cfm} / \mathrm{ton})$.

The user must also input two performance curves that describe the change in total cooling capacity and efficiency at part-load conditions:

1) Total cooling capacity modifier curve (function of temperature)

2) Total cooling capacity modifier curve (function of flow fraction)

The total cooling capacity modifier curve (function of temperature) is a biquadratic curve with two independent variables: wet-bulb temperature of the air entering the cooling coil, and dry-bulb temperature of the air entering the air-cooled condenser coil (wet-bulb temperature if modeling an evaporative-cooled condenser). The output of this curve is multiplied by the rated total cooling capacity to give the total cooling capacity at the specific entering air temperatures at which the DX coil unit is operating (i.e., at temperatures different from the rating point temperatures).

Note: The data used to develop the total cooling capacity modifier curve (function of temperature) should represent performance when the cooling coil is 'wet' (i.e., coil providing sensible cooling and at least some dehumidification). Performance data when the cooling coil is 'dry' (i.e., not providing any dehumidification) should not be included when developing this modifier curve. This model automatically detects and adjusts for 'dry coil' conditions

\section{COIL:HEATING:DX:VRFAIRLOOPCOIL}

\section{Overview}

This DX VRFAirloop model is modified using the same methodology, with the DX SingleSpeed model (object name Coil:Heating:DX:SingleSpeed) simulating the performance of an air-to- air DX heating system. The model uses performance information at rated conditions along with curve fits for variations 
in total capacity, energy input ratio and part-load fraction to determine the performance of the unit at partload conditions (DOE 1982). Adjustment factors are applied to total capacity and input power to account for frost formation on the outdoor coil. This model simulates the thermal performance of the indoor DX heating coil and the power consumption of the coupled VRF outdoor unit (compressors, fans, crankcase heaters and defrost heaters). The performance of the indoor supply air fan varies widely from system to system depending on control strategy (e.g., constant fan vs. AUTO fan, constant air volume vs. variable air volume), fan type, fan motor efficiency and pressure losses through the air distribution system. Therefore, this DX system model does not account for the thermal effects or electric power consumption of the indoor supply air fan.

\section{Auto Sizing}

In the old EnergyPlus 8.1 version, the heating coil was simply set equal to the cooling coil rated total capacity. For this version, the heating coil is independently sized given the sizing day outdoor air conditions, the mixing ratio (100\% outdoor air if DOAS unit), total flow rate, and the supply air set point. The method is outlined in the following equation.

$$
Q=\frac{\rho \dot{V}\left(H_{\text {mix }}-H_{s p}\right)}{\text { TotCapTempModFac }}
$$

The density, mix enthalpy, and supply enthalpy are determined using EnergyPlus built in psychrometric functions given pressure, humidity ratio, and dry-bulb temperature. The TotCapTempModFac is the Total heating capacity modifier curve (function of temperature) outlined below.

\section{Model Inputs}

The user must input the total heating capacity, air flow rate, and the volumetric airflow rate across the heating coil at rated conditions. The capacity input should be "gross" values, excluding any thermal or energy impacts due to the indoor supply air fan. The rating condition is considered to be outdoor air at 8.33C dry-bulb and 6.11C wet-bulb temperatures (i.e., air entering the outdoor coil), with air entering the indoor DX heating coil at $21.11 \mathrm{C}$ dry-bulb and $15.55 \mathrm{C}$ wet-bulb temperatures. The rated volumetric air flow across the DX heating coil should be between $0.00004027 \mathrm{~m} 3 / \mathrm{s}$ and $0.00006041 \mathrm{~m} 3 / \mathrm{s}$ per watt of rated total heating capacity $(300-450 \mathrm{cfm} / \mathrm{ton})$.

The total heating capacity modifier curve (function of temperature) can be a function of both the outdoor and indoor air dry-bulb temperature or only the outdoor air dry-bulb temperature. The user has the choice of a bi-quadratic curve with two independent variables, or a quadratic curve as well as a cubic curve with a single independent variable. The biquadratic curve is recommended if sufficient manufacturer data are available, as it provides sensitivity to the indoor air dry-bulb temperature and a more realistic output. The output of this curve is multiplied by the rated total heating capacity to give the total heating capacity at specific temperature operating conditions (i.e., at an outdoor or indoor air temperature different from the rating point temperature). 


\section{APPENDIX C. A SUMMARY OF TEST RESULTS-THE MODIFIED ENERGYPLUS}

\section{MODEL DESCRIPTION}

To test the modified code of EnergyPlus 8.1, a single zone building model (Table 23) was created to compare the original EnergyPlus 8.1 and the modified EnergyPlus. The building model descriptions are summarized in Table 23. Two HVAC systems were modeled in each version of EnergyPlus as described in Table 24: a VRF terminal unit with an outdoor air mixer (i.e., VRF_OAmixer.idf) for the original EnergyPlus 8.1 and a VRF terminal unit with an air-loop DOAS (i.e., VRF_airloopDOAS.idf) for the modified EnergyPlus 8.1. The same weather data (i.e., USA_TN_Knoxville-McGhee-TMY3.epw) were used for both models.

Table 23. EnergyPlus Building model

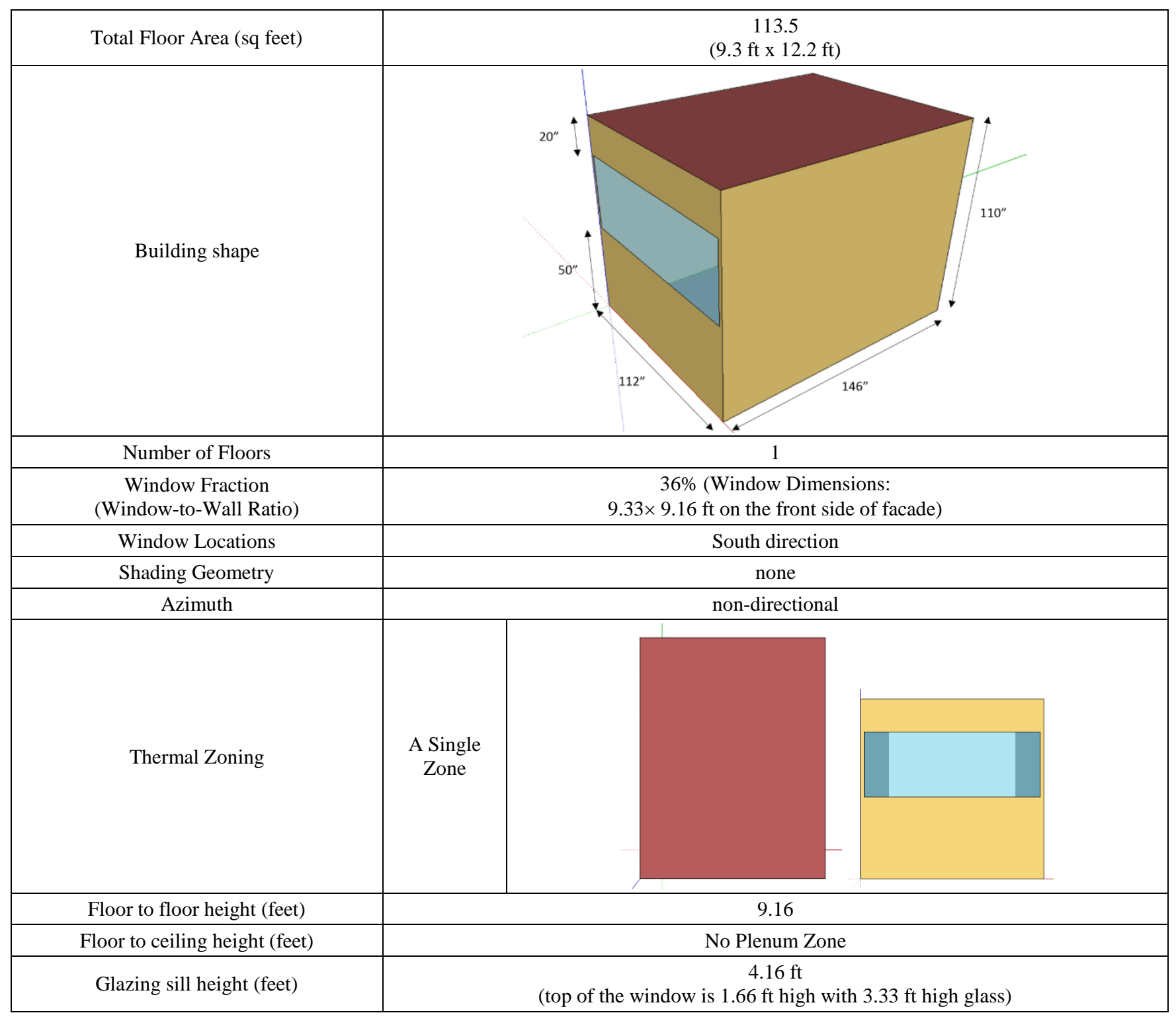


Table 23. (continued)

\begin{tabular}{|c|c|}
\hline Lighting & 0.99 \\
\hline Average power density $\left(\mathrm{W} / \mathrm{ft}^{2}\right)$ & Always on \\
\hline Schedule & 0.99 \\
\hline Plug load Schedule & Always on \\
\hline Average power density $\left(\mathrm{W} / \mathrm{ft}^{2}\right)$ & 0.0049 \\
\hline Occupancy Schedule & Always on \\
\hline Average people $\left(\right.$ Person/ $\left.\mathrm{ft}^{2}\right)$ & 0.5 \\
\hline Snfiltration Air Changes per Hour & Infiltration Half on Always on Schedule \\
\hline \multicolumn{2}{|c|}{ Schedule } \\
\hline Schedule & Infiltration Half on Always on Schedule \\
\hline Flow Rate per Zone Floor Area $\left(\mathrm{ft}^{3} / \mathrm{min}^{2}\right)$ & 0.06003925 \\
\hline
\end{tabular}

Table 24. EnergyPlus HVAC models

\begin{tabular}{|c|c|c|}
\hline System Type & VRF + OAmixer & VRF + Airloop DOAS \\
\hline Heating type & Heating:DX:Variable Refrigerant Flow & Heating:DX:Variable Refrigerant Flow \\
\hline Cooling type & Cooling:DX:Variable Refrigerant Flow & Cooling:DX:Variable Refrigerant Flow \\
\hline $\begin{array}{c}\text { Distribution and terminal } \\
\text { units }\end{array}$ & $\begin{array}{c}\text { Zone HVAC: Terminal Unit:Variable Refrigerant } \\
\text { Flow }\end{array}$ & $\begin{array}{c}\text { Ternimal Unit Availability Schedule: Always on } \\
\text { Supply Air Flow Rate (cfm): autosize }\end{array}$ \\
& $\begin{array}{c}\text { Ternimal Unit Availability Schedule: Always on } \\
\text { Supply Air Flow Rate (cfm): autosize }\end{array}$ & $\begin{array}{c}\text { Air Terminal:SingleDuct:VAV:NoReheat } \\
\text { Ternimal Unit Availability Schedule: Always on } \\
\text { Maximum Air Flow Rate (cfm): autosize } \\
\text { Zone Minimum Air Flow Input Method: Constant }\end{array}$ \\
\hline
\end{tabular}

\begin{tabular}{|c|c|c|}
\hline Outdoor Air System & VRF + OAmixer & VRF + Airloop DOAS \\
\hline Type & Outdoor Air Mixer (VRF) & $\begin{array}{c}\text { AirLoopHVAC: Outdoor Air System (DOAS); } \\
\text { No Outdoor Air Mixer for VRF }\end{array}$ \\
\hline $\begin{array}{c}\text { Design Specification: } \\
\text { Outdoor Air }(\mathrm{cfm})\end{array}$ & 50 Flow/zone $(0.02359 \mathrm{~m} 3 / \mathrm{s})$ & 50 Flow/zone $(0.02359 \mathrm{~m} 3 / \mathrm{s})$ \\
\hline $\begin{array}{c}\text { Controller: Outdoor Air } \\
\text { (Minimum/Maximum OA } \\
\text { Flow Rate ft3/min) }\end{array}$ & - & autosize \\
\hline
\end{tabular}

\begin{tabular}{|c|c|c|}
\hline HVAC Control & VRF + OAmixer & VRF + Airloop DOAS \\
\hline Thermostat Set point $\left({ }^{\circ} \mathrm{F}\right)$ & $75.2^{\circ} \mathrm{F}\left(24^{\circ} \mathrm{C}\right)$ Cooling $/ 69.8^{\circ} \mathrm{F}\left(21^{\circ} \mathrm{C}\right)$ Heating & $75.2^{\circ} \mathrm{F}\left(24^{\circ} \mathrm{C}\right)$ Cooling $/ 69.8^{\circ} \mathrm{F}\left(21^{\circ} \mathrm{C}\right) \mathrm{Heating}$ \\
\hline $\begin{array}{c}\text { DOAS Supply Air } \\
\text { Temperature }\left({ }^{\circ} \mathrm{F}\right)\end{array}$ & - & $75.2^{\circ} \mathrm{F}\left(24^{\circ} \mathrm{C}\right)$ Cooling $/ 69.8^{\circ} \mathrm{F}\left(21^{\circ} \mathrm{C}\right) \mathrm{Heating}$ \\
\hline Energy Recovery & - & - \\
\hline
\end{tabular}


Table 24. (continued)

\begin{tabular}{|c|c|c|}
\hline Coil:CoolingDX (VRF) & VRF + OAmixer & VRF + Airloop DOAS \\
\hline Availability Schedule & Always on & Always on \\
\hline $\begin{array}{c}\text { Gross Rated Total } \\
\text { Cooling Capacity (Btu/h) }\end{array}$ & autosize & autosize \\
\hline $\begin{array}{c}\text { Gross Rated Sensible } \\
\text { Heat Ratio }\end{array}$ & autosize & autosize \\
\hline $\begin{array}{l}\text { Rated Air Flow Rate } \\
(\mathrm{cfm})\end{array}$ & autosize & autosize \\
\hline Coil:HeatingDX (VRF) & VRF + OAmixer & VRF + Airloop DOAS \\
\hline Availability Schedule & Always on & Always on \\
\hline $\begin{array}{l}\text { Gross Rated Heating } \\
\text { Capacity }(\text { Btu/h) }\end{array}$ & autosize & autosize \\
\hline $\begin{array}{l}\text { Rated Air Flow Rate } \\
(\mathrm{cfm})\end{array}$ & autosize & autosize \\
\hline Coil:CoolingDX(DOAS) & VRF + OAmixer & VRF + Airloop DOAS \\
\hline Type & - & CoolingDX:VRFAirLoop (DX:Single:Speed) \\
\hline Availability Schedule & - & Always on \\
\hline $\begin{array}{c}\text { Gross Rated Total } \\
\text { Cooling Capacity (Btu/h) }\end{array}$ & - & autosize \\
\hline $\begin{array}{c}\text { Gross Rated Sensible } \\
\text { Heat Ratio }\end{array}$ & - & autosize \\
\hline $\begin{array}{l}\text { Rated Air Flow Rate } \\
(\mathrm{cfm})\end{array}$ & - & autosize \\
\hline Coil:HeatingDX(DOAS) & VRF + OAmixer & VRF + Airloop DOAS \\
\hline Type & - & HeatingDX:VRFAirLoop (DX:Single:Speed) \\
\hline Availability Schedule & - & Always on \\
\hline $\begin{array}{l}\text { Gross Rated Heating } \\
\text { Capacity (Btu/h) }\end{array}$ & - & autosize \\
\hline $\begin{array}{l}\text { Rated Air Flow Rate } \\
(\mathrm{cfm})\end{array}$ & - & autosize \\
\hline
\end{tabular}

\begin{tabular}{|c|c|c|}
\hline $\begin{array}{c}\text { Supply Fan: On/Off } \\
\text { (VRF) }\end{array}$ & VRF + OAmixer & VRF + Airloop DOAS \\
\hline Fan schedules & Always on & Always on \\
\hline $\begin{array}{c}\text { Supply Fan Total } \\
\text { Efficiency (\%) }\end{array}$ & $100 \%$ & 0.30109 \\
\hline $\begin{array}{c}\text { Supply Fan Pressure Rise } \\
\text { (inH20) }\end{array}$ & 0.30109 & autosize \\
\hline $\begin{array}{c}\text { Maximum Flow Rate } \\
\text { (cfm) }\end{array}$ & autosize & VRF + Airloop DOAS \\
\hline $\begin{array}{c}\text { Supply Fan: Variable } \\
\text { Volume (DOAS) }\end{array}$ & VRF + OAmixer & Always on \\
\hline $\begin{array}{c}\text { Fan schedules } \\
\text { Supply Fan Total } \\
\text { Efficiency (\%) }\end{array}$ & - & $100 \%$ \\
\hline $\begin{array}{c}\text { Supply Fan Pressure Rise } \\
\text { (inH20) }\end{array}$ & - & 4.01463 \\
\hline $\begin{array}{c}\text { Maximum Flow Rate } \\
\text { (cfm) }\end{array}$ & - & autosize \\
\hline
\end{tabular}

Air Conditioner (VRF)

Availability Schedule

\section{VRF + OAmixer}

Always on
VRF + Airloop DOAS

Always on 
Table 24. (continued)

\begin{tabular}{|c|c|c|}
\hline $\begin{array}{c}\text { Gross Rate Total Cooling } \\
\text { Capacity (Btu/h) }\end{array}$ & autosize & autosize \\
\hline $\begin{array}{c}\text { Gross Rated Cooling COP } \\
\text { (Btuh/Btuh) }\end{array}$ & 3.3 & 3.3 \\
\hline $\begin{array}{c}\text { Minimum Outdoor } \\
\text { Temeprature in Cooling } \\
\text { Mode }\left({ }^{\circ} \mathrm{F}\right)\end{array}$ & 21.2 & 21.2 \\
\hline $\begin{array}{c}\text { Maximum Outdoor } \\
\text { Temeprature in Cooling } \\
\left.\text { Mode ( }{ }^{\circ} \mathrm{F}\right)\end{array}$ & 109.4 & 109.4 \\
\hline $\begin{array}{c}\text { Gross Rate Total Heating } \\
\text { Capacity (Btu/h) }\end{array}$ & autosize & autosize \\
\hline $\begin{array}{c}\text { Gross Rated Heating COP } \\
\text { (Btuh/Btuh) }\end{array}$ & 3.4 & 3.4 \\
\hline $\begin{array}{c}\text { Minimum Outdoor } \\
\text { Temeprature in Cooling } \\
\text { Mode }\left({ }^{\circ} \mathrm{F}\right)\end{array}$ & -4 & -4 \\
\hline $\begin{array}{c}\text { Maximum Outdoor } \\
\text { Temeprature in Cooling } \\
\left.\text { Mode ( }{ }^{\circ} \mathrm{F}\right)\end{array}$ & 60.8 & 60.8 \\
\hline
\end{tabular}

\begin{tabular}{|c|c|c|}
\hline Sizing:Zone & VRF + OAmixer & VRF + Airloop DOAS \\
\hline $\begin{array}{c}\text { Zone Cooling Design } \\
\text { Supply Air Temperature } \\
\left({ }^{\circ} \mathrm{F}\right)\end{array}$ & $54.98^{\circ} \mathrm{F}\left(12.77^{\circ} \mathrm{C}\right)$ & $54.98^{\circ} \mathrm{F}\left(12.77^{\circ} \mathrm{C}\right)$ \\
\hline $\begin{array}{c}\text { Zone Heating Design } \\
\text { Supply Air Temperature }\end{array}$ & $119.98^{\circ} \mathrm{F}\left(48.88^{\circ} \mathrm{C}\right)$ & $119.98^{\circ} \mathrm{F}\left(48.88^{\circ} \mathrm{C}\right)$ \\
\hline
\end{tabular}

\begin{tabular}{|c|c|c|}
\hline Sizing:System & VRF + OAmixer & VRF + Airloop DOAS \\
\hline $\begin{array}{c}\text { Central Cooling Design } \\
\text { Supply Air Temperature } \\
\left({ }^{\circ} \mathrm{F}\right)\end{array}$ & - & $55.04^{\circ} \mathrm{F}\left(12.8^{\circ} \mathrm{C}\right)$ \\
\hline $\begin{array}{c}\text { Central Heating Design } \\
\text { Supply Air Temperature } \\
\left({ }^{\circ} \mathrm{F}\right)\end{array}$ & - & $53.96^{\circ} \mathrm{F}\left(12.2^{\circ} \mathrm{C}\right)$ \\
\hline
\end{tabular}

\section{SIMULATION RESULTS}

An original EnergyPlus 8.1 model (VRF+OAmixer) and the modified EnergyPlus model (VRF+Airloop DOAS) were compared under the same indoor and outdoor conditions for the summer month of July and the winter month of January. The comparison was mainly based on cooling and heating loads, indoor room conditions, and HVAC system outputs. The thermostat set temperatures for each model, provided in Table 24, were kept the same for both models.

Table 25. Total Energy End Uses

\begin{tabular}{|l|c|c|}
\hline & VRF + OAMixer & VRF + Airloop DOAS \\
\hline Heating & 198.8 & 236.2 \\
\hline Cooling & 155.2 & 175.1 \\
\hline Interior Lighting & 163.5 & 163.5 \\
\hline Interior Equipment & 163.5 & 163.5 \\
\hline Fans & 7.7 & 40.7 \\
\hline Total End Uses $[\mathrm{kWh}]$ & $\mathbf{6 8 8 . 7}$ & $\mathbf{7 7 9 . 1}$ \\
\hline
\end{tabular}




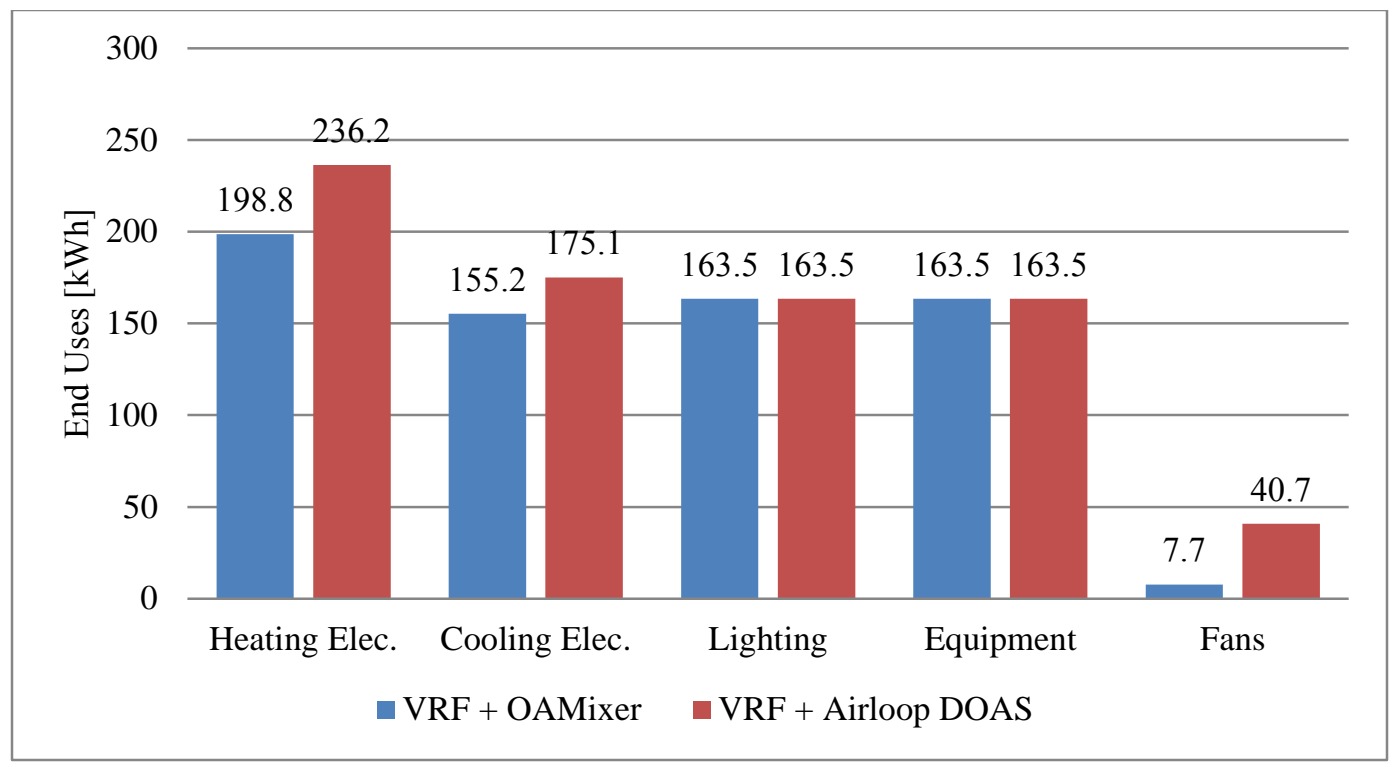

Figure 46. End Uses in Sub-systems.

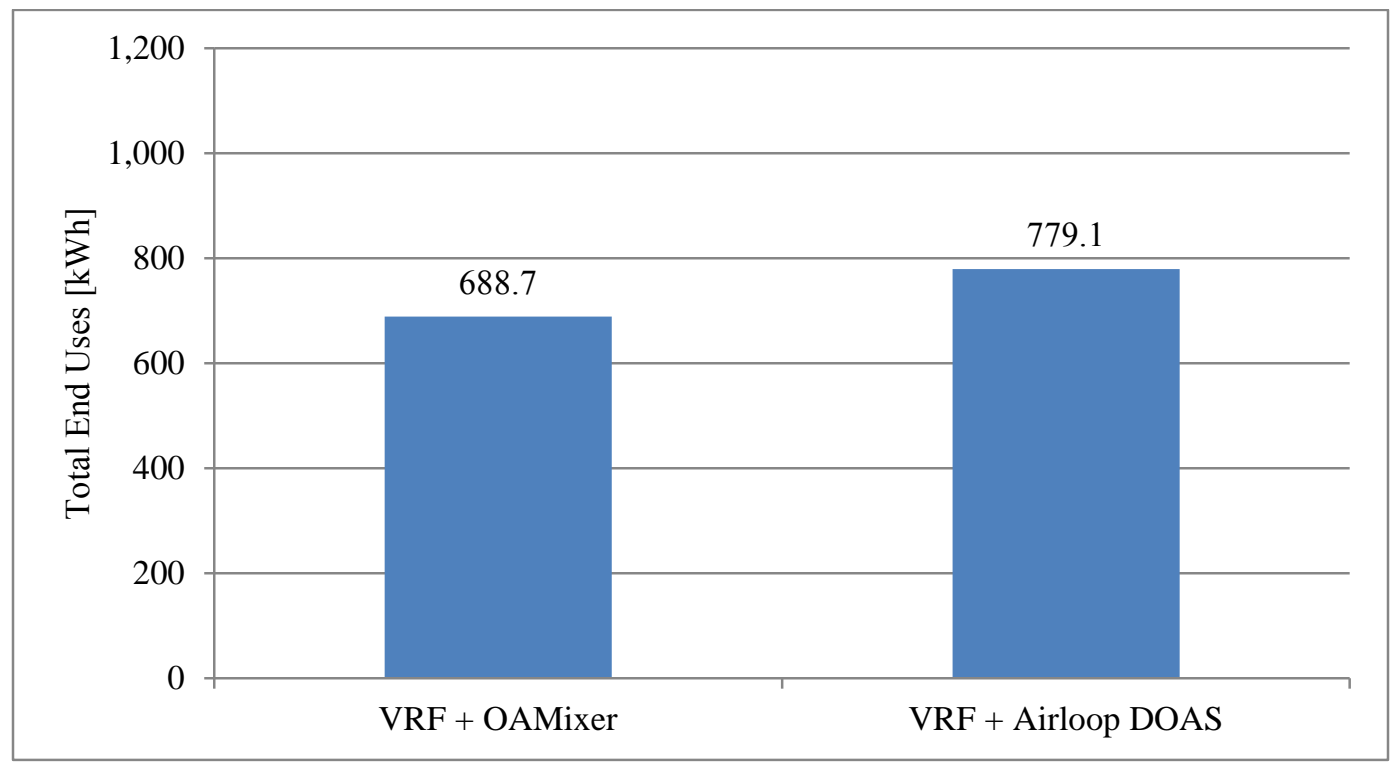

Figure 47. Total Energy End Uses.

The results show that the modified EnergyPlus model predicts slightly higher heating and cooling energy use compared with the original models (see Table 25, Figure 46, and Figure 47). That was expected because in the modified model, the zone and OA loads are removed separately using the terminal VRF and the air-loop DOAS with a VRF coil; whereas the original model removes the zone and OA loads simultaneously by mixing OA and return air from the zone and by using a single VRF coil to remove the mixed total heating or cooling energy. As two systems provide heating and cooling in the modified model, it has a tendency to overheat or overcool the zone, since two units are trying to provide heating and cooling at the same time separately to the zone. 
Figure 48 through Figure 53 show the comparisons of different output variables between the original and modified models during summer.

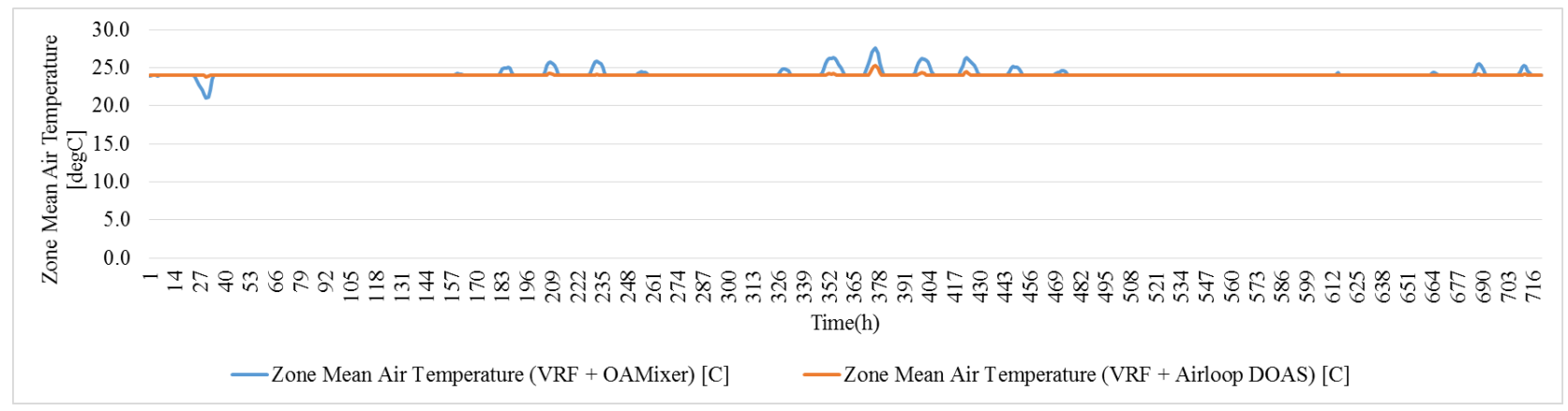

Figure 48. Zone Mean Air Temperature (July).

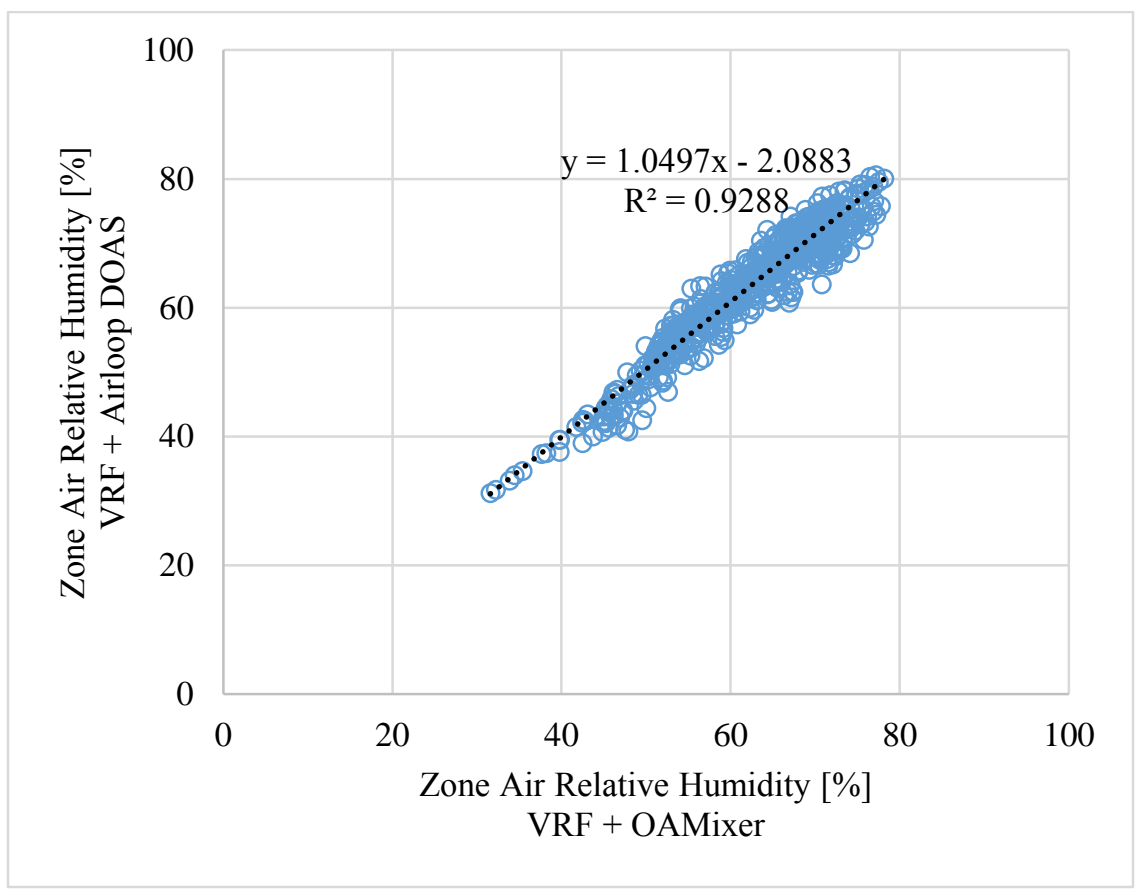

Figure 49. Zone Air Relative Humidity. 


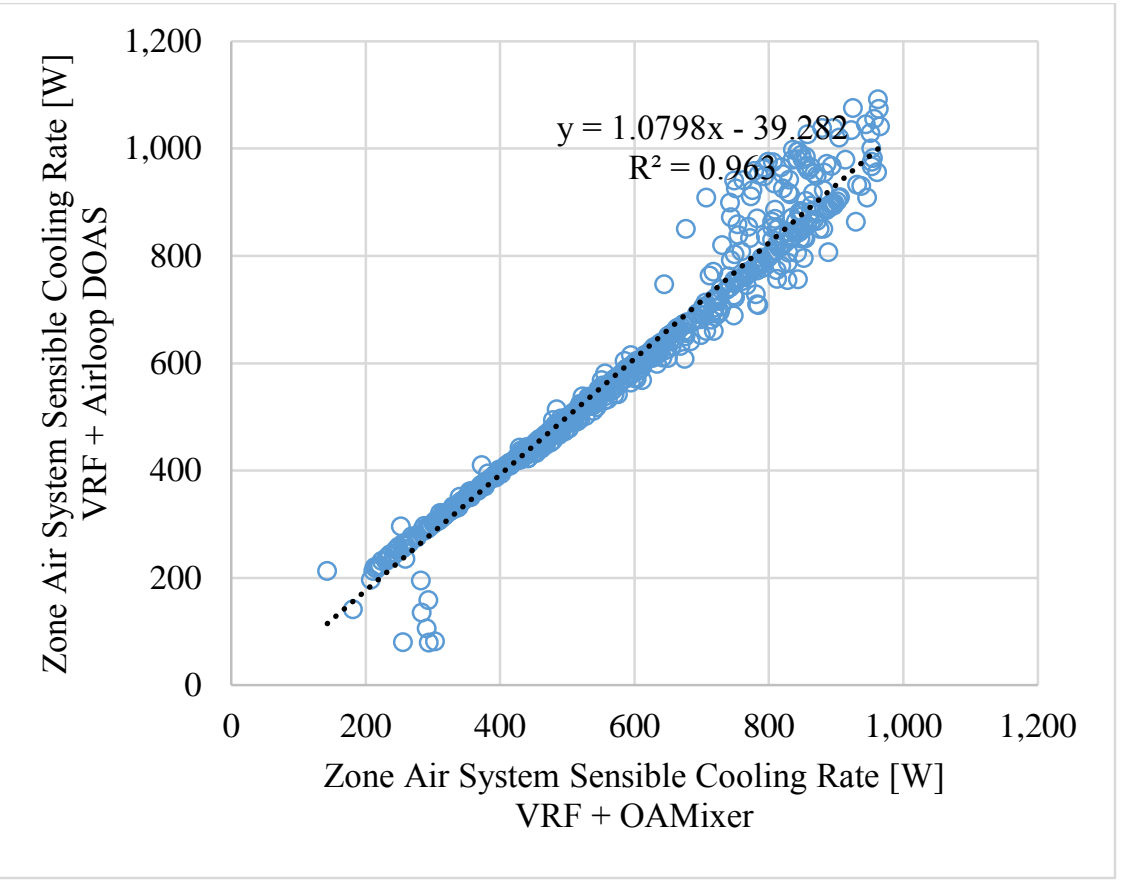

Figure 50. Zone Air System Sensible Cooling Rate.

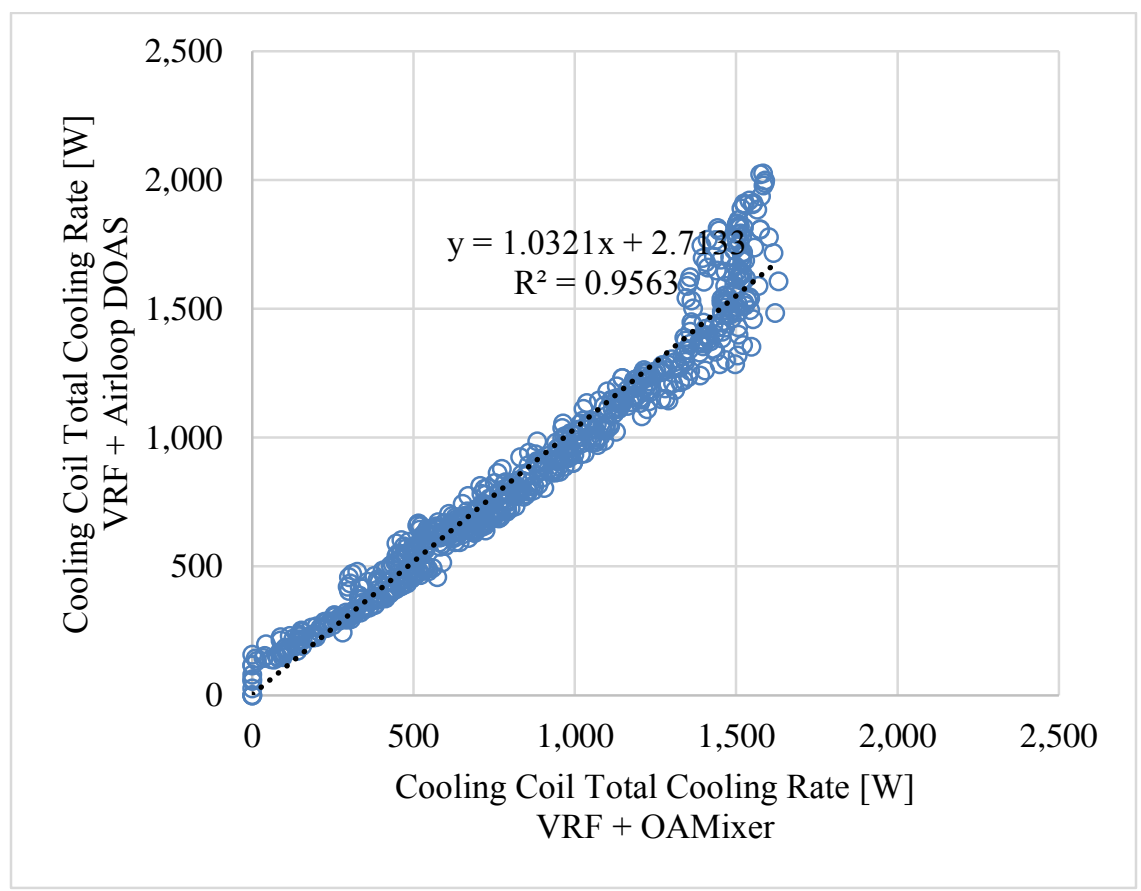

Figure 51. VRF Heat Pump Total Cooling Rate. 


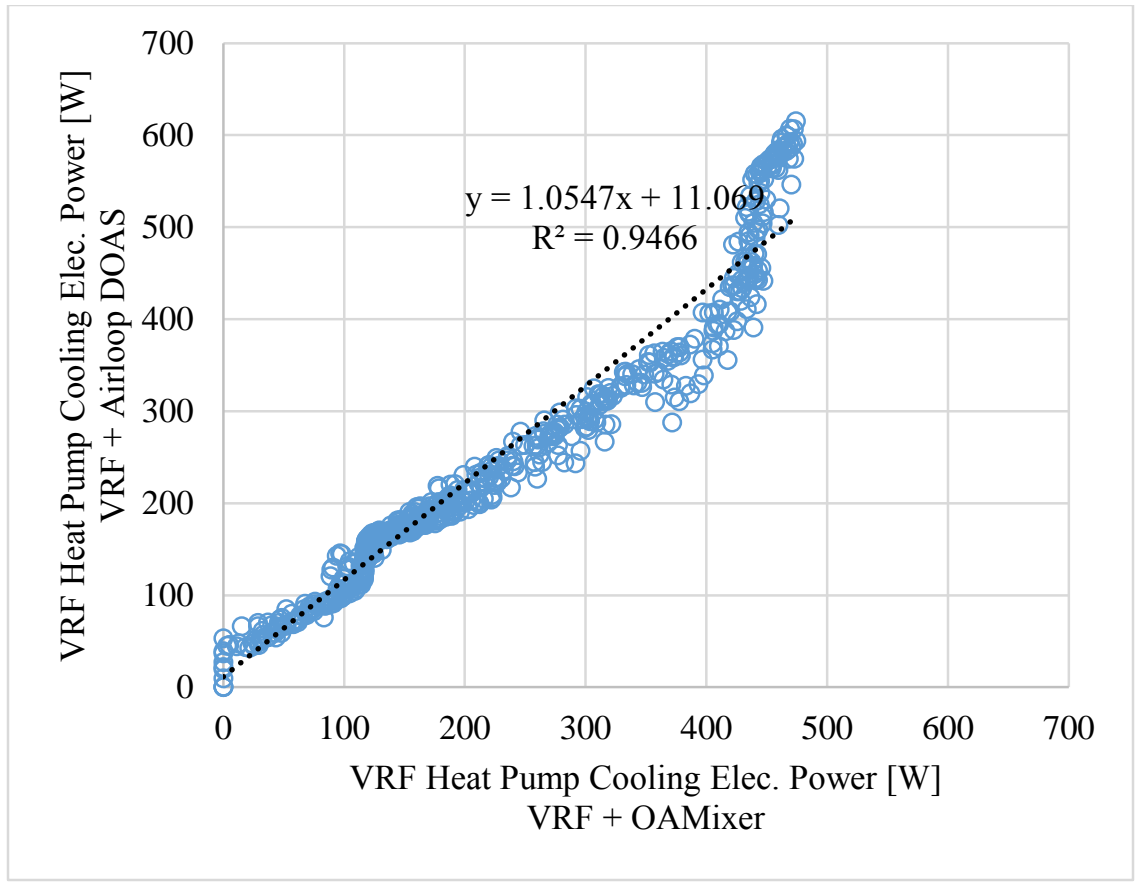

Figure 52. VRF Heat Pump Cooling Electric Power.

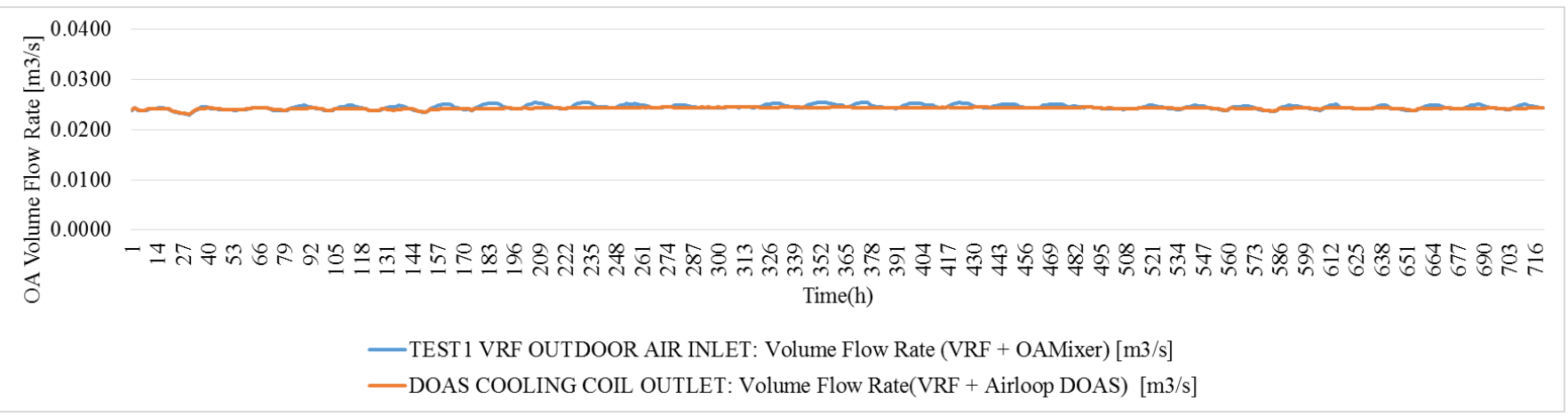

Figure 53. Outdoor Supply Air Volume Flow Rate.

Figure 54 through Figure 58 show the comparisons of different output variables between the original and modified models during winter. 


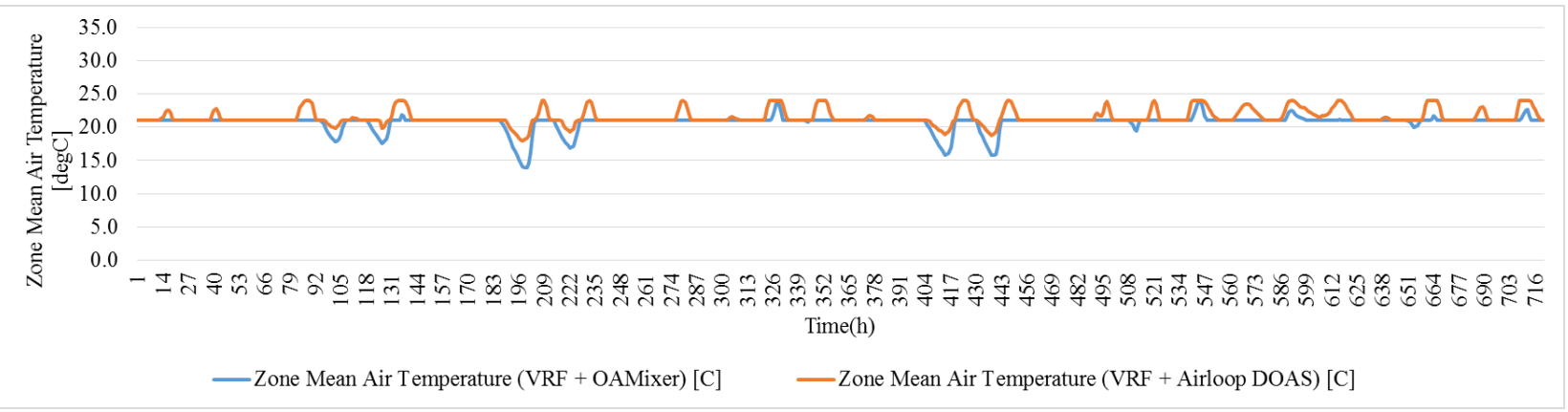

Figure 54. Zone Mean Air Temperature (January).

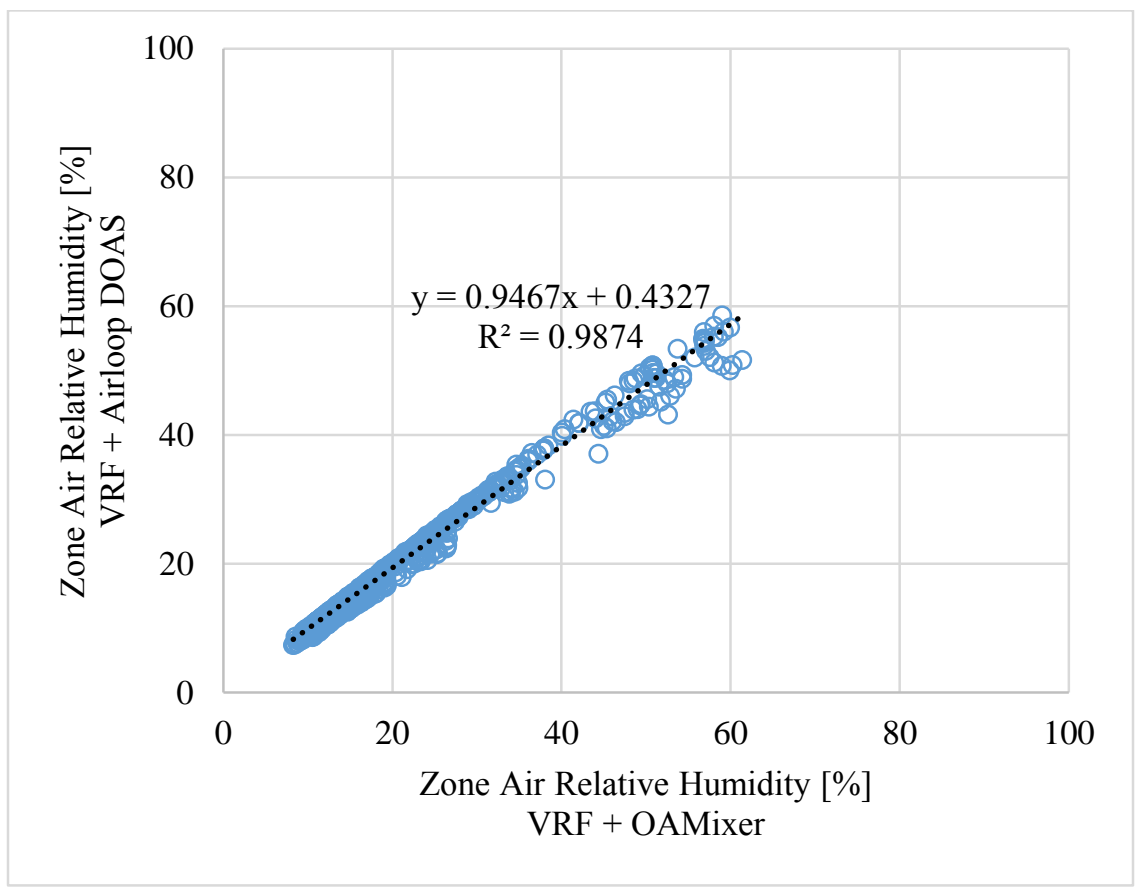

Figure 55. Zone Air Relative Humidity. 


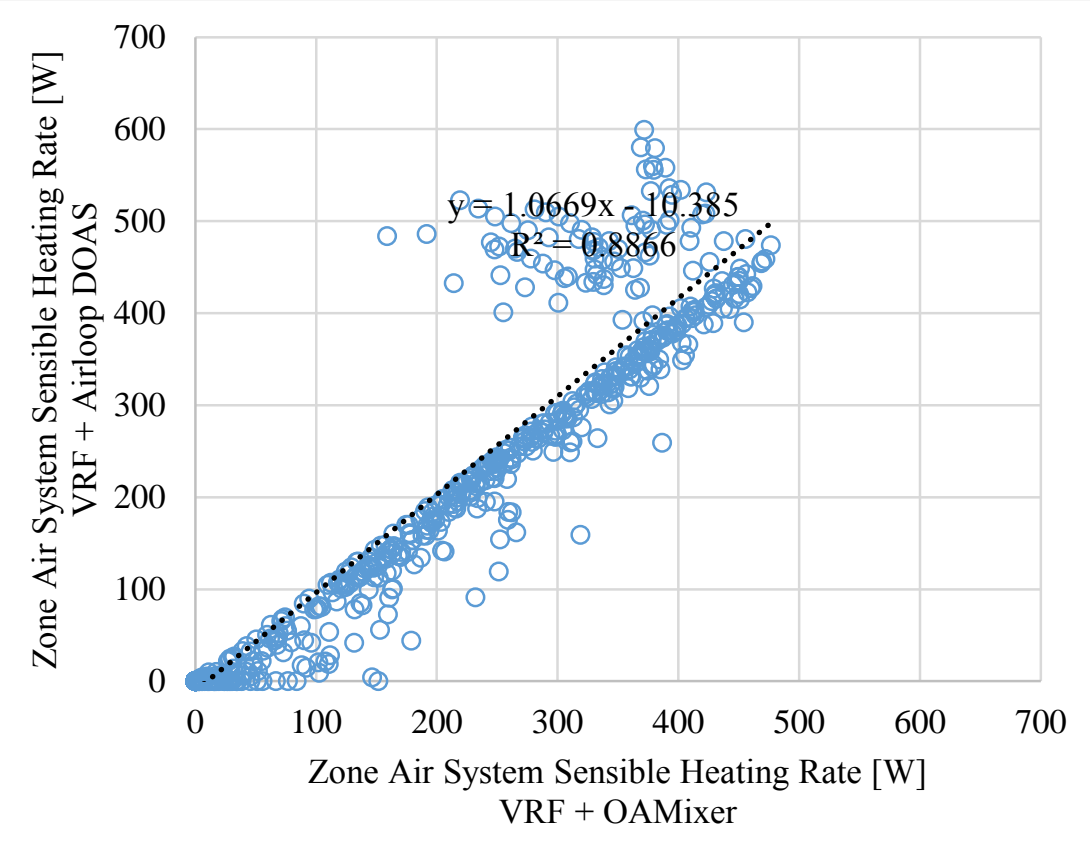

Figure 56. Zone Air System Sensible Heating Rate.

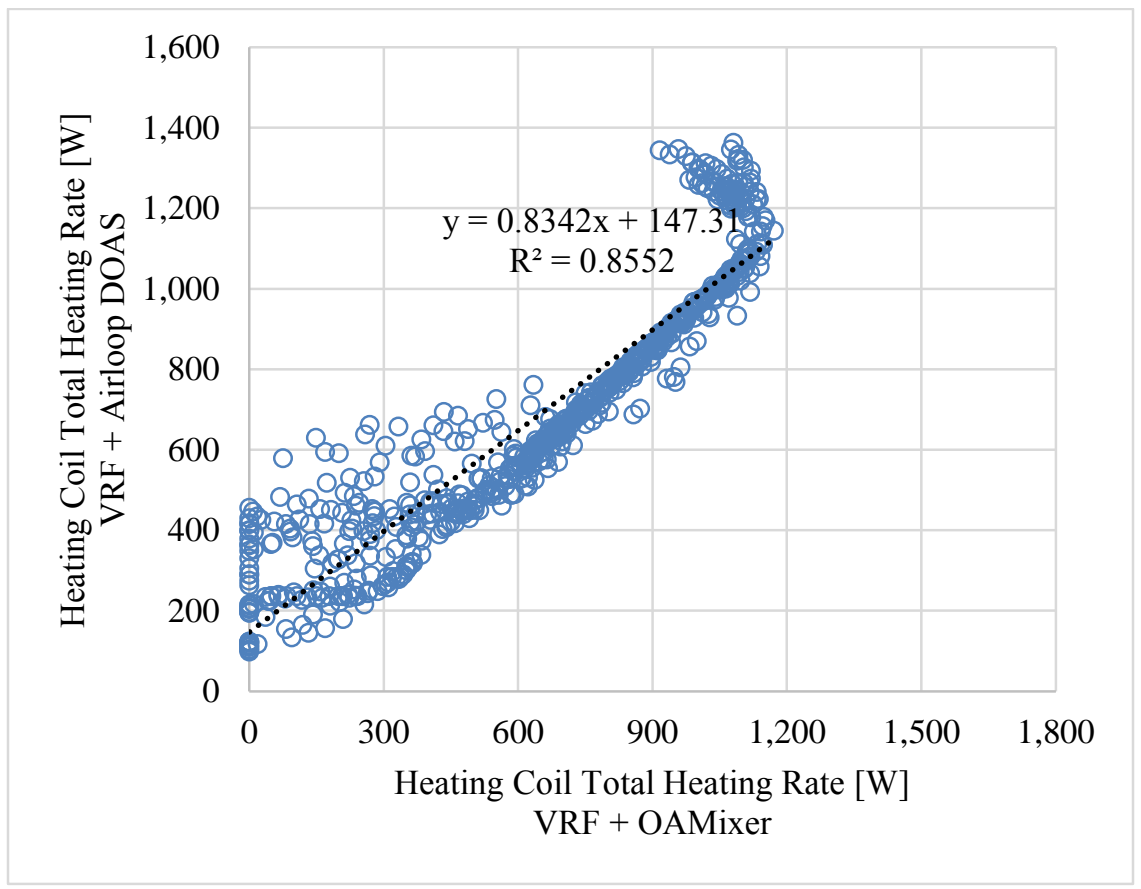

Figure 57. VRF Heat Pump Total Heating Rate. 


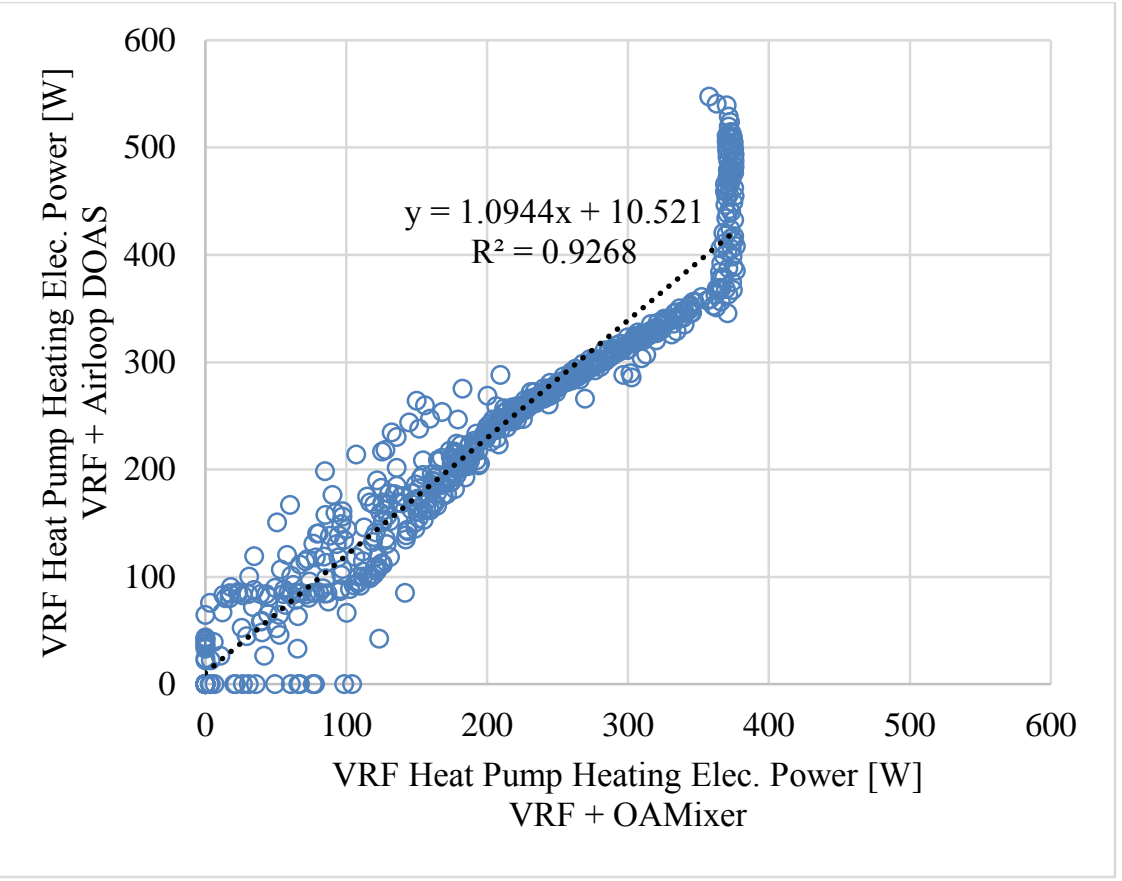

Figure 58. VRF Heat Pump Heating Electric Power. 


\section{APPENDIX D. TABLES OF THE MONTHLY TRENDS-MONTHLY HVAC ENERGY USE FOR VRF VERSUS RTU}

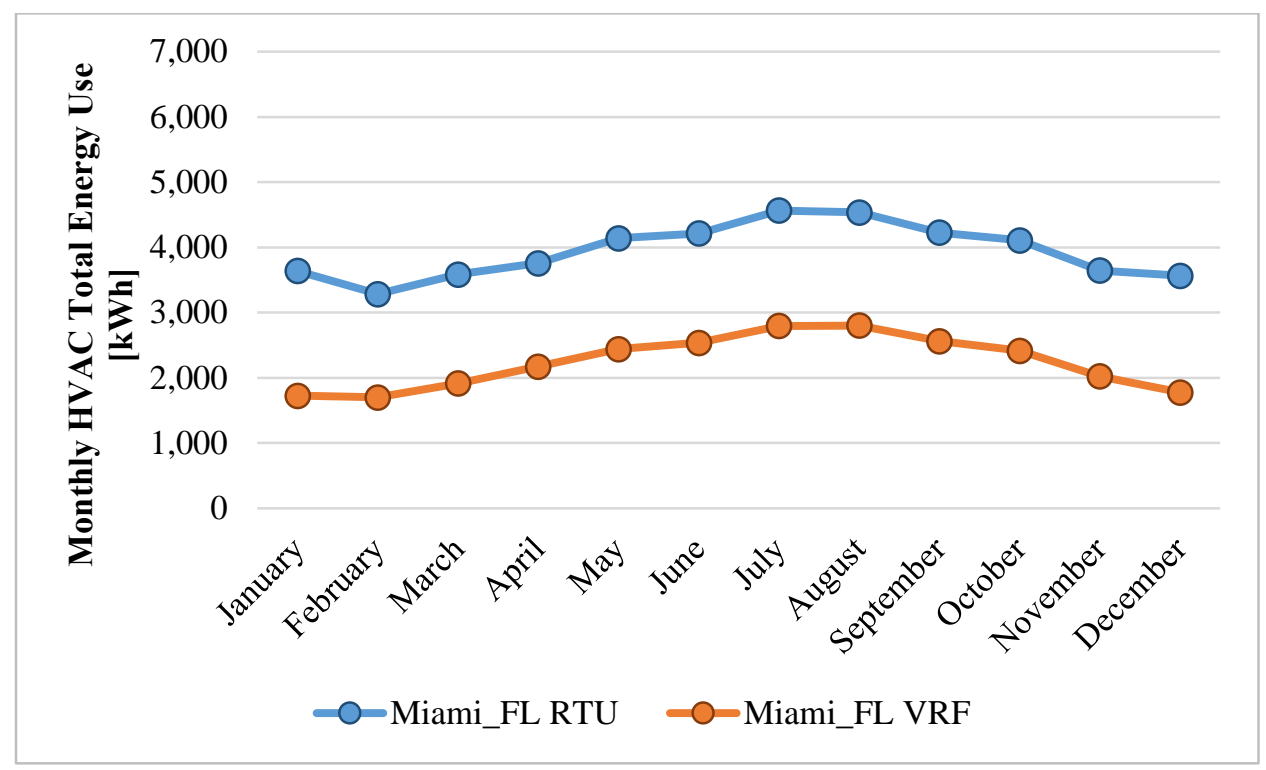

Figure 59. Monthly HVAC total energy use for the VRF versus the RTU in Miami, FL.

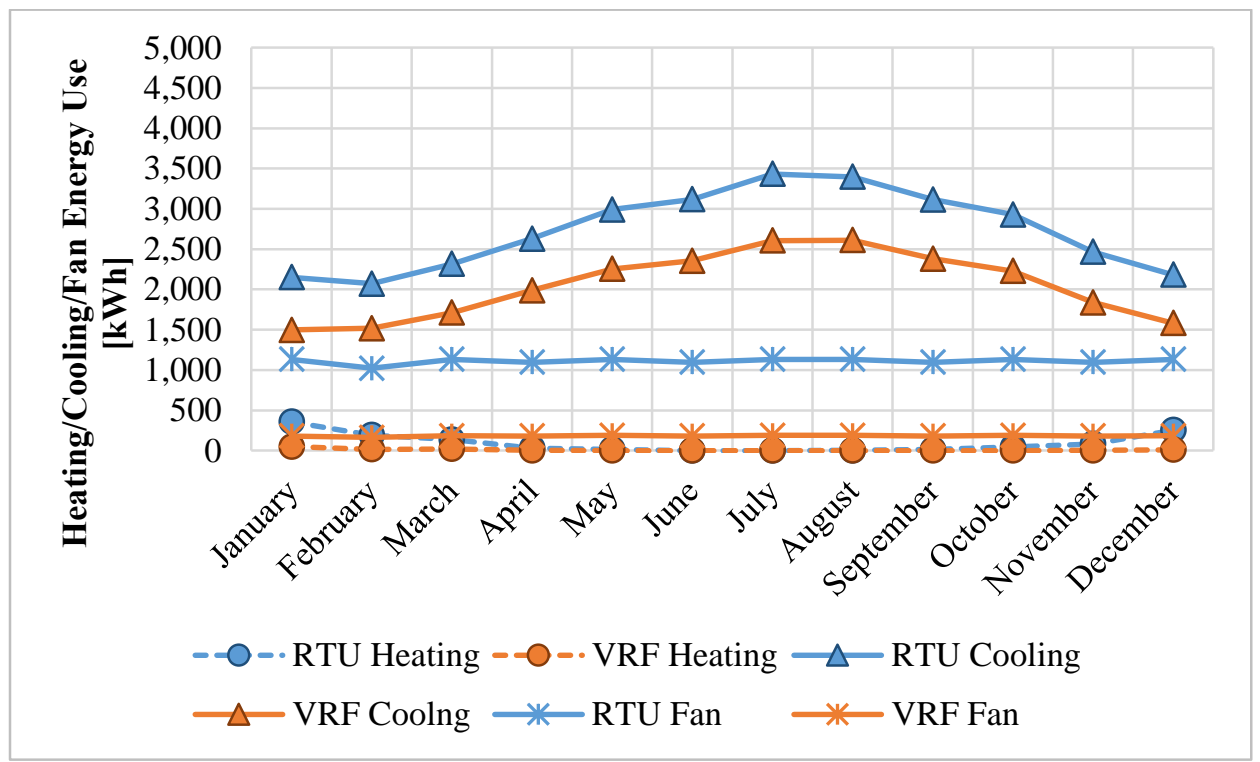

Figure 60. Monthly heating/cooling/fan energy use for the VRF versus the RTU in Miami, FL. 


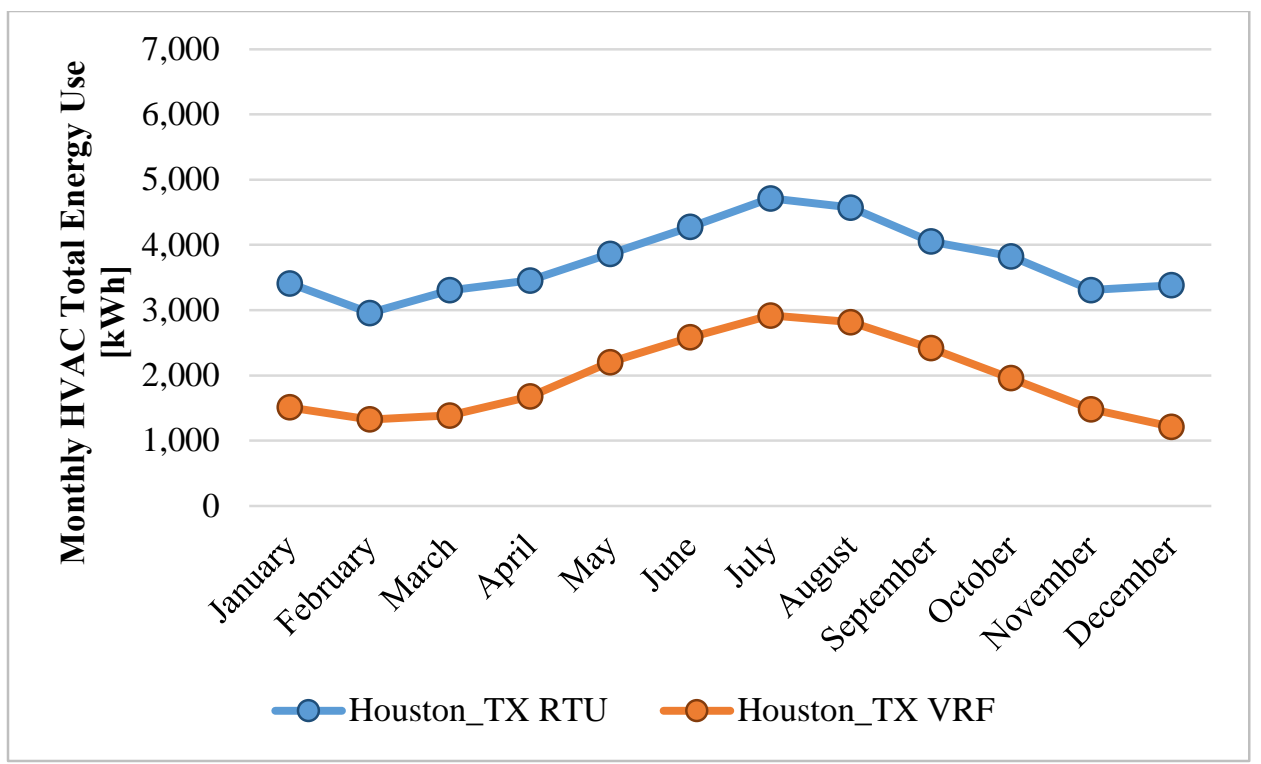

Figure 61. Monthly HVAC total energy use for the VRF versus the RTU in Houston, TX.

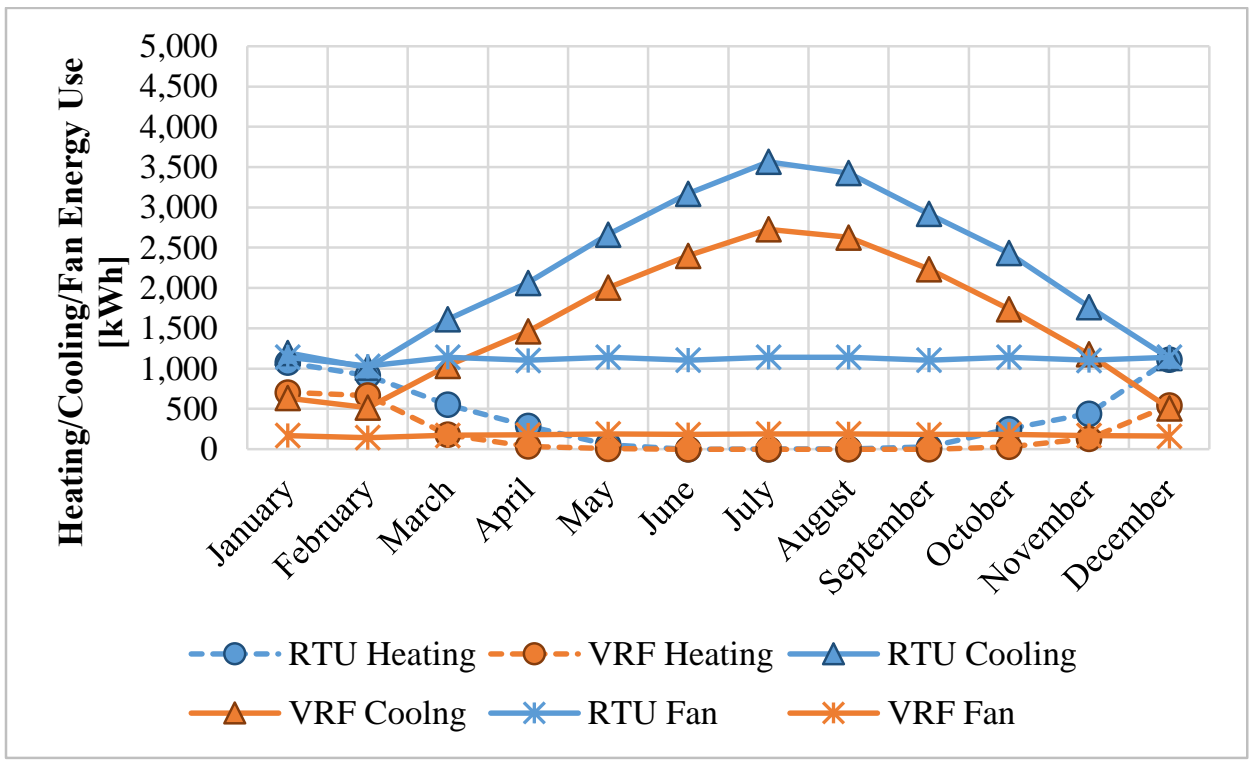

Figure 62. Monthly heating/cooling/fan energy use for the VRF versus the RTU in Houston, TX. 


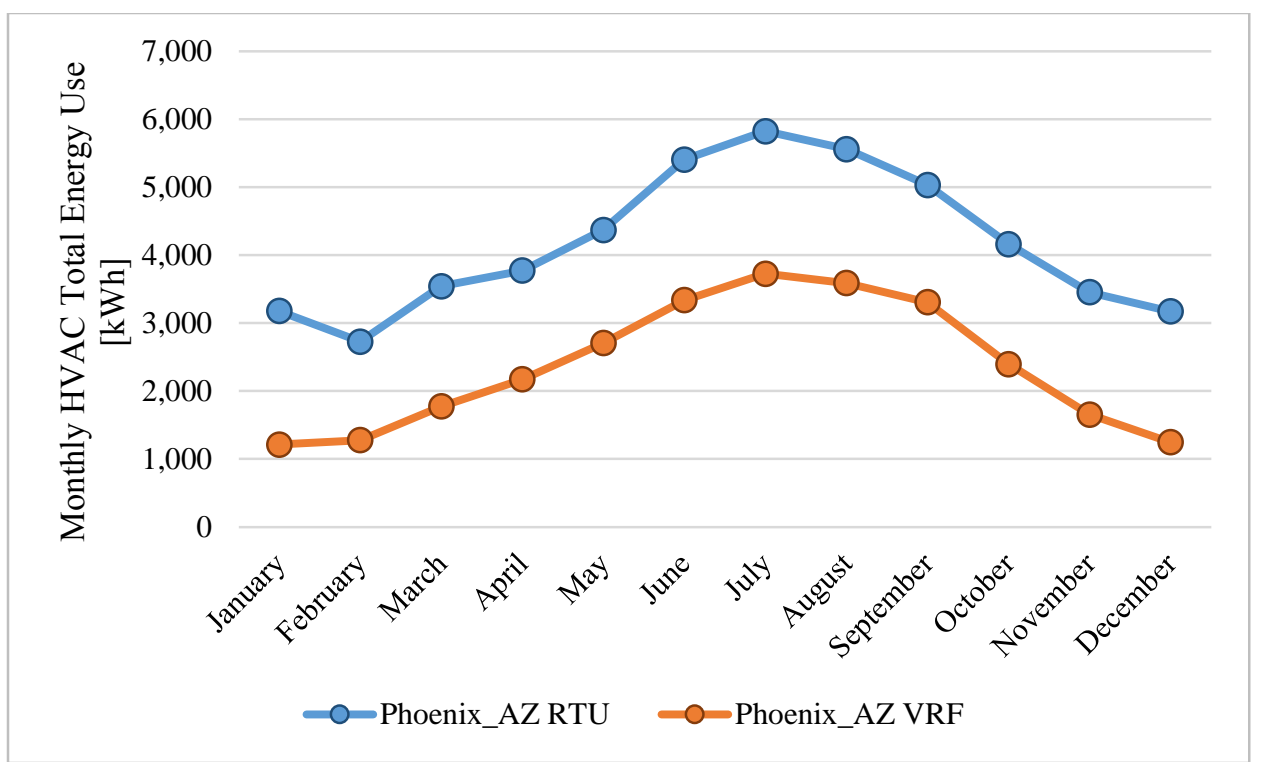

Figure 63. Monthly HVAC total energy use for the VRF versus the RTU in Phoenix, AZ.

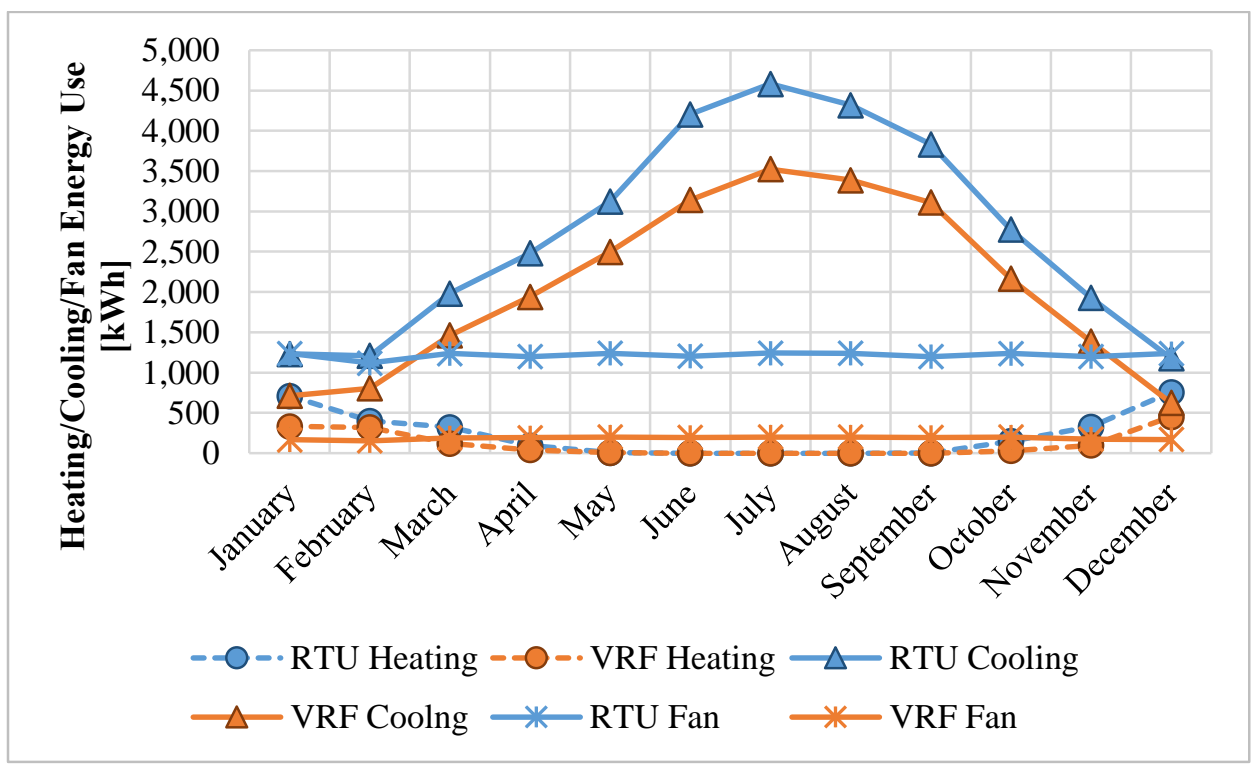

Figure 64. Monthly heating/cooling/fan energy use for the VRF versus the RTU in Phoenix, AZ. 


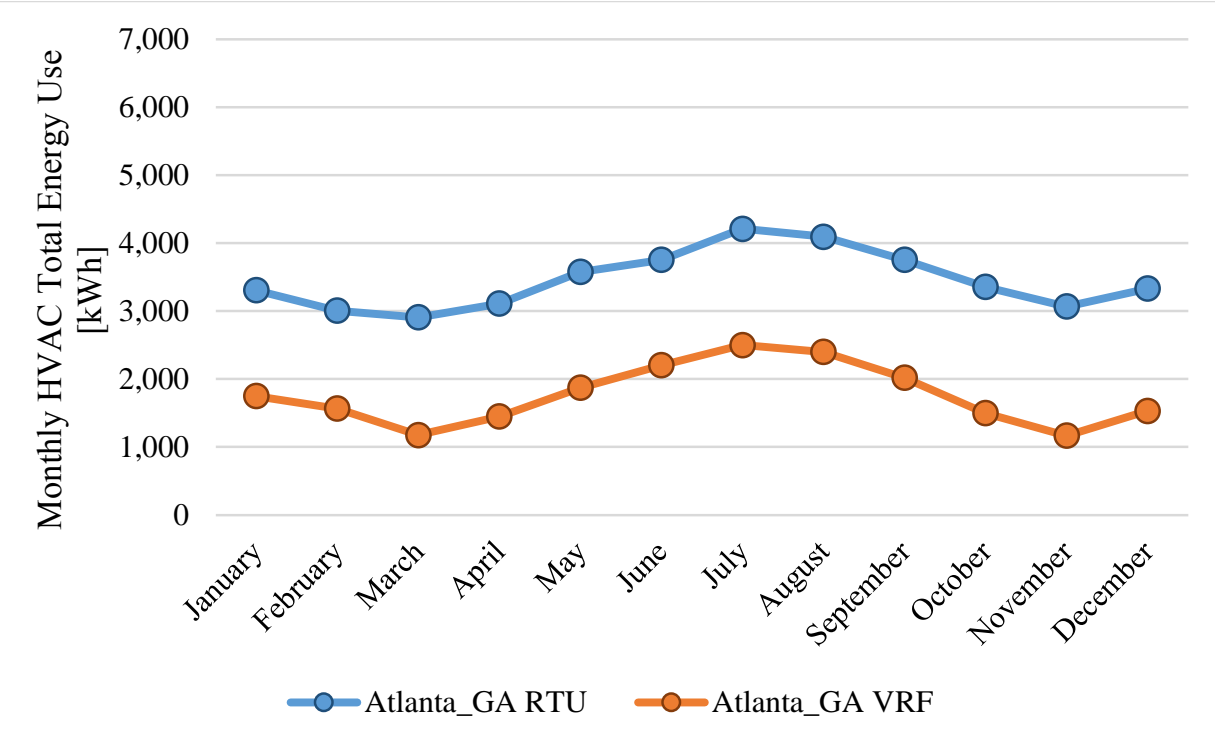

Figure 65. Monthly HVAC total energy use for the VRF versus the RTU in Atlanta, GA.

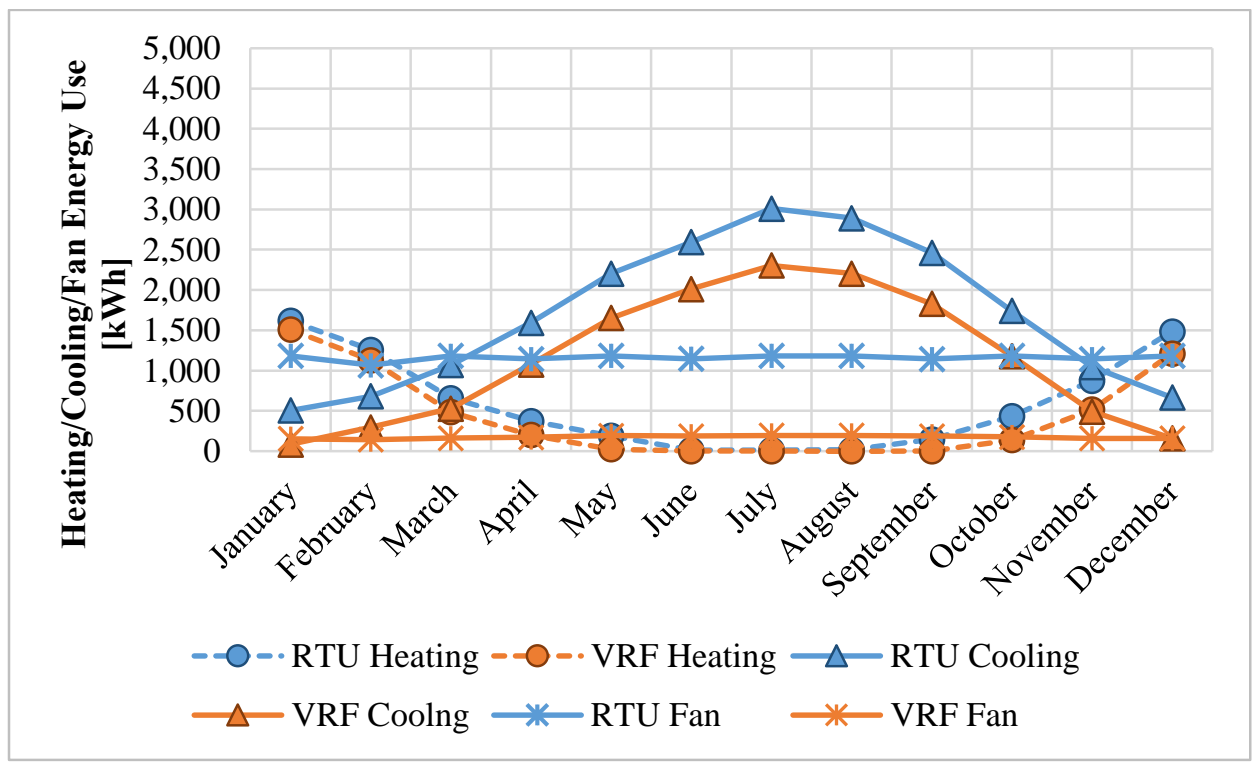

Figure 66. Monthly heating/cooling/fan energy use for the VRF versus the RTU in Atlanta, GA. 


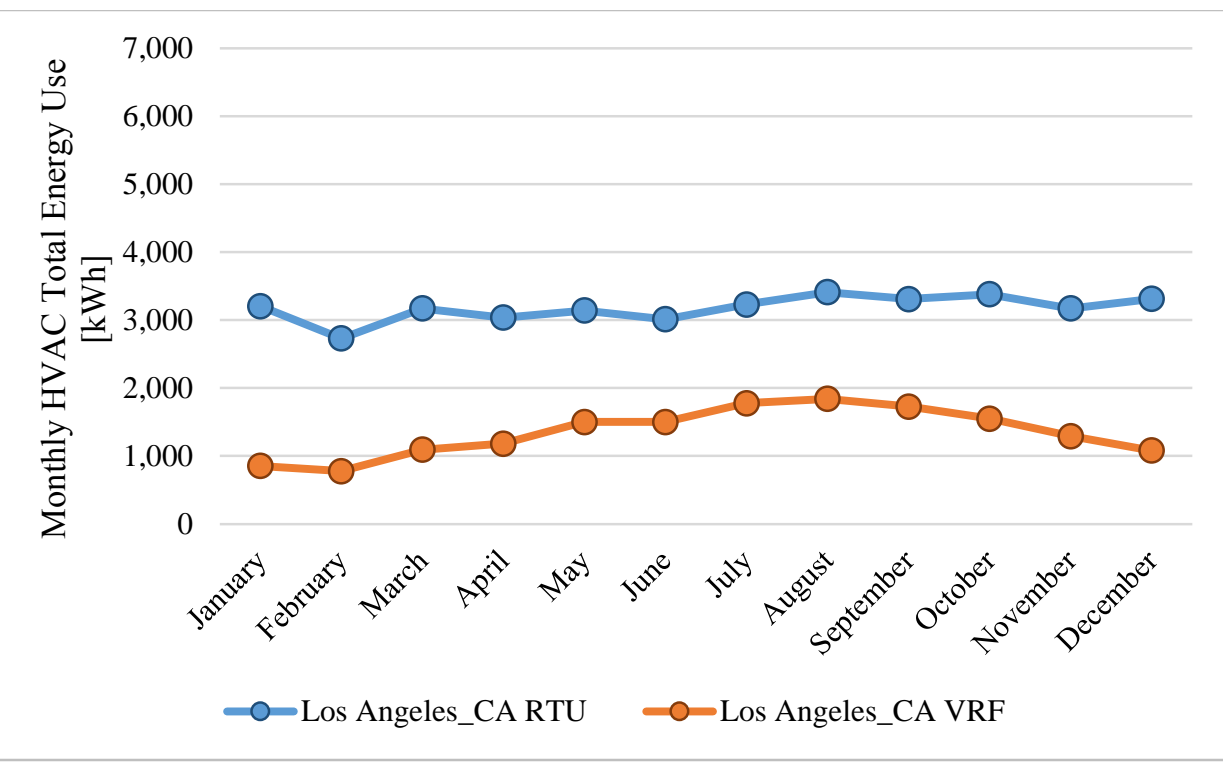

Figure 67. Monthly HVAC total energy use for the VRF versus the RTU in Los Angeles, CA.

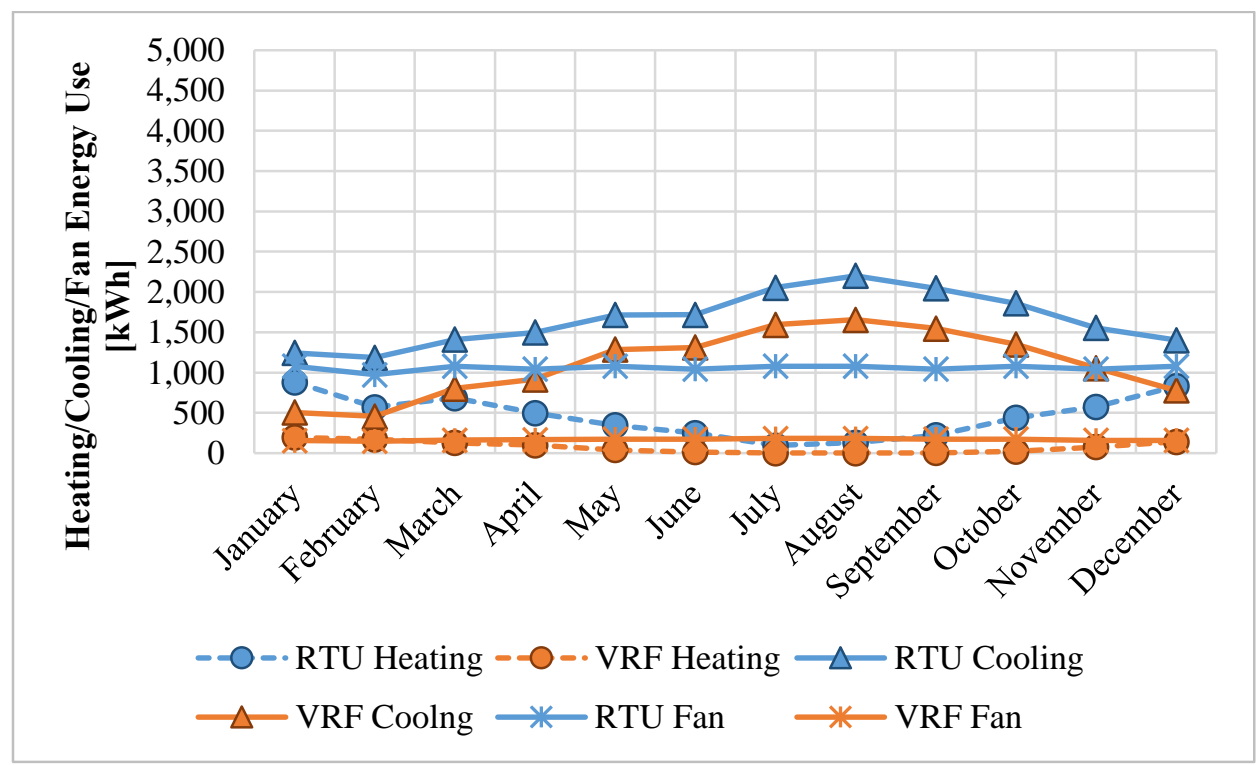

Figure 68. Monthly heating/cooling/fan energy use for the VRF versus the RTU in Los Angeles, CA. 


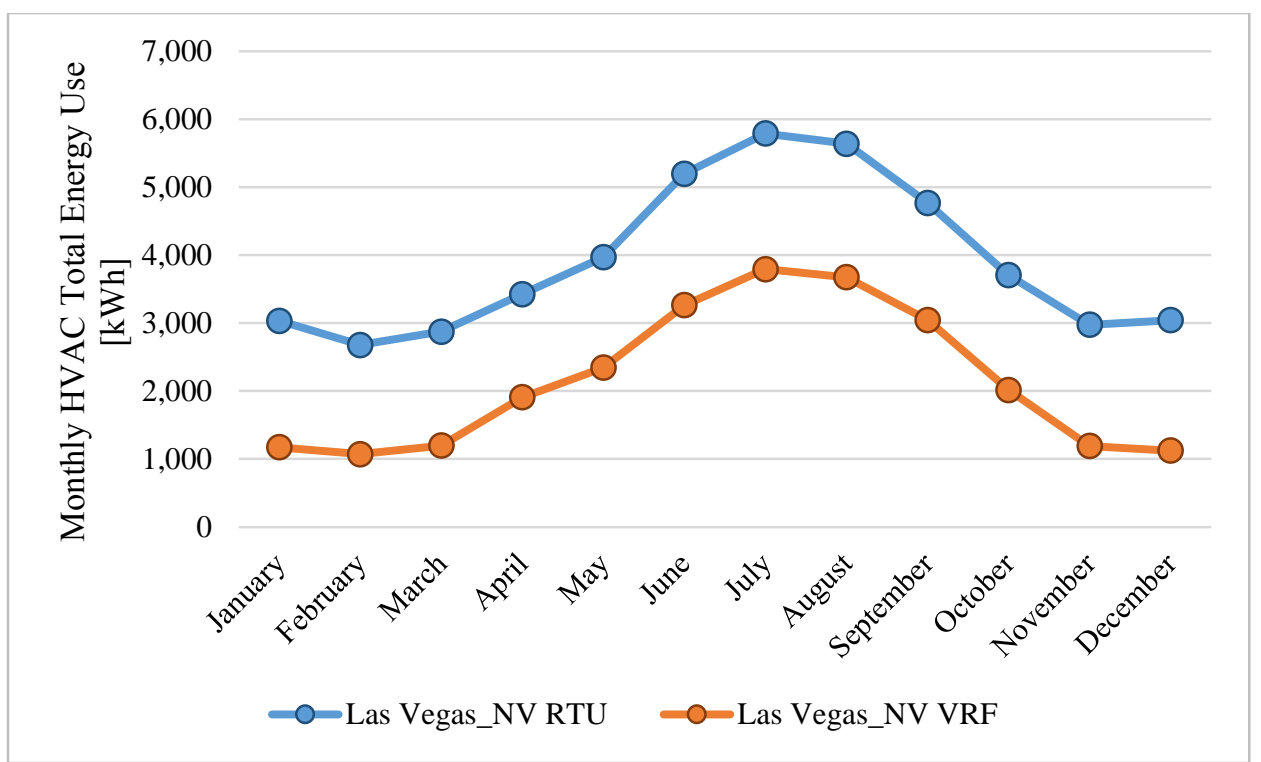

Figure 69. Monthly HVAC total energy use for the VRF versus the RTU in Las Vegas, NV.

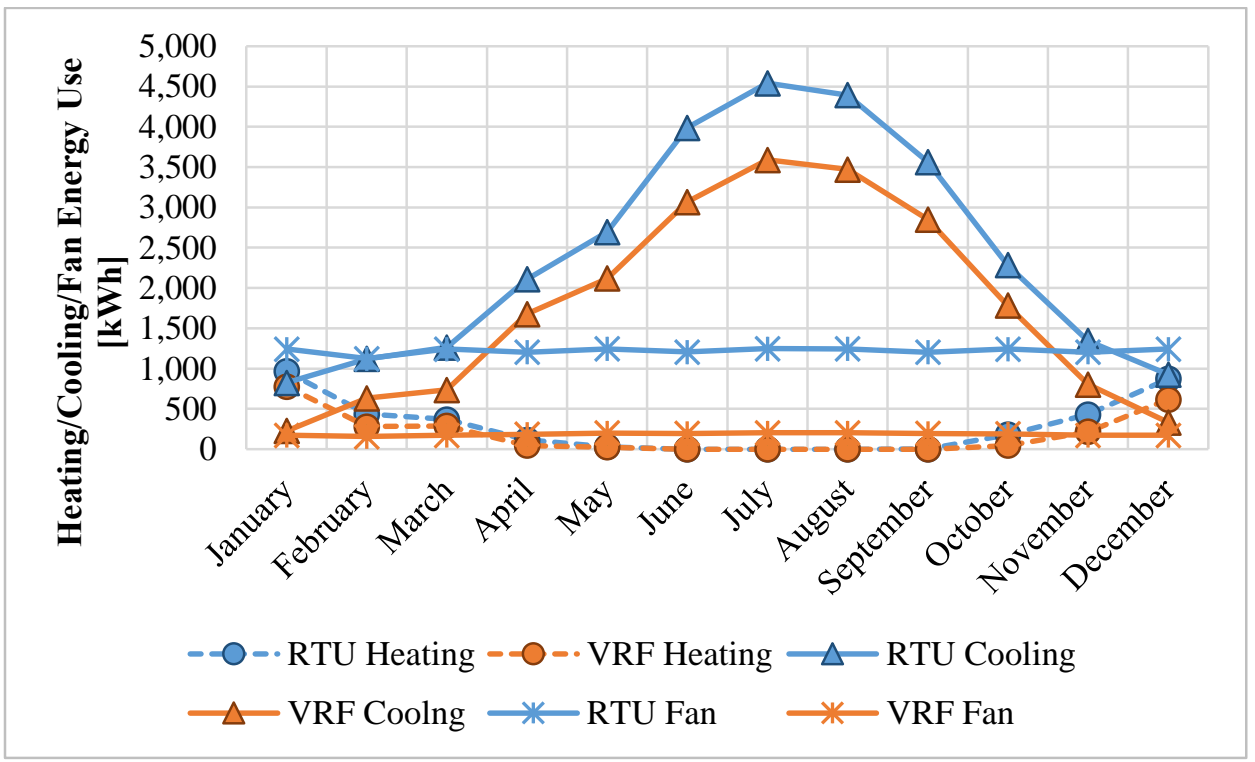

Figure 70. Monthly heating/cooling/fan energy use for the VRF versus the RTU in Las Vegas, NV. 


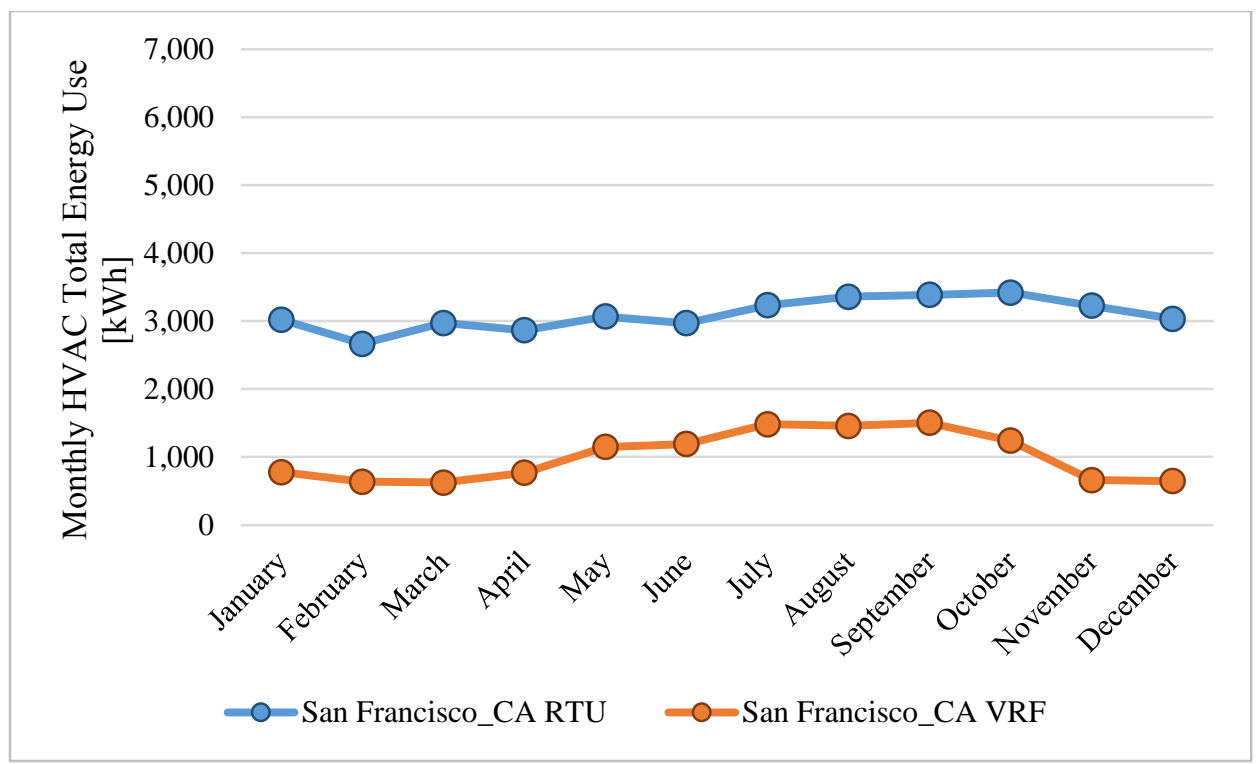

Figure 71. Monthly HVAC total energy use for the VRF versus the RTU in San Francisco, CA.

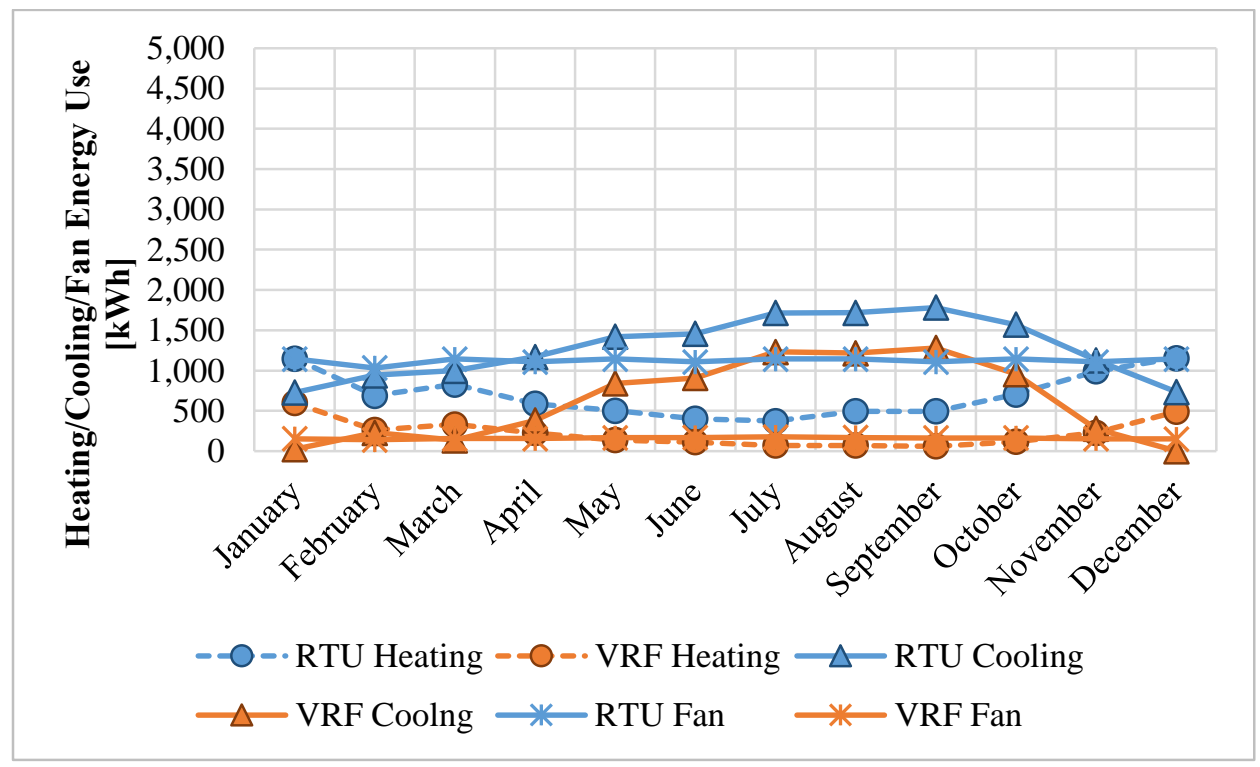

Figure 72. Monthly heating/cooling/fan energy use for the VRF versus the RTU in San Francisco, CA. 


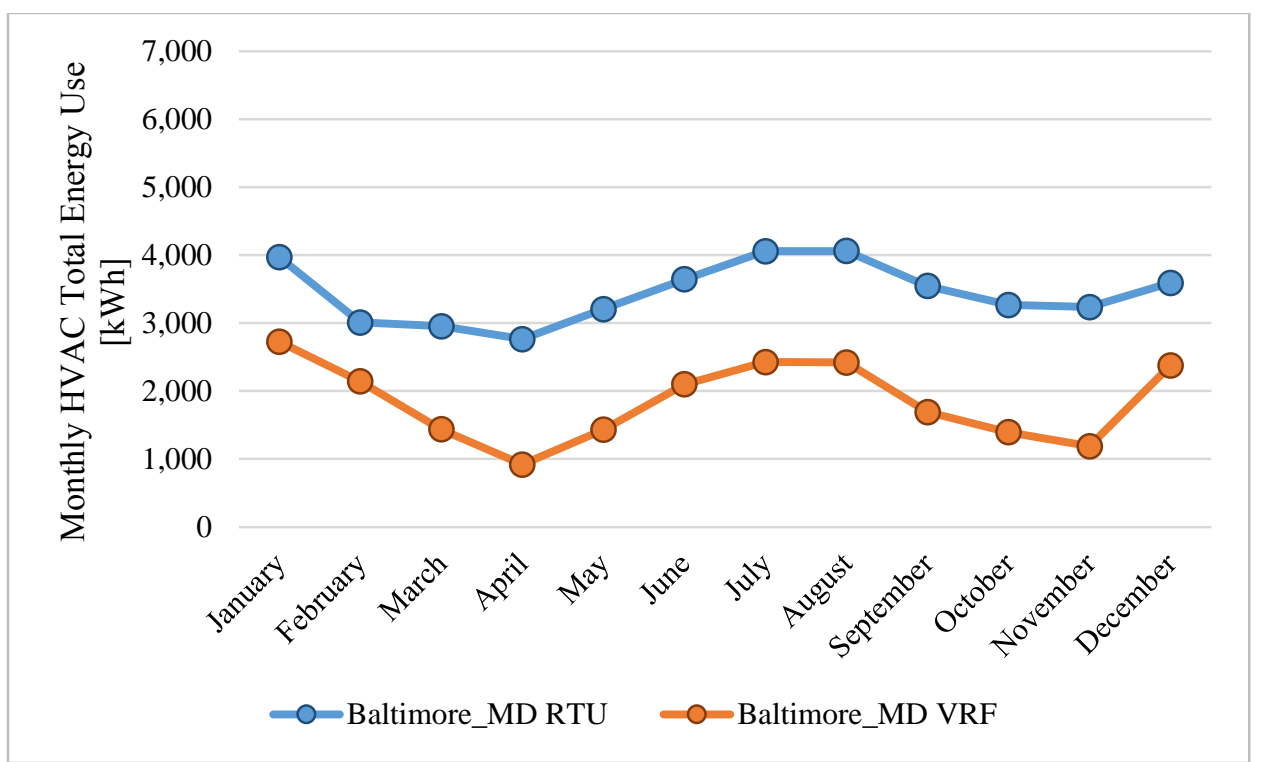

Figure 73. Monthly HVAC total energy use for the VRF versus the RTU in Baltimore, MD.

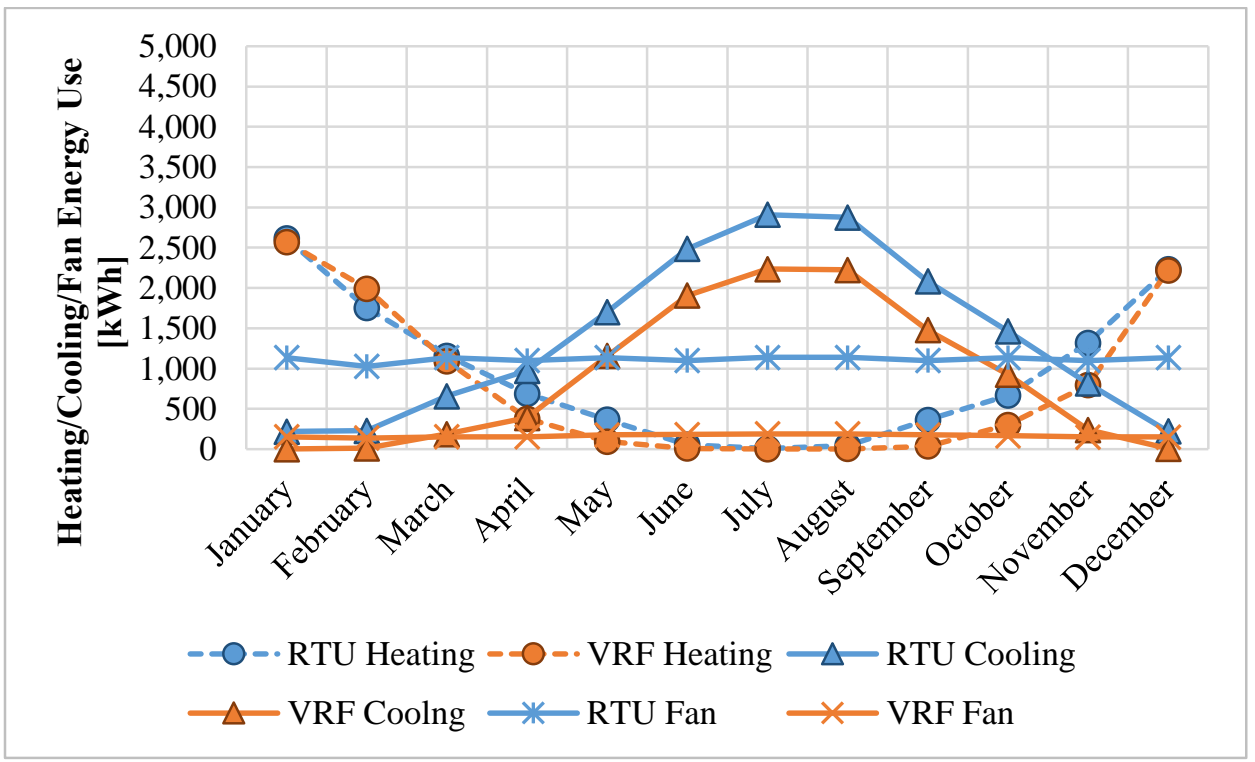

Figure 74. Monthly heating/cooling/fan energy use for the VRF versus the RTU in Baltimore, MD. 


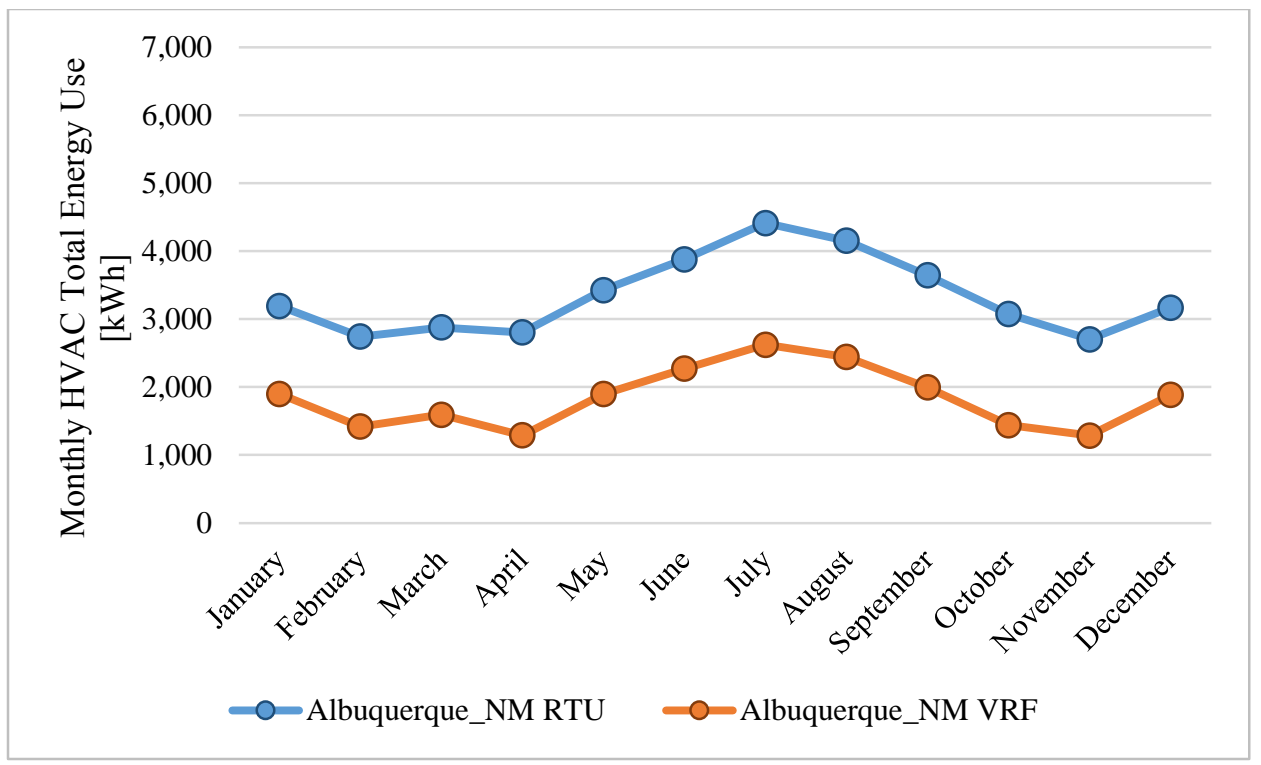

Figure 75. Monthly HVAC total energy use for the VRF versus the RTU in Albuquerque, NM.

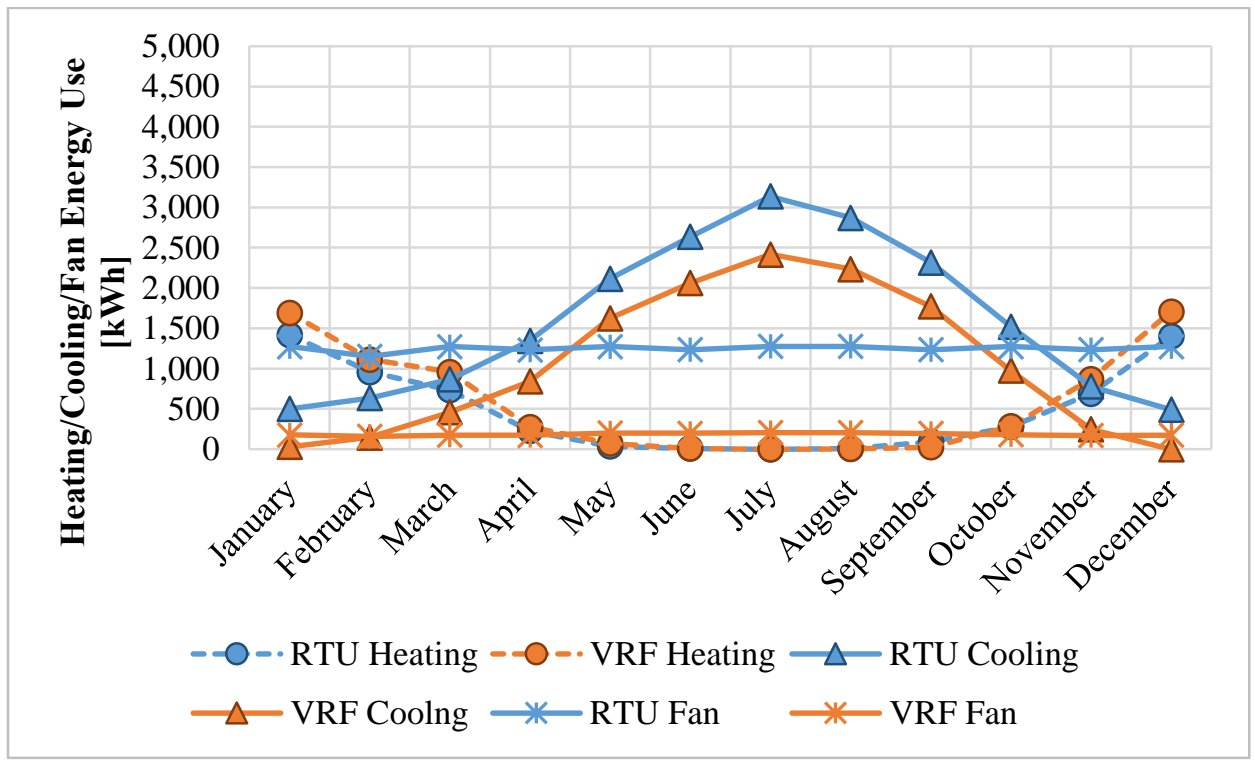

Figure 76. Monthly heating/cooling/fan energy use for the VRF versus the RTU in Albuquerque, NM. 


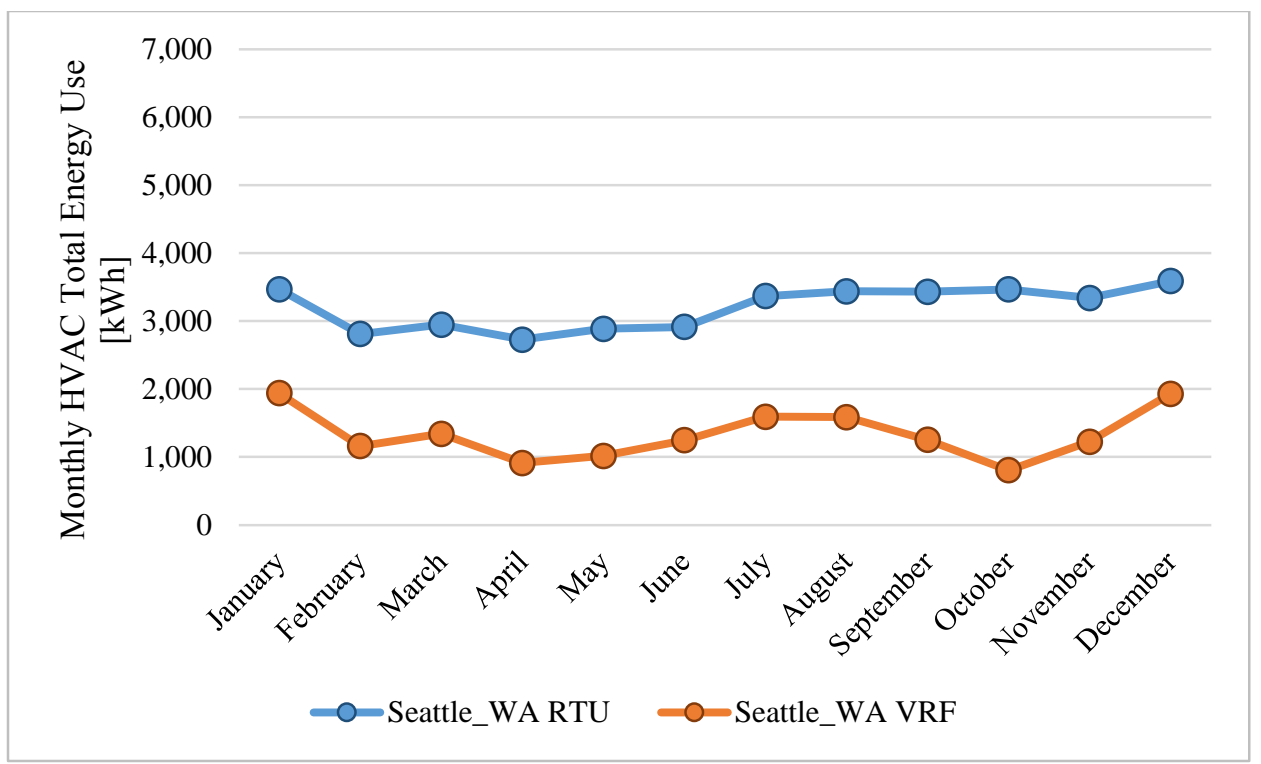

Figure 77. Monthly HVAC total energy use for the VRF versus the RTU in Seattle, WA.

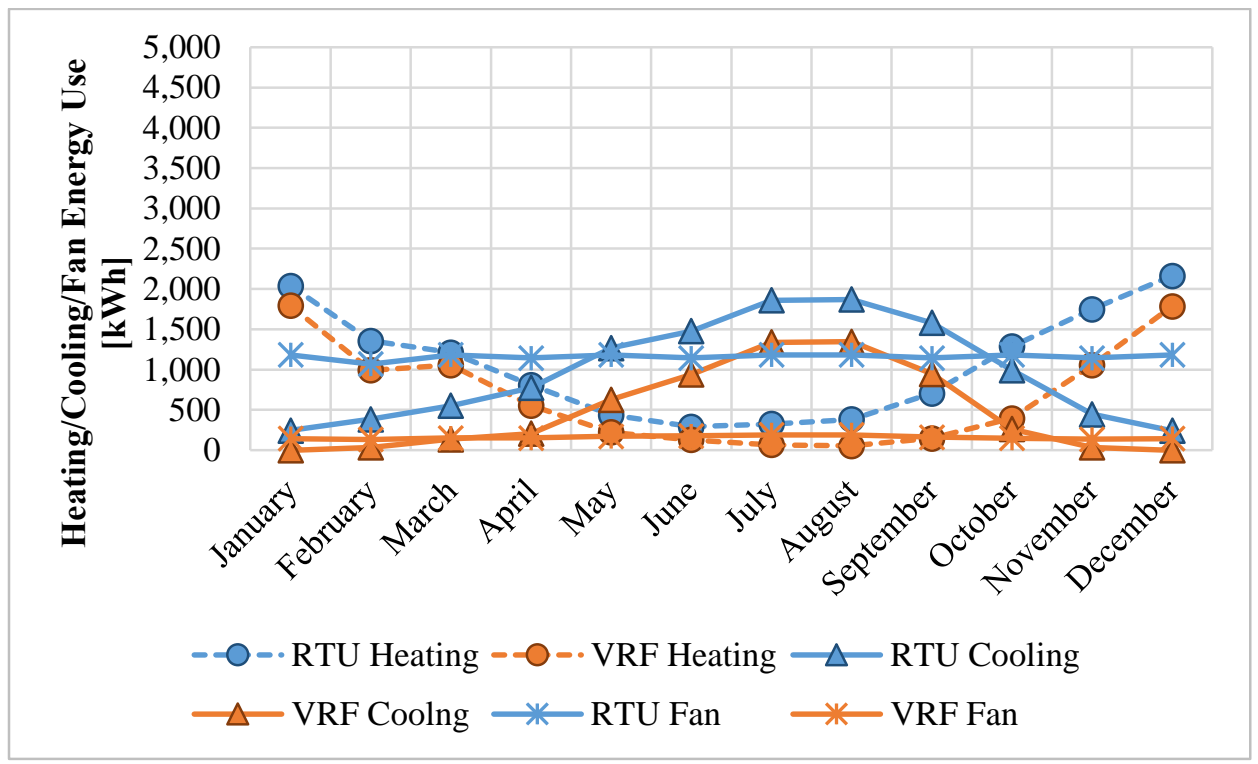

Figure 78. Monthly heating/cooling/fan energy use for the VRF versus the RTU in Seattle, WA. 


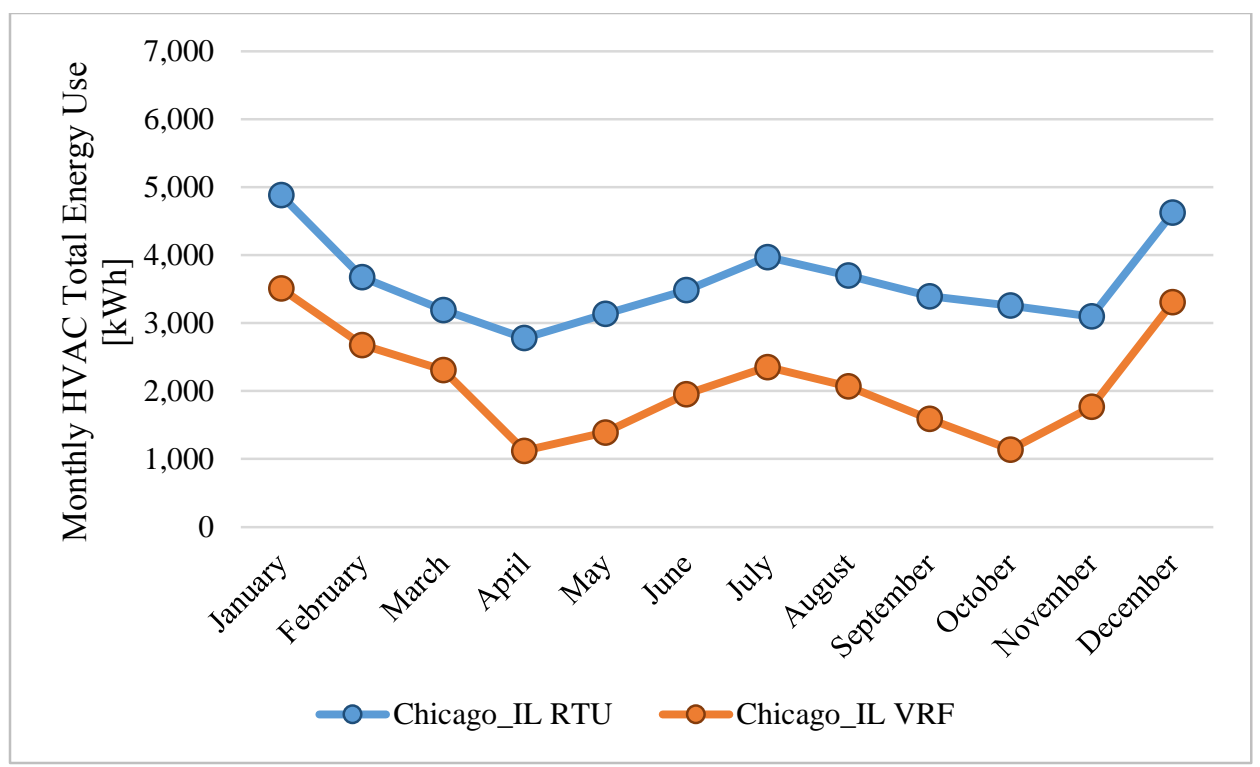

Figure 79. Monthly HVAC total energy use for the VRF versus the RTU in Chicago, IL.

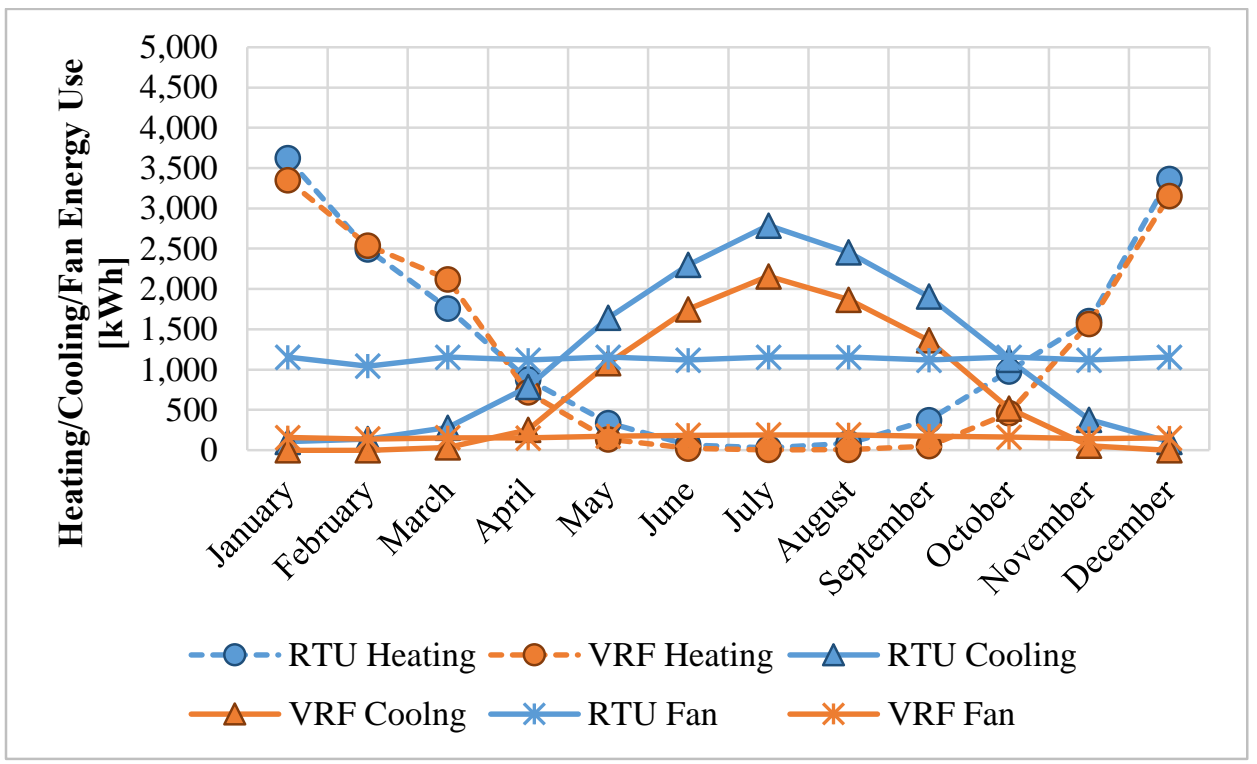

Figure 80. Monthly heating/cooling/fan energy use for the VRF versus the RTU in Chicago, IL. 


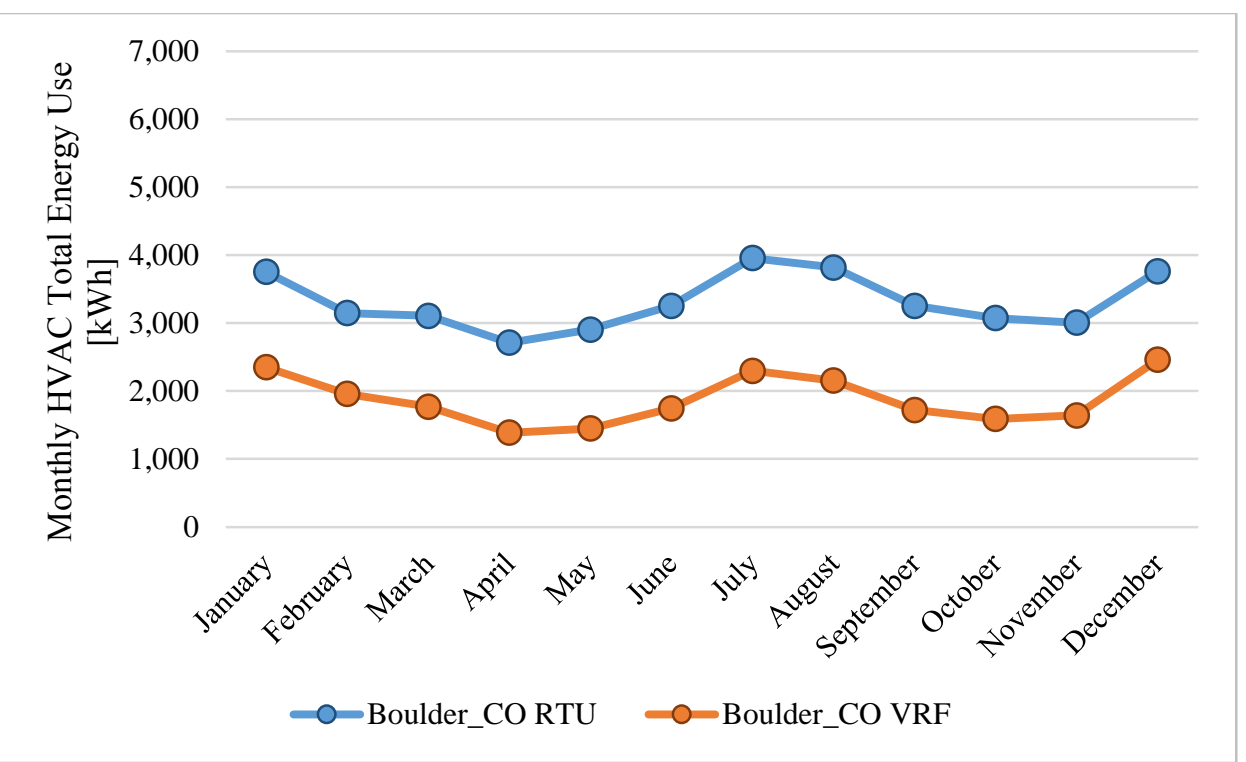

Figure 81. Monthly HVAC total energy use for the VRF versus the RTU in Boulder, CO.

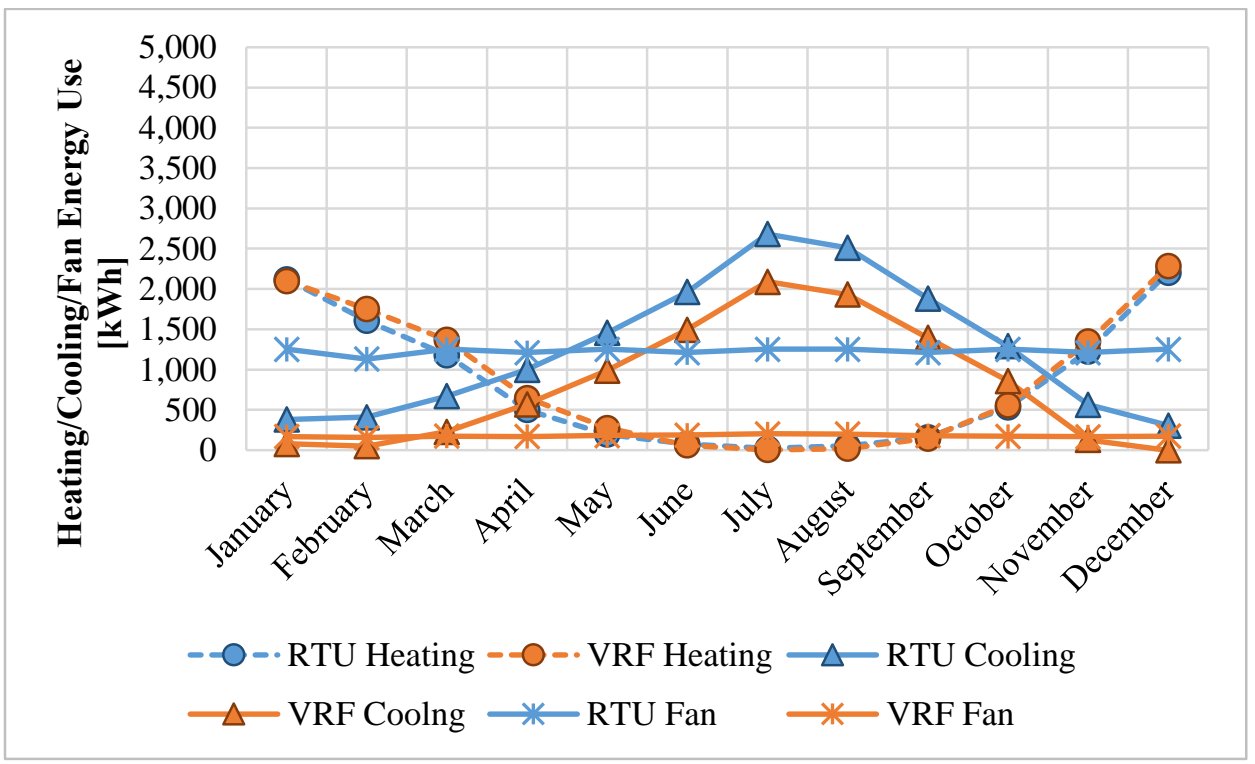

Figure 82. Monthly heating/cooling/fan energy use for the VRF versus the RTU in Boulder, CO. 